\title{
ESTUDO DE JUNÇÕES AERONÁUTICAS HÍBRIDAS (METAL-COMPÓSITO) UNIDAS MECANICAMENTE
}

\begin{abstract}
Dissertação apresentada a Escola de Engenharia de São Carlos, da Universidade de São Paulo, como parte dos requisitos para obtenção do título de Mestre em Engenharia Mecânica. Área de concentração: Aeronaves.
\end{abstract}

Orientador: Prof. Dr. Volnei Tita

São Carlos

2010 


\section{DEDICATÓRIA}

A minha amada esposa Suli Mara e ao meu adorado filho Carllo, pela motivação, pela compreensão, pelo apoio e acima de tudo pela força maior do amor que eles têm por mim e eu por eles. A Deus! - agradeço todos os dias por sermos muito abençoados. 


\section{AGRADECIMENTOS}

Ao Prof. Dr. Volnei Tita, pelo magnífico conhecimento transmitido, pelo excelente profissionalismo na orientação da evolução desta dissertação, pelas palavras de estímulo e confiança em todas as horas e, principalmente, pela compreensão e amizade demonstrada.

A Força Aérea Brasileira / Centro Logístico da Aeronáutica (FAB/CELOG), na qual eu tenho muito orgulho de ter servido, através dos meus ex-comandantes, pelo apoio e a sábia intenção de transformar-se em um pólo de pesquisa e desenvolvimento de novas tecnologias aeronáuticas e aeroespaciais.

Ao meu estimado amigo e professor Cap. Aparecido Prado pela disponibilidade prioritária em ministrar-me aulas particulares de inglês, as quais me proporcionaram condições de aprendizado e aprovação no exame de proficiência da língua, na forma de pré-requisito para o depósito deste trabalho.

Ao meu também estimado amigo Cesar M. Lima, companheiro de jornada, pela tenacidade e palavras de estímulo nas horas mais difíceis.

A todos os companheiros do Grupo de Estruturas Aeronáuticas (GEA), da EESC/USP, que colaboraram direta ou indiretamente para esta realização.

A empresa TAM pela gentileza de fornecer os corpos de provas, principalmente ao Engenheiro Emanuel Borges Nunes por ter realizado a fabricação dos mesmos.

Aos meus queridos pais, pela educação e formação, sem as quais eu não teria alcançado este objetivo. 


\section{RESUMO}

\section{VENTURINI, S. N. Estudo de junções aeronáuticas híbridas (metal-compósito) unidas}

mecanicamente. 2010. 177 p. Dissertação (Mestrado) - Escola de Engenharia de São Carlos, Universidade de São Paulo, São Paulo, 2010.

O presente trabalho consiste basicamente num estudo experimental de juntas híbridas metal-compósito unidas mecanicamente por fixadores. Foram analisadas juntas fabricadas através de uma chapa metálica de titânio unida a uma placa em compósito de fibra de carbono e resina epóxi por fixadores de monel. As juntas avaliadas são juntas simples (“single lap joint"), ou seja, as mesmas foram submetidas ao simples cisalhamento. Antes, porém, dos ensaios das juntas, foram fabricados corpos-de-prova (CDPs) do compósito seguindo as especificações das normas ASTM D3039 e ASTM D3518. Os ensaios de tração e cisalhamento dos CDPs de compósito possibilitaram a determinação de propriedades mecânicas, bem como de valores de resistência. Sob posse das propriedades e resistência média, foram executadas simulações computacionais via Método dos Elementos Finitos com o intuito de prever o comportamento mecânico das juntas a serem ensaiadas seguindo a norma ASTM D5961 e, assim, delinear estratégias para os ensaios. Os ensaios das juntas foram realizados, possibilitando assim a avaliação do comportamento mecânico de juntas híbridas e de seus mecanismos de falha. Por fim, as conclusões e as perspectivas para trabalhos futuros foram apresentadas.

Palavras-chave: juntas híbridas metal-compósito; juntas mecânicas; estruturas aeronáuticas em material compósito; ensaios experimentais (“experimental testing”) e mecanismos de falha. 


\begin{abstract}
VENTURINI, S. N. Study of aeronautic hybrid mechanical joints (metal-composite).

2010. 177 p. Dissertation (Master of Science) - School Engineering of São Carlos, University of São Paulo, São Carlos, 2010.

This work consists on an experimental investigation of hybrid joints (metal-composite) joined by fasteners. For this work, hybrid joints of titanium joined to composite (carbon fiber with epoxy resin) by monel fasteners were manufactured. Only single lap joints were investigated. However, before manufacturing specimens of joints, composite specimens were tested following the ASTM D3039 e ASTM D3518. The tensile and shear tests provided the mechanical properties and strength values of the composite. Finite element analyses of the hybrid joints were carried out, using average mechanical properties and strength values. These simulations followed the specifications of ASTM D5961 in order to predict the mechanical behavior of the joints during the experimental tests, as well as, provide a good strategy for the test setup. The experimental tests were carried out, observing the mechanical behavior and failure mechanisms of the hybrid joints. Finally, the conclusions and perspective of future works were showed.
\end{abstract}

Keywords: hybrid joints metal-composite; fastener joints; composite aeronautical structures; failure mechanisms. 


\section{LISTA DE FIGURAS}

Figura 1 - Compósito Polimérico Reforçado (CPR): (a) fuselagem em CPR; (b) falhas intra e interlaminares.

Figura 2 - (a) laminado; (b) lâmina ortotrópica: sistema global e local de coordenadas...........9

Figura 3 - Mecanismos de danificação / falha em CPR: (a) danificações Intralaminares, Anderson (1995); (b) falhas interlaminares, Tita (2003) .................................................... 11

Figura 4 - Procedimento de análise de uma estrutura laminada.......................................... 14

Figura 5 - Distribuição de tensões normais e de cisalhamento em um corpo sólido............... 16

Figura 6 - Distribuição de esforços na parede do furo e no fixador. ..................................... 18

Figura 7 - Fator de concentração de tensão devido ao furo na chapa..................................... 19

Figura 8 - Determinação da carga de escoamento através do Método do Módulo Secundário

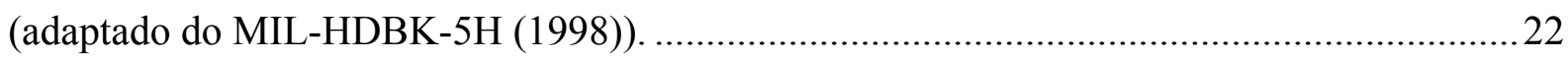

Figura 9 - Seqüência dos principais modos de falhas em uma junta metal-metal (MIL-HDBK-

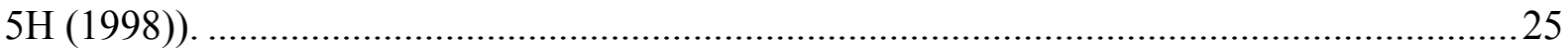

Figura 10 - Definição das cargas que agem em uma junta metálica, Morris (2004)..............26

Figura 11 - Influência da carga transferida no comportamento da fadiga em juntas rebitadas sob cisalhamento, Morris (2004).

Figura 12 - Influência da flexibilidade em função da transferência de carga, Morris (2004). 28

Figura 13 - Configuração de ensaio sob cisalhamento para junta padrão, Morris (2004)......28

Figura 14 - Metodologia para a determinação do fator de flexibilidade total da junta

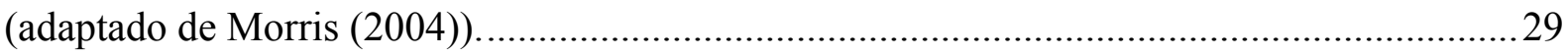

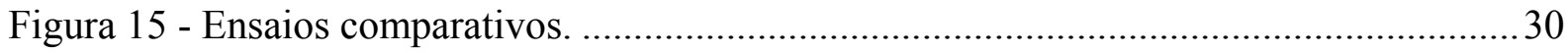

Figura 16 - (a) CDP configurado com fixador e furo escariado; (b) CDP convencional, Morris

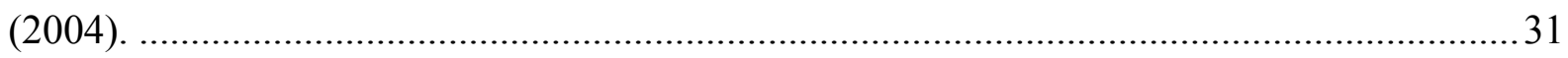

Figura 17 - Fatores que influenciam no modo de falha. .................................................... 32

Figura 18 - Tensão no laminado acrescida do seu fator de concentração, Suong e Tsai (2002). 
Figura 19 - Modo de falha por tração (MIL-HDBK-17-3F (2002)).

Figura 20 - Modo de falha combinado por tração e cisalhamento (MIL-HDBK-17-3F (2002)).

Figura 21 - Modo de falha por "bearing": (a) defeito na forma circular; (b) delaminação no laminado (MIL-HDBK-17-3F (2002)).

Figura 22 - Ensaio de "bearing" e do modo de falha até a ruptura: (a) Procedimento A (duplo cisalhamento); (b) Procedimento B (simples cisalhamento), ASTM 5961 (2007).

Figura 23 - Cisalhamento no fixador: (a) simples; (b) duplo. 37

Figura 24 - Ensaios comparativos por duplo cisalhamento. 38

Figura 25 - Efeito do carregamento externo em uniões simples 39

Figura 26 - Efeito do carregamento externo em uniões duplas. 39

Figura 27 - Calço para anular ou minimizar o efeito do Momento Fletor Secundário nas uniões simples.

Figura 28 - Modo especial de falha no fixador e no laminado.

Figura 29 - Fator de redução da resistência ao "bearing" em função da razão D/t (MILHDBK-17-1F (2002))

Figura 30 - Fator de redução da resistência ao "bearing” em função do calço, Mil-Hdbk-17-1F (2002).

Figura 31 - Definição das cargas combinadas por "bearing” e " by-pass".

Figura 32 - Exemplo de interação de "bearing” e "by-pass" (MIL-HDBK-17-1F (2002)). ....45

Figura 33 - Esquema de um sistema de ensaio "bearing" e "bay-pass" desenvolvido pela NASA (MIL-HDBK-17-1F (2002)).

Figura 34 - CDP para ensaio de "bearing” e "by-pass” (MIL-HDBK-17-1F (2002)).

Figura 35 - Modo de falha por cisalhamento (MIL-HDBK-17-3F (2002)).

Figura 36 - Modos de falhas por cisalhamento devido à ação dos esforços externos solicitantes.

Figura 37 - Dados de falha para "bearing" em função do cisalhamento, devido ao carregamento externo, como uma função das tensões de "bearing" e cisalhamento (MILHDBK-17-3F (2002)). 
Figura 38 - Junta unida por pinos e colada formada por material compósito, Lees e Makarov (2004).

Figura 39 - Ensaios ao simples cisalhamento, Lees e Makarov (2004). 52

Figura 40 - Alguns exemplos de parâmetros particulares da junção, Lees e Makarov (2004).53

Figura 41 - Ilustração esquemática de uma união híbrida entre uma chapa de alumínio e um laminado de matriz polimérica reforçada com fibra de vidro, Matsuzaki, Shibata e Todoroki (2007).

Figura 42 - Junta híbrida entre laminado reforçado com fibra de vidro e chapa de alumínio: (a) Configuração do CDP; (b) CDP ensaiado, Matsuzaki, Shibata e Todoroki (2007)..... 55

Figura 43 - Propagação da trinca em uniões híbrida compósito-alumínio durante os ensaios de simples cisalhamento: (a) juntas híbridas simplesmente coladas; (b) juntas híbridas parafusadas-coladas, Matsuzaki, Shibata e Todoroki (2007).

Figura 44 - Exemplos de falhas visíveis e diferentes entre si (AMS HANDBOOK - VOL. 21

- COMPOSITES (2005)).

Figura 45 - Exemplo de Inspeção por Ultrasom (AMS HANDBOOK - VOL. 21 COMPOSITES (2005)).

Figura 46 - Exemplo de Inspeção por Raio-X (AMS HANDBOOK - VOL. 21 COMPOSITES (2005)).

Figura 47 - Exemplo de Análise de Infravermelho por Transformada de Fourier - FTIR (AMS HANDBOOK - VOL. 21 - COMPOSITES (2005)).

Figura 48 - Exemplo de micrografia de uma secção transversal obtida de um compósito carbono-epóxi (AMS HANDBOOK - VOL. 21 - COMPOSITES (2005)). .66

Figura 49 - Fluxograma proposto para determinação da tensão próxima ao início da falha da junção por meio de ensaios não destrutivos.

Figura 50 - Metodologia Geral. 76

Figura 51 - (a) Equipamentos e bolsa de vácuo; (b) Materiais utilizados em uma cura por bolsa de vácuo típica..... 78

Figura $52-\mathrm{CDP}\left[0^{\circ} / 90^{\circ}\right]_{6}$ conforme ASTM D3039. 80

Figura 53 - Generalização do processo de fabricação dos CDPs $\left[0^{\circ} / 90^{\circ}\right]_{6}$ e $\left[+45^{\circ} /-45^{\circ}\right]_{6} \ldots . . .81$

Figura $54-\mathrm{CDP}\left[+45^{\circ} /-45^{\circ}\right]_{6}$ conforme ASTM D3518. 82

Figura 55 - Distâncias requisitadas para fixadores instalados em compósitos. 85 
Figura 56 - Modos de falha em compósitos, Niu (1995).

Figura 57 - Defeitos típicos de furações e broca recomendada para furação em compósito. ..86

Figura 58 - Tripod: dispositivo de furação para garantir tolerâncias de perpendicularismo. .. 87

Figura 59 - Acabamento das arestas do furo.

Figura 60 - Tolerâncias de montagem para fixadores do tipo sólido.

Figura 61 - Tolerâncias de montagem. 90

Figura 62 - Galifon: sistema de cravação hidráulico.

Figura 63 - CDP de compósito fixado à máquina de ensaios.

Figura 64 - Curva típica de tensão-deformação do ensaio de tração (ASTM D3039 (2006)). 97

Figura 65 - Modos típicos de falhas e seus códigos para CDPs ensaiados sob tração (ASTM

D3039 (2006)).

Figura 66 - (a) Curva de tensão de cisalhamento em função das distorções angulares; (b) Campo de tensões no plano 1-2 do corpo de prova para cisalhamento ensaiado sob tração....99

Figura 67 - Curva típica de tensão-deformação do ensaio de cisalhamento (ASTM D3518/D $3518 \mathrm{M}(2001))$. 100

Figura 68 - CDP com dois fixadores ao simples cisalhamento (ASTM D5961/D5961M-05 (2007)).

Figura 69 - Vista geral do aparato dos ensaios experimentais das junções híbridas. 104

Figura 70 - Caracterização de falhas por "bearing" e "bearing-bypass" (ASTM D5961/D5961M (2007)).

Figura 71 - Rotação imaginária do rebite devido à força de tração e a folga do conjunto. ... 106

Figura 72 - Efeito da sobreposição na distribuição de tensões devido à ação do momento fletor no fixador e da folga na junta.

Figura 73 - Trabalho esquemático da junta em serviço, considerando-se somente o efeito do momento fletor no fixador e da folga do conjunto. 108

Figura 74 - Exemplo de ensaio cíclico $\left(\mathrm{CDP} 4-0^{\circ} / 90^{\circ}\right)$.

Figura 75 - Exemplo de ensaio monotônico (CDP5 - 0\%/90).

Figura 76 - Curvas resultantes dos ensaios dos CDPs $\left[0^{\circ} / 90^{\circ}\right]_{6}$. 
Figura 77 - Exemplo de ensaio cíclico $\left(\mathrm{CDP} 5-+45^{\circ} /-45^{\circ}\right)$.

Figura 78 - Exemplo de ensaio monotônico (CDP4 - +45\% $\left.-45^{\circ}\right)$

Figura 79 - Curvas resultantes dos ensaios dos CDPs $\left[+45^{\circ} /-45^{\circ}\right]_{6}-$ dados dos "strain-gages" (ASTM D3518).

Figura 80 - CDP de ensaio seguindo as orientações da norma ASTM 5961.

Figura 81 - Modelo MEF da junta: malha, condições de contorno e carregamentos.

Figura 82 - Detalhe da malha de Elementos Finitos na região do fixador.

Figura 83 - Detalhe dos nós na região do fixador.

Figura 84 - Campo de Tensões Principais na junta (Compósito 1) - Detalhe do elemento mais solicitado

Figura 85 - Esforços atuantes nas juntas: (a) Compósito 1 (b) Compósito 2.

Figura 86 - CDPs de junções híbridas em metal-compósito $\left[0^{\circ} / 90^{\circ}\right]_{6}$ e $\left[+45^{\circ} /-45^{\circ}\right]_{6}$, respectivamente.

Figura 87 - Dimensões dos CDPs das juntas.

Figura 88 - Detalhamento da falha na parte em compósito da junta:

(a) $0^{\circ} / 90^{\circ} \mathrm{e}$

(b) $+45^{\circ} /-45^{\circ}$.

Figura 89 - (a) Deformação lateral da parede do furo devido à tensão de "bearing" - (b) Ruptura do material na parte em compósito devido à tensão de "bypass" na forma de tração (CDP 1 - 0/90)

Figura 90 - Procedimento para a determinação da carga mínima de descarregamento e carregamento da junção - CDP Ti - Compósito $\left[0^{\circ} / 90^{\circ}\right]_{6}$.

Figura 91 (a) e (b) - Propriedades mecânicas da união Ti - Compósito [0 $\left.0^{\circ} / 90^{\circ}\right]_{6}$ obtidas através do Método do Módulo Secundário. 128

Figura 92 - Curvas da tensão x deformação individual das uniões Ti - Compósito $\left[0^{\circ} / 90^{\circ}\right]_{6}$ 131

Figura 93 - Curva força x deformação do ensaio global das junções Ti - Compósito $\left[0^{\circ} / 90^{\circ}\right]_{6}$

Figura 94 - (a) Deformação permanente na parede lateral do furo pelo efeito "bearing" - (b) Ruptura na parte em compósito devido à ação de "bearing" (CDP 1 - [+/-45]6). 
xviii

Figura 95 - Propriedades mecânicas da união Ti-Compósito $\left[ \pm 45^{\circ}\right]_{6}$ obtidas através do Método do Módulo Secundário.

Figura 96 - Curvas da tensão x deformação individual das uniões Ti - Compósito [+45\%/$\left.45^{\circ}\right]_{6}$.

Figura 97 - Curva força x deformação do ensaio das junções Ti - Compósito $\left[-45^{\circ} /+45^{\circ}\right]_{6} \cdot 138$

Figura 98 - Falha não prevista observada em um determinado CDP Ti - Compósito $\left[0^{\circ} / 90^{\circ}\right]$

Figura 99 - Junções de Ti - Compósito $\left[0^{\circ} / 90^{\circ}\right]_{6}$ : Numérico x Experimental........................ 143

Figura 100 - Junções de Ti - Compósito $\left[ \pm \mathbf{4 5}^{\circ}\right]_{6}$ : Numérico x Experimental..................... 143 


\section{LISTA DE TABELAS}

Tabela 1 - Tensões de ruptura ao simples cisalhamento nos fixadores (MIL-HDBK-5H (1998)).

Tabela 2 - Furo nominal e diâmetro do corpo do fixador (in) (MIL-HDBK-5H (1998))........23

Tabela 3 - Modos de falhas mais comuns observados nos fixadores (MIL-HDBK-17-1F (2002)).

Tabela 4 - Descrição do tecido em fibra de carbono $\left(\right.$ Hexcel $\left.^{\mathrm{TM}}\right)$........................................ 71

Tabela 5 - Algumas propriedades da resina epóxi - Hex Ply M20 - $\mathrm{Hexel}^{\mathrm{TM}} \ldots \ldots \ldots \ldots \ldots \ldots \ldots \ldots . . . . . . . . . . .72$

Tabela 6 - Exemplo de propriedades das fibras pré-impregnada com resina epóxi ("prepreg”)

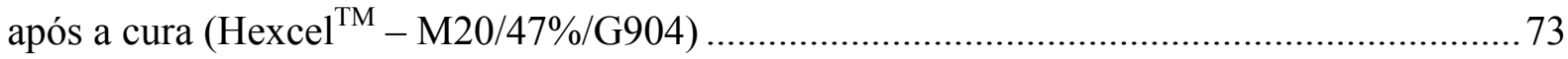

Tabela 7 - Resistência ao cisalhamento dos rebites, NIU (1988)......................................... 73

Tabela 8 - Elementos da liga Monel (fixadores) em porcentagem por peso (MS 20615

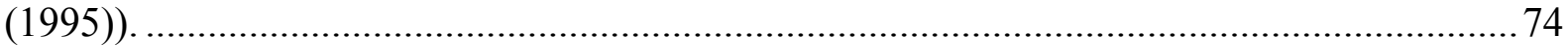

Tabela 9 - Composição da liga de Titânio: 6,0 Al - 4,0 V em porcentagem por peso (AMS

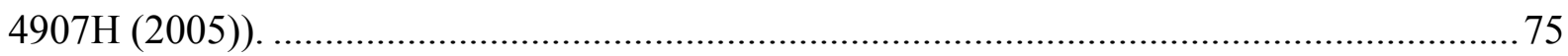

Tabela 10 - Propriedades mecânicas mínimas da chapa de Titânio (SI) (AMS

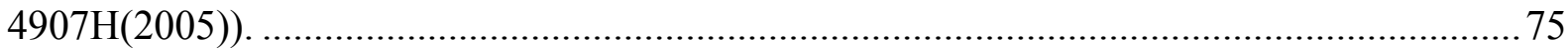

Tabela 11 - Parâmetros de cura para CDPs de tração (ASTM D3039/D3039M)....................81

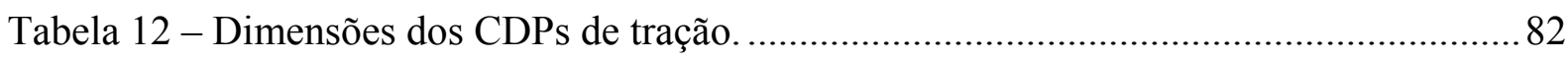

Tabela 13 - Dimensões dos CDPs de cisalhamento (ASTM D3518/D3518M) …..................83

Tabela 14 - Diâmetros recomendados para fixadores sólidos.............................................. 88

Tabela 15 - Valores dos parâmetros para o CDP (ASTM D5961(2007))............................. 102

Tabela 16 - Resultados dos ensaios dos CDPs de tração (ASTM D3039)............................ 113

Tabela 17 - Resultados dos ensaios dos CDPs de cisalhamento (ASTM D3518).................115

Tabela 18 - Valores extraídos da literatura para os materiais metálicos (MIL-HDBK-5J)... 119

Tabela 19 - Propriedades mecânicas da camada em compósito. 119

Tabela 20 - Fator de Reserva do elemento crítico em compósito da união. 
Tabela 21 - Dimensões das juntas híbridas (onde: $\mathrm{C}$ indica uma medida no compósito; $\mathrm{M}$ indica uma medida no metal e $\mathrm{T}$ indica uma medida total).

Tabela 22 - Diferença na forma da obtenção dos valores das propriedades dos CDPs $0^{\circ} / 90^{\circ}$

Tabela 23- Variação das propriedades das junções devido ao empilhamento das camadas. . 135

Tabela 24 - Tensão atuante na região crítica das uniões híbridas.

Tabela 25 - Métodos de obtenção das cargas teóricas máximas admissíveis em comparação com a obtida nos ensaios dos CDPs. 


\section{LISTA DE SÍMBOLOS}

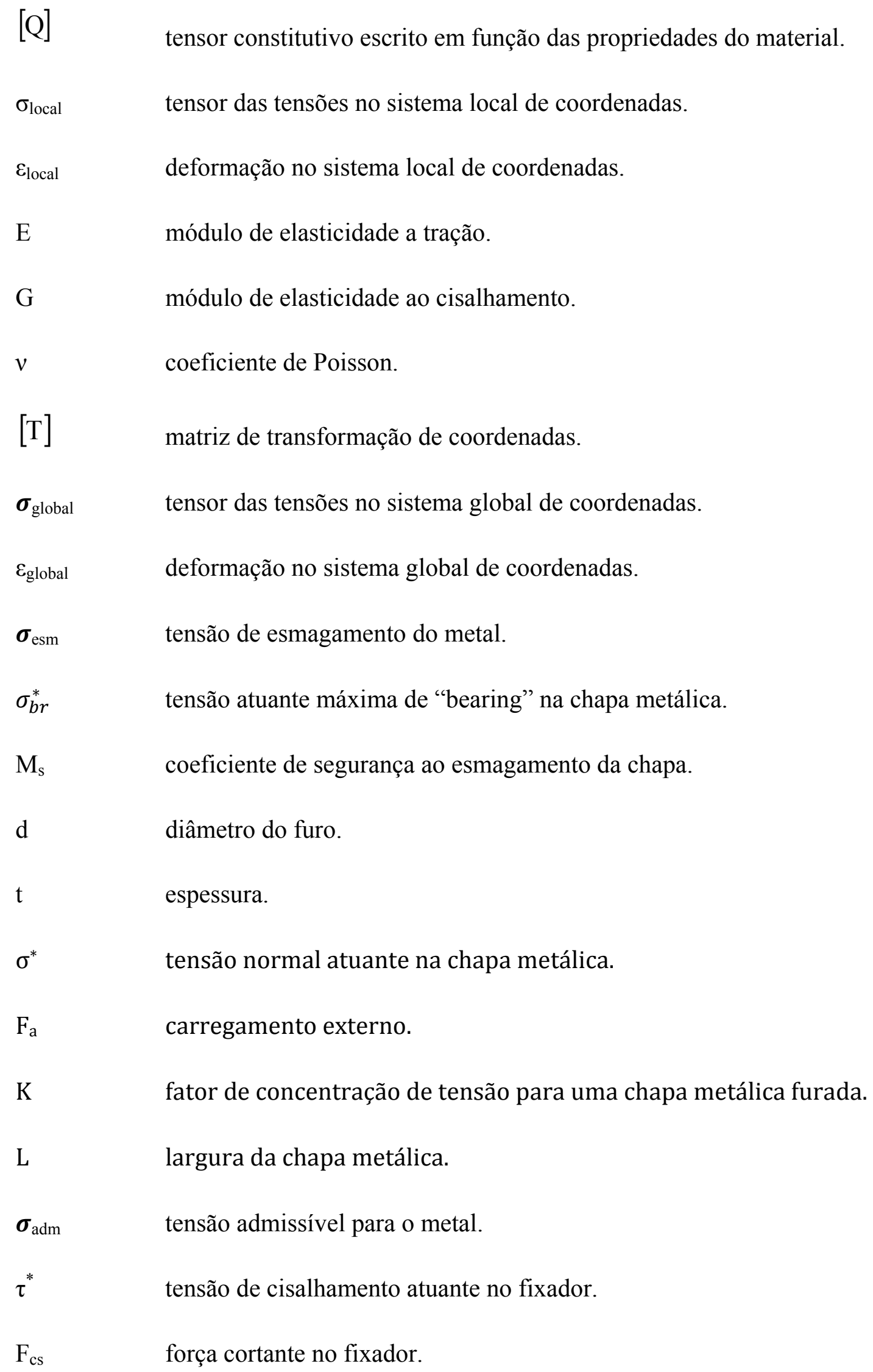


D diâmetro nominal do corpo do fixador.

$\tau_{\mathrm{adm}} \quad$ tensão admissível ao cisalhamento do fixador.

$\sigma_{\mathrm{e}} \quad$ tensão de escoamento do metal sob tração.

f flexibilidade de uma junta.

$\delta \quad$ elongação da junta em função da presença do fixador.

$\sigma_{M}^{\prime} \quad$ tensão crítica atuante em um laminado furado.

$\mathrm{P}_{\mathrm{n}} \quad$ carga total aplicada no laminado furado.

$\mathrm{P}_{\mathrm{f}} \quad$ carga absorvida pela parede do furo do laminado.

$\mathrm{P}_{\mathrm{bp}} \quad$ carga de "by-pass" do laminado.

e distância de borda do laminado.

$\mathrm{X}_{\mathrm{T}} \quad$ tensão de ruptura sob tração na direção das fibras do laminado.

$\mathrm{X}_{\mathrm{T}}{ }_{\mathrm{T}} \quad$ deformação por tração.

$\Delta \mathrm{l}$ deslocamento por tração.

$\mathrm{S}_{12}$ tensão de ruptura sob cisalhamento.

$\gamma \quad$ distorção angular por cisalhamento.

A área da secção transversal do CDP.

$\mathrm{L}_{\mathrm{i}} \quad$ comprimento inicial do corpo-de-prova (CDP). 


\section{SUMÁRIO}

1. INTRODUÇÃO, JUSTIFICATIVAS E OBJETIVOS ...................................................1

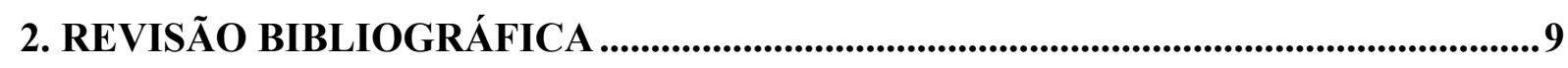

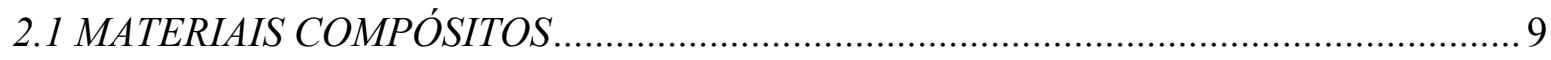

2.2 JUNTAS HÍBRIDAS EM METAL - COMPÓSITO (MECANISMOS DE FALHAS)...... 16

2.2.1 MECANISMOS DE FALHAS: PARTE METÁLICA ............................................. 18

ESMAGAMENTO DA PAREDE DO FURO PELO FIXADOR ("BEARING") ............................18

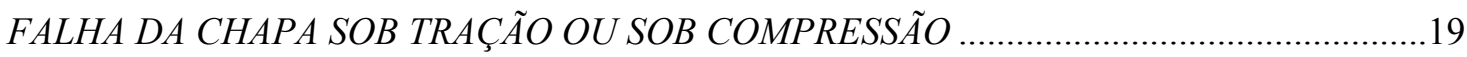

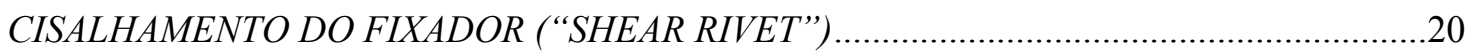

ASPECTOS GERAIS DE PROJETO DE JUNTAS METÁLICAS.............................................21

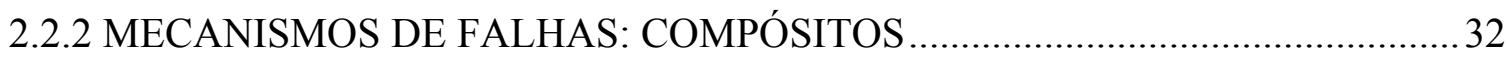

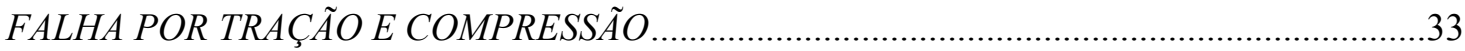

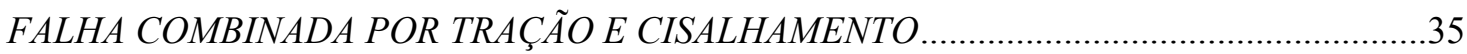

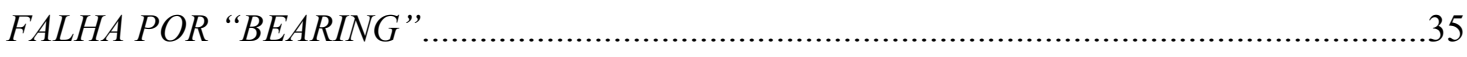

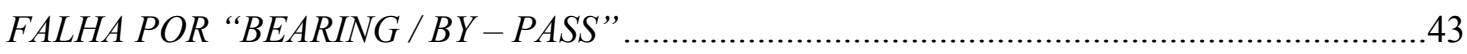

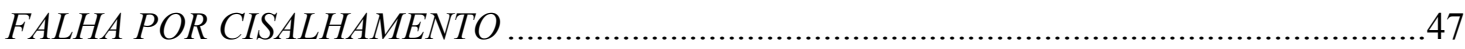

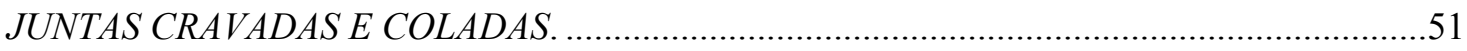

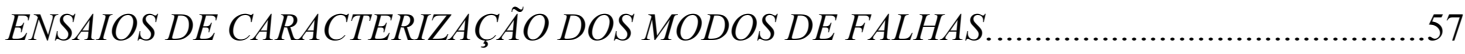

3. MATERIAIS E MÉTODOS.........................................................................................

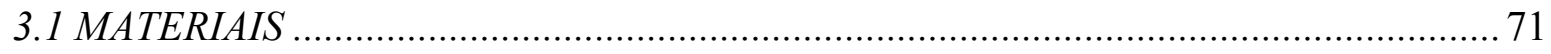

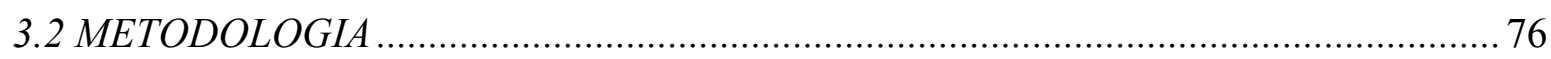

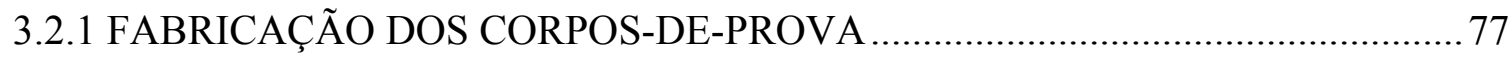

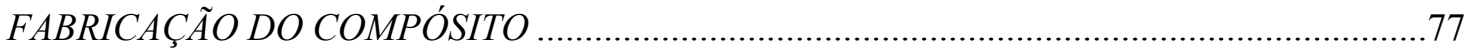

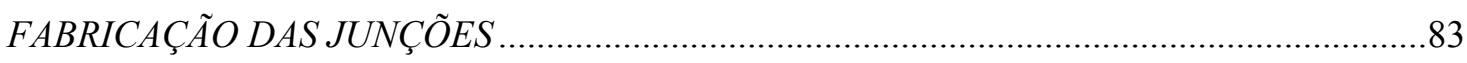

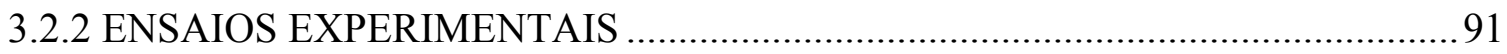

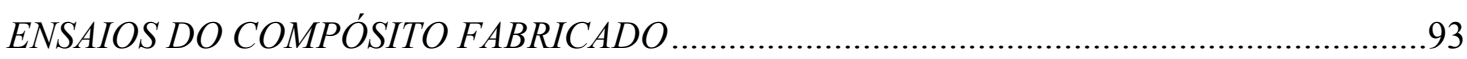

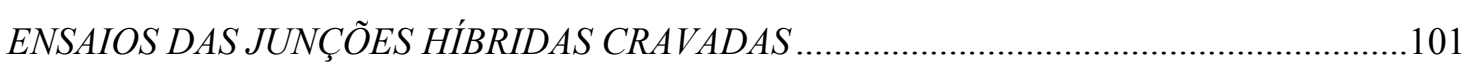

4. RESULTADOS E DISCUSSÕES ..........................................................................111

4.1 RESULTADOS EXPERIMENTAIS DOS COMPÓSITOS FABRICADOS.................... 111

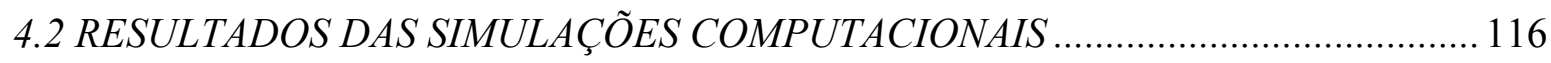

4.3 RESULTADOS EXPERIMENTAIS DAS JUNTAS HÍBRIDAS CRAVADAS ................ 123

5. CONCLUSÕES E PERSPECTIVAS PARA TRABALHOS FUTUROS .....................145

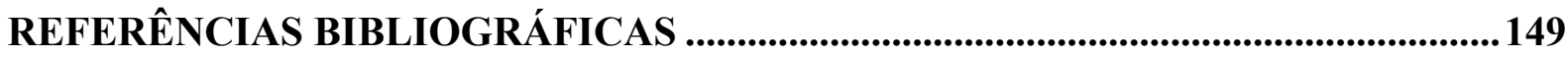




\section{INTRODUÇÃO, JUSTIFICATIVAS E OBJETIVOS}

A aplicação de materiais compósitos é uma realidade atual, principalmente no segmento de indústrias aeronáutica e aeroespacial. Ao longo do tempo, diversos projetos foram construídos considerando as propriedades desses materiais.

Entre estes projetos, citam-se: o F-111, Vought A-7, F-18, F-22, na área militar. No segmento civil, o Lockheed L-1011, Rutan Voyager, Boeing 777, Airbus 380, Boeing 787. O compósito pode ser considerado um material multifase que apresenta uma combinação de propriedades, possibilitando um melhor desempenho desse material em cada fase da sua composição, caso sejam empregadas individualmente, Callister (2002).

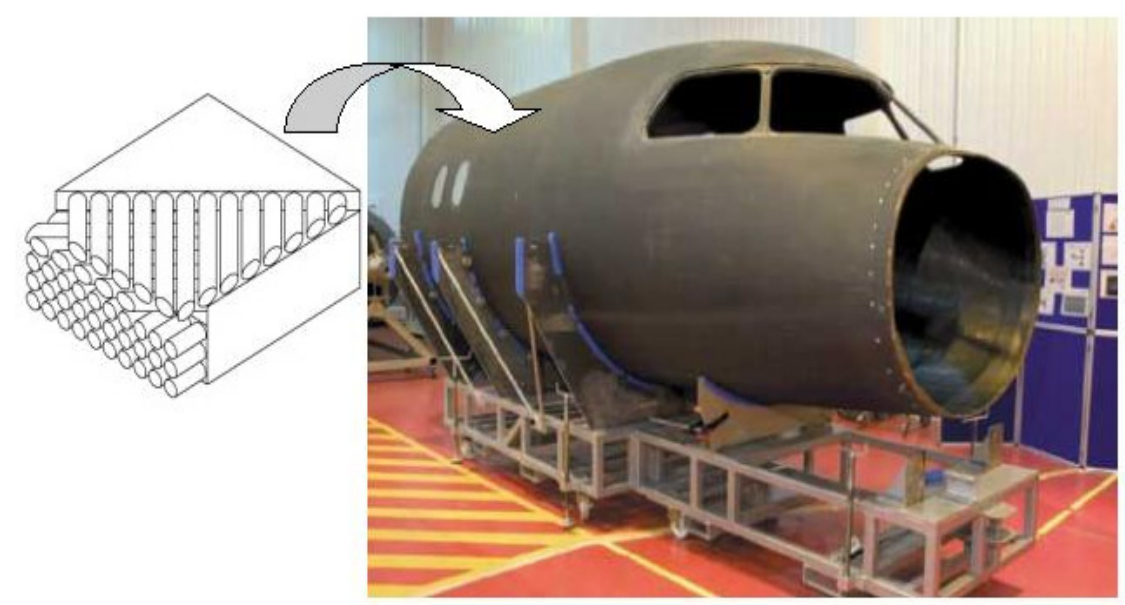

(a)

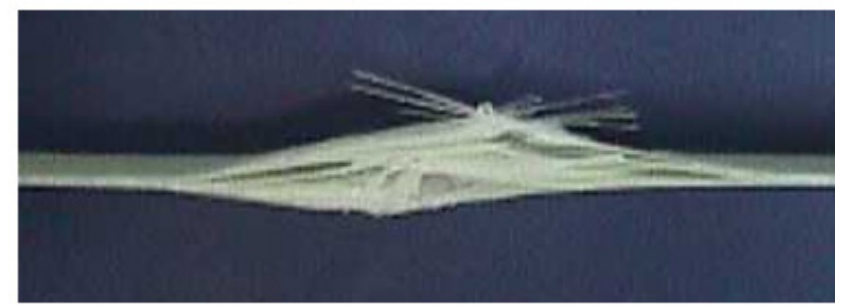

(b)

Figura 1 - Compósito Polimérico Reforçado (CPR): (a) fuselagem em CPR; (b) falhas intra e interlaminares. 
De acordo com esse princípio de ação combinada, procura-se moldar os melhores arranjos de propriedades através de uma combinação criteriosa de dois ou mais materiais distintos.

Esses materiais, que formam o compósito podem ser classificados como aglomerante (fase contínua ou matriz) e o de reforço (fase dispersa). O aglomerante mantém os reforços unidos, transmitindo-lhes o carregamento aplicado. Os reforços têm como função suportar os carregamentos transmitidos pelo aglomerante.

Devido à grande variedade de compósitos, Callister (2002), os classifica como: compósitos reforçados por partículas; compósitos reforçados por fibras e compósitos estruturais.

Neste trabalho serão abordados, especificamente, os compósitos estruturais laminados. Eles possuem uma resina polimérica como matriz e fibras longas como reforços empilhados em camadas. Cada camada possui um conjunto de fibras sob uma dada direção e é chamada de lâmina como mostra a Figura (1(a)). No texto, os Compósitos Poliméricos Reforçados Laminados receberão a sigla “CPR”.

A inerente anisotropia associada aos CPR permite que se projetem as propriedades do material juntamente com as características geométricas e funcionais da estrutura para se obter o desempenho desejado.

A combinação de valores de resistência e de rigidez proporcionada pelo caráter anisotrópico do material e, principalmente o peso, tornou os CPR muito atrativos para as indústrias aeronáuticas e aeroespaciais. Em se tratando de rigidez e resistência tem-se que as mesmas podem ser projetadas em função dos requisitos de projeto, ou seja, pode-se desenvolver o projeto do material em função do carregamento ao qual a estrutura está sendo 
solicitada. Aumentando-se a rigidez, sem necessariamente incrementar o peso total da estrutura, pode-se obter um aumento do desempenho da aeronave. Vale ressaltar que os custos de uma aeronave estão diretamente associados ao processo de produção ao qual o material será submetido para obtenção do componente final. Quanto aos custos, torna-se interessante considerar o fator de utilização de material que é expresso pela relação entre o peso de matéria-prima utilizada pelo peso do componente final. Enquanto que para metais tem-se um fator de utilização de material de 15 - 25, para materiais compósitos tem-se 1,2 - 1,3, Jones (1999).

No entanto, a anisotropia presente nos materiais compósitos pode ser vista como um fator positivo ou negativo. Pois, se por um lado, é concedida a possibilidade de não apenas selecionar o material, mas também projetá-lo em conjunto com a estrutura visando a uma alta eficiência, por outro lado, a anisotropia associada à heterogeneidade faz com que haja uma grande dificuldade em se prever com precisão os modos de falha intra e interlaminares do material, como mostra a Figura (1(b)). Essa dificuldade de prever o comportamento mecânico reflete diretamente na confiabilidade dos componentes fabricados, e torna-se ainda mais séria para componentes de alta responsabilidade, nos quais a combinação de danos por fadiga ou por impacto e de efeitos do meio ambiente podem causar falha catastrófica. Isto obriga o emprego de elevados coeficientes de segurança que evidenciam a subutilização das potencialidades desses materiais, acarretando assim um custo mais elevado para o produto final, Tita (2003).

Por conseguinte, a aplicação desses materiais em estruturas aeronáuticas primárias tais como: longarinas, painéis de revestimentos, cavernas e etc., somente, tornar-se-á viável com o desenvolvimento e a avaliação de modelos de falha que permitam representar coerentemente os fenômenos físicos envolvidos. Dessa forma, atualmente, inúmeros pesquisadores têm 
tomado este desafio como objeto de estudo. Por outro lado, deve-se destacar que estruturas metálicas (por exemplo: em alumínio) são requisitadas em algumas regiões de aeronaves, devido à presença de elevadas temperaturas em função de vôo supersônico. Além disso, fuselagens dianteiras, de bordos de ataque de empenagens e asas apresentam mais desgaste do que outras regiões, requisitando reparo com maior freqüência. Dessa forma, torna-se mais estratégico projetar essas estruturas empregando material metálico ou uma cobertura de material metálico. Portanto, faz-se necessário combinar partes metálicas com partes em compósito gerando, assim, estruturas híbridas (metal-compósito). Cabe ressaltar que vários parâmetros de projeto podem interferir no comportamento mecânico das juntas híbridas. Dentre esses parâmetros, destacam-se a influência do passo entre os fixadores; a distância da borda; o diâmetro do furo; o diâmetro do fixador; o tipo da liga do fixador; a espessura e largura da junta; o tipo de liga da parte metálica; o empilhamento das camadas do compósito; o tipo de fibra e de matriz do compósito.

Diante do cenário apresentado, o presente trabalho justifica-se, e tem como objetivo geral estudar o comportamento mecânico de juntas híbridas metal-compósito, unidas através de fixadores mecânicos, avaliando, principalmente, os mecanismos de falhas, sob carregamento quase-estático, em função da configuração da junta e de outros parâmetros como, por exemplo, o tipo de fixador empregado.

Devido à amplitude do presente objetivo geral, o mesmo é dividido nos objetivos específicos a seguir:

1. Realizar uma revisão bibliográfica visando compreender os trabalhos científicos mais relevantes bem como os mais recentes que foram desenvolvidos nas áreas de junções híbridas metal-compósito e ainda pesquisar na literatura as propriedades dos materiais metálicos e compósitos, bem como metodologias de ensaios; 
2. Fabricar e realizar ensaios experimentais em corpos-de-prova (CDPs) de materiais compósitos (epóxi reforçada com fibra de carbono) seguindo as normas ASTM 3039 e ASTM 3518, a fim de caracterizar os mesmos mecanicamente;

3. Prever o comportamento mecânico em junções híbridas (titânio com compósito polimérico reforçado) com auxilio de análises via Elementos Finitos, definindo uma melhor estratégia para os ensaios experimentais a serem realizados;

4. Fabricar e realizar ensaios experimentais em juntas híbridas metal-compósito, baseando-se na ASTM D5961, bem como, seguindo as estratégias definidas no sub-objetivo anterior;

5. Analisar criteriosamente os resultados, apresentando conclusões que possam ser utilizadas na forma de um guia geral para projeto de juntas híbridas metal-compósito unidas mecanicamente.

Dessa forma, o presente trabalho visa contribuir para a previsão do comportamento mecânico de junções aeronáuticas híbridas (metal-compósito) unidas mecanicamente, através do emprego de simulações computacionais e ensaios experimentais, sendo este constituído pelos seguintes capítulos:

Capítulo 1: Constitui-se de uma contextualização e motivação ao ressaltar a importância de um estudo mais detalhado de modelos de uniões formadas por materiais compósitos e metálicos, utilizados em estruturas aeronáuticas civis e militares de última geração.

Capítulo 2: Apresenta uma revisão bibliográfica com foco nos modos de falhas dos materiais compósitos e metálicos em juntas fixadas mecanicamente. Estes modos de falhas são fortemente influenciados pelos fatores de concentração de tensão, pelo diâmetro do 
fixador, pela espessura, pelo passo entre os fixadores, pela distância de borda e, mais significativamente ainda, pela orientação das camadas do material compósito. Foram abordados, genericamente, trabalhos referentes à estrutura híbrida unidas mecanicamente, coladas e, simultaneamente, coladas e unidas mecanicamente. Por fim, foram apresentadas algumas técnicas de ensaios não destrutivos como forma de caracterização dos modos de falha.

Capítulo 3: São agrupados e descritos os materiais e métodos pertinentes à abordagem deste trabalho. Foram apresentadas as propriedades dos materiais disponíveis na literatura e a metodologia para a fabricação e ensaios dos corpos de prova (CDPs), tanto de caracterização do compósito quanto para as junções híbridas (metal-compósito). A empresa TAM LINHAS AÉREAS S.A. forneceu os materiais, produzindo os CDPs de caracterização dos compósitos e os referentes às junções híbridas, sendo os laminados empilhados nas direções $+45^{\circ} / 45^{\circ}$ e $0^{\circ} / 90^{\circ}$. Os ensaios foram baseados em normas ASTM ("American Society for Testing and Materials”) e realizados em uma máquina de tração de capacidade de $100 \mathrm{KN}$, onde se pôde obter os valores das propriedades mecânicas do compósito e avaliar o comportamento das junções metal-compósito.

Capítulo 4: O tratamento dos resultados experimentais é mostrado neste capítulo. Com os valores das propriedades resultantes dos ensaios de caracterização do material compósito, foi possível desenvolver um estudo via MEF (Método dos Elementos Finitos), tendo por finalidade o conhecimento prévio do comportamento mecânico da estrutura híbrida, principalmente em função do empilhamento das camadas. A metodologia adotada para o ensaio das junções híbridas foi através da aplicação do "Método do Módulo Secundário", constante na especificação MIL - HDBK - 5H(1998), até então utilizado na obtenção das propriedades mecânicas de uniões metal-metal. Uma grande contribuição deste 
trabalho reside na demonstração da aproximação dos valores encontrados na análise via MEF em relação aos obtidos experimentalmente, empregando a norma supracitada.

Capítulo 5: Para finalizar este estudo, foi concluído que a análise via MEF é imprescindível para o prévio conhecimento do comportamento mecânico da estrutura. O "Método do Módulo Secundário" demonstrou-se eficaz na obtenção das propriedades mecânicas de junções híbridas. Por fim, apresentam-se as perspectivas de trabalhos futuros uma vês que existe um enorme campo de pesquisas nesta área em função das possibilidades de se variar os parâmetros que englobam este tipo de estrutura aeronáutica. 


\section{REVISÃO BIBLIOGRÁFICA}

A revisão bibliográfica subdividiu-se em dois grandes tópicos:

\subsection{MATERIAIS COMPÓSITOS}

2.2 JUNTAS HÍBRIDAS (MECANISMOS DE FALHAS)

\subsection{MATERIAIS COMPÓSITOS}

Uma estrutura aeronáutica fabricada em CPR é formada por um conjunto de lâminas empilhadas (laminado) que possuem diferentes orientações de fibra conforme Figura (2(a)). Desta forma, sob cada lâmina há um sistema local de coordenadas baseado nos eixos de ortotropia (1, 2, e 3), onde a direção 1 é paralela à fibra, a direção 2 é perpendicular à fibra e pertence ao plano da lâmina 1-2 e a direção 3 é perpendicular à fibra, sendo normal ao plano da lâmina 1-2 como mostra a Figura (2(b)).

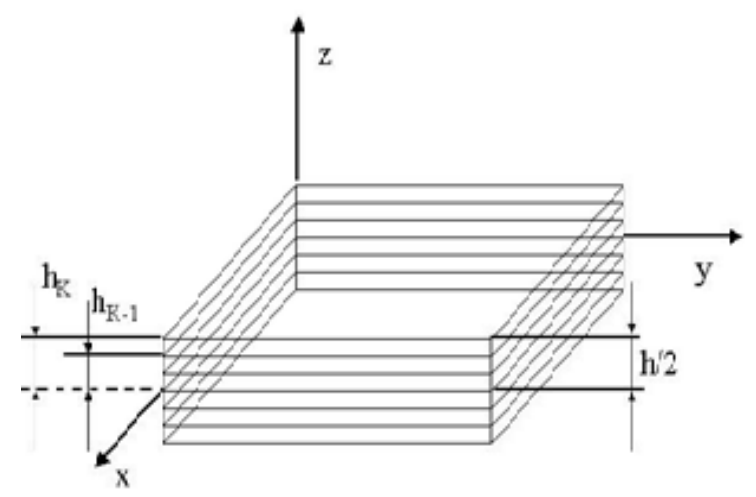

(a)

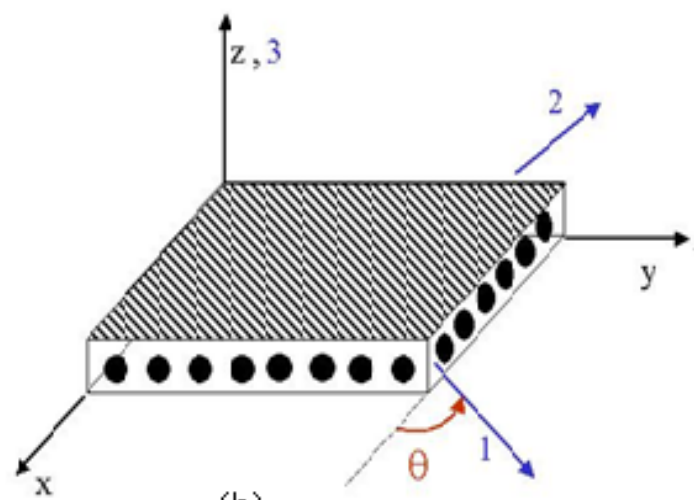

(b)

Figura 2 - (a) laminado; (b) lâmina ortotrópica: sistema global e local de coordenadas.

A combinação da rigidez de cada lâmina irá constituir a rigidez do laminado final. Portanto, dependendo da orientação das fibras e da seqüência de empilhamento das lâminas 
pode-se ter uma determinada rigidez estrutural desejada, Vinson e Sierakowski (1986). No entanto, se por um lado é possível projetar a rigidez da estrutura aeronáutica em função do carregamento aplicado, por outro, é muito difícil prever o complexo processo de falha de uma estrutura laminada.

As estruturas aeronáuticas fabricadas em CPR apresentam, além dos fenômenos de instabilidade (flambagem local, flambagem global, "crippling”, etc.), dois tipos de fenômenos de falha característicos quando são submetidas a um dado carregamento:

Fenômenos Intralaminares: ocorrem dentro das lâminas e correspondem a danos da matriz, da fibra ou da interface fibra-matriz;

Fenômenos Interlaminares: ocorrem entre as lâminas e correspondem especificamente ao fenômeno conhecido por delaminação que se caracteriza pela separação de duas lâminas adjacentes.

Segundo Anderson (1995), os compósitos que possuem uma fraca interação fibramatriz sofrerão a quebra da interface, proporcionando o descolamento entre a fibra e matriz ("debonding") conforme Figura (3(a)) (mecanismo 3). No entanto, para os compósitos com uma forte interação, haverá, provavelmente, o rompimento da fibra que produzirá assim o mecanismo de "Pull-Out" conforme Figura (3(a)) (mecanismo 1). Tal mecanismo caracterizase pelo arrancamento da fibra de dentro da matriz que geralmente ocorre após a propagação de uma fissura. Antes da ocorrência do "Pull-Out" pode haver a formação do mecanismo de "Fiber Bridging" (mecanismo 2) da Figura (3(a)), desde que o compósito possua fibras frágeis de alta resistência, matrizes dúcteis e interface forte. Sendo assim, a fissura se propaga pela matriz e a fibra forma uma ponte interligando as duas superfícies da matriz fraturada. Por outro lado, a fronteira da fissura dá origem a regiões com concentração de tensão até mesmo fora do plano de propagação. A região localizada à frente da fissura, que está se propagando, 
concentra altas tensões, podendo também levar à "Fratura da Fibra" (mecanismo 4) devido a sua alta fragilidade, ou à "Danificação da Matriz" (mecanismo 5), ambas mostradas na Figura (3(a)).

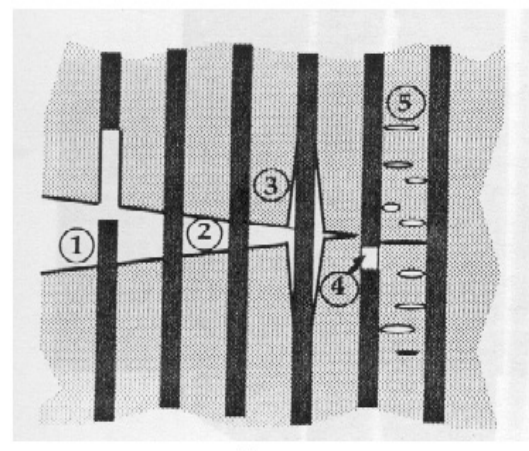

(a)

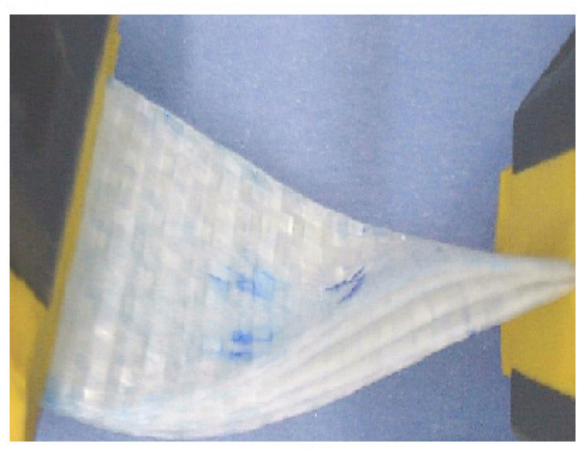

(b)

Figura 3 - Mecanismos de danificação / falha em CPR: (a) danificações Intralaminares, Anderson (1995); (b) falhas interlaminares, Tita (2003).

Estudos demonstram que o mecanismo de falha dos compósitos laminados se assemelha ao dos metais no que diz respeito à evolução do processo. Ou seja, assim como nos metais, a falha nos materiais compósitos inicia-se por pequenos mecanismos (danos intralaminares) para depois então ocorrer os mecanismos mais visíveis (falha interlaminar), Anderson (1995). Normalmente o processo de danificação inicia-se em lâminas que tenham orientação de fibra próxima a $90^{\circ}$ em relação aos carregamentos. Após o aparecimento do primeiro dano, o carregamento na estrutura tende a ser re-distribuído vindo a provocar o aparecimento de mais regiões danificadas na mesma lâmina ou em outras lâminas. Esse processo ocorre sucessivamente até que essas regiões danificadas se unem, formando assim uma fissura discreta. As fronteiras das fissuras que se formaram numa determinada lâmina encontram lâminas adjacentes com ângulos de orientação diferente. Neste momento, as tensões de cisalhamento interlaminares crescem abruptamente e levam o laminado a iniciar o processo de delaminação conforme Figura (3(b)). Dessa forma, tem-se que o processo de 
falha de um laminado é complexo, ocorrendo de forma progressiva. Nota-se assim, a dificuldade em se prever o comportamento mecânico de estruturas aeronáuticas em CPR, obrigando muitas vezes a utilização de elevados coeficientes de segurança durante a fase de desenvolvimento do projeto. Segundo Matthews e Rawlings (1994), a falha de uma estrutura em CPR ocorre no momento em que a mesma não pode mais satisfazer a função para o qual foi projetada. Sendo assim, durante a fase de desenvolvimento do projeto torna-se necessário o emprego de um critério de danificação/falha que seja capaz de identificar a ocorrência de um dano intralaminar ou então de uma falha interlaminar. Tal critério pode ser expresso matematicamente na forma de uma função relacionando as tensões/deformações atuantes com valores limites de resistência/elongações determinados experimentalmente. No entanto, o caráter anisotrópico intrínseco aos materiais compósito laminados faz com que a determinação das tensões/deformações atuantes não seja uma tarefa simples, sendo necessário recorrer a alguns fundamentos da Mecânica dos Sólidos.

O tensor das tensões $\boldsymbol{\sigma}_{\mathrm{Global}}$ contém as componentes de tensão do ponto material em relação ao sistema global de coordenadas $(\mathrm{x}, \mathrm{y}, \mathrm{z})$ de acordo com a Figura (2(b)). Segundo Keunings (1992), num material ortotrópico, segundo as direções de ortotropia, não há acoplamentos entre tensões normais e distorções angulares bem como não há acoplamentos entre tensões de cisalhamento e deformações normais. Sendo assim, tensões normais não produzem distorções angulares e tensões de cisalhamento não produzem deformações normais. Com base nessa afirmação e com base em estudos que demonstram a simetria do tensor constitutivo para materiais ortotrópicos, tem-se que a Lei de Hooke assumirá a seguinte forma:

$$
\sigma_{\text {Local }}=[Q] \varepsilon_{\text {Local }}
$$


Onde:

[Q] = tensor constitutivo escrito em função das propriedades do material, Vinson e Sierakowsky (1986)

Nota-se através da equação (1) o cálculo do tensor $\sigma_{\text {Local }}$ que contém as componentes de tensão do ponto material em relação ao sistema local de coordenadas $(1,2,3)$ como mostra a Figura 2(b). Além disso, uma lâmina ortotrópica unidirecional pode ser também transversalmente isótropa o que acarreta em: $E_{22}=E_{33} ; G_{12}=G_{13}$ e $v_{12}=v_{13}$. Para que se possa calcular a matriz de rigidez da lâmina em relação ao sistema global de coordenadas é necessário aplicar uma transformação de coordenadas, conforme a equação (2):

$$
[\bar{Q}]=[T]^{-1}[Q] \cdot[T]
$$

onde:

$$
[\mathrm{T}]=\text { matriz de transformação de coordenadas. }
$$

Com isso, torna-se possível o cálculo do tensor $\boldsymbol{\sigma}_{\mathrm{Global}}$ bem como escrever as componentes de tensão no sistema local em função das componentes de tensão global:

$$
\begin{gathered}
\sigma_{\text {Global }}=[\bar{Q}] \varepsilon_{\text {Global }} \\
\sigma_{\text {Local }}=[\mathrm{T}] \sigma_{\text {Global }}
\end{gathered}
$$

Sob posse do tensor $\sigma_{\text {Local }}$, pode-se assim verificar se uma dada camada da estrutura aeronáutica irá resistir aos carregamentos aplicados.

Na Figura (4) tem-se todo procedimento de análise para uma estrutura laminada. Notase pelo procedimento que inicialmente deve-se estabelecer um Modelo de Material a fim de 
que a rigidez do laminado possa ser calculada. Com base nos carregamentos atuantes e na rigidez do laminado, pode-se calcular o campo de deslocamentos de um dado ponto material em relação ao sistema global de coordenadas utilizando as Equações de Equilíbrio do sistema. Sob posse dos deslocamentos, é possível obter as deformações para o sistema global de coordenadas aplicando as Equações de Compatibilidade. Essas deformações ao serem substituídas nas Relações Constitutivas da equação (3) fornecem as componentes de tensão do ponto material em relação ao sistema de coordenadas global. No entanto, a grande maioria dos Critérios de Falha ou de Danificação para materiais compósitos laminados é estabelecida para analisar a falha de uma lâmina. Sendo assim, utiliza-se a equação (4) para obter as componentes de tensão do ponto material em relação ao sistema de coordenadas local. Além disso, há muitos critérios de falha escritos em função das deformações. Neste caso, deve-se aplicar diretamente a transformação [T] ao vetor das deformações escrito em função das coordenadas globais. Por fim, para que o procedimento possa ser empregado é necessário escolher um Critério de Falha ou de Danificação que seja adequado.

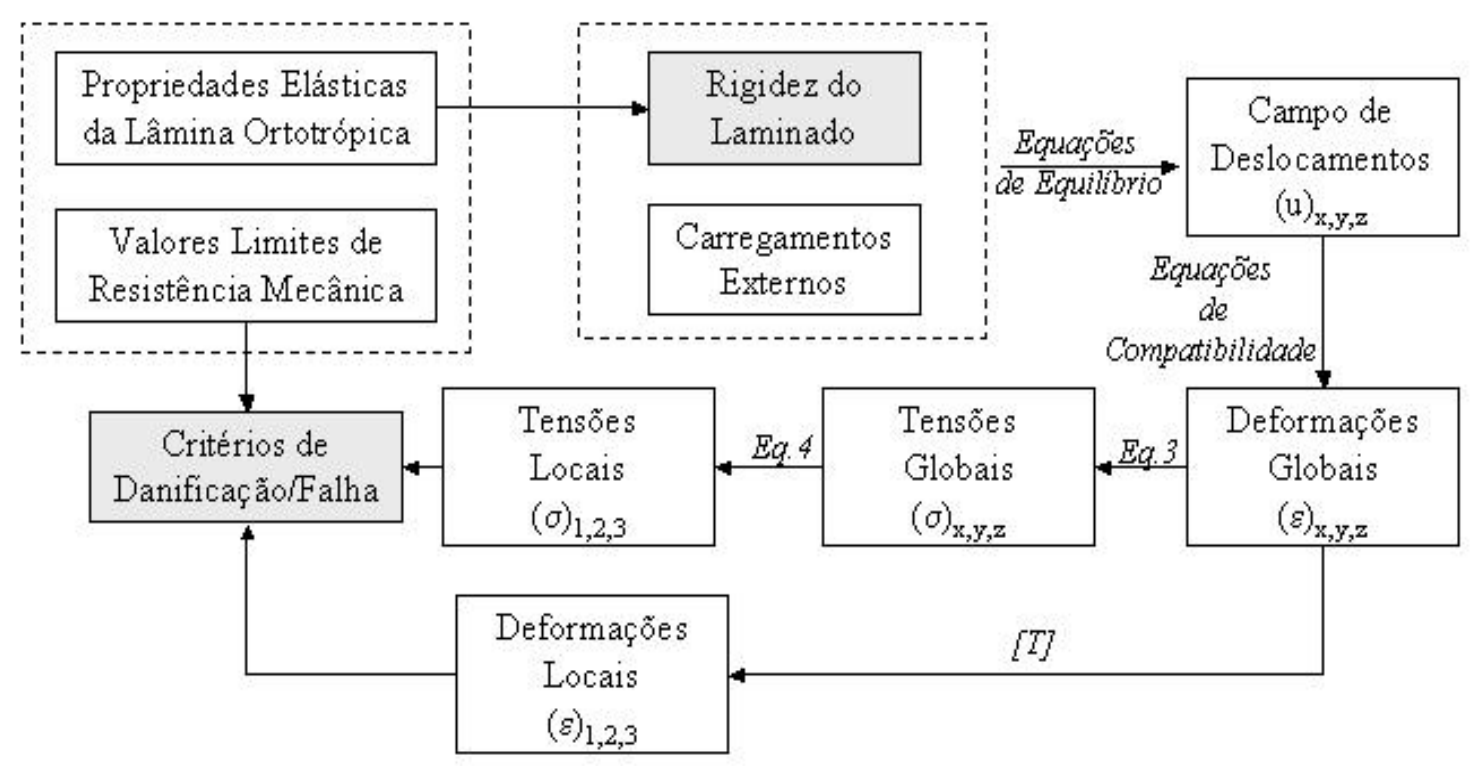

Figura 4 - Procedimento de análise de uma estrutura laminada. 
No entanto, a escolha de um critério para compósitos é algo complexo, pois necessita satisfazer três requisitos: 1) Ser o mais geral possível, podendo assim avaliar vários estudos de caso; 2) Ser capaz de representar de forma consistente os fenômenos físicos envolvidos e 3) Não necessitar de muitos experimentos para estabelecer uma superfície no espaço das tensões.

Devido principalmente à complexidade em modelar os fenômenos físicos intra e interlaminares, tem-se na literatura a descrição de inúmeras contribuições. Somente no trabalho de Rowlands (1985) foram apresentados e comentados 21 critérios e de acordo com o relatório de París (2001), há 53 referências sob a aplicação de critérios de danificação/falha para CPR. Além disso, deve-se destacar que é possível encontrar na literatura uma gama de trabalhos que buscam prever o comportamento mecânico de estruturas fabricadas a partir de CPR (Dávila, Camanho e Moura (2001); Williams e Vaziri (2001); Tita, Carvalho e Santos (2002); Kostopoulos et al (2002) e Tita (2003)).

Mais recentemente Turon et al (2006) propuseram um modelo de delaminação progressiva baseado em conceitos da Mecânica do Dano. Renard e Thionnet (2006) propuseram uma Lei de Evolução do Dano para degradar as componentes da matriz constitutiva. Paepegen, Baere e Degrieck (2006a) realizaram ensaios experimentais de cisalhamento e, posteriormente, desenvolveram um modelo de degradação para o módulo de cisalhamento no plano $\left(\mathrm{G}_{12}\right)$. Paepegen, Baere e Degrieck (2006b) e Stephen e Wisnom (2006) realizaram análise Progressiva de Dano de corpos-de-prova de tração em material compósito com a finalidade de avaliar o efeito de entalhes na evolução de danos inter e intralaminar. Coutellier, Walrick e Geoffroy (2006) realizaram análises computacionais via elementos finitos de estruturas laminadas, empregando conceitos da Mecânica da Fratura e da 
Mecânica do Dano. Ianucci (2006) avaliou placas planas laminadas sob impacto, empregando o método dos elementos finitos e modelando a degradação das propriedades mecânicas.

Considerando-se o que foi revisto, serão realizadas simulações computacionais com o intuito de prever o comportamento mecânico de juntas híbridas durante os ensaios experimentais, bem como, visando orientar os mesmos.

\subsection{JUNTAS HÍBRIDAS EM METAL-COMPÓSITO (MECANISMOS DE FALHAS)}

Inicialmente, torna-se conveniente uma recordação da distribuição das tensões em um corpo sólido, mostrada pela figura (5).

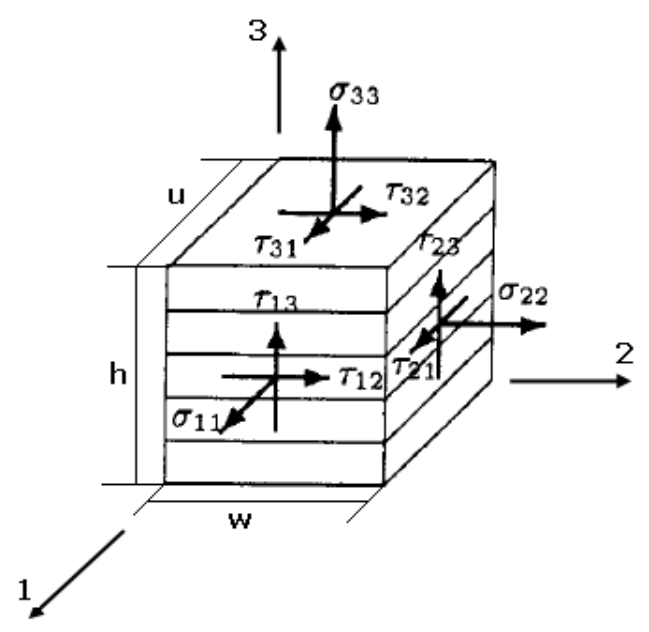

Figura 5 - Distribuição de tensões normais e de cisalhamento em um corpo sólido.

Segundo Niu (1988), as considerações gerais de projeto de uma junta, talvez a maior fonte comum de falhas em estruturas aeronáuticas, são de suma importância entre todos os aspectos do projeto considerados por ocasião da análise estrutural. As falhas podem ocorrer por várias razões, mas geralmente se dão por causa de algum fator, tais como: momento secundário devido à excentricidade do carregamento; concentrações de tensão; deflexões 
excessivas e outras condições, todas de difícil avaliação. Esses fatores não somente afetam o comportamento estático, mas também possuem uma forte influência na vida em fadiga da junta e na estrutura adjacente.

Destacam-se alguns aspectos, como potencial de falha prematura, a serem considerados no projeto de uma junta:

1) Excentricidade e seus efeitos na junta e na estrutura adjacente - se há excentricidade, devido ao desalinhamento da carga, o momento secundário gerado deve ser resistido pela estrutura adjacente. Os parafusos e rebites carregados pelo efeito desta excentricidade podem produzir conexões excessivamente tensionadas;

2) Vida em fadiga - deve-se realizar um estudo detalhado para o seu adequado dimensionamento;

3) Combinação de fixadores - não é uma boa prática empregar parafusos e rebites combinados em uma junta. Devido ao melhor ajuste dos rebites, os parafusos não obterão uma condição proporcional de distribuição da carga. Em outras palavras, os rebites defletem muito até que ocorra a ação da carga nos parafusos. Isto leva a uma sobrecarga nos rebites, podendo induzir a uma falha prematura;

4) Reparos ou emendas na estrutura - devem ser projetados e executados com critérios adequados através de especificações pertinentes, pois podem ocasionar falhas prematuras;

5) Fixadores para montagem com interferência - devem ser selecionados cuidadosamente para não produzir concentração de tensão, podendo ocasionar fissura no seu corpo e, conseqüentemente, a falha do mesmo. 


\subsubsection{MECANISMOS DE FALHAS: PARTE METÁLICA}

A seguir, serão apresentados os modos de falhas em juntas mecânicas constituídas por chapas metálicas, bem como, aspectos gerais associados ao projeto de juntas.

ESMAGAMENTO DA PAREDE DO FURO PELO FIXADOR ("BEARING")

$\mathrm{O}$ esmagamento ocorrerá quando a tensão gerada pela força $\mathrm{P}$, exercida pelo fixador na chapa, possuir intensidade e sentido contrário igual ou superior ao valor da resistência ao esmagamento do material da chapa, como mostra a Figura (6).
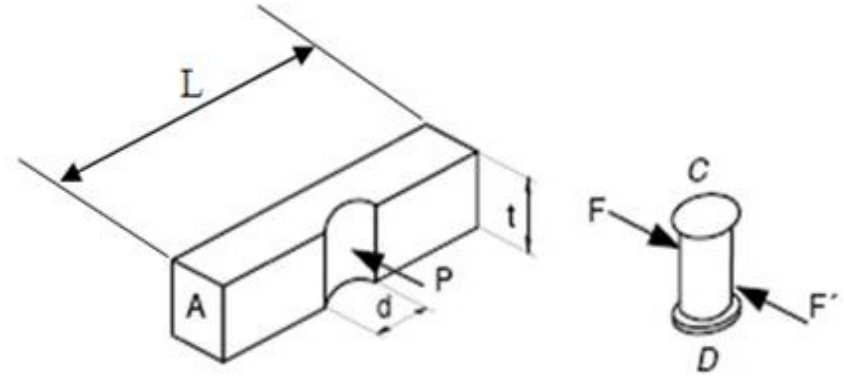

Figura 6 - Distribuição de esforços na parede do furo e no fixador.

Então, tem-se que a tensão atuante deverá ser inferior à tensão de esmagamento ("bearing") $\left(\sigma_{\text {esm }}\right)$ :

$$
\sigma_{b r}^{*}=\frac{P}{d . t} \cdot M_{S} \leq \sigma_{e s m}
$$

Onde:

$$
\begin{aligned}
& \sigma_{b r}^{*}=\text { tensão atuante de "bearing" na chapa metálica } \\
& \mathrm{M}_{\mathrm{s}}=\text { coeficiente de segurança ao esmagamento da chapa } \\
& \mathrm{d}=\text { diâmetro do furo } \\
& \mathrm{t}=\text { espessura da chapa }
\end{aligned}
$$




\section{FALHA DA CHAPA SOB TRAÇÃO OU SOB COMPRESSÃO}

A resistência da chapa sob tração ou sob compressão é uma função da relação do diâmetro do furo com a largura da chapa (d / L), mostrada na Figura (6). Quanto maior for esta relação, menor será a área de resistência a tração ou à compressão, até que a tensão atuante nesta área supere o limite de escoamento do material, ocorrendo, neste instante, a falha por tração ou por compressão na chapa. Nota-se, também, que o fator de concentração de tensão (por exemplo: quando existir um furo na chapa), conforme mostra a Figura (7) deverá ser considerado. Sendo assim, caso o furo seja circular, tem-se que assumir o triplo do valor da tensão atuante.

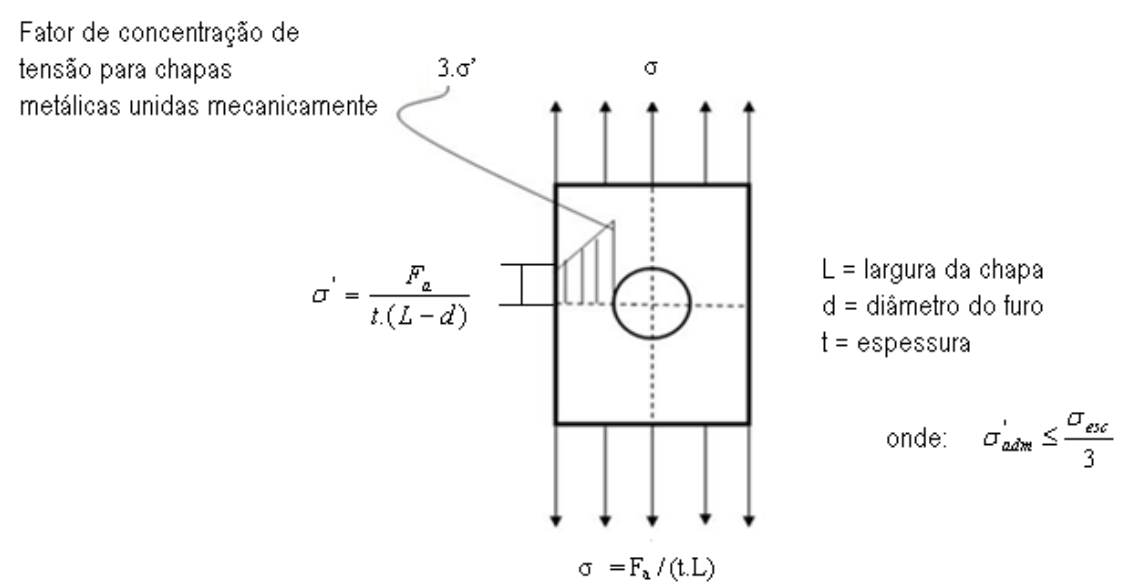

Figura 7 - Fator de concentração de tensão devido ao furo na chapa.

Desta forma, tem-se que a tensão atuante causada pelo carregamento externo $\mathrm{F}_{\mathrm{a}}$, amplificada pelo fator de concentração de tensão $\mathrm{K}$, deverá ser inferior à tensão admissível $\left(\sigma_{\mathrm{adm}}\right)$ da chapa, que é dada através dos limites do escoamento à tração ou à compressão do material:

$$
\sigma^{*}=\frac{F_{a}}{t .(L-d)}(K) \leq \sigma_{a d m}
$$


onde:

$$
\begin{aligned}
& \sigma^{*}=\text { tensão normal atuante na chapa metálica } \\
& \mathrm{L}=\text { largura da chapa metálica } \\
& \mathrm{d}=\text { diâmetro do furo } \\
& \mathrm{t}=\text { espessura da chapa } \\
& \mathrm{F}_{\mathrm{a}}=\text { carregamento externo } \\
& \mathrm{K}=\text { fator de concentração de tensão para uma chapa metálica furada }
\end{aligned}
$$

\section{CISALHAMENTO DO FIXADOR ("SHEAR RIVET”)}

O mecanismo de falha através de cisalhamento do fixador ("shear rivet") é evitado de tal forma que a tensão de cisalhamento atuante seja inferior à tensão admissível ao cisalhamento $\left(\tau_{\mathrm{adm}}\right)$ :

$$
\tau^{*}=\frac{F_{c s}}{\frac{\pi}{4} \cdot D^{2}} \leq \tau_{a d m}
$$

onde:

$$
\begin{aligned}
& \tau^{*}=\text { tensão de cisalhamento atuante no fixador } \\
& \mathrm{F}_{\mathrm{cs}}=\text { força cortante no fixador } \\
& \mathrm{D}=\text { diâmetro nominal do corpo do fixador }
\end{aligned}
$$


A Tabela (1) mostra a tensão de ruptura ao cisalhamento puro em função de diferentes diâmetros e materiais de fixadores.

Tabela 1 - Tensões de ruptura ao simples cisalhamento nos fixadores (MIL-HDBK-5H (1998)).

\begin{tabular}{|c|c|c|c|c|c|c|c|c|c|c|c|}
\hline Diâmetro & (D) & $3 / 32$ & $1 / 8$ & $5 / 32$ & $3^{\prime} 16$ & $1 / 4$ & $5 / 16$ & $3 / 8$ & $7 / 16$ & $1 / 2$ & $9 / 16$ \\
\hline Material & $\begin{array}{c}\tau \\
\text { (Ksi) }\end{array}$ & \multicolumn{10}{|c|}{ Força última de cisalhamento (lb) } \\
\hline $1100 \mathrm{~F}$ & 9 & & & & & & & & & & \\
\hline $5056(B)$ & 28 & 203 & 363 & 556 & 802 & 1450 & 2290 & 3280 & & & \\
\hline $2117-\mathrm{T} 3(\mathrm{AD})$ & 30 & 217 & 388 & 596 & 862 & 1550 & 2460 & 3510 & & & \\
\hline 2017-T31(D) & 34 & 247 & 442 & 675 & 977 & 1760 & 2790 & 3970 & & & \\
\hline 2017-T3(D) & 38 & 275 & 494 & 755 & 1090 & 1970 & 3110 & 4450 & & & \\
\hline 2024-T31(DD) & 41 & 296 & 531 & 815 & 1180 & 2120 & 3360 & 4800 & & & \\
\hline Monel & 49 & 355 & 635 & 973 & 1400 & 2540 & 4020 & 5730 & & & \\
\hline 7075-H75 & 38 & 275 & 494 & 755 & 1090 & 1970 & 3110 & 4450 & & & \\
\hline A-286 CRES & 90 & - & - & 1726 & 2485 & 4415 & 6906 & 9938 & & & \\
\hline $\begin{array}{l}\text { Ti-6A1-4V } \\
\text { \& Alloy Steel }\end{array}$ & 95 & - & - & 1822 & 2623 & 4660 & 7290 & 10490 & 14280 & 18650 & 23610 \\
\hline Alloy Steel & 108 & - & - & 2071 & 2982 & 5300 & 8280 & 11930 & 16240 & 21210 & 26840 \\
\hline Alloy Steel & 125 & - & - & 2397 & 3452 & 6140 & 9590 & 13810 & 18790 & 24540 & 31060 \\
\hline $\mathrm{H}-11$ Steel & 132 & - & - & 2531 & 3645 & 6480 & 10120 & 14580 & 19840 & 25920 & 32800 \\
\hline
\end{tabular}

ASPECTOS GERAIS DE PROJETO DE JUNTAS METÁLICAS

A junta aeronáutica é projetada para trabalhar com um coeficiente de segurança adequado. Segundo requisitos aeronáuticos, este coeficiente pode ser uma função direta da tensão de escoamento do material. No caso do esmagamento da chapa ("bearing”), o coeficiente de segurança $\left(\mathrm{M}_{\mathrm{s}}\right)$ deve ser estipulado, de acordo com as características do projeto, para a definição da tensão máxima atuante (equação 5). Desta forma, tem-se que as demais tensões máximas atuantes são dadas por:

$$
\begin{gathered}
\sigma_{\max }^{*} \leq \frac{\sigma_{a d m}}{1,5}=\frac{\frac{\sigma_{e}}{3}}{1,5}=\frac{\sigma_{e}}{4,5} \\
\tau_{\max }^{*} \leq \frac{\tau_{a d m}}{1,5}
\end{gathered}
$$


Assim, a equação (8) pode representar a tensão máxima de trabalho para chapas furadas sob tração ou sob compressão, ao passo que a equação (9) pode representar a tensão máxima de trabalho para fixador sob cisalhamento puro. Desta forma, estas tensões podem ser uma função direta da tensão de escoamento/admissível do material, considerando-se um coeficiente de segurança de 1,5 para o dimensionamento da estrutura.

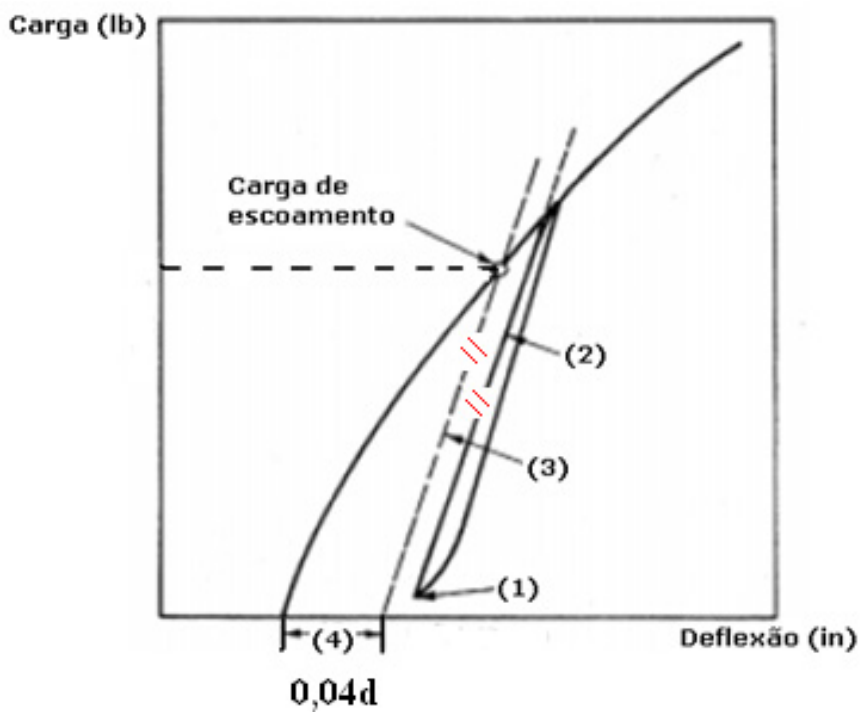

Figura 8 - Determinação da carga de escoamento através do Método do Módulo Secundário (adaptado do MIL-HDBK-5H (1998)).

No entanto, os valores de tensão máxima dependem dos valores da tensão de escoamento $\left(\sigma_{\mathrm{e}}\right)$. Segundo a especificação MIL - HDBK - 5H (1998), a carga de escoamento da junta, para todos os tipos de fixadores, é definida como sendo aquela que resulta em uma projeção imaginária da rigidez da estrutura sobre o eixo de Deflexão (elongação) do ensaio da junta, sendo que o ponto de partida adotado no eixo de Deflexão corresponde a 0,04 do diâmetro nominal do furo (d) (Figura (8)).

O método mais empregado para a determinação da carga de escoamento é conhecido como "Método do Módulo Secundário" e está mostrado na Figura (8). Consiste na obtenção de uma função de "módulo secundário", durante o ensaio da junta, compreendida como a 
linha elástica originada por um ciclo fechado de descarregamento e re-carregamento. $\mathrm{O}$ descarregamento se dá até uma redução de $10 \%$ a $20 \%$ do valor da carga estimada de escoamento (1). A junta então é recarregada e a carga de escoamento real é definida pela reta imaginária (3). A reta imaginária tracejada é paralela à linha elástica de "módulo secundário" obtida a partir do re-carregamento do ciclo (2). Porém, há uma condição de contorno admitida como sendo a deflexão permanente da junta com valor igual a 0,04 do diâmetro nominal do furo. Vale ressaltar que este procedimento é válido desde que o fixador seja ensaiado na dimensão nominal do furo (d), de acordo com a Tabela (2).

Tabela 2 - Furo nominal e diâmetro do corpo do fixador (in) (MIL-HDBK-5H (1998)).

\begin{tabular}{|c|c|c|c|c|}
\hline \multirow{2}{*}{$\begin{array}{l}\text { Diâmetro do } \\
\text { fixador (D) }\end{array}$} & \multicolumn{2}{|c|}{\begin{tabular}{c|} 
Corpo deformbivel \\
Dibmetro nominal do furo
\end{tabular}} & \multicolumn{2}{|c|}{$\begin{array}{c}\text { Corpo náo deformavel } \\
\text { Dibmetro nominal do corpo }\end{array}$} \\
\hline & $\begin{array}{l}\text { Rebiter } \\
\text { gólidos }\end{array}$ & $\begin{array}{l}\text { Fixador de } \\
\text { funo cege }\end{array}$ & $\begin{array}{l}\text { Fixador de } \\
\text { corpo sólide }\end{array}$ & $\begin{array}{l}\text { Fixador de } \\
\text { furo cege }\end{array}$ \\
\hline $\begin{array}{l}1 / 16 \\
3 / 32\end{array}$ & $\begin{array}{l}0.067 \\
0.096\end{array}$ & 0.098 & $\ldots$ & $\ldots$ \\
\hline$=4$ & $\ldots$ & $\ldots$ & 0.112 & $\ldots$. \\
\hline $1 / 8$ & 0.1285 & $\begin{array}{l}0.130 \\
0.144\end{array}$ & 0.125 & $\ldots$ \\
\hline$\# 6$ & & & 0.138 & \\
\hline $5 / 32$ & 0.159 & $\begin{array}{l}0.162 \\
0.178\end{array}$ & 0.156 & 0.163 \\
\hline$=8$ & & & 0.164 & \\
\hline $3 / 16$ & 0.191 & $\begin{array}{l}0.194 \\
0.207\end{array}$ & 0.188 & 0.198 \\
\hline$=10$ & $\ldots$ & $\ldots$ & 0.190 & $\ldots$ \\
\hline$=12$ & $\ldots$ & $\ldots$ & 0.216 & $\ldots$ \\
\hline $7 / 32$ & & & 0.219 & $\ldots$ \\
\hline $1 / 4$ & 0.257 & $\begin{array}{l}0.258 \\
0.273\end{array}$ & 0.250 & 0.259 \\
\hline $5 / 16$ & 0.323 & & 0.312 & 0.311 \\
\hline $3 / 8$ & 0.386 & $\ldots$ & 0.375 & 0.373 \\
\hline $7 / 16$ & $\ldots$ & ... & 0.438 & 0.436 \\
\hline $1 / 2$ & $\ldots$ & $\ldots$ & 0.500 & 0.497 \\
\hline $9 / 16$ & $\ldots$ & $\ldots$ & 0.562 & $\ldots$ \\
\hline $5 / 8$ & $\ldots$ & $\ldots$ & 0.625 & $\ldots$ \\
\hline $3 / 4$ & $\ldots$ & $\ldots$ & 0.750 & $\ldots$ \\
\hline $7 / 8$ & $\ldots$ & $\ldots$ & 0.875 & $\ldots$ \\
\hline 1 & $\ldots$ & ... & 1.000 & $\ldots$ \\
\hline $1-1 / 8$ & $\ldots$ & $\ldots$ & 1.125 & $\ldots$ \\
\hline $1-1 / 4$ & $\ldots$ & ... & 1.250 & $\ldots$ \\
\hline $1-3 / 8$ & $\ldots$ & $\ldots$ & 1.375 & $\ldots$ \\
\hline $1-1 / 2$ & $\ldots$ & $\ldots$ & 1.500 & $\ldots$ \\
\hline
\end{tabular}

Para melhor entendimento da Tabela (2), faz-se necessário estabelecer algumas definições, tais como:

* Fixador de corpo deformável: um fixador cujo corpo é deformado durante o processo normal de instalação; 
* Diâmetro nominal do furo: os diâmetros nominais dos furos para fixadores de corpos deformáveis devem ser de acordo com a Tabela (2). Quando os ensaios são realizados com diâmetros de furos diferentes daqueles listados, a dimensão do furo usada deve ser cuidadosamente avaliada;

* Fixador de corpo não deformável: um fixador cujo corpo não deforma durante o processo normal de instalação;

* Diâmetro nominal do corpo: os diâmetros nominais dos corpos de fixadores os quais equivalem a aqueles usados para dimensões padrões de parafusos.

Por outro lado, para o desenvolvimento do projeto de juntas mecânicas, é interessante que haja uma visão geral do comportamento das ocorrências de falhas, em função de alguns parâmetros, tais como: diâmetro nominal do furo (d); espessura da chapa (t). Verifica-se que há 3 trechos distintos na curva (Figura (9)), caracterizando o fenômeno de "bearing" (trecho 1), o fenômeno de cisalhamento do fixador (trecho 3) e uma zona de transição entre esses dois fenômenos (trecho 2). Na Figura (9), no trecho de falha por "bearing", tem-se um incremento acentuado da carga com o aumento da razão t/d, ao passo que, no trecho de transição, este incremento da carga a é mais lento. Finalmente, no trecho de falha por cisalhamento, verificase que praticamente não há incremento da carga com o aumento da razão t/d. Isto é plenamente coerente, uma vez que para se evitar falha do fixador, deve-se alterar outros parâmetros associados ao mesmo, como por exemplo: material, tipo da cabeça, tratamento térmico, etc. 


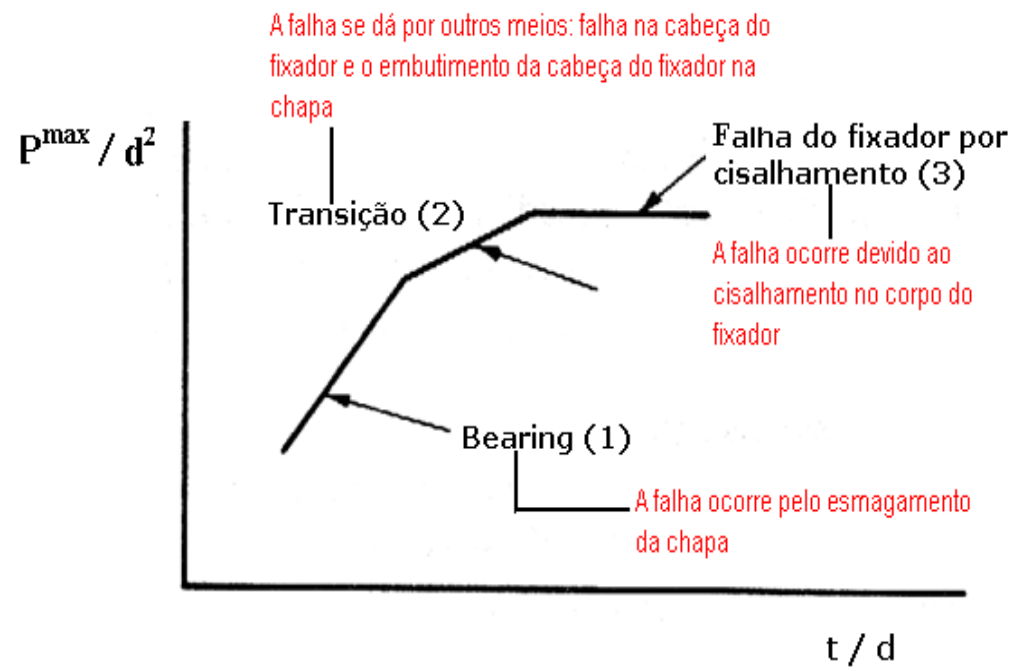

Figura 9 - Seqüência dos principais modos de falhas em uma junta metal-metal (MIL-HDBK-5H (1998)).

Verifica-se assim que o projeto de juntas é algo complexo, e, portanto, pode-se encontrar na literatura diversas contribuições que tratam sobre este assunto. Uma dessas contribuições que merece destaque é o trabalho desenvolvido por Morris (2004). O referido pesquisador estudou a possibilidade de definir uma expressão padrão, bem como, métodos de ensaios para a determinação da flexibilidade de uma junta. Dessa forma, a flexibilidade da junta é uma medida da influência dos elementos que a constitui, tais como: rebites; parafusos; pinos e metais. A flexibilidade da junta é um importante parâmetro na determinação da vida em fadiga de uma junta aeronáutica, sendo que a mesma pode ser definida como:

$$
f=\frac{\delta}{F_{a}}
$$

onde:

$$
\begin{aligned}
& \delta\left(\Delta_{1}\right)=\text { elongação da junta em função da presença do fixador. } \\
& \mathrm{F}_{\mathrm{a}}=\text { carga externa. }
\end{aligned}
$$


Vale ressaltar que a carga externa $\left(\mathrm{F}_{\mathrm{a}}\right)$ pode ser dividida em outras forças como mostra a Figura (10):

$\mathrm{F}_{\mathrm{bp}}=$ carga de "bypass";

$\mathrm{F}_{\mathrm{br}}=$ carga de "bearing" (atua entre o corpo do fixador e o furo da chapa);

$\mathrm{F}_{\mathrm{fr}}=$ carga de fricção (atua entre o contato das chapas da união).

$$
\mathrm{Fa}=\mathrm{Fbr}+\mathrm{Fbp}+\mathrm{Ffr}
$$
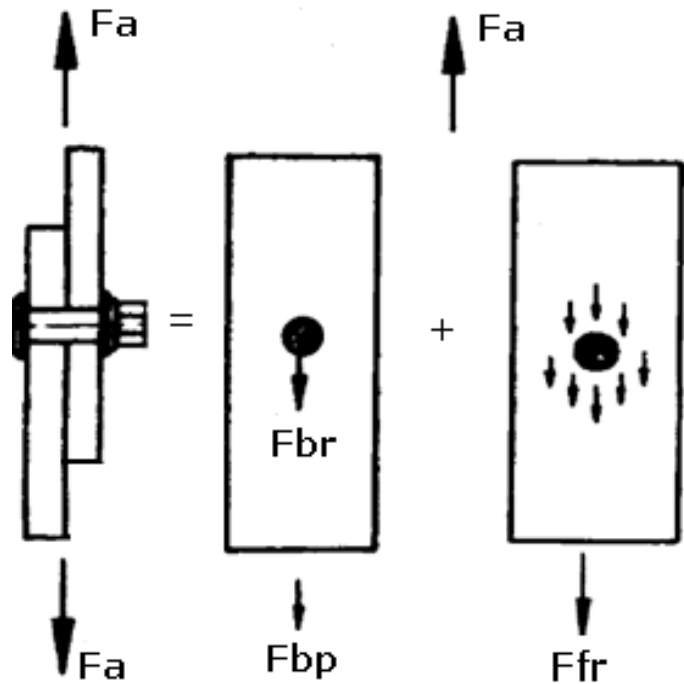

Figura 10 - Definição das cargas que agem em uma junta metálica, Morris (2004).

Por outro lado, a carga transferida para a chapa tem uma grande influência na vida em fadiga da junta como mostra a Figura (11). Sendo que esta carga é mais significativa para a primeira fileira de fixadores.

Nota-se assim que a flexibilidade do fixador exercerá influência preponderante na vida em fadiga da junta. 


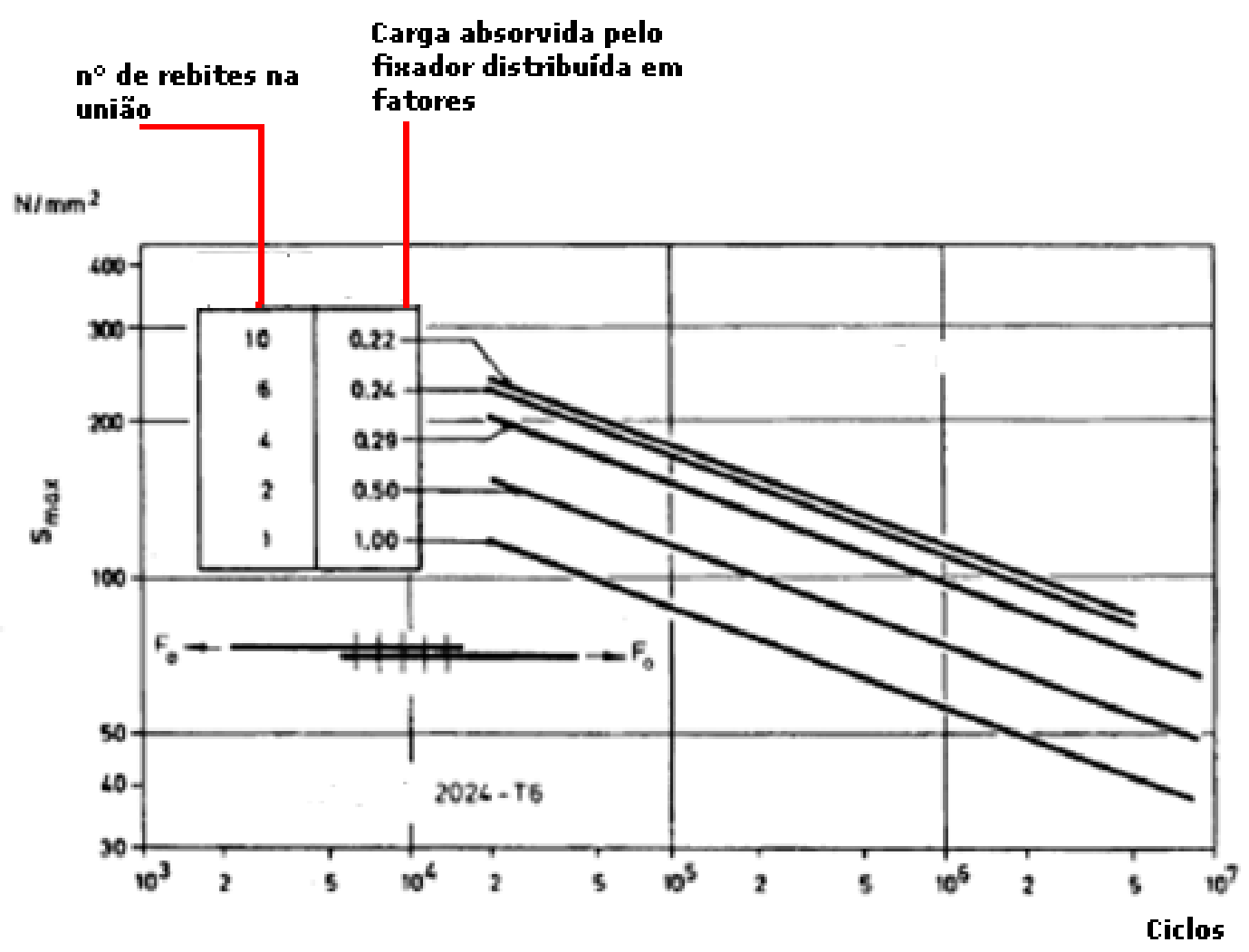

Figura 11 - Influência da carga transferida no comportamento da fadiga em juntas rebitadas sob cisalhamento, Morris (2004).

A conclusão de que a flexibilidade do fixador será fundamental para a vida em fadiga da junta é confirmada através da Figura (12), pois a mesma exerce forte influência sobre a carga transferida para os demais elementos da junta. Considerando que a carga $F_{l t}$ é dada pela soma da carga de "bearing" $F_{b r}$ com a carga de fricção $F_{\text {fr }}$, tem-se que com o aumento da flexibilidade dos fixadores, a carga transferida para a chapa reduz drasticamente, de $50 \%$ da total, até valores abaixo de 10\% para juntas simples em alumínio (“single lap joint - SLJ”) e para patamares iguais a 30\% para juntas duplas em alumínio (“double lap joint - DLJ"). 


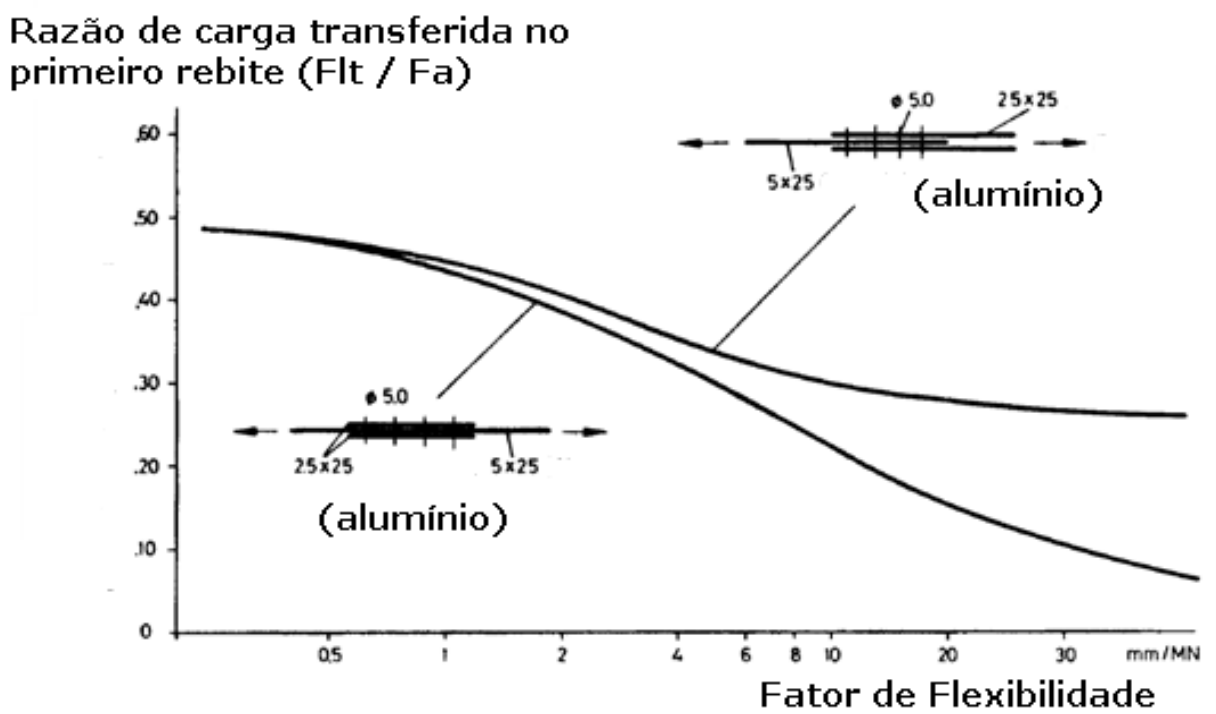

Figura 12 - Influência da flexibilidade em função da transferência de carga, Morris (2004).

Experimentalmente, o fator de flexibilidade do fixador pode ser medido usando-se corpos de prova sob cisalhamento, empregando extensômetros montados com dois fixadores dispostos de forma simétrica conforme mostrado na Figura (13).

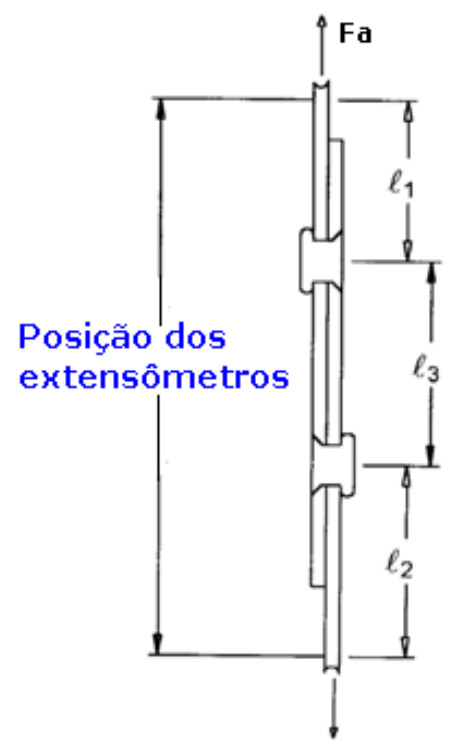

Figura 13 - Configuração de ensaio sob cisalhamento para junta padrão, Morris (2004).

De acordo com a especificação acima mencionada, as seguintes equações devem ser consideradas: 


$$
\begin{gathered}
f_{\text {total }}=\frac{\Delta l}{F_{a}} \\
f_{\text {chapa }}=\frac{\bar{l}}{E_{\text {chapa }} A} ; \text { onde } \Rightarrow \bar{l}=l_{1}+\frac{1}{2} l_{3}+l_{2} \\
f_{\text {fixador }}=2\left(f_{\text {total }}-f_{\text {chapa }}\right)
\end{gathered}
$$

Segundo Morris (2004), a flexibilidade de uma junta pode ser obtida por meio de uma curva carga-deslocamento, como mostra a Figura (14).

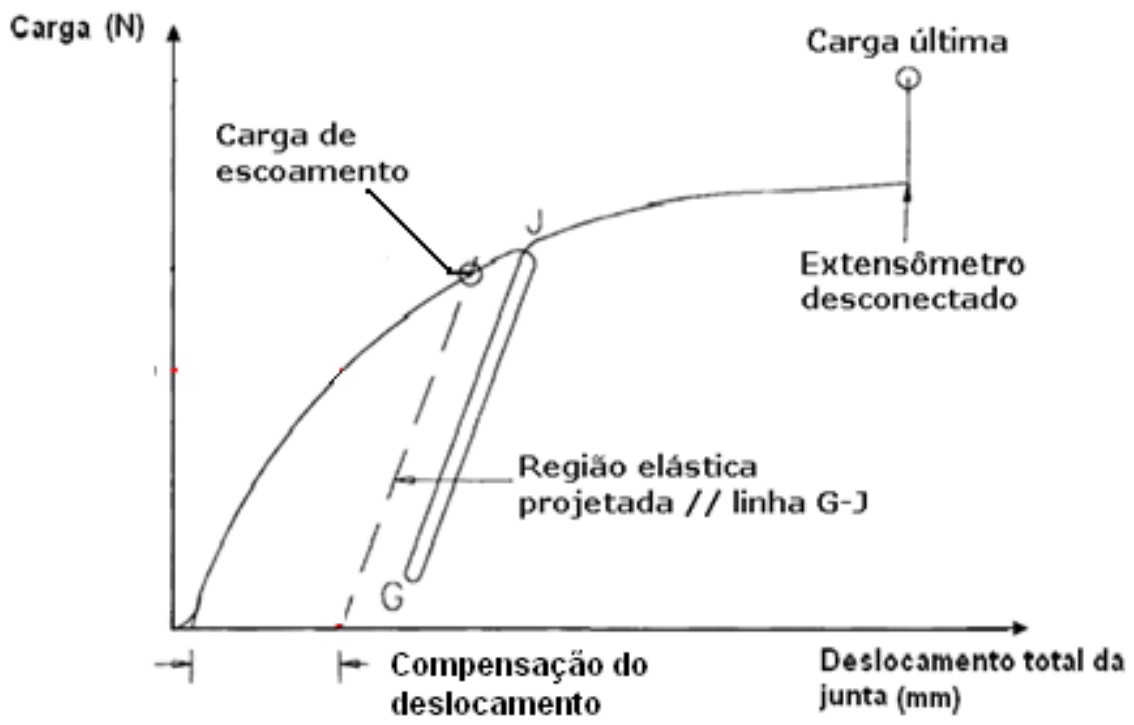

Figura 14 - Metodologia para a determinação do fator de flexibilidade total da junta (adaptado de Morris (2004)).

Vale destacar que vários parâmetros podem ser considerados como influenciadores potenciais na flexibilidade da junta: 
- Configuração da junta: quase todas as análises consideram o caso de uma junta simples ("single lap joint") contendo dois rebites. Observou-se que a flexibilidade total medida para uma junta simples foi, aproximadamente, duas vezes maior do que para uma junta dupla (“double lap joint”);

- Expansão do furo: se bem nivelado e ajustado, um fixador irá influenciar a tensão ao longo do seu corpo e ao redor do furo. Uma tensão residual gerada por uma interferência de montagem também afetará o comportamento da junta. Este efeito fica bem visível através da Figura (15).

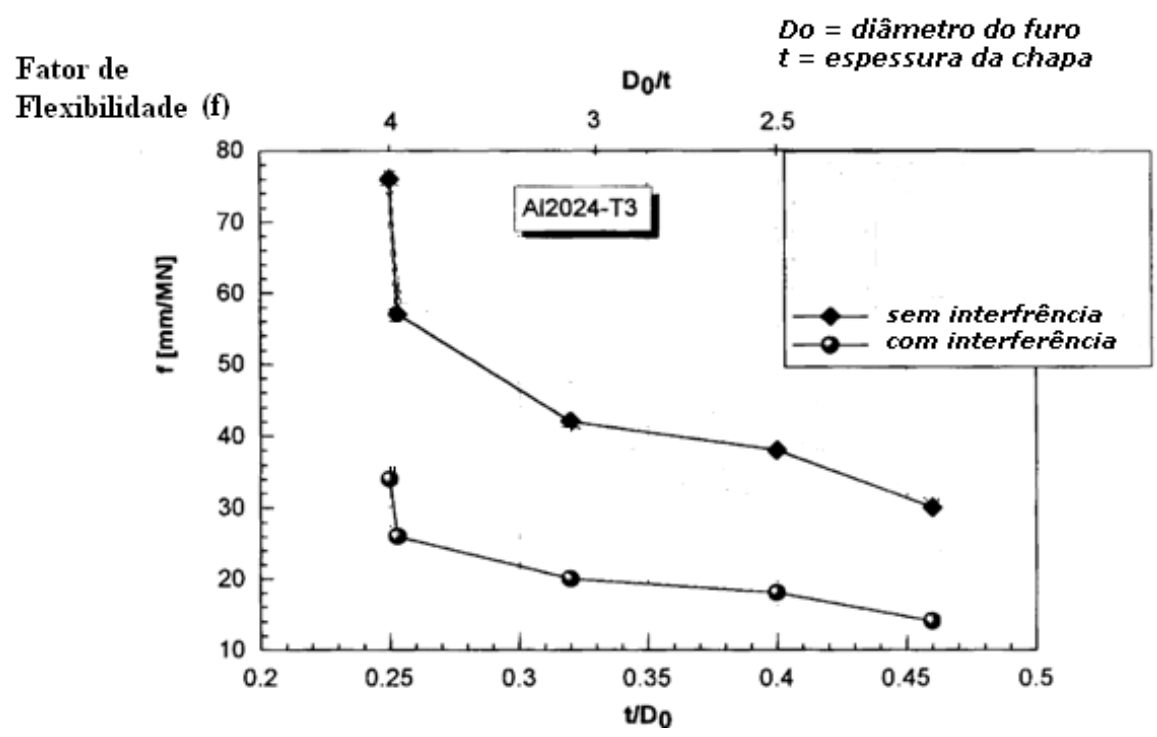

Figura 15 - Ensaios comparativos.

- Tipo do fixador: pode-se esperar que uma junta parafusada tenha uma resposta diferente de uma produzida com rebites forjados, por exemplo.

- Tipo da cabeça do fixador: a maioria dos modelos teóricos adota que a cabeça dos elementos mecânicos permanece nivelada (cabeça plana) com a superfície da chapa e que somente o centro do corpo se deforma. 
- Condição das superfícies de atrito: a condição das superfícies de contato podem também influenciar na fricção entre elas. Ao se aplicar teflon entre chapas polidas, ficou demonstrada uma pequena influência desta ação.

- Rigidez na direção da espessura: cuidados especiais devem ser tomados no caso de uma configuração híbrida de uma união em metal - compósito, no sentido de se evitar que a cabeça do fixador danifique a parte metálica, se esta for muito fina, ou a parte em compósito, provocando danos permanentes, tais como: entalhes; delaminação; embutimento, etc. Tais danos são menos predominantes quando são empregados fixadores em furos escariados (Figura 16(a)), e são mais predominantes em furos comuns (Figura 16(b)).
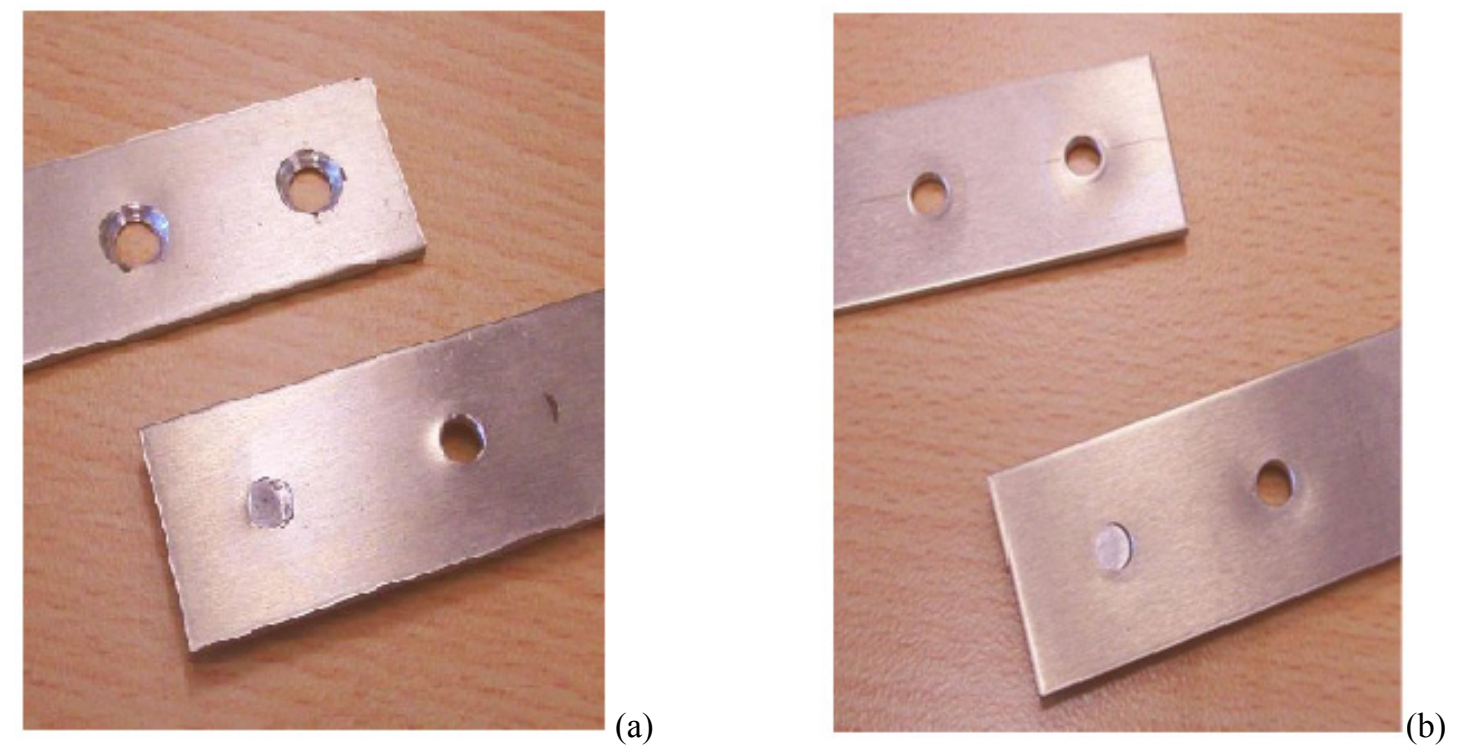

Figura 16 - (a) CDP configurado com fixador e furo escariado; (b) CDP convencional, Morris (2004).

Sumarizando, tem-se que quanto maior a flexibilidade dos fixadores, menor será a carga transferida para as chapas da junção, e, então, haverá um acréscimo da durabilidade (vida em fadiga) da junção. Vale ressaltar que o principal foco do presente trabalho não é o estudo da fadiga e sim do comportamento quase-estático da estrutura. No entanto, o processo 
completo de uma análise de fadiga, com previsão de vida de estruturas críticas, passa primeiramente por uma análise estática das referidas estruturas.

\subsubsection{MECANISMOS DE FALHAS: COMPÓSITOS}

As normas técnicas MIL-HBK-17-1F e MIL-HDBK-17-3F (2002) abordam falhas em uniões mecânicas formadas, exclusivamente, por materiais compósitos. Uma importante análise em ensaios de junções é a seleção do tipo de método de ensaio com a devida atenção ao modo de falha. A ocorrência de um modo particular de falha na união está relacionada, dentre outros efeitos, com a geometria e com a seqüência de empilhamento das lâminas. As junções fixadas mecanicamente em material compósito podem falhar por diversos modos, como será evidenciado posteriormente. A provável ocorrência de um modo particular de falha pode estar relacionada com o diâmetro do fixador (D), com a largura do laminado (L), com a distância de borda (e), com a espessura (t) e com o passo (p), conforme mostra a Figura (17).

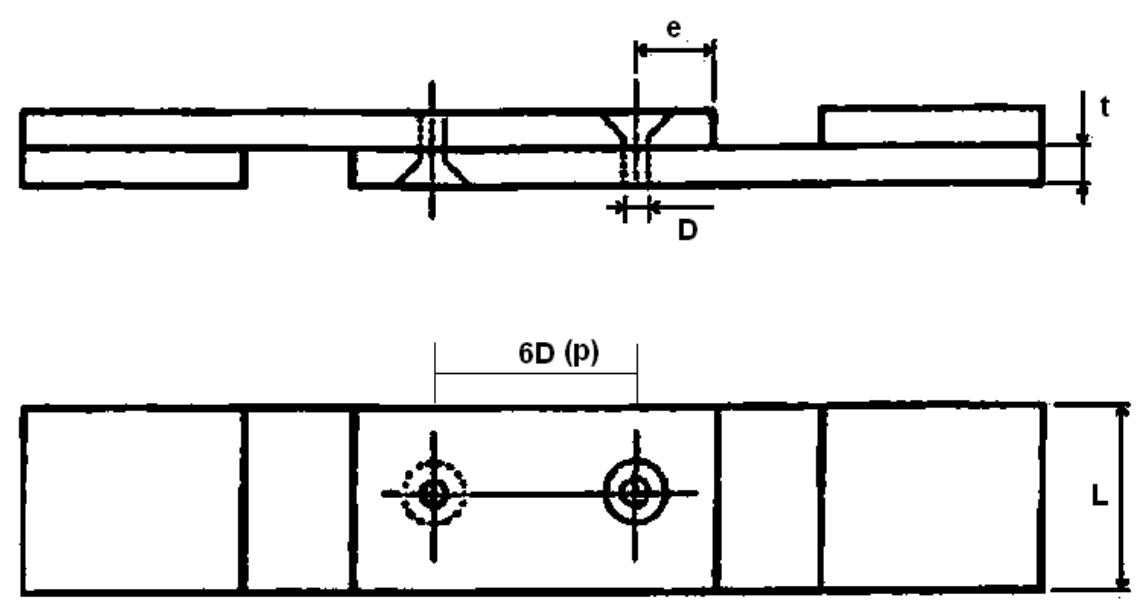

Figura 17 - Fatores que influenciam no modo de falha. 
A seguir, serão apresentados os principais modos de falhas em juntas mecânicas constituídas por compósitos poliméricos reforçados.

\section{FALHA POR TRAÇÃO E COMPRESSÃO}

As falhas por tração ou por compressão, na secção crítica (secção onde está localizado o furo), ocorrem em função do diâmetro do furo da placa em compósito. Quanto maior for este diâmetro, menor será a área resistente à força de tração ou de compressão e, conseqüentemente, menor será a tensão admissível da estrutura. A tensão atuante para um laminado fixado mecanicamente passa a ser um valor específico de tensão $\left(\sigma^{\prime}{ }_{M}\right)$ como o definido por Suong e Tsai (2002). Os referidos pesquisadores desenvolveram diretrizes de projeto, considerando uma união híbrida metal-compósito, como uma função da tensão atuante no material metálico. Partindo das hipóteses mostradas pelas equações (14) e (15), um fator de concentração de tensões para um laminado é obtido através da equação (16). Este fenômeno ocorre quando fica caracterizado um incremento na tensão atuante $(\sigma)$, por exemplo, para o caso de uma leve pressão de montagem do rebite (normalmente desprezada), deve ser computado o acréscimo da tensão $\sigma^{\prime}{ }_{M}$ de acordo com a Figura (18).

$$
\sigma_{M}^{\prime}>\sigma
$$

Em uma região onde:

$$
\sigma_{\text {local de ruptura }}<\sigma_{\text {global de ruptura }}
$$

Tem-se que a tensão atuante no laminado é dada por:

$$
\sigma_{M}^{\prime}=\sigma^{\prime} \cdot\left\{1+\sqrt{2 \sqrt{\frac{E_{1}}{E_{2}}}-v_{12}+\frac{E_{1}}{G_{12}}}\right\}
$$


Onde:

$\mathrm{E}_{1}$ e $\mathrm{E}_{2}=$ módulos de elasticidade nas direções $0^{\circ}$ e $90^{\circ}$, respectivamente

$\mathrm{G}_{12}=$ módulo de elasticidade ao cisalhamento

$v_{12}=$ coeficiente de Poisson

$\sigma^{\prime}=$ é a tensão atuante na extremidade adjacente ao furo da junção
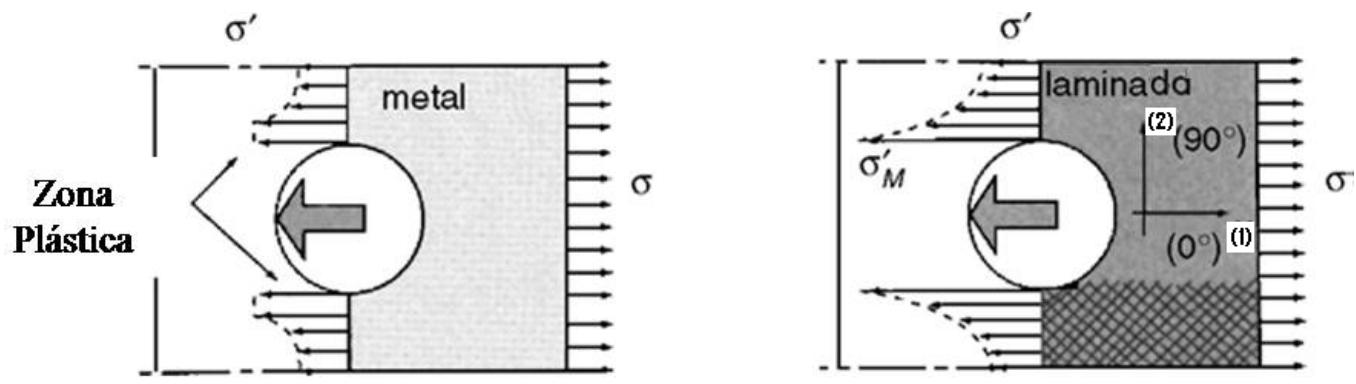

Figura 18 - Tensão no laminado acrescida do seu fator de concentração, Suong e Tsai (2002).

A ruptura é caracterizada pela insuficiência de empilhamento de fibras na direção do principal carregamento $\left(0^{\circ}\right)$ e também pela pressão lateral exercida pelo fixador na parede do furo. A Figura (19) ilustra esta ocorrência.

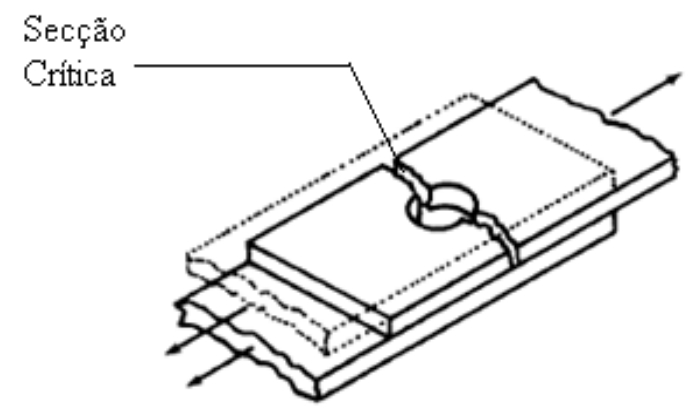

Figura 19 - Modo de falha por tração (MIL-HDBK-17-3F (2002)). 


\section{FALHA COMBINADA POR TRAÇÃO E CISALHAMENTO}

Estas falhas podem ser compreendidas como uma combinação dos modos de falhas por tração e por cisalhamento. Ocorrem quando a secção crítica possui pouca distância de borda, ou seja, há pouco material entre a borda do furo da placa e a aresta lateral da mesma. Isto promove uma baixa resistência ao cisalhamento à ação dos esforços externos solicitantes. Os danos originam-se por meio da tração pura na secção crítica, ou, na grande maioria dos casos, iniciam-se na extremidade da aresta lateral antes de iniciar-se nas adjacências do furo, como mostrado na Figura (20). Nesta situação, a falha deu-se por tensões combinadas de tração e cisalhamento.

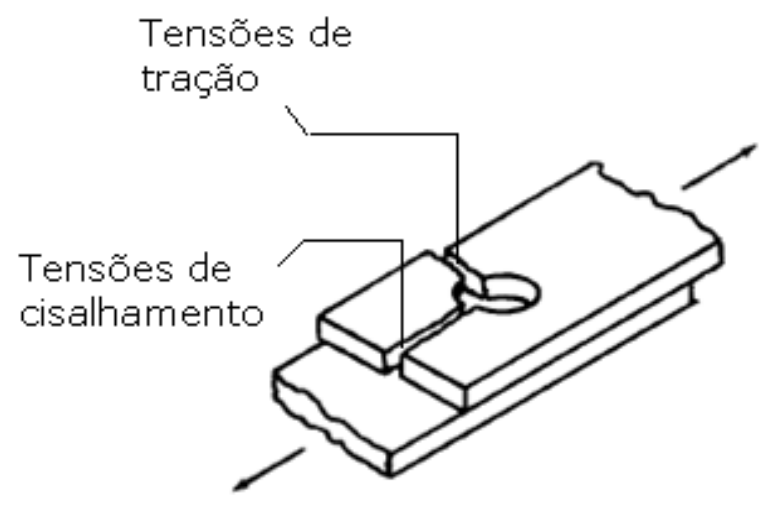

Figura 20 - Modo de falha combinado por tração e cisalhamento (MIL-HDBK-17-3F (2002)).

FALHA POR “BEARING”

Define-se "bearing" como sendo o esmagamento do furo provocado pela pressão exercida pelo fixador na parede do furo, devido ao carregamento externo, como visto anteriormente. Quando esta pressão é excessiva, conduz para uma mudança na forma circular do furo como mostra a Figura (21(a)), ou então, na ocorrência de delaminações, como mostra 
a Figura (21(b)). Desta maneira, a tensão de "bearing" $\left(\boldsymbol{\sigma}_{\mathrm{br}}\right)$ na parede lateral do furo, torna-se semelhante, matematicamente, a aquela de esmagamento $\left(\boldsymbol{\sigma}_{\text {esm }}\right)$, como fora dimensionado, anteriormente, para materiais metálicos.

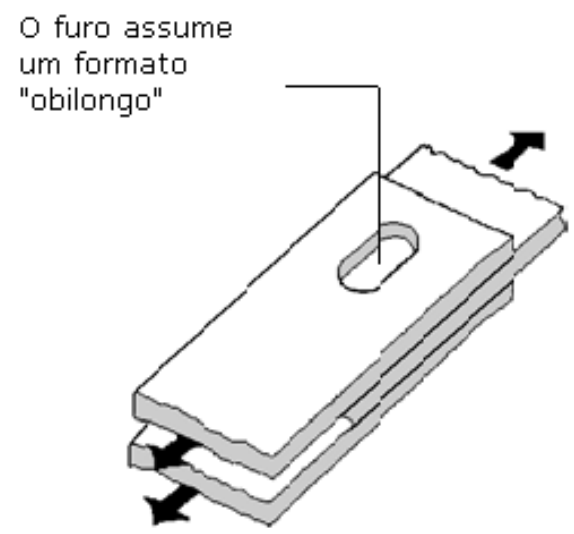

(a)

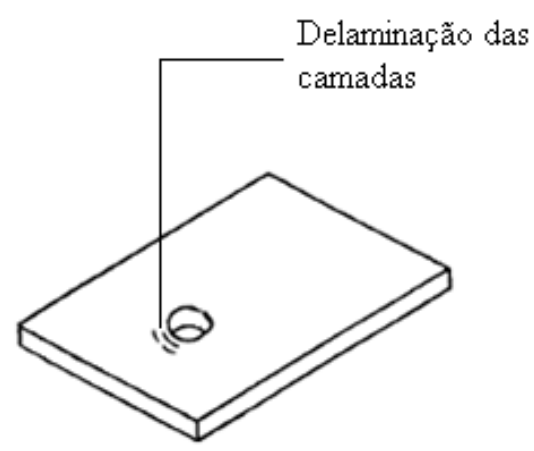

(b)

Figura 21 - Modo de falha por "bearing": (a) defeito na forma circular; (b) delaminação no laminado (MIL-HDBK-17-3F (2002)).

Os ensaios podem ser realizados em corpos-de-prova (CDPs) projetados tanto em juntas simples ("single lap joint" - significa dizer que os ensaios corresponderão ao simples cisalhamento), como em juntas duplas (“double lap joint” - significa dizer que os ensaios corresponderão ao duplo cisalhamento), através dos seguintes procedimentos:

Especificação ASTM D 5961 - Procedimento A: estabelece requisitos para ensaios ao duplo cisalhamento, como mostra a Figura (22(a));

Especificação ASTM D 5961 - Procedimento B: estabelece requisitos para ensaios ao simples cisalhamento, como mostra a Figura (22(b)). 


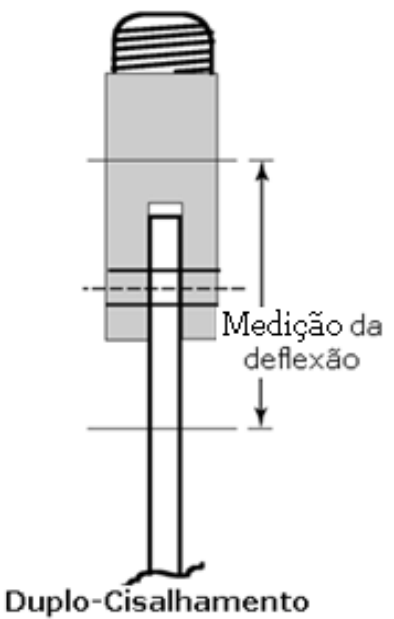

(a)

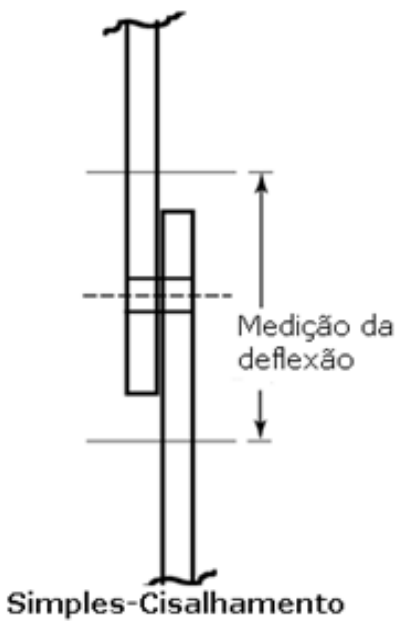

(b)

Figura 22 - Ensaio de "bearing" e do modo de falha até a ruptura: (a) Procedimento A (duplo cisalhamento); (b) Procedimento B (simples cisalhamento), ASTM 5961 (2007).

No caso do simples cisalhamento pode ocorrer o rompimento do fixador em uma secção transversal do seu corpo. Conseqüentemente, no duplo cisalhamento o rompimento pode ocorrer em duas secções transversais no corpo do fixador, conforme mostram as Figuras (23(a)) e (23(b)), respectivamente.

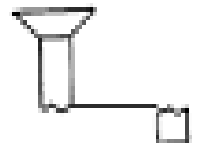

(a)

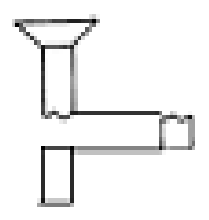

$(6)$

Figura 23 - Cisalhamento no fixador: (a) simples; (b) duplo.

A verificação do efeito "bearing" e do modo de falha que caracterizou a ruptura do CDP é mais comum utilizando-se configurações para suportarem ao simples cisalhamento, resultando em elevadas concentrações de tensões nas paredes dos furos, quando comparadas com configurações para o duplo cisalhamento as quais possuem uma área maior de resistência ao "bearing", devido à diferença de espessura entre ambos. Em outras palavras, os valores das tensões que causam falhas por "bearing", observadas nos ensaios de duplo cisalhamento, 
não podem ser especificados para aplicações em juntas submetidas ao simples cisalhamento, ou seja, os valores das tensões que causam falhas ao simples cisalhamento são mais significativos para os projetos de estruturas aeronáuticas unidas mecanicamente. Isto justifica, em parte, o emprego de SLJ (uniões simples) no presente trabalho.

Os ensaios ao duplo cisalhamento são utilizados somente para avaliarem os diferentes tipos de materiais e suas combinações na formação de uniões em compósitos como mostra a Figura (24), por exemplo: matrizes (poliméricas; metálicas e cerâmicas), reforçadores (fibra de vidro; fibra de carbono; titânio e outros) e fixadores (alumínio; aço; monel; titânio e outros). Como visto anteriormente, os dados obtidos nestes ensaios não são usados para fins de projeto da junta, mas, unicamente, para comparar os diferentes tipos de junções produzidas em materiais compósitos e seus fixadores.

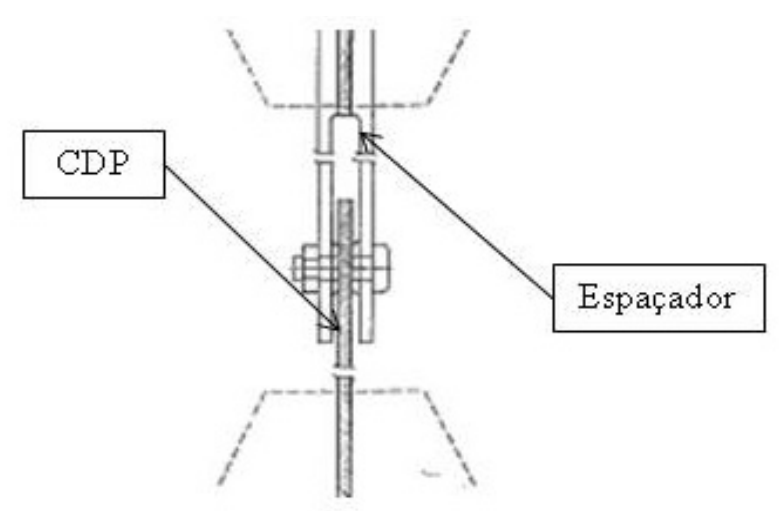

Figura 24 - Ensaios comparativos por duplo cisalhamento.

Nota-se ainda, que a configuração de ensaio de "bearing" ao simples cisalhamento é mais representativa para a maior parte das aplicações de junções mecânicas aeronáuticas. A superposição simples induz cargas não somente de cisalhamento no fixador e de esmagamento na parede do furo, mas também de flexão (Momento Fletor Secundário) nos 
pontos de união como mostra a Figura (25), enquanto que na de superposição dupla o efeito das tensões devido à flexão são nulos como mostra a Figura (26).

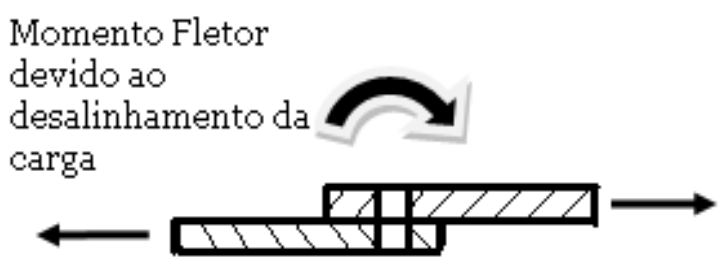

Figura 25 - Efeito do carregamento externo em uniões simples.

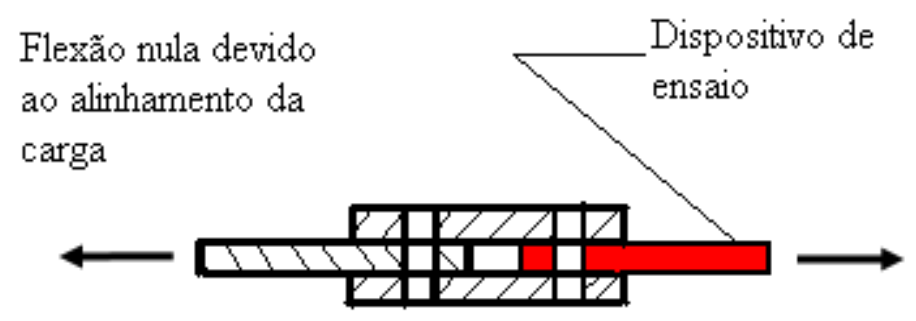

Figura 26 - Efeito do carregamento externo em uniões duplas.

Os CDPs de uniões simples necessitam ser adaptados através da aplicação de calços de acordo com a Figura (27), para assegurar que o alinhamento da linha de carga nas superfícies sobrepostas das duas placas unidas, anulará, ou então, minimizará o Momento Fletor Secundário. Tal orientação foi utilizada para o desenvolvimento do presente trabalho.

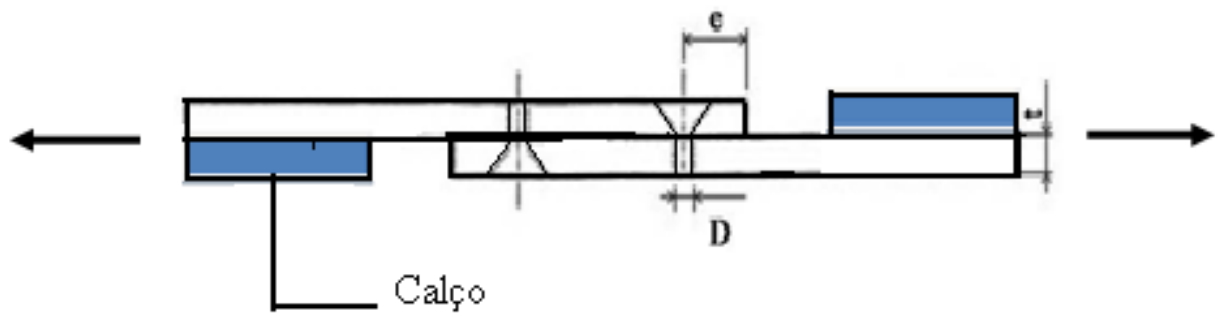

Figura 27 - Calço para anular ou minimizar o efeito do Momento Fletor Secundário nas uniões simples. 
Sumarizando, conclui-se ainda que ensaios para verificação de resistência ao "bearing” devam ser realizados em uniões de superposição simples, pelo fato das mesmas apresentarem ampla aplicação em estruturas aeronáuticas reais. A limitação do ensaio é a tolerância do calço. Vale ressaltar sobre a dificuldade de se ter especificações em relação à utilização dos calços entre às camadas dos laminados para eliminar o desalinhamento das cargas e o Momento Fletor Secundário. No entanto, a espessura do calço tem uma grande influência na resistência ao "bearing". Uma prática aeroespacial comum é a aplicação de calço de alumínio, de espessura equivalente a do laminado e com tolerância máxima admitida nas suas dimensões de 0,03 in $(0,762 \mathrm{~mm})$.

A configuração simples de CDPs com dois fixadores, conforme ASTM D 5961 Procedimento B (2007), pode ser usada não somente para obtenção de dados de projetos, mas também para avaliação do comportamento dos fixadores. Além dos fixadores, esta geometria do CDP permite que seja avaliada a resistência ao "bearing", juntamente com a carga de desvio (“by-pass”), na forma de tensão de tração nas duas placas. Vale lembrar que a carga de "by-pass" é aquela que não foi absorvida pelos elementos de fixação, como já foi abordado anteriormente. Em outras palavras, nesta condição, não está sendo avaliado o puro "bearing”, pois uma parcela do esforço externo solicitante vai ser transformada em tensões de tração. $\mathrm{O}$ nível da carga de tração devido ao "by-pass" será baixo para a configuração especificada nesta norma, porém, quaisquer variações nas combinações dimensionais dos CDPs (D; e; L; t - Figura (27)) devem ser padronizadas para assegurar que a transferência da carga por meio do "by-pass" não ultrapasse $20 \%$ da prevista para a falha por tração nos laminados da junta. Além disso, tem-se que a falha nos fixadores, através do seu embutimento no laminado, como mostra a Figura (28), bem como os demais modos de falha do fixador apresentados na Tabela (3), fornecem uma medida de resistência da junta para um particular tipo de fixador. 


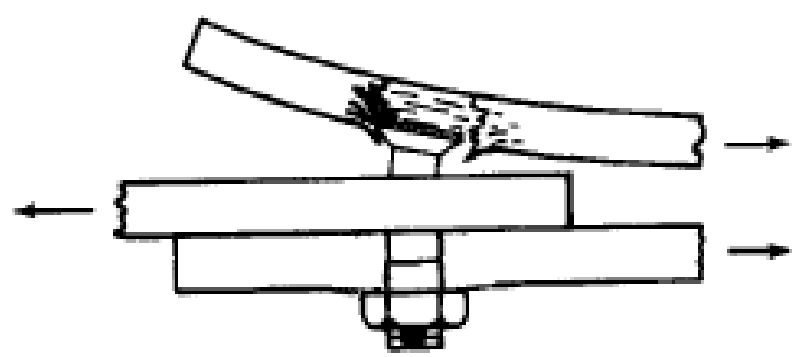

Figura 28 - Modo especial de falha no fixador e no laminado.

Tabela 3 - Modos de falhas mais comuns observados nos fixadores (MIL-HDBK-17-1F (2002)).

DENOMINAÇÃo
Falha pela Deformação Côncava na Cabeça
Falha por Tração no Corpo
Falha por Cisalhamento na Área de
Falhão na Interseção "Cabeça x
Corpo"

Uma das vantagens das uniões fixadas mecanicamente em relação às unidas por processo de colagem reside na possibilidade da desmontagem das mesmas.

Dados de ensaios demonstram que a redução da resistência ao "bearing", nos pontos de fixação das juntas em compósitos, depende praticamente do diâmetro do fixador; da 
espessura do laminado; da espessura dos calços e do tipo do material do calço. Segue na Figura (29) um exemplo de curva da redução da resistência, considerando-se a relação do diâmetro (D) do fixador e a espessura (t) do laminado.

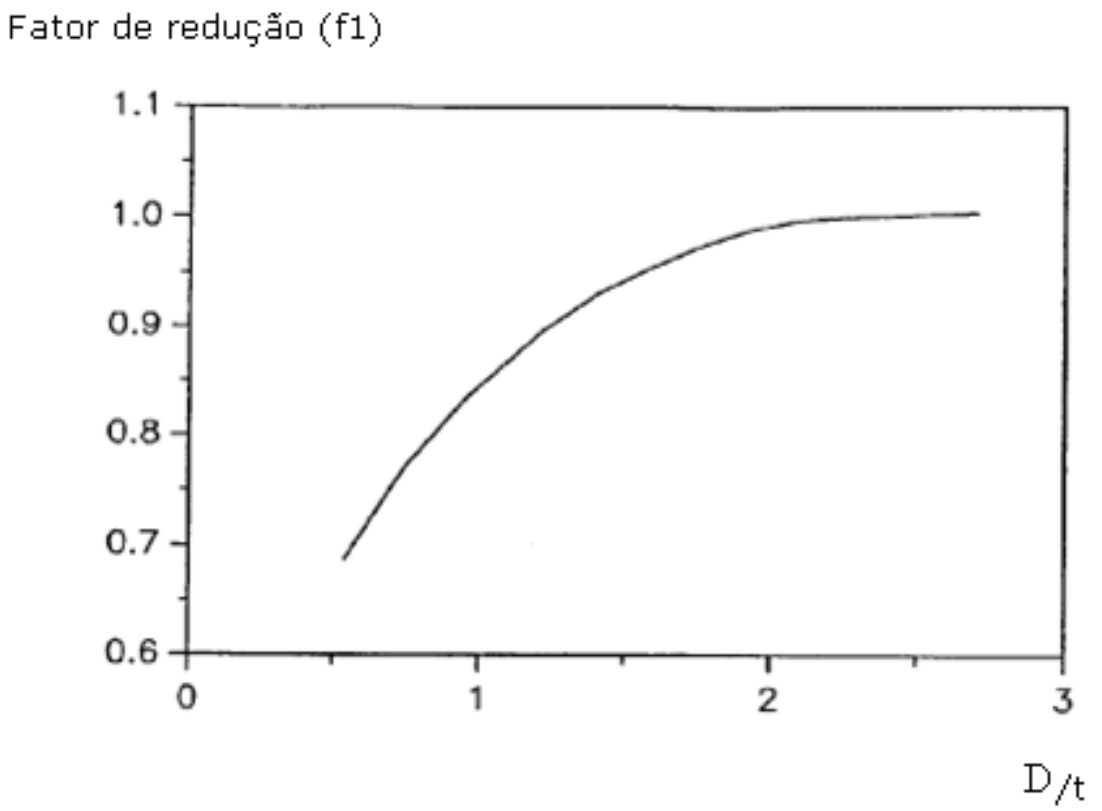

Figura 29 - Fator de redução da resistência ao "bearing” em função da razão D/t (MIL-HDBK-17-1F (2002)).

O fator de redução $\left(f_{1}\right)$ indica que para uma dada espessura da placa, quanto menor for o diâmetro do fixador (D), maior será a perda da resistência ao "bearing" no laminado. Para que não ocorra esta perda é necessário que o projeto considere uma relação D/t superior a 2,2.

Por outro lado, a Figura (30) mostra através do fator de redução $\left(f_{2}\right)$ como os calços podem influenciar na queda da resistência ao "bearing". Em outras palavras, o projeto dos calços tem que contemplar a tolerância dimensional de usinagem ou laminação de 0,03 in máxima e não especificar, para sua confecção, material poroso ou então materiais muito elásticos (por exemplo: borracha) que produzem um efeito de mola. Assim, os calços devem ser fabricados em material metálico (chapa) ou em compósito reforçado para serem rígidos. Desta maneira, praticamente, não haverá perda da resistência ao "bearing" na parede do furo da placa. 


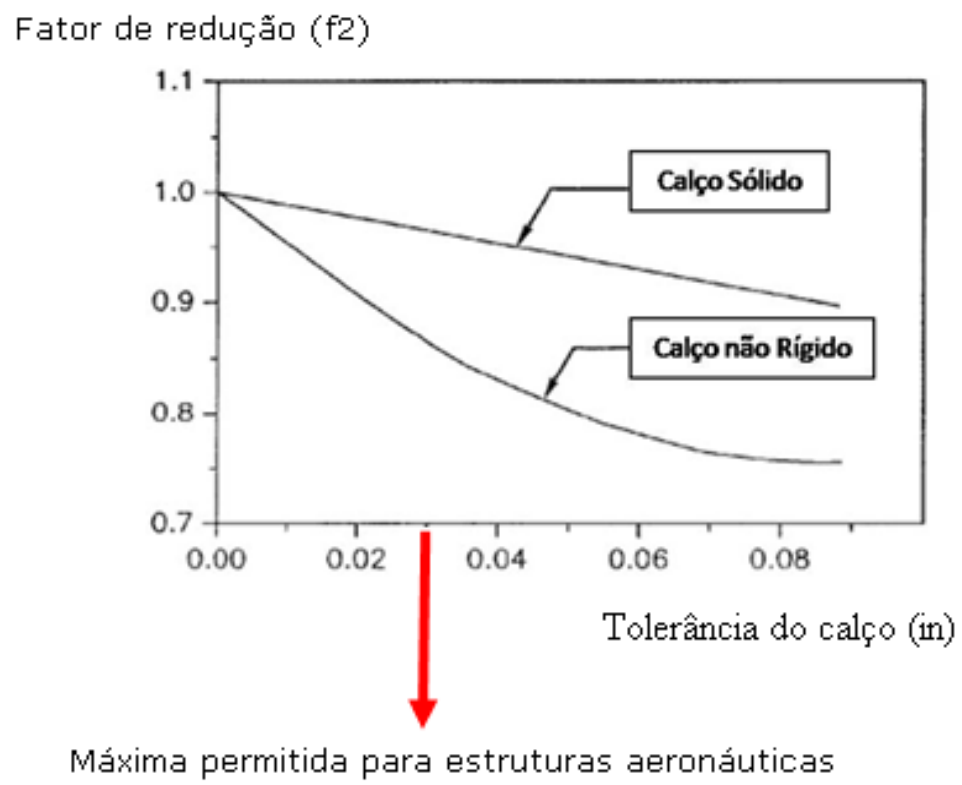

Figura 30 - Fator de redução da resistência ao "bearing" em função do calço, Mil-Hdbk-17-1F (2002).

A tensão de "bearing" admissível para um particular sistema de material é obtida por meio do emprego de ensaios com configurações que minimizam ao máximo a flexão no fixador, a fim de se obter uniformidade na tensão através da espessura, como demonstrado anteriormente.

FALHA POR “BEARING / BY - PASS”

De acordo com os comentários mencionados, é importante que se obtenha dados que demonstrem a transferência de carga por "by-pass" nos projetos de estruturas em compósito, presentes em junções mecânicas.

A tensão de "by-pass" atuante $\left(\boldsymbol{\sigma}_{\mathrm{bp}}\right)$ pode ser definida pela equação (17) como sendo a diferença entre a carga total aplicada $\left(\mathrm{P}_{\mathrm{n}}\right)$ e a absorvida pela parede do furo $\left(\mathrm{P}_{\mathrm{f}}\right)$, devido à presença do fixador, dividida pela área da secção transversal total do laminado como mostra a Figura (31): 


$$
\sigma_{b p}=\frac{P_{n}-P_{f}}{L . t}=\frac{P_{b p}}{L . t}
$$

Onde:

$$
\begin{aligned}
& \boldsymbol{\sigma}_{\mathrm{bp}}=\text { tensão de "by }- \text { pass" } \\
& \mathrm{P}_{\mathrm{n}}=\text { carga total aplicada } \\
& \mathrm{P}_{\mathrm{f}}=\text { carga absorvida pela parede do furo } \\
& \mathrm{P}_{\mathrm{bp}}=\text { carga de "by-pass" }
\end{aligned}
$$

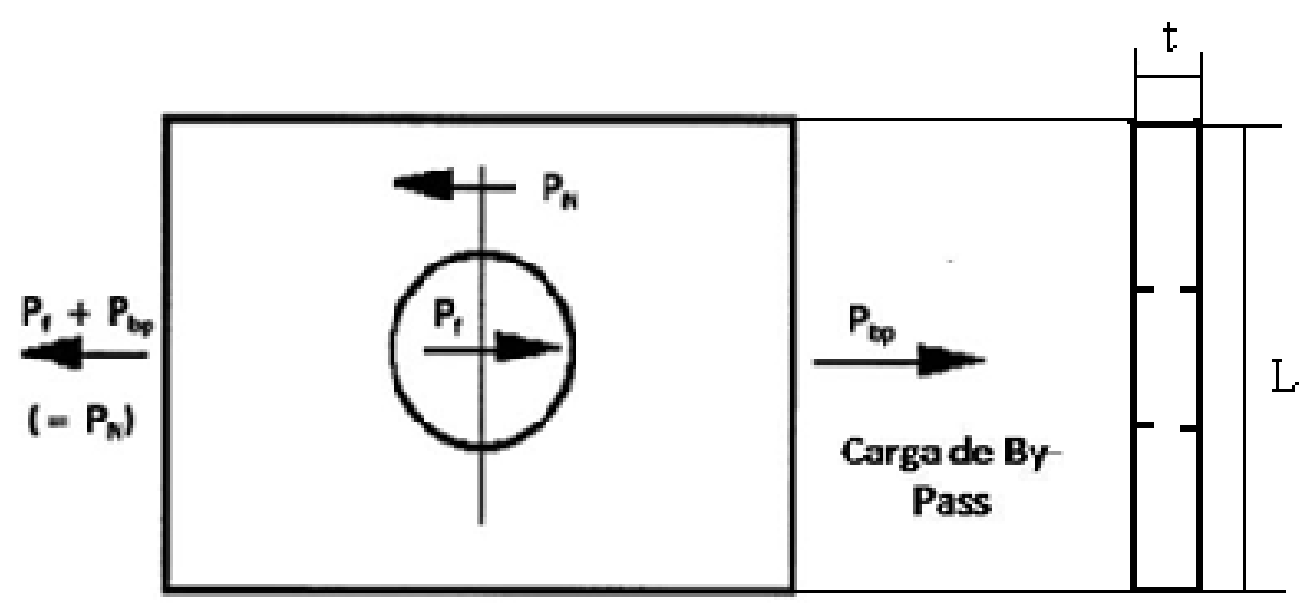

Figura 31 - Definição das cargas combinadas por "bearing” e "by-pass".

O carregamento por "bearing" e "by-pass" sempre ocorrerá quando existir carga no fixador. Desta forma, verifica-se que os projetos aeronáuticos de juntas fixadas mecanicamente contemplam cinco possibilidades de falhas no laminado como uma função da carga no fixador versus a deformação nos elementos da junção, como mostra a Figura (32). 


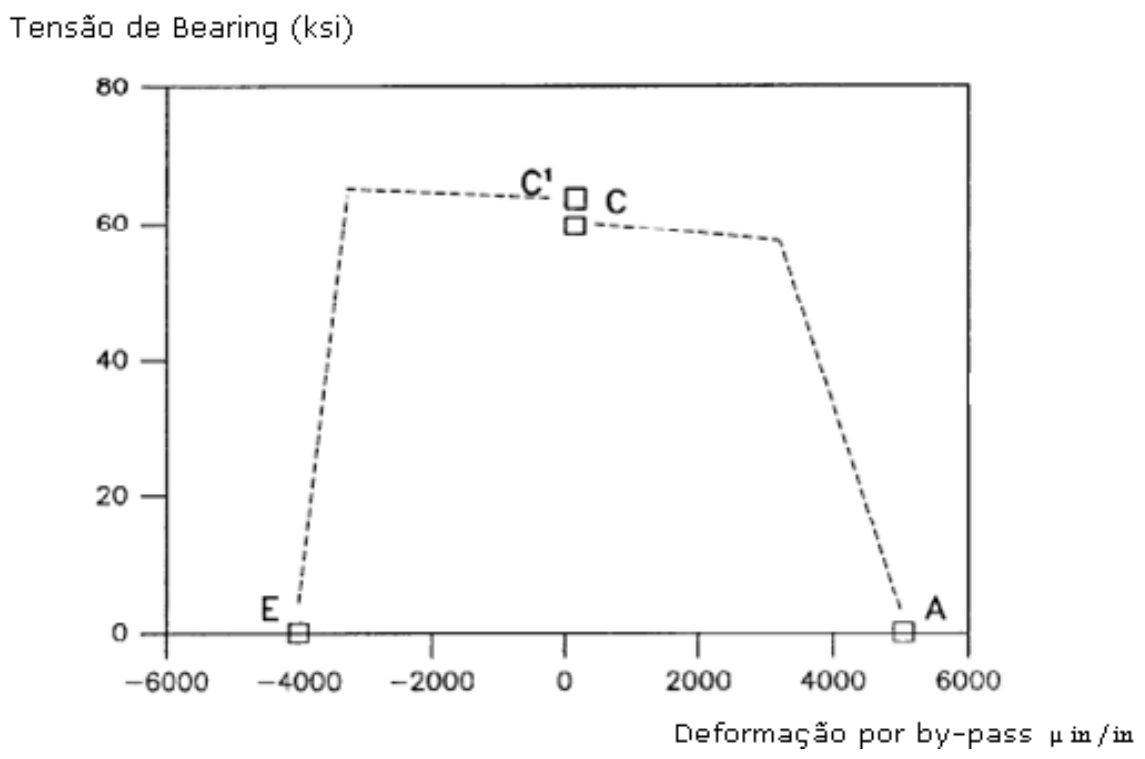

Figura 32 - Exemplo de interação de "bearing" e "by-pass" (MIL-HDBK-17-1F (2002)).

Na Figura (32), para a tensão de "bearing” nula (fixador descarregado), a falha se dá por tração (ponto A) ou compressão pura (ponto E). Por outro lado, quando a tensão de “bearing” é máxima, tem-se que as resistências de uma junta de fixador único, onde a reação ao carregamento se dá neste fixador, representam as resistências ao puro "bearing" para a tração e compressão, respectivamente, tem-se os pontos C e C'. Na prática, os pontos C e C' não são muitos diferentes, tanto que um ensaio de tração para avaliação do limite de resistência ao puro "bearing" é normalmente suficiente. Quando ocorrer uma situação combinada de tensão de "bearing" e "by-pass", automaticamente haverá uma diminuição nos limites de resistência a deformação por tração e compressão. As linhas A-C e E-C' demonstram este fenômeno, respectivamente. Os pontos da Figuras (32) podem ser diferentes para cada tipo de laminado; tipos de fixadores e condições ambientais, contudo, inúmeras variações podem ser representadas por este levantamento.

O método de ensaio recomendado para "bearing" e "by-pass" deve fornecer um carregamento, exclusivamente para o fixador, independentemente dos outros elementos da 
junta, sendo que a carga é medida diretamente neste elemento mecânico. Assim, a tensão de "bearing" pode ser calculada sem necessitar das medidas de deformação nos outros elementos da união. As instalações de ensaios requerem uma ou mais células de carregamento separadas da máquina o que é um fato complicador para os procedimentos de testes. Pesquisadores desenvolveram equipamentos especializados para sincronizar o carregamento entre $o$ elemento mecânico e o CDP. Um exemplo disto pode ser visualizado na Figura (33), que mostra um sistema de ensaio desenvolvido pela NASA-Langley Research Center.

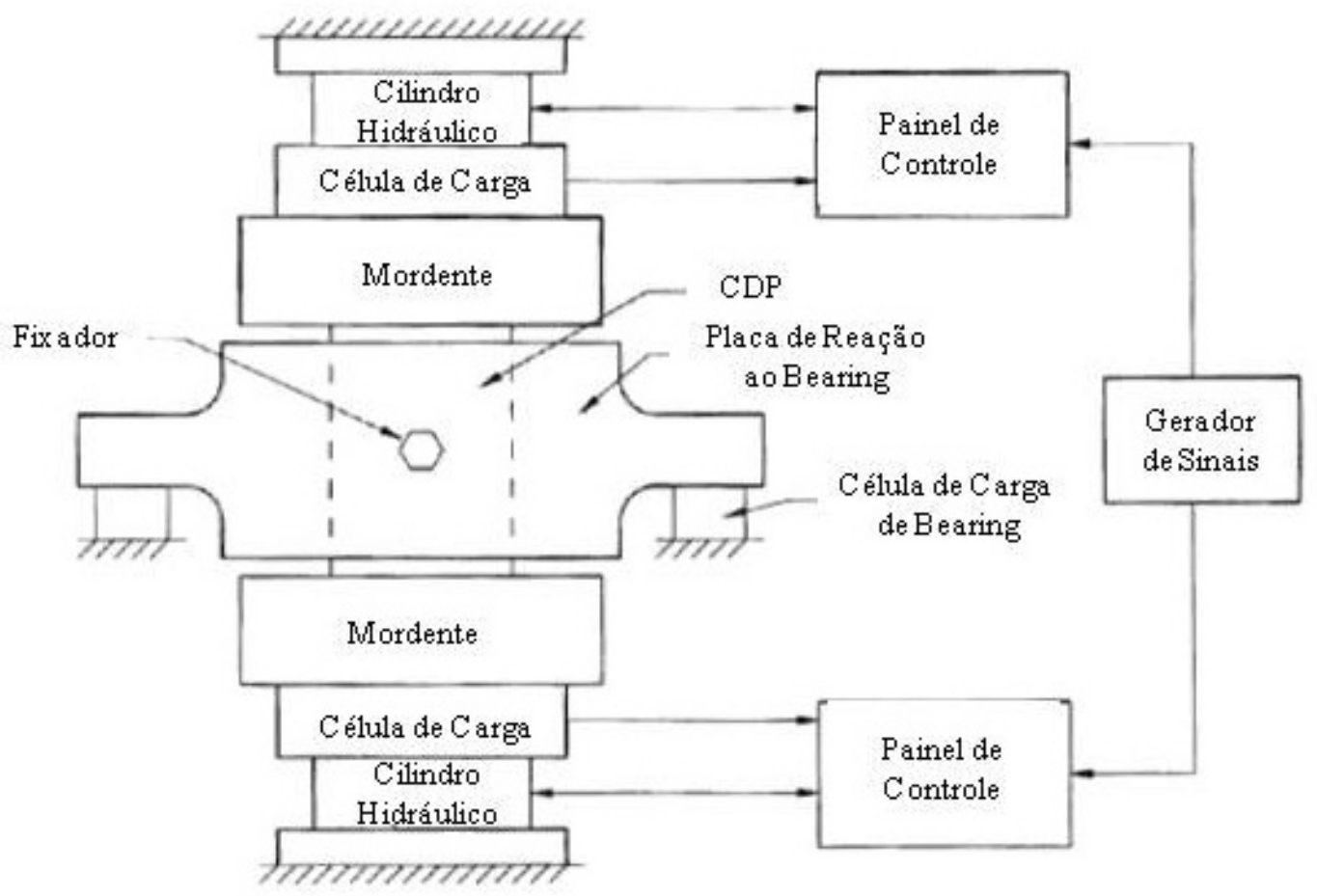

Figura 33 - Esquema de um sistema de ensaio "bearing" e "bay-pass" desenvolvido pela NASA (MIL-HDBK-17-1F (2002)).

Nota-se ainda pela Figura (34) que o CDP possui um furo adicional para evidenciar se ocorreu qualquer falha por cisalhamento no laminado, devido ao carregamento externo. 


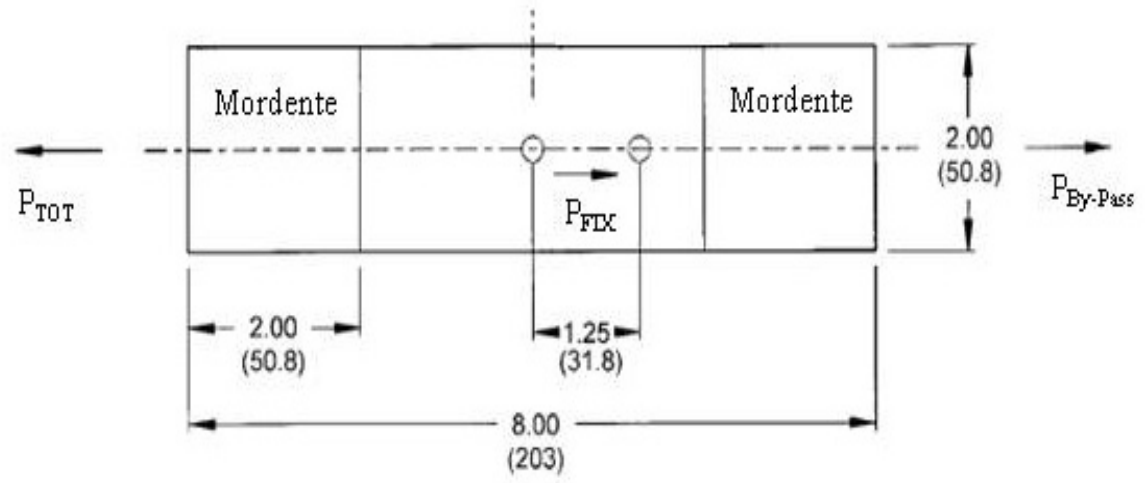

Figura 34 - CDP para ensaio de "bearing" e "by-pass" (MIL-HDBK-17-1F (2002)).

FALHA POR CISALHAMENTO

A tensão admissível de cisalhamento na placa devido ao carregamento externo é a sua capacidade de resistir à falha por cisalhamento puro, correspondente a um dado carregamento externo, como mostra a Figura (35).

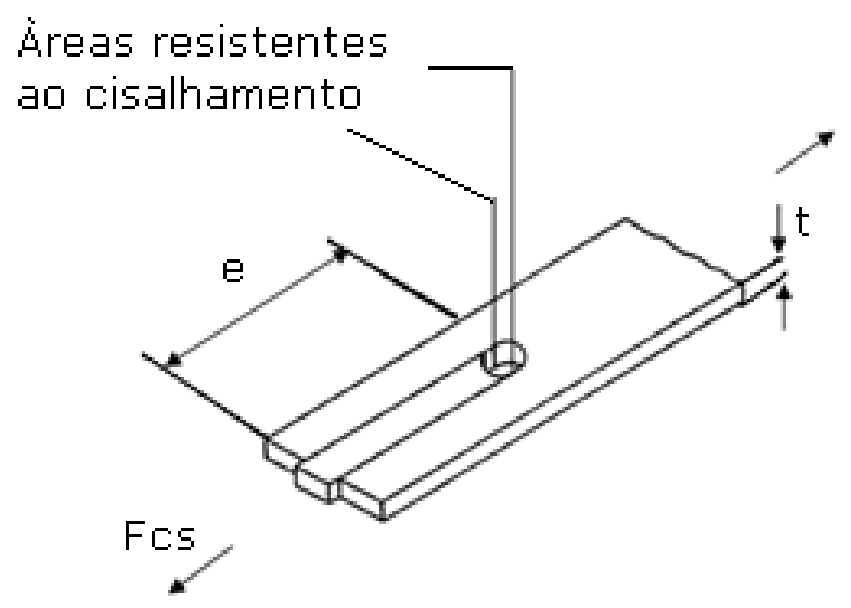

Figura 35 - Modo de falha por cisalhamento (MIL-HDBK-17-3F (2002)).

A tensão de cisalhamento $\left(\tau_{\mathrm{cs}}\right)$ atuante é dada através da equação (18), como segue: 


$$
\tau_{c s}=\frac{F_{c s}}{\text { 2.e.t }}
$$

onde:

$$
\begin{aligned}
& \mathrm{F}_{\mathrm{cs}}=\text { força de cisalhamento } \\
& \mathrm{e}=\text { comprimento da área resistente (distância de borda) } \\
& \mathrm{t}=\text { espessura do laminado }
\end{aligned}
$$

As junções em compósitos são, normalmente, projetadas para evitar este modo de falha. Contudo, uma redução na distância de borda (e) no seu valor típico de três vezes o diâmetro do fixador (3D), pode induzir o CDP a falhar por cisalhamento. Desta maneira, estes CDPs, conjuntamente com procedimentos específicos, são usados para determinar a resistência ao cisalhamento na união. O modo de falha ao cisalhamento em uniões de compósito fixadas mecanicamente, pode ser evitado pela manutenção da distância mínima de borda e uma seqüência de empilhamento com números adequados de camadas a $\pm 45^{\circ}$ e $90^{\circ}$. $\mathrm{Na}$ realidade, seria muito difícil criar um modo de falha ao cisalhamento limite de projeto, considerando-se somente à distância “3D”, sem que houvesse a existência de um agrupamento excessivo de camadas na direção do principal carregamento (orientadas a $0^{\circ}$ ). Em contrapartida, em algumas situações, particularmente em retrabalhos ou reparos, distâncias pequenas de borda podem ser produzidas. Neste caso, a capacidade da resistência dos laminados ao cisalhamento deve ser conhecida, obrigatoriamente, na situação em que o laminado não falharia por cisalhamento na distância nominal (típica) de borda.

Embora um CDP para ensaio ao puro "bearing” seja usado também para determinar a sua resistência ao cisalhamento, interpretações errôneas têm ocorrido na análise de ensaios, onde se imagina que uma pequena relação de e/D reduz a resistência ao "bearing" de uma junta. Na realidade, os CDPs com pequenas relações de e/D falham preponderantemente na 
parte inferior da junta por cisalhamento do que por "bearing". A falha por "bearing" altera o formato circular do furo e provoca a delaminação nas camadas do laminado. A Figura (36) representa o deslocamento do macho paralelo à direção das fibras, na forma de dispositivos de ensaios, para a obtenção das tensões máximas ao cisalhamento.
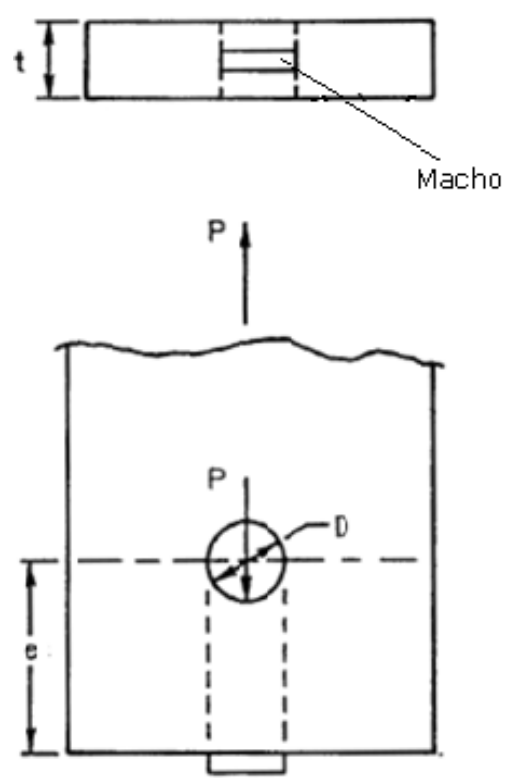
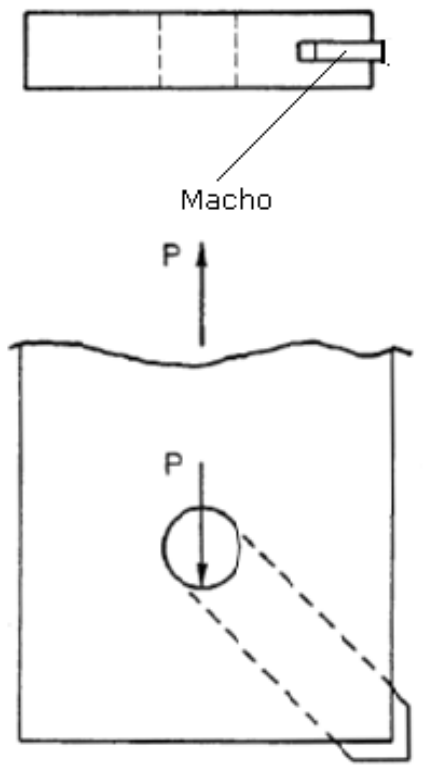

Figura 36 - Modos de falhas por cisalhamento devido à ação dos esforços externos solicitantes.

A forma do modo de falha variar como uma função da razão e/D e do empilhamento das camadas é ilustrada na Figura (37). Entre os vários resultados apresentados, destaca-se uma faixa constante de tensão de falha por cisalhamento, contrariamente a tensão de "bearing" e a variação da relação e/D. A falha por "bearing" somente foi obtida quando se atingiu uma relação e/D igual a 2,5, considerando uma tensão de aproximadamente 125 Ksi e para um laminado de configuração com maior número de camadas orientadas a $45^{\circ}$ e $90^{\circ}$ (Figura (37)). Os dados também mostram uma redução na resistência ao cisalhamento quando há o empilhamento a $0^{\circ}$, ou seja, na direção principal do carregamento (Figura (37)). Contudo, os dados para laminados com $50 \%$ ou mais do empilhamento concentrado na direção do principal carregamento mostram falhas por cisalhamento para uma mesma faixa de tensão, independentemente da distância da borda (e) ser igual a 2D ou 8D. Então, conclui-se 
que um acréscimo adicional na distância de borda, exclusivamente, não pode ser representativo para aumentar o limite de resistência ao cisalhamento de laminados com elevada concentração de fibras na direção do principal carregamento. Como prevenção a falha por cisalhamento, primeiramente, deve-se evitar grandes concentrações de empilhamentos dos reforçadores naquela direção e especificar, no mínimo, a distância típica de borda (3D). A conclusão é que a resistência ao cisalhamento é mais dependente do empilhamento do laminado do que da distância de borda (e).

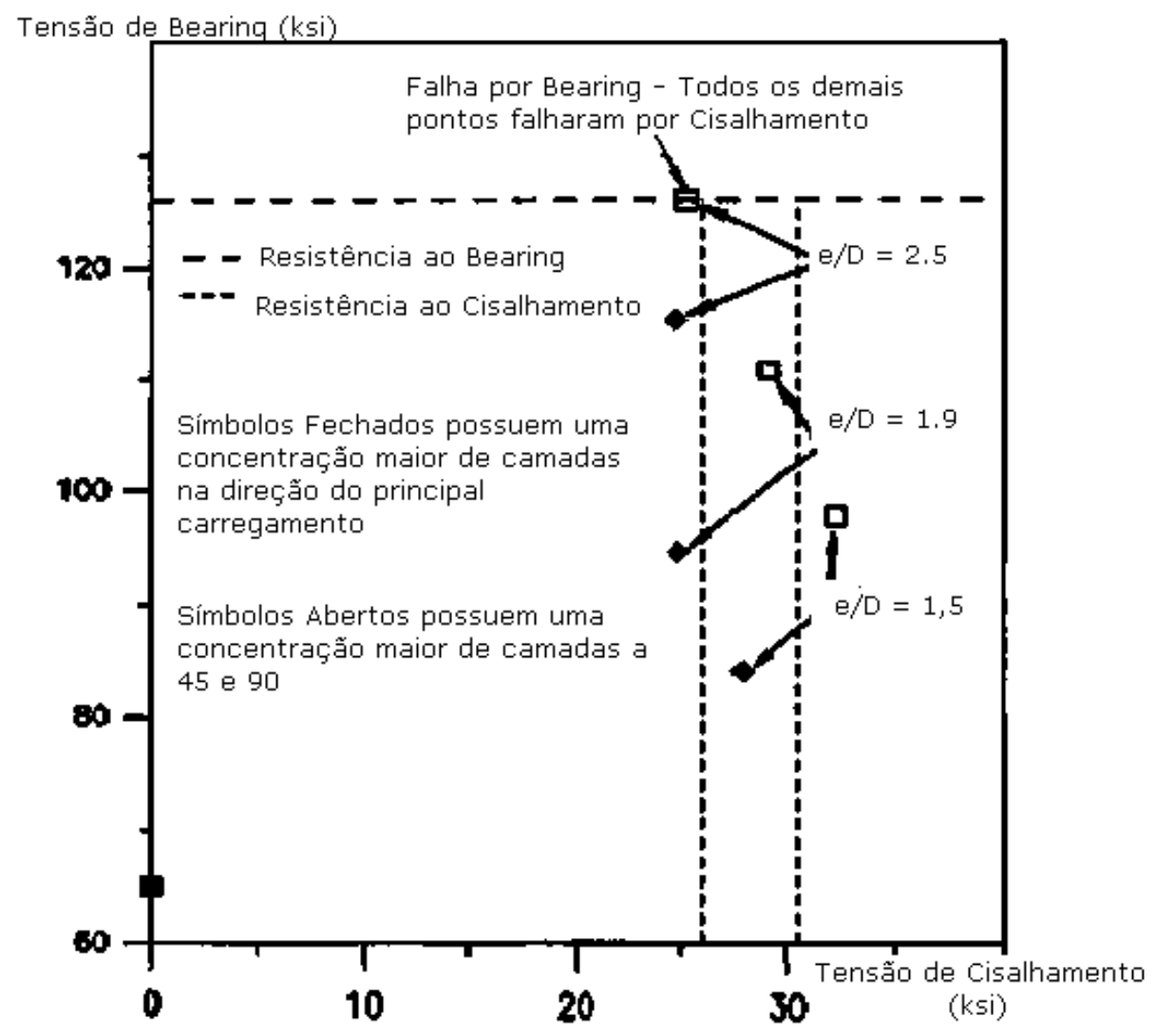

Figura 37 - Dados de falha para "bearing" em função do cisalhamento, devido ao carregamento externo, como uma função das tensões de "bearing" e cisalhamento (MIL-HDBK-17-3F (2002)).

Por fim, em função das juntas simples sempre estarem presentes nas estruturas aeronáuticas e ainda das mesmas não poderem falhar em serviço, elas continuam sendo, até os dias de hoje, objeto de estudo de vários pesquisadores. 
Segundo Less e Makarov (2004), as resistências em sistemas de uniões conectadas mecanicamente e coladas são combinadas para desenvolverem um sistema de conexão melhorado para estruturas em materiais compósitos. O princípio do aumento da resistência é baseado na inserção de pinos de pequenos diâmetros através de uma junção colada. Os pinos comportam-se como reforços locais nas regiões altamente solicitadas das junções, capacitando uma junta colada absorver um incremento de carga antes da falha. Em uma série de ensaios em amostras do tipo "single lap joint" (junta simples), usando amostras de polímeros reforçadas com fibra de vidro somente colados e somente pinados, os pesquisadores observaram a ocorrência de mecanismos de falha na região da junta. Por outro lado, as amostras unidas por pinos e coladas simultaneamente falharam distante da união, aliados a um razoável aumento do carregamento que causa a falha. Estas características intrínsecas foram obtidas considerando-se o material do pino, diâmetro do pino, número de pinos e possibilidades de configurações como mostra a Figura (38).

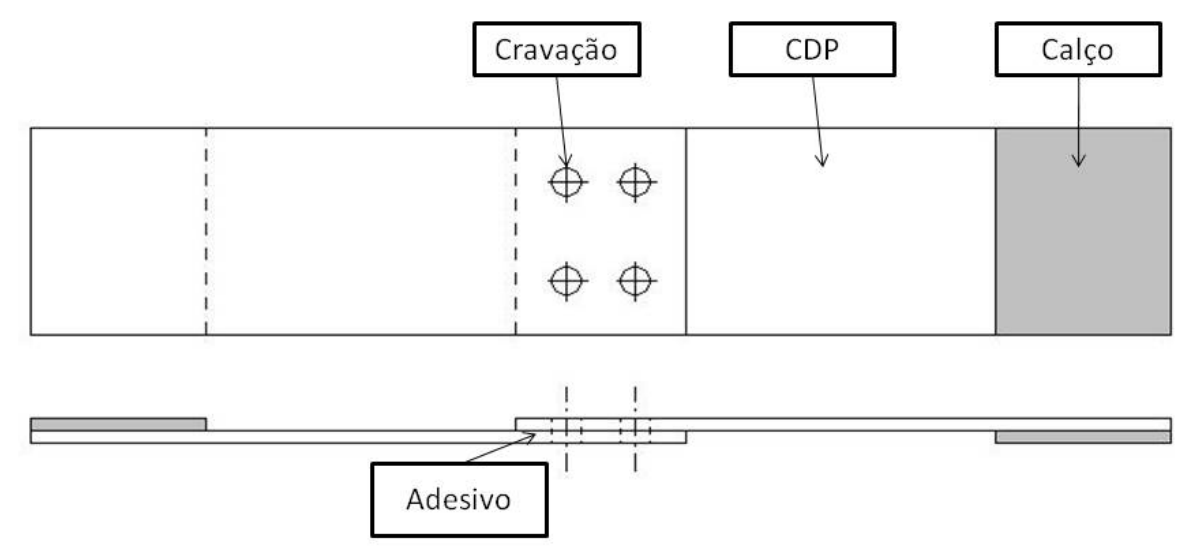

Figura 38 - Junta unida por pinos e colada formada por material compósito, Lees e Makarov (2004).

Os resultados demonstraram o potencial dos sistemas pinados e colados. Contudo, trabalhos adicionais são necessários para confirmar a sensibilidade dos resultados variando-se 
parâmetros; tais como: o tipo das fibras; a geometria da região de sobreposição (“overlap"); a interface colada e a configuração da junta. No estudo de Lees e Makarov (2004), o ensaio foi conduzido usando uma máquina de tração de 15 toneladas a uma velocidade de $1,0 \mathrm{~mm} / \mathrm{min}$, como mostra a Figura (39). Embora a área colada estivesse paralela no início de cada ensaio, o momento fletor induzido pela geometria do CDP ao simples cisalhamento causou um significante re-alinhamento na união. Para a maioria dos casos, três CDPs foram ensaiados para cada particular combinação de parâmetros da junção mostrados na Figura (40).

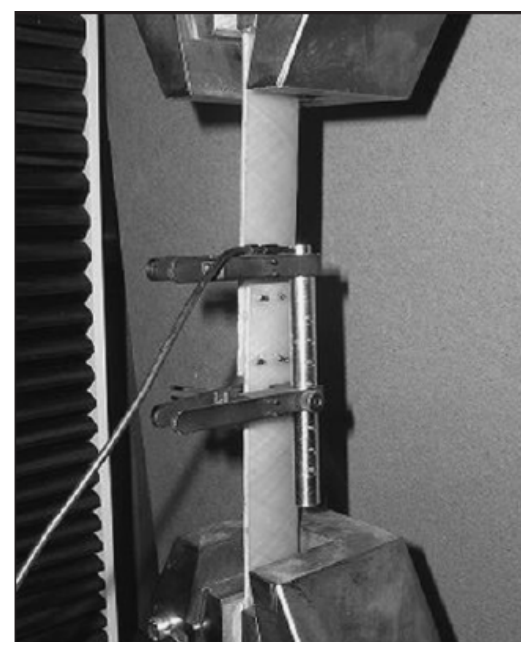

Figura 39 - Ensaios ao simples cisalhamento, Lees e Makarov (2004).

Os autores concluíram que em aplicações reais de uniões formadas por matrizes poliméricas com reforçadores de fibra de vidro e submetidas ao cisalhamento puro, quando a vida em serviço exigir um acréscimo no limite de resistência, uma opção de projeto é a aplicação das junções do tipo "pinado e colada". Além disso, corretamente projetadas, as junções unidas por pinos e coladas apresentaram patamares de resistência superiores aos das junções somente unidas por pinos ou coladas isoladamente. Por fim, o diâmetro e a quantidade de pinos, sua disposição, bem como a configuração da união, são fatores importantes de projeto para determinar uma melhor distribuição da carga nos pontos de 
cravação e, conseqüentemente, capacitar a junta para suportar um aumento na solicitação dos esforços externos.

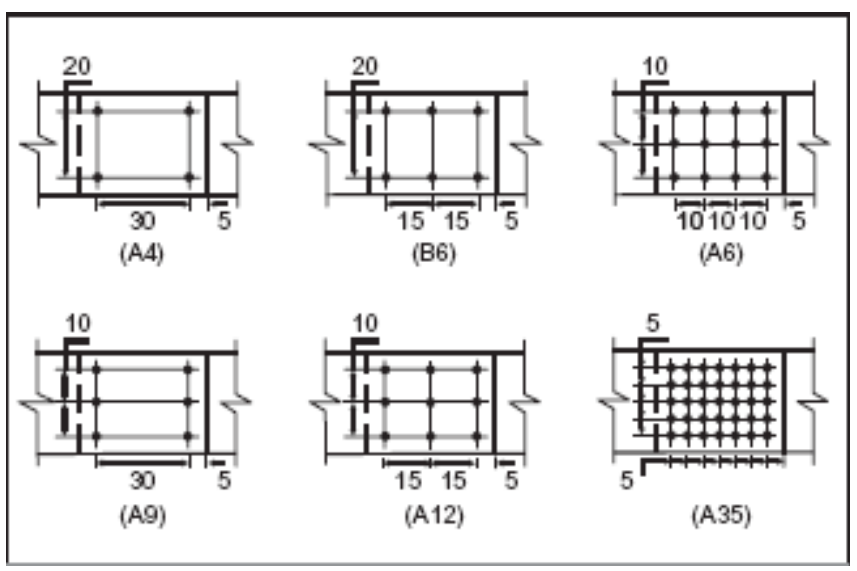

Figura 40 - Alguns exemplos de parâmetros particulares da junção, Lees e Makarov (2004).

Matsuzaki, Shibata e Todoroki (2007) propuseram o estudo de um método de formação de união híbrida metal-compósito juntamente com a investigação experimental da sua resistência. Buscando um melhor desempenho, foi desenvolvido outro tipo de união híbrida, usando uma chapa em liga de alumínio Al 5052-F e uma chapa em material compósito de resina epóxi reforçada com fibra de vidro, unidas mecanicamente por fixadores, bem como, coladas por adesivo. Os ensaios realizados para verificação da resistência ao simples cisalhamento em uniões "Single Lap Joint” demonstraram que as junções híbridas em metal-compósito propostas possuem uma resistência ao cisalhamento máxima 1,84 vezes superior a da junção híbrida unida simplesmente pelo processo mecânico (cravada). A ilustração esquemática da Figura (41) mostra a formação de uma união híbrida metalcompósito. O método proposto requer um processo de cura único, tanto para parte em material compósito, quanto para a área de colagem entre as partes, obtendo-se uma maior eficiência na união. Neste processo de fabricação, os parafusos são instalados no laminado ainda "seco" (não impregnado com resina epóxi), antes do processo de cura. Os furos são confeccionados por ferramentas de corte, de forma que, após a montagem do parafuso, as 
camadas de fibra de vidro permaneçam íntegras, ou, em outras palavras, sem apresentar descontinuidade de forma, evitada pela não interferência do fixador com a fibra. A concentração de tensão pode ser diminuída, desde que a folga entre o elemento fixador e o furo da placa seja preenchida com resina abundante. Estas ações impedem que ocorra uma diminuição no limite de resistência a fadiga. Complementarmente, desde que os fixadores estejam revestidos totalmente pela resina durante o processo de cura, a junta permanecerá perfeitamente impermeável e resistente a corrosão, sendo adequada para especificação em estruturas aeronáuticas.

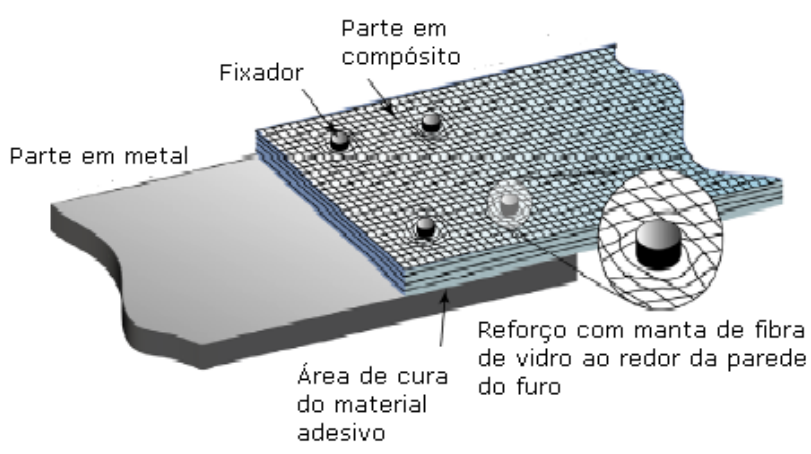

Figura 41 - Ilustração esquemática de uma união híbrida entre uma chapa de alumínio e um laminado de matriz polimérica reforçada com fibra de vidro, Matsuzaki, Shibata e Todoroki (2007).

Os autores Matsuzaki, Shibata e Todoroki (2007) utilizaram os Padrões Industriais Japoneses (“Japanese Industrial Standards - JIS K 6850”) para o projeto dos CDPs das junções híbridas em metal-compósito, unidas pelo processo mecânico e de adesão (colagem), que foram confeccionadas na forma de "Single Lap Joint". Este método de ensaio estabelece procedimentos para verificação da resistência ao cisalhamento na área fixada-colada, através do carregamento por tração. O laminado é formado, então, por camadas empilhadas a $0^{\circ}$ e $90^{\circ}$. As camadas a $0^{\circ}$ estão localizadas na direção longitudinal do CDP e as camadas a $90^{\circ}$ ficam em contato com o alumínio (parte metálica da junta). Vale ressaltar que o CDP pode ser especificado para uma ou duas fileiras de parafusos. Os parafusos são inseridos nos furos da 
chapa de alumínio, conjuntamente com as mantas de fibra de vidro totalmente "seca" dispostas sobre esta. Nesta etapa, não são admitidos danos de descontinuidade causados pelo fixador na manta de fibra de vidro. Em seguida, a resina epóxi é depositada para impregnar a fibra e os vazios entre os elementos fixadores e as partes que compõem a união. O laminado é formado por três mantas de fibra de vidro e a montagem é feita com o auxílio de parafusos e porcas, como mostram as Figura (42 (a)) e (42 (b)).

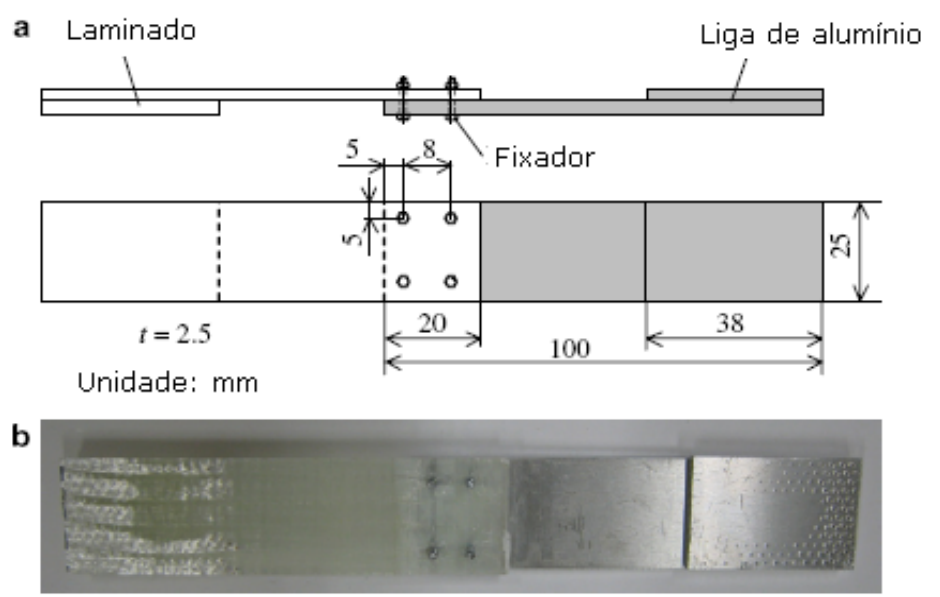

Figura 42 - Junta híbrida entre laminado reforçado com fibra de vidro e chapa de alumínio: (a) Configuração do CDP; (b) CDP ensaiado, Matsuzaki, Shibata e Todoroki (2007).

Os pesquisadores realizaram ensaios em cinco CDPs somente colados; três CDPs simplesmente parafusados e seis CDPs parafusados e colados. A resistência da junta foi definida pela equação (19) a qual possibilita comparar o comportamento das juntas "coladas"; “parafusadas" e "parafusadas-coladas", como segue:

$$
S_{j h}=\frac{P_{p j h}}{A_{a j h}}
$$

Onde:

$\mathrm{S}_{\mathrm{jh}}=$ a máxima resistência ao cisalhamento para união metal-compósito; 
$\mathrm{P}_{\mathrm{pjh}}=\mathrm{a}$ carga máxima aplicada durante o ensaio;

$\mathrm{A}_{\mathrm{ajh}}=\mathrm{a}$ área de adesão da junta, desconsiderando-se sua redução devido à presença dos furos de fixação.
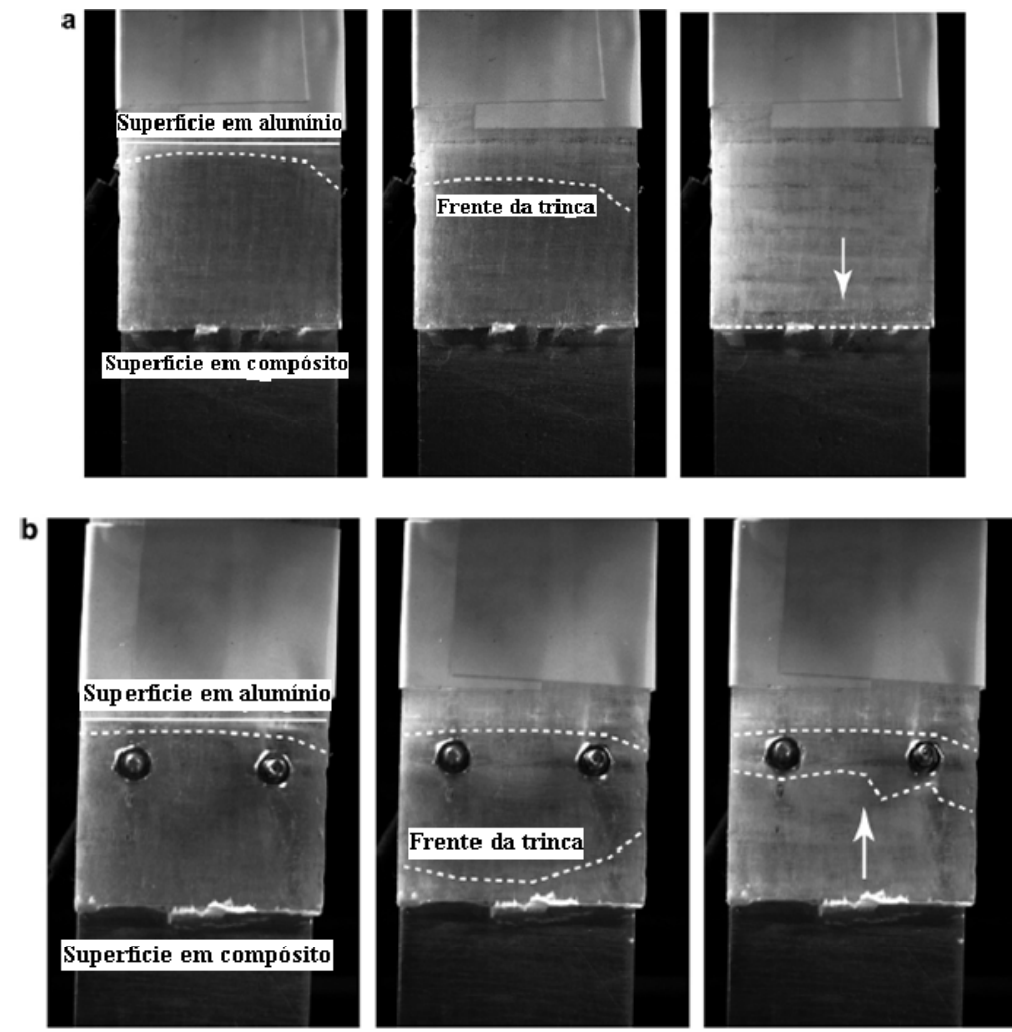

A linha cheia mostra as superfícies do compósito e alumínio sobrepostas. A linha tracejada mostra a frente da trinca

Figura 43 - Propagação da trinca em uniões híbrida compósito-alumínio durante os ensaios de simples cisalhamento: (a) juntas híbridas simplesmente coladas; (b) juntas híbridas parafusadas-coladas, Matsuzaki,

Shibata e Todoroki (2007).

Os autores verificaram as diferenças na eficiência do impedimento da propagação da trinca, do ponto de vista quase-estático, entre a junta híbrida parafusada-colada e a simplesmente colada, usando dois parafusos fixados com porcas. Sendo translúcida, a área colada na superfície da parte em compósito reforçada com fibra de vidro, a mesma torna-se branca quando a trinca ocorre entre às áreas de aderência da junção. A evolução da frente da trinca pode ser observada através do monitoramento da placa em compósito durante o ensaio. 
A Figura (43(a)) demonstra que a origem da propagação da trinca nas juntas simplesmente coladas se dá na superfície em alumínio da união. A trinca propaga-se para a superfície em compósito até a ruptura total da junta. Contrariamente, a Figura (43(b)) mostra o caso de uma junta parafusada-colada com dois parafusos, indicando que quando a trinca, originada na superfície de alumínio, progride para a área junto aos parafusos, onde a mesma não mais propaga, provavelmente porque uma grande parte da carga aplicada é transferida para os fixadores. Quando a falha se inicia na superfície em compósito da união, a ruptura ocorre na área colada. Uma conclusão importante dos pesquisadores foi que a presença dos parafusos nas junções parafusadas-coladas contribuiu para a prevenção da propagação da trinca.

Deve-se destacar que no presente trabalho não serão abordadas às juntas parafusadas e coladas, mas somente, as juntas unidas mecanicamente por fixadores. Torna-se de suma importância, primeiramente, entender os mecanismos de falha e todo o comportamento mecânico de juntas unidas exclusivamente por fixadores para então, futuramente, serem realizados trabalhos sobre juntas unidas por fixadores e coladas simultaneamente.

\section{ENSAIOS DE CARACTERIZAÇÃO DOS MODOS DE FALHAS}

Segundo a ASM Handbook - Vol. 21 - Composites (2005), os objetivos da investigação laboratorial são para determinar se o material foi manufaturado de acordo com as especificações e/ou para identificar qualquer problema potencial que possa ter influenciado na falha da peça. A investigação laboratorial inicia-se através de uma análise visual completa das peças falhadas para verificar o tipo e a localização do dano e até idéias iniciais de como a falha pôde ter ocorrido. Práticas de ensaios não destrutivos devem também ser adotadas a fim de se verificar todas as conclusões das observações visuais do dano e até encontrar outro dano que pode ou não pode ser visível. Torna-se necessário que todos os danos no componente 
sejam encontrados e avaliados a fim de possibilitar o entendimento do modo e seqüência da falha. A próxima etapa da investigação corresponde à verificação dos materiais e processos, incluindo também tomada de medidas, onde for possível, para assegurar que a peça apresentou conformidade dimensional. Em seguida, as amostras devem ser removidas para o exame da química do material. As secções transversais são preparadas para permitir a avaliação do tipo de empilhamento e a contagem das camadas e suas orientações. A temperatura de transição vítrea e o grau de cura da resina devem ser determinados empregando técnicas de análises térmicas para garantir que a peça foi produzida de acordo com os seus requisitos. As superfícies fraturadas devem ser segregadas e analisadas usando a observação visual e o Microscópio Eletrônico de Varredura (MEV) a fim de determinar os locais da iniciação das falhas; direção do crescimento da fratura; influências ambientais e os modos de falhas. As análises químicas para identificar materiais de origem desconhecida ou agentes contaminantes devem também ser realizadas.

Se a investigação laboratorial sobre estes aspectos não explana adeqüadamente o modo de falha, testes adicionais podem ser feitos para definir mais adiante a causa da falha. Os testes adicionais devem incluir ensaios mecânicos para verificar a resistência do material e os seus módulos, análise da tensão a fim de se determinar a tensão de ruptura e a seqüência dos eventos de fratura. A análise da falha é concluída quando a causa da falha foi adeqüadamente esclarecida. Vale ressaltar que o presente trabalho não tem como objetivo identificar a causa raiz que gerou a falha da junção híbrida, mas sim, entender o comportamento mecânico da mesma.

O procedimento detalhado para a análise de falhas em compósitos pode seguir os passos mostrados adiante. 
* Revisão dos registros da vida em serviço disponível, materiais e métodos de processamento, requisitos de projeto e registros de fabricação.

Os registros da vida em serviço são uma boa fonte de procura de informações para determinar:

a. Quanto tempo o componente fraturado ficou em serviço;

b. Se, ou não, o componente sofreu manutenção adequada durante seu histórico em serviço;

c. Se e quando o componente foi alguma vez reparado ou revisado;

d. Os tipos e magnitudes das cargas atuantes até a falha e se, ou não, as cargas ocorreram típicas ou atípicas;

e. As condições ambientais durante o serviço e se, ou não, aquele ambiente apresentou conformidade com o especificado em projeto;

f. Se, ou não, existem outras falhas similares correspondentes a falha detectada neste particular componente.

Uma revisão dos materiais e métodos de processamento, dos requisitos de projeto e do processo de fabricação estabelece uma determinação da origem da fibra, resina e adesivo, bem como o tipo e números de camadas e suas orientações, os requisitos dimensionais e suas tolerâncias, pressão, temperatura, condições ambientais e o ciclo de cura usado no processamento dos materiais correspondente ao componente acabado.

Uma análise destas informações deve fornecer respostas para questões considerando se: o projeto, os materiais, o processo de fabricação, o carregamento, as condições ambientais, a manutenção ou os procedimentos de reparos, podem ter implicado no surgimento da falha. 


\section{Análise visual e ensaios não destrutivos.}

A análise visual é normalmente o primeiro passo do processo de evolução para a especificação dos ensaios não destrutivos. Os objetivos de uma verificação visual são para documentar todos os danos e para determinar como o componente poderia ter se separado e tentar perceber qual fratura específica que deu origem ao surgimento da falha no componente. O objetivo em definir a fratura inicial/principal, a qual deu origem a todas subseqüentes, é reduzir o número de necessidade de análise adicional de superfícies danificadas, a fim de se determinar a causa da falha. A Figura (44) mostra três estágios diferentes na falha de um rotor de helicóptero. A área denominada como "A" descreve uma região de iniciação por fadiga, a área "B" descreve uma região de falha curva interlaminar (delaminação) e a área "C" descreve uma área de trituração da fibra durante a fratura final.

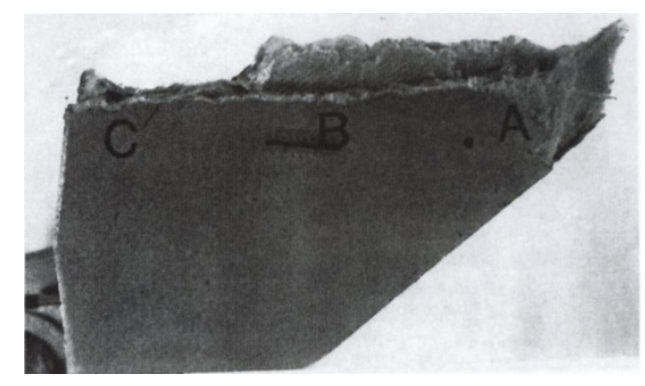

Figura 44 - Exemplos de falhas visíveis e diferentes entre si (AMS HANDBOOK - VOL. 21 COMPOSITES (2005)).

Estas três regiões distintas são visualmente aparentes na superfície fraturada e são indicativas de tipos diferentes de carregamento na peça durante o surgimento da falha.

Embora a maior parte das fraturas interlaminares seja visualmente aparente, os compósitos, por causa da sua construção laminada, também apresentarão fraturas intralaminares (dentro da camada), que podem ficar encobertas da visão. Como resultado, os Ensaios Não Destrutivos (END), utilizados para detectar estas falhas intralaminares, 
freqüentemente, representam uma etapa particularmente crítica na análise das estruturas em compósito.

A maior parte dos métodos de inspeção por END bem sucedidas para materiais compósitos incluem: Ultrasom, Líquidos Penetrantes e Raio-X. A inspeção por Ultrasom detecta defeitos internos na peça e deve operar na faixa de 1 a $25 \mathrm{MHz}$ para as ondas acústicas transmitidas. Os níveis de atenuação (diminuição da intensidade) dos sinais são então mensurados, agrupados simultaneamente, e atribuídos diferentes níveis cinzentos ou coloridos na escala dos registros mapeados. O aumento do nível da atenuação do sinal corresponde ao maior defeito (dano) interno do componente. A Figura (45) descreve um registro de inspeção ultrasônica proveniente de uma região de um radome danificado.

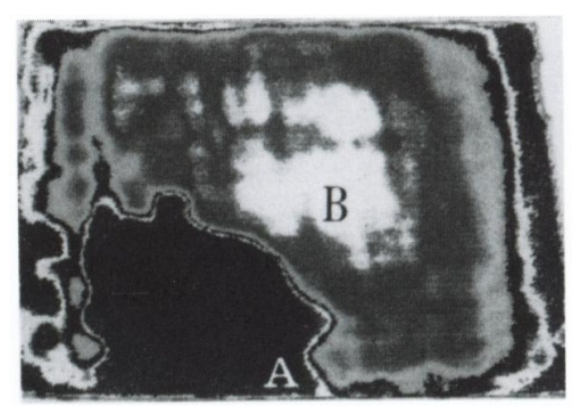

Figura 45 - Exemplo de Inspeção por Ultrasom (AMS HANDBOOK - VOL. 21 - COMPOSITES (2005)).

Neste caso, o sinal é fortemente atenuado na região escura formada pelo defeito, identificada como Seção “A”, onde uma delaminação ocorreu. Nenhuma atenuação do sinal, de qualquer maneira, foi notada na área clara mostrada na Seção "B”, significando que não existe defeito naquela região. Uma atenuação moderada do sinal pode ser notada nas áreas mais escuras ao redor da área não danificada da Seção "B". A atenuação moderada do sinal é, provavelmente, indicativa de algum defeito menor no compósito, tais como micro-fissuras na resina ou separação da fibra-matriz. 
A detecção do defeito nos compósitos usando Raio-X é realizada nas mesmas formas básicas em relação aos metais, exceto o procedimento que antecede a inspeção, onde um líquido penetrante impenetrável por Raio-X é aplicado para o interior das fissuras superficiais expostas no CDP, com a finalidade de ampliar a visibilidade do defeito. Geralmente, o equipamento de Raio-X opera na faixa de 10 a $50 \mathrm{KV}, 5 \mathrm{~mA}$ com líquido penetrante a base de di-iodobutano (revelador colorido), na forma da obtenção dos melhores resultados. A Figura (46) detalha o defeito de um compósito com reforçadores a $45^{\circ}$, seguido de um ensaio de tração. A radiografia foi obtida antecedida da adição e penetração do revelador de diiodobutano, partindo-se das bordas e seguindo em direção ao centro do CDP. O uso do penetrante para revelar este tipo de defeito é normalmente importante para definir a profundidade do dano interlaminar (delaminação) em um CDP, antes de ocorrer a ruptura completa.

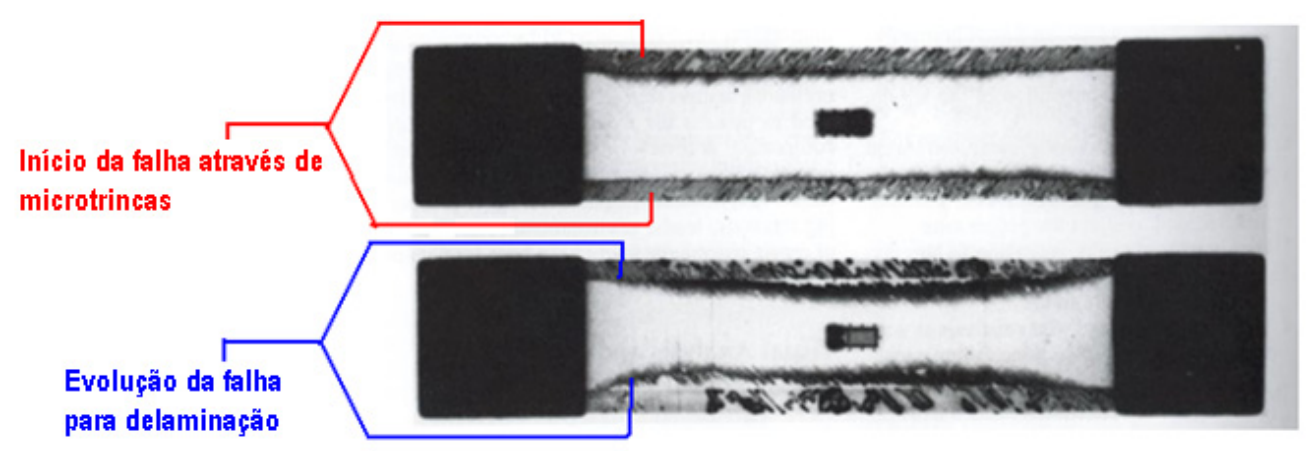

Figura 46 - Exemplo de Inspeção por Raio-X (AMS HANDBOOK - VOL. 21 - COMPOSITES (2005)).

Da análise da vista de topo (planta) das radiografias da Figura (46), conclui-se que mostram a progressão da falha em função do carregamento por tração, ou seja, a uma determinada carga a falha inicia-se na forma de microtrincas e evolui para delaminação nas bordas, antes de ocorrer a ruptura do CDP. Em complemento as radiografias com aplicação do revelador colorido, as inspeções com Raio-X padrão (convencional), pode fornecer informações considerando o número de camadas e a orientação do reforçador. Defeitos nas 
resinas ou adesivos também ficarão aparentes com a infiltração de água na forma de coração ou caroço. A orientação, tamanho da célula e materiais da rede de estruturas na forma de colméia ("honeycomb”), particularmente de núcleos não metálicos, podem normalmente ser determinados com a inspeção de Raio-X convencional.

O uso de qualquer destas técnicas de aplicação não-destrutivas requer que alguma prévia avaliação seja atribuída ao tipo da falha, provavelmente, a ser encontrada, tanto para o método Ultrasônico quanto para o de Raio-X com a aplicação do líquido penetrante colorido, sendo que os fluídos penetrarão para o interior das superfícies fraturadas. Estes fluídos podem alterar a natureza química das superfícies fraturadas, as quais podem ter iniciado e/ou propagado a falha. Técnicas de análise da superfície, tal como Espectroscopia Fotoelétron por Raio-X ("x-ray photoelectron spectroscopy" - XPS), são usadas para definir o tipo de contaminação na superfície danificada, sendo recomendada, quando for o caso, sua aplicação antes dos demais métodos mencionados.

\section{Verificação dos materiais e métodos de processamento.}

O primeiro passo da investigação na porção degenerada é para verificar que os materiais e métodos de processamento corretos foram usados na manufatura do componente. Estas análises incluem a verificação:

$\checkmark$ Da fibra, da resina e do sistema de colagem (adesivo);

$\checkmark$ Do tamanho, tipo, número, localização e orientação de todas as camadas e suas interfaces (áreas coladas);

$\checkmark$ Do ciclo de cura aplicado no componente.

A verificação da resina e o sistema de colagem são normalmente conduzidos usando uma tecnologia conhecida como Espectroscopia de Infravermelho, que está baseada na 
Transformada de Fourier ("Fourier Transform Infrared" - FTIR) na forma de espectroscopia. Cada resina ou adesivo usado no compósito apresenta um espectro por infravermelho único, como mostra a Figura (47).

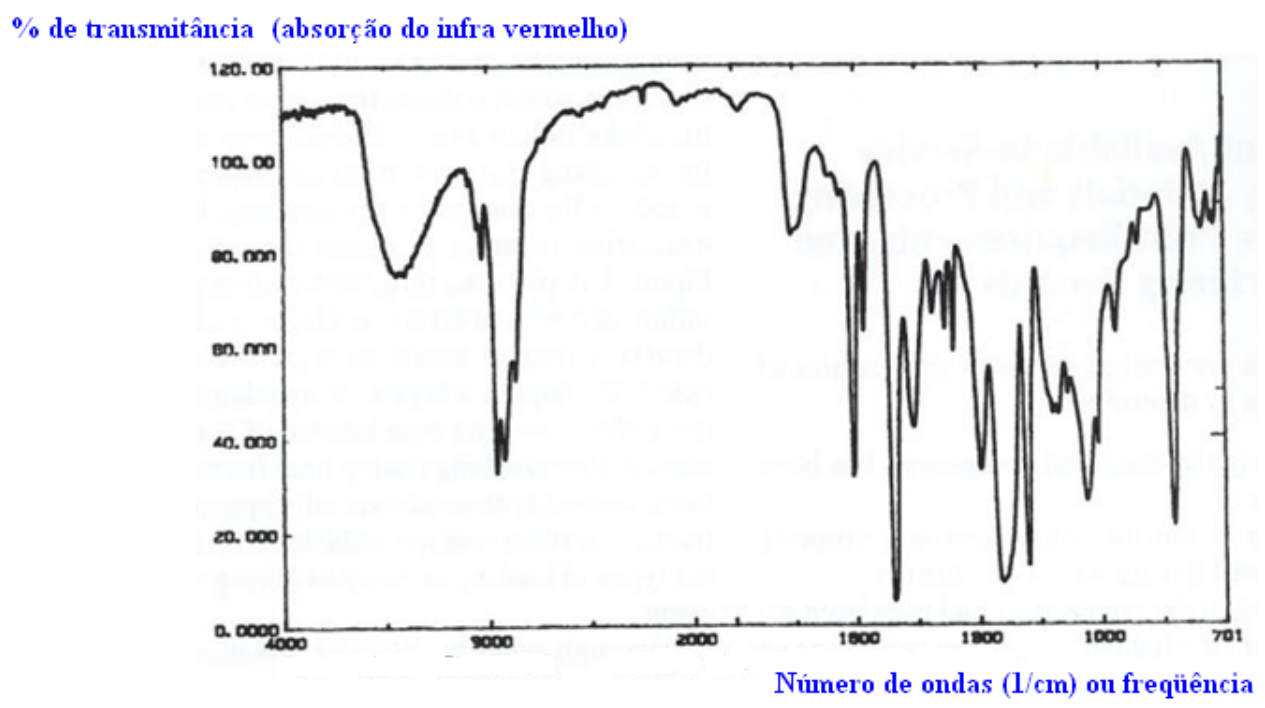

Figura 47 - Exemplo de Análise de Infravermelho por Transformada de Fourier - FTIR (AMS HANDBOOK - VOL. 21 - COMPOSITES (2005)).

O espectro obtido para a resina ou adesivo no componente é então comparado com o espectro padrão em um banco de dados de materiais. Esta análise normalmente revela o tipo de material específico. Adicionalmente, se muitos bancos de dados de espectros padrões estão disponíveis para comparação, a técnica por FTIR pode ainda ser capaz de verificar uma resina específica e sua manufatura, por exemplo, Cytec FM 73 epóxi. O espectro obtido durante esta análise pode também mostrar picos que não são indicativos do material que está sendo analisado. Os picos que indicam um contaminante potencial, podem ser aqueles que demonstram a causa da falha. A técnica de FTIR é também usada para verificar o tipo da fibra. Além disso, a análise visual é normalmente empregada para identificar as fibras, tais como: carbono; vidro; boro e aramida. 
Seguindo com a verificação do material, o próximo passo no processo é para determinar a temperatura de transição vítrea e o teor da cura para toda a resina e do sistema de colagem. Para tanto são empregadas às técnicas de análises térmicas, tais como: Análises Termomecânicas ("Thermomechanical Analysis" - TMA) e Calorímetro de Varredura Diferencial ou Calorimetria Exploratória Diferencial ("Differential Scanning Calorimery" DSC), instrumentos termodinâmicos padrões. Cabe ressaltar que o detalhamento destas técnicas não são objetos do presente trabalho.

Determinação das características da fibra, da matriz, da fração de volume em vazios e a verificação do empilhamento das camadas e suas orientações.

As falhas em compósitos podem também ser o resultado da fibra, da matriz e da fração de volume em vazios impróprios ou empilhamentos das camadas e suas orientações incorretas. Para a determinação das características da fibra, da matriz e da fração de volume em vazios, duas técnicas são normalmente usadas: o método da análise química da matriz e o método de análise micro estrutural. No método da análise química da matriz, o compósito é primeiro pesado em ar e água para determinar a sua densidade, aplicando-se o princípio de Archimedes.

Após, o compósito é submerso em ácido nítrico quente até a resina ser extraída e nada permanecer além das fibras. As fibras e a resina são então pesadas e um cálculo é feito para determinar a porcentagem em volume das fibras e da resina, usando-se medidas de densidade padrão. De posse do valor encontrado para a densidade do compósito ensaiado e do percentual em volume da fibra e da resina, o percentual de vazios pode, então, ser determinado.

As fibras, a matriz e as frações em volume de vazios podem também ser determinadas por meios metalográficos, selecionando-se diversas amostras da secção transversal, como evidencia a Figura (48). Estas secções devem ser selecionadas tanto perto quanto longe das 
superfícies fraturadas, usando-se técnicas de análises de imagens para determinar os percentuais médios de cada elemento constituinte.

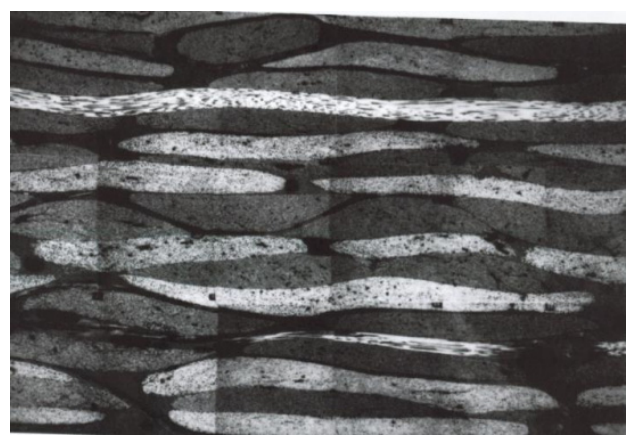

Figura 48 - Exemplo de micrografia de uma secção transversal obtida de um compósito carbono-epóxi (AMS HANDBOOK - VOL. 21 - COMPOSITES (2005)).

O emprego impróprio do empilhamento das camadas e sua orientação podem também ser a causa da falha em materiais compósitos. O número e a orientação das camadas podem ser examinados através de simples procedimentos metalográficos de seccionamento transversal.

\section{$\underline{\text { Revisão de compósitos - parâmetros de processamento. }}$}

O conhecimento exato dos métodos de processamento empregados na manufatura do componente também é útil quando se avalia a causa da falha. Saber se a peça foi fabricada usando-se bolsa de vácuo, pressão ou técnicas de autoclave facilitam o analista a entender melhor como as características micro-estruturais do compósito podem ter afetado as propriedades mecânicas globais do componente. Por exemplo, os componentes processados em autoclave geralmente exibem baixas frações de vazios e têm melhor consolidação e propriedades mecânicas mais elevadas em relação aos componentes moldados por pressão ou bolsa de vácuo. Adicionalmente, para saber que tipo de temperatura e sistema de pressão foi utilizado, o ciclo de cura real deve ser examinado para certificar que as pressões apropriadas, 
a razão da rampa de cura, a exposição térmica e os ciclos de resfriamento estavam em conformidade com os requisitos especificados pelos fornecedores dos materiais.

\section{Fractografia e análise da superfície.}

$\mathrm{Na}$ Fractografia, os compósitos podem apresentar modos de falhas relativamente simples ou extremamente complexos. As falhas complexas podem abranger uma ou mais fraturas interlaminares e intralaminares ou translaminares e, por esse motivo, muitas superfícies fraturadas poderão necessitar de exame. Para reduzir o número de ensaios, deve-se tomar uma decisão em relação a aquelas superfícies que tem mais probabilidade de fornecer informações mais úteis. Esta decisão normalmente representa uma das mais difíceis tarefas envolvidas na análise da falha de compósitos. Geralmente, a seleção das superfícies a serem examinadas depende inicialmente do tipo da falha predominante apresentado pelo componente e em seguida a necessidade de analisar as fraturas secundárias a fim de explanar a fratura primária.

Normalmente, a fractografia é usada para determinar o modo da falha, o local da iniciação, a direção do crescimento da trinca e todas as influências do meio ambiente sobre a falha. Nesta fase do processo de investigação, pode-se verificar se as fraturas translaminares foram causadas por carregamentos de tração, compressão, cisalhamento, flexão ou fadiga, bem como, se as fraturas inter e intralaminares foram causadas por sobrecarga de ciclos de fadiga, ou então, por modos combinados de carregamentos.

As técnicas das análises da superfície consistem em inúmeras técnicas de análises químicas que também podem ser utilizadas para definir os contaminantes superficiais notados durante a avaliação fractográfica. Algumas destas técnicas incluem a Espectroscopia de 
Fotoelétron por Raio-X - XPS (“X-ray photoelectron spectroscopy”), a Espectroscopia de Infravermelho por Transformada de Fourier - FTIR ("fourier transform infrared"), Espectroscopia de Massa de Íon Secundário - SIMS (“secondary íon mass spectroscopy”) e Espectroscopia de Elétron de Auger - AES (“Auger electron spectroscopy”).

Ensaios mecânicos e análise de tensões.

Os ensaios mecânicos associados à análise de tensões permitem obter um conhecimento preciso dos níveis de cargas e tensões na operação do componente e é um dos ingredientes críticos envolvidos na definição da origem da falha. Embora os métodos de análise fractográfico e visual possam identificar a origem, a direção e o modo da propagação da trinca, a análise de tensão é a técnica que mais freqüentemente dá a explicação quantitativa para a causa da falha. Dessa forma, foram assim amplamente empregados no presente trabalho.

Ainda, em se tratando de ensaios mecânicos, presume-se que as técnicas de ensaios não destrutivos de Ultra-Som e Raios-X, podem auxiliar na detectação da tensão próxima ao início da falha na estrutura, como demonstra o fluxograma da Figura (49). Este processo consiste, basicamente, dos seguintes passos:

1. Ensaia-se o CDP (junta unida mecanicamente) de acordo com especificações contidas em normas, empregando o "Método do Módulo Secundário" (MILHDBK-5H, 1998) e visando determinar a Tensão Admissível "Teórica” da junta;

2. Ensaia-se o próximo CDP (junta unida mecanicamente) até que o mesmo atinja o valor da Tensão Admissível “Teórica”, onde o ensaio é interrompido; 
3. O CDP ensaiado é submetido à inspeção por Ultra-Som e Raio-X, a fim de ser visualizado alguma descontinuidade (defeito) no material. Caso não seja detectado nenhum defeito, passa-se a ensaiar o próximo CDP com um incremento de tensão;

4. Repeti-se o passo anterior até que seja detectado algum defeito fora da faixa de tolerância de projeto. Nesta situação, pode-se garantir que seria obtido um valor de Tensão Admissível mais próximo do real, especificando-se, assim, um coeficiente de segurança para o projeto.

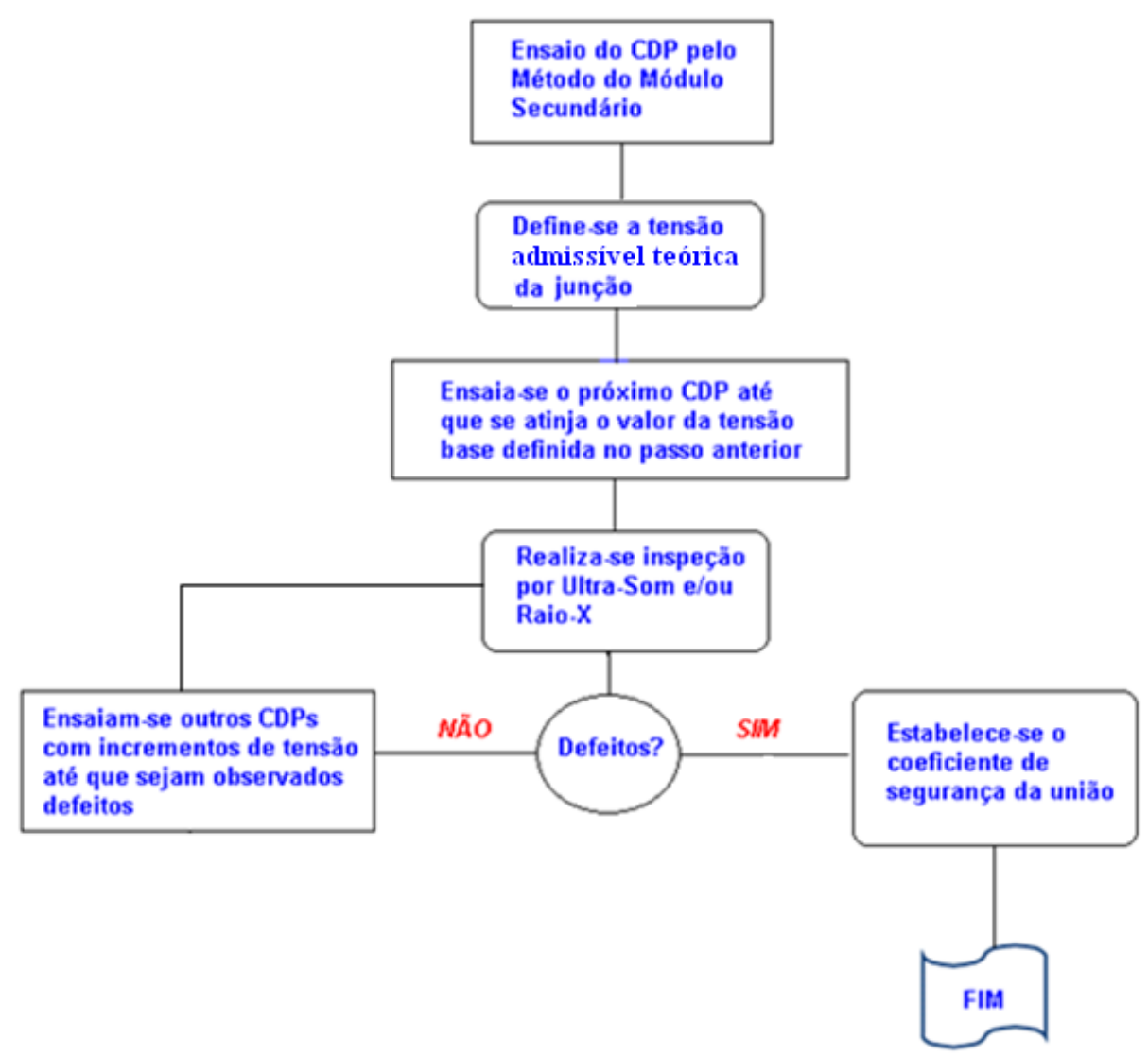

Figura 49 - Fluxograma proposto para determinação da tensão próxima ao início da falha da junção por meio de ensaios não destrutivos.

Os procedimentos de análise da tensão para materiais compósitos podem ser relativamente complexos e como eles são fabricados pela laminação de camadas altamente 
anisotrópicas, uma variedade quase infinita de resistências e módulos direcionais pode ser alcançada. Por causa desta peculiaridade, um conjunto diferente de propriedades materiais tem que ser considerada para cada falha examinada. Como complicação posterior, devido a sua construção laminada e anisotrópica, variações significativas de tensão podem surgir dentro do próprio laminado. Como resultado, deve-se considerar a falha em cada camada individualmente, bem como uma perda de rigidez para o laminado como um todo. Verifica-se assim, que há certo grau de complexidade para ser determinado o estado de tensões de um laminado e/ou de cada lâmina que o compõem. Dessa forma, no presente trabalho será empregada a análise de tensões com o auxílio do Método dos Elementos Finitos. Além disso, haverá uma análise de falha empregando um programa que vem sendo desenvolvido pelo Grupo de Estruturas Aeronáuticas da EESC/USP. 


\section{MATERIAIS E MÉTODOS}

Neste capítulo serão abordados em detalhes todos os materiais utilizados na fabricação dos corpos-de-prova (CDPs), bem como, a metodologia adotada para o estudo proposto.

\subsection{MATERIAIS}

As juntas híbridas estudadas neste trabalho são formadas pela combinação dos seguintes materiais: placa em compósito de resina epóxi reforçada com fibra de carbono; placa de liga de titânio e fixadores de liga Níquel-Cobre (mais conhecida como liga de Monel). Segue assim uma descrição mais detalhada dos materiais que constituem a junção.

Com relação ao compósito, o reforço é baseado num tecido em fibra de carbono, com especificação G0904 D 1070 TCT da Hexcel $^{\text {TM }}$. Vale ressaltar que estes tecidos são aplicados em estruturas de material compósito que requerem alto desempenho, por exemplo, estruturas aeronáuticas.

Tabela 4 - Exemplo de tecido em fibra de carbono $\left(\right.$ Hexcel $\left.^{\mathrm{TM}}\right)$.

\begin{tabular}{cc} 
TECIDO & CARACTERÍ́sTICA \\
Tipo dos fios & Malha: HTA 5131 3K \\
\hline Peso nominal & $193 \mathrm{~g} / \mathrm{m}^{2}$ \\
\hline Tipo do tecido & Plano \\
\hline Comprimento padrão & $1070 \mathrm{~mm}$ \\
\hline Espessura & $0,20 \mathrm{~mm}$
\end{tabular}

Quanto à matriz polimérica, utilizou-se a resina epóxi, com especificação HexPly M20 da Hexcel $^{\mathrm{TM}}$, que é aplicada onde são requeridas altas temperaturas combinada com um ciclo de cura rápido. Devido a sua flexibilidade de processamento (bolsa de vácuo com ou sem autoclave) é adequada para estruturas aeronáuticas primárias e secundárias e, também, para 
reparos em compósitos. A HexPly M20 (Tabela 5) compreende uma resina epóxi modificada, baseada num enorme sucesso do uso em estruturas primárias nas aeronaves da Airbus, Lockheed, McDonnell Douglas e Westland. Pode ser pré-impregnada com fibras de carbono, vidro ou aramida (Kevlar). Sua cura se dá a $130^{\circ} \mathrm{C}$, resultando em um compósito reforçado com fibras e resistente a altas temperaturas, sendo que seu fornecedor indicou os seguintes ciclos de cura: 1)Em Autoclave: $130^{\circ} \mathrm{C}$ por 2 horas sob 4 bar de pressão; 2)Com Bolsa de Vácuo: $130^{\circ} \mathrm{C}$ por 2 horas sob 1 bar de pressão.

Tabela 5 - Algumas propriedades da resina epóxi - HexPly M20 - Hexcel $^{\mathrm{TM}}$.

\section{PROPRIEDADES}

Resistência a compressão

Deformação sob compressão

Módulo de compressibilidade

Densidade da resina curada

Temperatura de transição vítrea $(\mathrm{Tg})$

\section{RESULTADOS}

$175 \mathrm{MPa}$

\begin{tabular}{cc}
\hline Deformação sob compressão & $9,2 \%$ \\
\hline Módulo de compressibilidade & $3,06 \mathrm{GPa}$ \\
\hline Densidade da resina curada & $1,27 \mathrm{~g} / \mathrm{cm}^{3}$ \\
\hline Temperatura de transição vítrea $(\mathrm{Tg})$ & $150^{\circ} \mathrm{C}$
\end{tabular}

A Tabela (6) mostra valores de módulo de elasticidade e resistência para um compósito após a cura, sendo que o mesmo é constituído de fibra de carbono unidirecional pré-impregnada com resina epóxi. Deve-se ressaltar que no presente trabalho foram utilizados reforços com tecido bi-direcional de fibra de carbono Tabela (4) pré-impregnado com resina epóxi Tabela (5). Somado a isto, tem-se que as propriedades do material compósito dependem intrinsecamente do processo de fabricação, assim, a seguir, será detalhada toda a metodologia de fabricação dos corpos-de-prova em material compósito, bem como, de ensaios experimentais para a determinação de propriedades mecânica e valores de resistência de forma mais precisa. 
Tabela 6 - Exemplo de propriedades das fibras de carbono unidirecionais pré-impregnada com resina epóxi (“prepreg”), após a cura (Hexcel $\left.{ }^{\mathrm{TM}}-\mathrm{M} 20 / 47 \% / \mathrm{G} 904\right)$.

\begin{tabular}{ccc} 
PROPRIEDADE & TEMPERATURA & $\begin{array}{c}\text { CARBONO } \\
\text { UNIDIRECINAL (0 }\end{array}$ \\
Resistência sob tração, $\mathrm{MPa}$ & $120^{\circ} \mathrm{C}$ & 2162 \\
\hline Módulo de Elasticidade sob tração, $\mathrm{GPa}$ & $120^{\circ} \mathrm{C}$ & 270 \\
\hline Resistência sob compressão, $\mathrm{MPa}$ & $23{ }^{\circ} \mathrm{C} / 120^{\circ} \mathrm{C}$ & $900-776$ \\
\hline Módulo Elasticidade sob compressão, $\mathrm{GPa}$ & $23{ }^{\circ} \mathrm{C} / 120^{\circ} \mathrm{C}$ & $230-236$ \\
\hline Resistência ao cisalhamento no plano, $\mathrm{MPa}$ & $23^{\circ} \mathrm{C} / 120^{\circ} \mathrm{C}$ & $72-74$ \\
\hline $\begin{array}{c}\text { Módulo de Elasticidade sob cisalhamento no } \\
\text { plano, GPa }\end{array}$ & $23^{\circ} \mathrm{C} / 120^{\circ} \mathrm{C}$ & $4,9-3,2$ \\
\hline
\end{tabular}

Tabela 7 - Resistência ao cisalhamento de rebites, Niu (1988).

\begin{tabular}{|c|c|c|c|}
\hline \multicolumn{2}{|r|}{ REBITE } & \multicolumn{2}{|c|}{$\begin{array}{l}\text { RESISTÊNCIA AO } \\
\text { CISALHAMENTO (MPa) }\end{array}$} \\
\hline LIGA & CONDIÇÃO & MÍNIMA & MÁXIMA \\
\hline Al 1100 & $\begin{array}{l}\mathrm{F}=\text { como fabricado (laminado, estrudado, trefilado, } \\
\text { etc..). }\end{array}$ & $\mathrm{N} / \mathrm{A}^{(*)}$ & $\mathrm{N} / \mathrm{A}$ \\
\hline Al 5056 & H32 = trabalhado a frio (encruado em níveis). & 166 & $\mathrm{~N} / \mathrm{A}$ \\
\hline Al 2117 & T4 = solubilizado e envelhecido naturalmente (atmosfera). & 179 & $\mathrm{~N} / \mathrm{A}$ \\
\hline Al 2119 & $\begin{array}{l}\text { T81 = solubilizado, trabalhado a frio e envelhecido } \\
\text { artificialmente (forno). }\end{array}$ & 220 & $\mathrm{~N} / \mathrm{A}$ \\
\hline Al 2119 & T62 = solubilizado e envelhecido artificialmente (forno). & 220 & $\mathrm{~N} / \mathrm{A}$ \\
\hline Al 2017 & T4 & 241 & 290 \\
\hline Al 2024 & $\mathrm{~T} 4$ & 255 & $\mathrm{~N} / \mathrm{A}$ \\
\hline Al 7050 & $\begin{array}{l}\text { T73 = solubilizado e superenvelhecido (aplicado onde é } \\
\text { requerida a resistência a corrosão sob tensão). }\end{array}$ & 282 & 317 \\
\hline $\mathrm{Ti} 45 \mathrm{Cb}$ & - & 345 & 407 \\
\hline $\begin{array}{l}\mathrm{Ni}-\mathrm{Cu} \\
\text { (Monel) }\end{array}$ & - & 338 & 407 \\
\hline
\end{tabular}

$(*)$ N/A - não se aplica 
Com relação aos fixadores, foram utilizados rebites na liga Niquel-Cobre (Monel), conforme especificação dada pela "Military Specification - MS 20615" (1995). Por possuírem elevada resistência ao cisalhamento, Tabela (7), e, principalmente, por apresentarem compatibilidade galvânica com elementos que forma a união (titânio e fibras de carbono). A Tabela (8) detalha a composição química dos fixadores a serem utilizados.

Tabela 8 - Elementos da liga Monel (fixadores) em porcentagem por peso (MS20615 (1995)).

\begin{tabular}{cc} 
ELEMENTO & QUANTIDADE $(\%)$ \\
Níquel & 2,50 \\
\hline Ferro (Max) & 0,5 \\
\hline Alumínio (Max) & 2,0 \\
\hline Magnésio (Max) & 0,2 \\
\hline Carbono (Max) & 0,5 \\
\hline Silício (Max) & 0,015 \\
\hline Enxofre (Max) & 0,006 \\
\hline Chumbo (Max) & 0,006 \\
\hline Estanho (Max) & 0,02 \\
\hline Zinco (Max) & 0,02 \\
\hline Fósforo (Max) & RESTANTE \\
\hline Cobre &
\end{tabular}

Com relação à parte metálica da junta, optou-se pela liga de titânio $-6,0 \mathrm{Al}-4,0 \mathrm{~V}$, conforme especificação da "Aerospace Material Specification - AMS 4907H” (2005). A mesma foi selecionada, além das propriedades mecânicas apresentadas (Tabela 10), por possuir também resistência ao impacto e manter as propriedades em temperaturas até $-253{ }^{\circ} \mathrm{C}$. A sua aplicação é indicada para estruturas que em serviço operem sob tais condições, bem como para junções onde são requeridos processos de soldagem. Ainda, ressalta-se o fato de não apresentar incompatibilidade galvânica em contato com o compósito reforçado com fibras 
de carbono. A Tabela (9) detalha a composição química da placa de titânio a ser utilizada, em seguida, a Tabela (10) evidencia propriedades mecânicas de placas de titânio em função da espessura.

A título de exemplo, aviões da Boeing operados pela TAM LINHAS AÉREAS S.A. utilizam junções híbridas Titânio-Compósito unidas mecanicamente.

Tabela 9 - Composição da liga de Titânio - 6,0 Al - 4,0 V em porcentagem por peso (AMS 4907H (2005)).

\begin{tabular}{ccc} 
ELEMENTO & MÍNIMO & MÁXIMO \\
Alumínio & 5,50 & 6,50 \\
\hline Vanádio & 3,50 & 4,50 \\
\hline Ferro & 0,25 \\
\hline Oxigênio & 0,13 \\
\hline Carbono & 0,08 \\
\hline Nitrogênio & 0,05 \\
\hline Hidrogênio & 0,0125 \\
\hline Ítrio & 0,005 \\
\hline Titânio & RESTANTE
\end{tabular}

Tabela 10 - Propriedades mecânicas mínimas da chapa de Titânio (SI) (AMS 4907H (2005)).

\begin{tabular}{ccccccc}
$\begin{array}{c}\text { Espessura } \\
(\mathbf{m m})\end{array}$ & $\begin{array}{c}\text { Resistência } \\
\text { a tração } \\
\text { (MPa) }\end{array}$ & $\begin{array}{c}\text { Limite ao } \\
\text { escoamento } \\
(\mathbf{M P a})\end{array}$ & $\begin{array}{c}\text { Deflexão } \\
\text { em 2" } \\
(\%)\end{array}$ & $\begin{array}{c}\mathbf{E} \\
(\mathbf{M P a})\end{array}$ & $\begin{array}{c}\mathbf{G} \\
(\mathbf{M P a})\end{array}$ & $\mathbf{v}$ \\
$0,20-0,38$ & 896 & 827 & 6 & $110 \times 10^{3}$ & $43 \times 10^{3}$ & 0,31 \\
$0,38-0,64$ & 896 & 827 & 8 & $110 \times 10^{3}$ & $43 \times 10^{3}$ & 0,31 \\
$0,64-25,4$ & 896 & 827 & 10 & $110 \times 10^{3}$ & $43 \times 10^{3}$ & 0,31 \\
$25,4-76,2$ & 862 & 793 & 10 & $110 \times 10^{3}$ & $43 \times 10^{3}$ & 0,31 \\
\hline
\end{tabular}




\subsection{METODOLOGIA}

A metodologia adotada para este trabalho de mestrado, detalhada na Figura (50), pode ser sintetizada nas seguintes etapas: 1) Revisão bibliográfica e estudo orientado; 2) Fabricação de CDPs em compósito; 3) Ensaios de CDPs em compósito; 4) Projeto de experimentos via elementos finitos (definição de estratégias para ensaios experimentais); 5) Verificação e possíveis alterações nos parâmetros de ensaios 6) Simulação via Elementos Finitos para se prever o comportamento mecânico das junções híbridas; 7) Fabricação de junções; 8) Ensaios de junções; 9) Análise de resultados; 10) Conclusões e proposta para trabalhos futuros de junções híbridas.

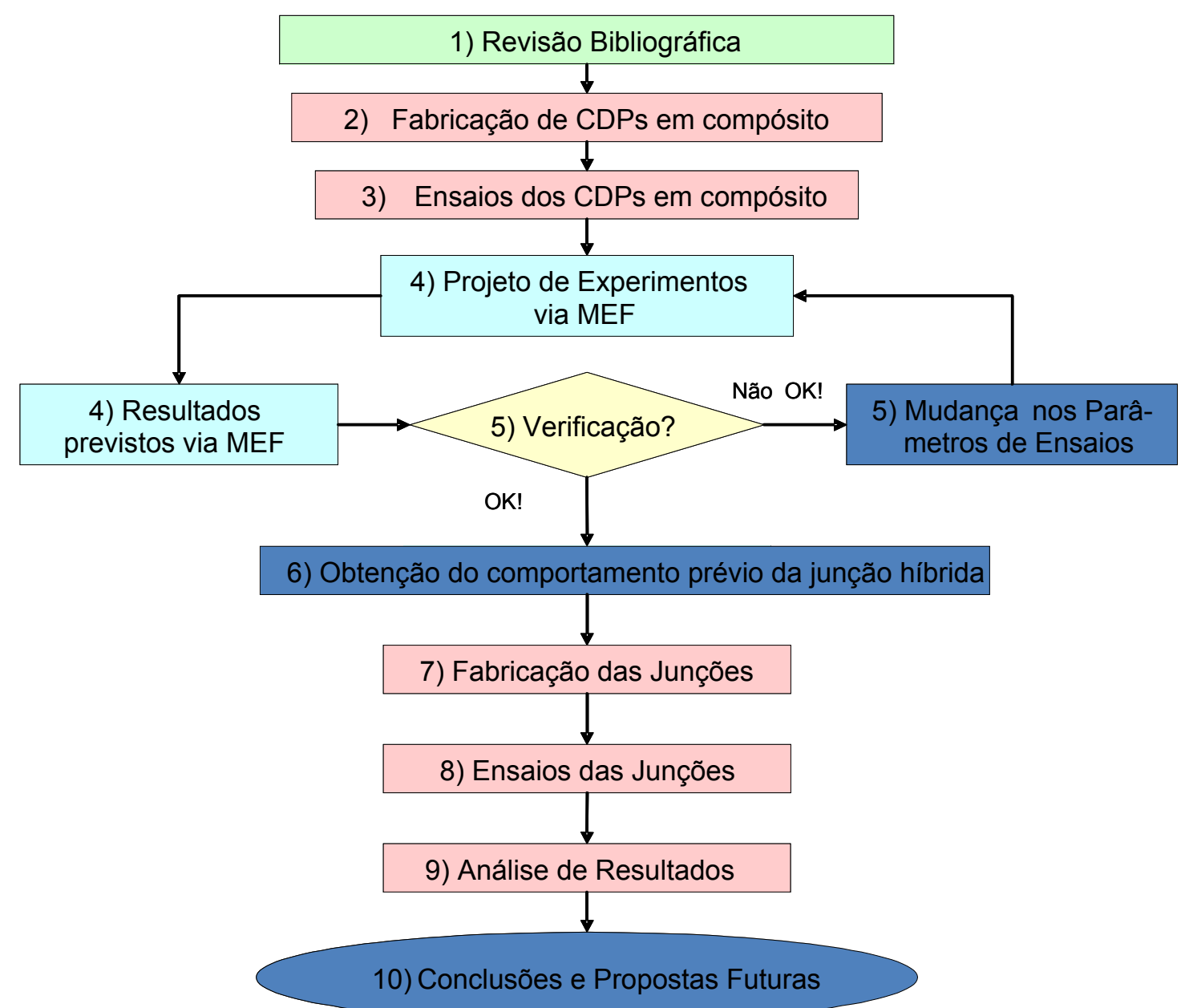

Figura 50 - Metodologia Geral. 


\subsubsection{FABRICAÇÃO DOS CORPOS-DE-PROVA}

\section{FABRICAÇÃO DO COMPÓSITO}

A escolha do método de compactação por bolsa de vácuo se justifica pelo fato de que este método é muito usual na indústria aeronáutica, bem como é o mais difundido e aplicado nas situações de reparos que envolvem materiais desta natureza. A técnica de compactação por bolsa de vácuo, mostrada nas Figuras (51 (a) e 51 (b)), garante versatilidade e facilidade operacional, desde dentro de salas controladas até em campo aberto (por exemplo: confecção de reparos).

O processo por cura com bolsa de vácuo, por sua vez, consiste basicamente dos seguintes elementos:

- Bolsa de vácuo: é utilizada para isolar o laminado do ambiente externo. Dentro do ambiente criado pela bolsa deve-se contar com uma pressão relativa menor do que a pressão presente no lado externo. A diferença de pressão aliada à flexibilidade deste filme isolante garante que a pressão externa trabalhe a favor da compactação dos tecidos e adesivos. Considerando o fato de que este material estará precariamente isolado da fonte térmica que alimenta o processo de cura, torna-se primordial selecionar um material capaz de manter a temperatura segundo a qual a resina deverá ser submetida. A escolha errônea deste material deve comprometer o isolamento do meio e conseqüentemente promover parâmetros de temperatura inadequados, compactação e fluxo de ar no interior da bolsa indevido;

- Selante de vácuo: deve unir a bolsa de vácuo e a placa base que suporta o laminado a ser curado. Esta união garante que o fluxo de ar para o interior da bolsa seja mantido nas condições adequadas para o desenvolvimento do processo de cura. Este material deve ser aplicado também nas regiões de inserção de conexões para o interior da bolsa como é o caso 
dos termopares, mangueiras de vácuo e cabos de alimentação de mantas térmicas (fontes de energia necessárias para a elevação de temperatura no interior da bolsa);

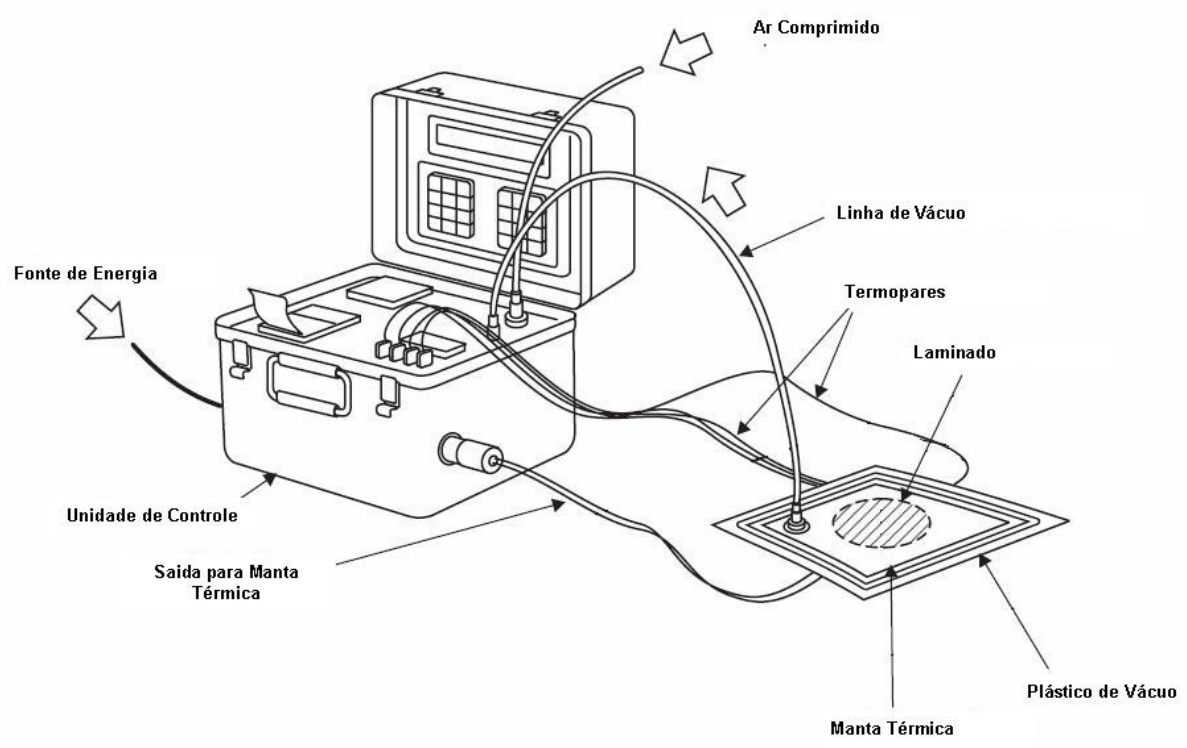

(a)

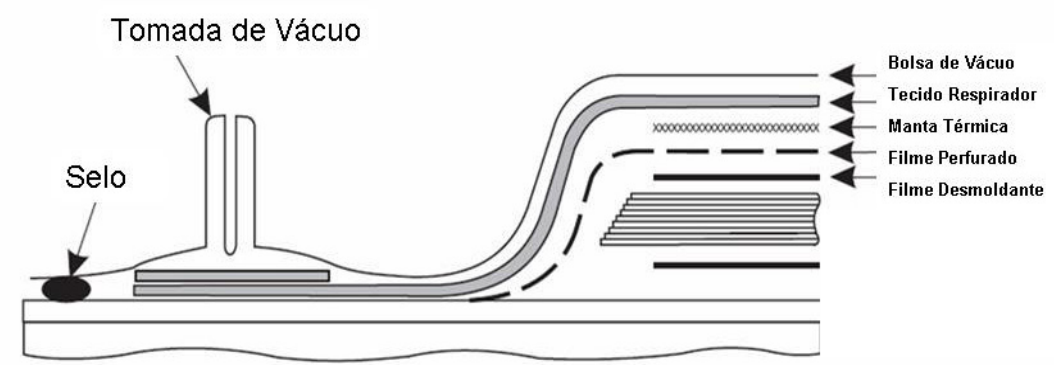

(b)

Figura 51 - (a) Equipamentos e bolsa de vácuo; (b) Materiais utilizados em uma cura por bolsa de vácuo típica.

- Respirador: deve garantir que o fluxo de voláteis e gases (por exemplo, o ar) percorra a bolsa exteriormente permitindo assim a distribuição homogênea da pressão sobre esta. Não deve ocorrer interrupção do fluxo de gases dentro da bolsa e interferência na troca de calor entre o laminado e o meio externo;

- Removedor de excesso: é essencial para remover o excesso de resina polimérica do laminado. Este material deve garantir a proporção adequada da fração volumétrica. A remoção em excesso eleva a porosidade, enquanto o excesso de resina polimérica (matriz) reduz a capacidade mecânica do laminado; 
- “Peel Ply”: é um filme inerte com a estrutura a ser curada, utilizado para auxiliar na remoção dos demais materiais da bolsa de vácuo, garantindo uma superfície limpa, rica em resina polimérica e com qualidade superficial mínima para promover adesão das camadas de proteção superficiais as quais devem ser aplicadas sobre o laminado;

- Filme perfurado: deve garantir que o removedor de excesso não fique demasiadamente aderido ao laminado, além disto, o mesmo deve permitir que o excesso de adesivo e gases flua para o removedor de excesso, bem como para o exterior da bolsa;

- Manta térmica: possui a finalidade de prover energia para acelerar as reações químicas que ocorrem durante a cura da matriz. Utiliza-se uma manta térmica construída com resistência elétrica capaz de transformar energia elétrica proveniente do controlador de temperatura em energia térmica $(5000 \mathrm{~W} / 220 \mathrm{~V})$.

Além disso, para o controle do processo de cura, foram utilizados quatro termopares do tipo J e um controlador Heatcon HCS 9200B de forma adequada. Antes, porém, da cura, deve-se ressaltar que houve o processo de laminação manual ("hand lay up") para realizar o empilhamento desejado das lâminas constituintes do laminado. Durante todo o processo de fabricação, cuidados básicos com limpeza e controle de umidade foram considerados conforme previsto nos procedimentos da empresa TAM - LINHAS AÉREAS S.A.

Dois tipos de CDPs foram fabricados com o intuito de determinar, principalmente, parâmetros essenciais para uma posterior análise das juntas híbridas metal-compósito. Os CDPs foram então confeccionados segundo as normas ASTM D3039/D3039M (2006) e D3518/D3518M (2001), sendo que os parâmetros determinados através de ensaios são: 
- Especificação ASTM D3039: tensão de ruptura sob tração ou resistência à tração $\left(\mathrm{X}_{\mathrm{T}}\right)$; limite de deformação por tração $\left(\mathrm{X}^{\prime}{ }_{\mathrm{T}}\right)$; módulo de elasticidade a tração $\left(\mathrm{E}_{11}\right) \mathrm{e}$ coeficiente de Poisson no plano da lâmina plano 1-2 ( $\left.v_{12}\right)$;

- Especificação ASTM D3518: resistência ao cisalhamento $\left(\tau_{12}\right)$; limite de deformação angular por cisalhamento $\left(\gamma_{12}\right)$ e módulo de elasticidade ao cisalhamento no plano da lâmina plano 1-2 $\left(\mathrm{G}_{12}\right)$;

Para atender às necessidades impostas pela norma ASTM D3039 foram fabricados 05 CDPs constituídos em camadas de "prepreg” Hexcel M20/47\%/G904 com empilhamento $\left[0^{\circ} / 90^{\circ}\right]_{6}$, como mostra a Figura (52).

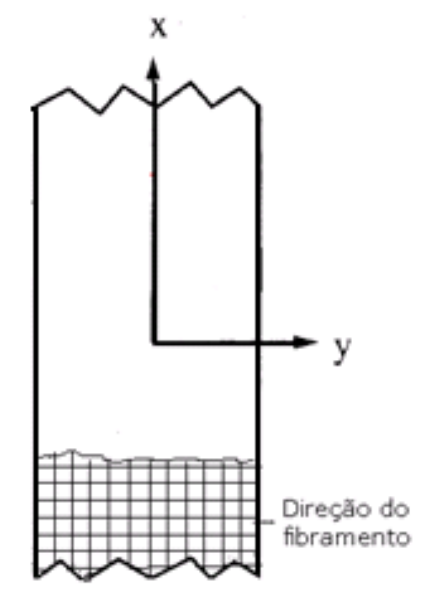

Figura $52-\mathrm{CDP}\left[0^{\circ} / 90^{\circ}\right]_{6}$ conforme ASTM D3039.

Nas duas superfícies externas do laminado foram adicionadas duas camadas de filme adesivo CYTEC $^{\mathrm{TM}}$ FM73M.06 de maneira a enriquecer a quantidade de resina polimérica na superfície do CDP, diminuindo a porosidade e aprimorando o acabamento externo.

Com o intuito de garantir que os mesmos parâmetros de cura e compactação fossem aplicados em todos os CDPs, propôs-se confeccioná-los numa única moldagem, ou seja, em 
uma única placa, que, posteriormente, foi cortada e usinada em seções menores, seguindo assim, algumas recomendações especificadas pela norma, conforme mostra a Figura (53).

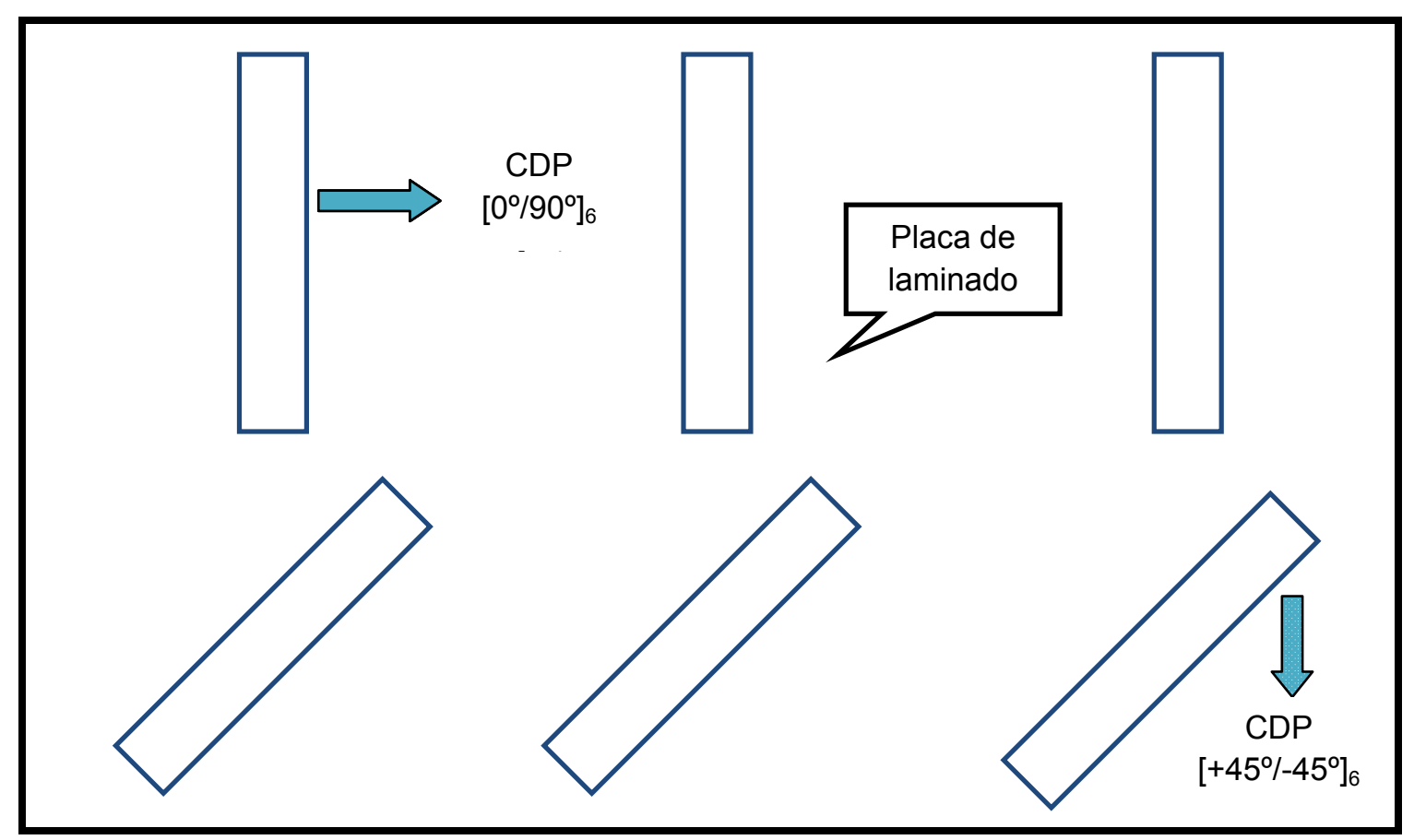

Figura 53 - Generalização do processo de fabricação dos CDPs $\left[0^{\circ} / 90^{\circ}\right]_{6}$ e $\left[+45^{\circ} /-45^{\circ}\right]_{6}$.

Durante o procedimento de cura, estabeleceram-se os parâmetros de fabricação evidenciados na Tabela (11).

Tabela 11 - Parâmetros de cura para CDPs de tração (ASTM D3039/D3039M)

\begin{tabular}{|c|c|}
\hline \multicolumn{2}{|c|}{ D3039/D3039M } \\
\hline Parametros & Valores \\
\hline Vácuo (in. $\mathrm{Hg})$ & 23 \\
\hline Rampa de Subida $\left({ }^{\circ} \mathrm{C} / \mathrm{min}.\right)$ & 3 \\
\hline Temperatura de Cura $\left({ }^{\circ} \mathrm{C}\right)$ & 120 \\
\hline Tempo de Exposição $(\mathrm{min})$. & 90 \\
\hline Rampa de Descida $\left({ }^{\circ} \mathrm{C} / \mathrm{min}.\right)$ & -3 \\
\hline Temperatura Final de Cura $\left({ }^{\circ} \mathrm{C}\right)$ & 50 \\
\hline
\end{tabular}


Deve-se ressaltar que a fim de garantir que os parâmetros propostos pelo fabricante do material (CytecTM e Hexcel ${ }^{\mathrm{TM}}$ ) fossem seguidos, utilizaram-se todos os equipamentos de controle de cura descritos anteriormente.

Tabela 12 - Dimensões dos CDPs de tração.

\begin{tabular}{|c|c|c|c|c|c|c|c|c|c|}
\hline \multicolumn{10}{|c|}{ ENSAIO D3039 } \\
\hline CDP & $\mathbf{W} \mathbf{1}(\mathbf{m m})$ & $\mathbf{W} \mathbf{2}(\mathbf{m m})$ & $\mathbf{W} \mathbf{( \mathbf { m m } )}$ & $\mathbf{T 1} \mathbf{( \mathbf { m m } )}$ & $\mathbf{T} \mathbf{( \mathbf { m m } )}$ & $\mathbf{T 3} \mathbf{( \mathbf { m m } )}$ & $\mathbf{W m} \mathbf{( m m})$ & $\mathbf{T m} \mathbf{( \mathbf { m m } )}$ & $\mathbf{S}\left(\mathbf{m m}^{\mathbf{2}}\right)$ \\
\hline 1 & 26,05 & 26,05 & 26,00 & 2,00 & 2,00 & 2,00 & 26,03 & 2,00 & 52,07 \\
\hline 2 & 26,60 & 26,60 & 26,60 & 2,00 & 2,00 & 2,00 & 26,60 & 2,00 & 53,20 \\
\hline 3 & 26,00 & 26,10 & 26,00 & 2,00 & 2,00 & 2,00 & 26,03 & 2,00 & 52,07 \\
\hline 4 & 26,00 & 26,20 & 26,20 & 2,00 & 2,00 & 2,00 & 26,13 & 2,00 & 52,27 \\
\hline 5 & 26,50 & 26,10 & 26,20 & 2,00 & 2,00 & 2,00 & 26,27 & 2,00 & 52,53 \\
\hline
\end{tabular}

A tabela (12) mostra as dimensões dos CDPs de tração fabricados com o empilhamento $[0 / 90]_{6}$. Verifica-se que foram realizadas medidas em três regiões distintas $(1,2$ e 3) ao longo do comprimento do CDP. Foram medidas as larguras (W) e espessuras (T), calculando-se, assim, a largura média (Wm) e a espessura média (Tm) para, então, obter-se a área da secção transversal de cada CDP.

De maneira análoga à anteriormente mencionada, os CDPs baseados na ASTM D3518 foram fabricados com empilhamento de lâminas a $\left[+45^{\circ} /-45^{\circ}\right]_{6}$, como mostra a Figura (54).

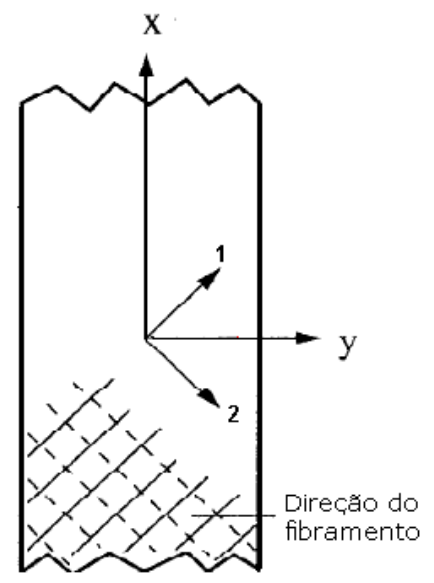


Tabela 13 - Dimensões dos CDPs de cisalhamento (ASTM D3518/D3518M).

\begin{tabular}{|c|c|c|c|c|c|c|c|c|c|}
\hline \multicolumn{10}{|c|}{ ENSAIO D3518 } \\
\hline CDP & $\mathbf{W} \mathbf{1}(\mathbf{m m})$ & $\mathbf{W} \mathbf{2}(\mathbf{m m})$ & $\mathbf{W} \mathbf{3}(\mathbf{m m})$ & $\mathbf{1} \mathbf{( \mathbf { m m } )}$ & $\mathbf{T 2} \mathbf{( \mathbf { m } )}$ & $\mathbf{T 3} \mathbf{( \mathbf { m m } )}$ & $\mathbf{W m} \mathbf{( \mathbf { m m } )}$ & $\mathbf{T m} \mathbf{( \mathbf { m m } )}$ & $\mathbf{S}\left(\mathbf{m m}^{\mathbf{2}}\right)$ \\
\hline 1 & 26,00 & 26,00 & 26,00 & 2,00 & 2,00 & 2,00 & 26,00 & 2,00 & 52,00 \\
\hline 2 & 26,15 & 26,00 & 25,96 & 2,00 & 2,00 & 2,00 & 26,04 & 2,00 & 52,07 \\
\hline 3 & 26,20 & 26,20 & 26,20 & 2,00 & 2,00 & 2,00 & 26,20 & 2,00 & 52,40 \\
\hline 4 & 26,00 & 26,00 & 26,00 & 2,00 & 2,00 & 2,00 & 26,00 & 2,00 & 52,00 \\
\hline 5 & 26,15 & 26,09 & 26,00 & 2,05 & 2,05 & 2,05 & 26,08 & 2,05 & 53,46 \\
\hline
\end{tabular}

A tabela (13) mostra as dimensões dos CDPs de cisalhamento fabricados com o empilhamento $[+/-45]_{6}$. Verifica-se que foram realizadas medidas em três regiões distintas (1, 2 e 3) ao longo do comprimento do CDP. Foram medidas as larguras (W) e espessuras (T), calculando-se, assim, a largura média (Wm) e a espessura média (Tm) para, então, obter-se a área da secção transversal de cada CDP.

Por fim, vale ressaltar que os ensaios nos CDPs segundo as normas ASTM D3039 e ASTM D3518 podem ser aplicados com diferentes propósitos, sendo estes: qualificar materiais para pesquisa e desenvolvimento; certificar a qualidade dos processos de fabricação; analisar elementos estruturais e especificar requisitos em projetos diversos. Os resultados obtidos dos ensaios serão apresentados e discutidos no Capítulo 4.

\section{FABRICAÇÃO DAS JUNÇÕES}

Inicialmente, vale ressaltar que neste capítulo será descrito em detalhe o processo de fabricação das juntas, porém detalhes em relação à geometria dos CDPs serão apresentados somente no Capítulo 4, após a discussão dos resultados obtidos pelas simulações computacionais. 
A fabricação das juntas híbridas metal-compósito fixadas mecanicamente seguiu basicamente as seguintes etapas: 1) Corte das placas da junta; 2) Alinhamento das placas; 3)Localização dos fixadores; 4)Furação piloto; 5)Furação final; 6)Instalação e cravação dos fixadores. Segue assim, um detalhamento das etapas supracitadas.

Para a Etapa 1, que consiste do corte das placas da junta, foram cortadas placas de material compósito e placas de titânio. As placas em compósitos foram fabricadas através do processo de cura por bolsa de vácuo, como descrito anteriormente. O corte diamantado foi empregado para seccionar as placas em material compósito, e se justifica pelo fato de que há a necessidade de evitar quaisquer danos de delaminação do laminado. O corte com facas paralelas (por guilhotina) foi empregado para seccionar as chapas metálicas de titânio. Além do processo de corte por facas paralelas, realizou-se o acabamento das arestas resultantes do processo de corte com a finalidade de evitar quaisquer erros e danos que pudessem ser ocasionados durante a montagem.

A Etapa 2 consiste no alinhamento das placas cortadas para a correta instalação dos fixadores. Vale destacar que o alinhamento foi pautado, principalmente, pela região de sobreposição (“overlap”) especificada em projeto. Além disso, deve-se lembrar dos comentários efetuados no Capítulo 2 (Revisão Bibliográfica) que aborda questões relacionadas aos mecanismos de falha. Uma regra básica que foi observada para evitar que um mecanismo de falha prepondere durante o ensaio é manter uma distância mínima entre a borda da junta e o centro da furação de pelo menos duas e meia vezes o diâmetro do fixador, como mostra a Figura (55). 


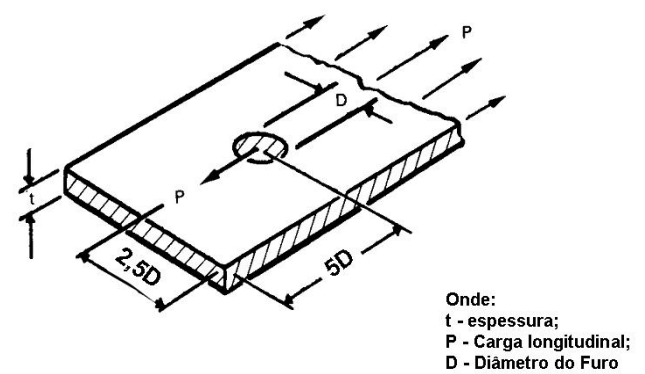

Figura 55 - Distâncias requisitadas para fixadores instalados em compósitos.

Busca-se atender as distâncias requisitadas para fixadores pelo fato de que as juntas feitas com materiais compósitos devem ser projetadas considerando como crítico o modo de falha por "bearing", conforme visto anteriormente e mostrado na Figura (56 (c)). Além do modo de falha do tipo por "bearing" são observados também na Figura (56): "shear out" (a); "net failure" (b); "cleavage" (d); "fasteners pull through" e delaminação (e); "fastener failure" (f). Todos estes mecanismos foram comentados anteriormente (Capítulo 2) e serão discutidos e avaliados no Capítulo 4.

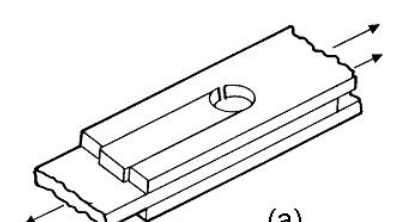

(a)

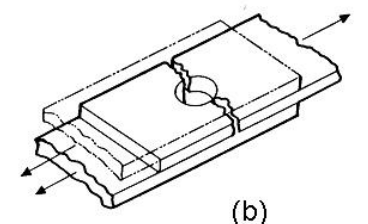

(b)

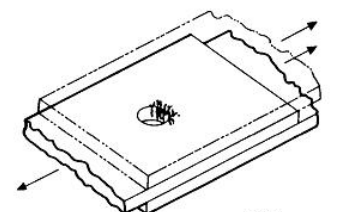

(c)

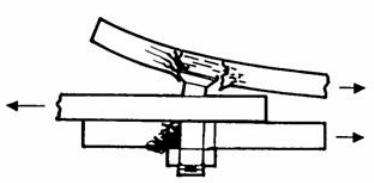

(e)

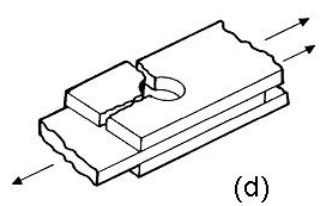

(d)

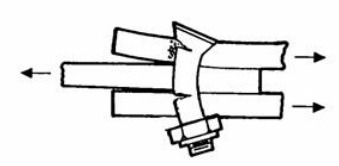

(f)

Figura 56 - Modos de falha em compósitos, Niu (1995). 
Após o alinhamento das lâminas e correto posicionamento das placas, as mesmas foram temporariamente presas com ferramentas tipo grampo para a execução do processo de localização dos furos dos fixadores. A Etapa 3 de localização dos furos de fixação foi realizada com uma caneta do tipo pincel, sendo que a tolerância da marcação é de aproximadamente um milímetro. Em seguida a marcação, partiu-se para a Etapa 4, que foi a furação piloto. Para garantir que o furo final ficasse isento de qualquer tipo de defeito que pudesse influenciar no resultado do ensaio, sugeriu-se que furos pilotos fossem feitos antes da furação final (Etapa 5). Como prática padrão, os manuais aeronáuticos recomendam que as furações piloto sejam feitas com brocas de diâmetros entre 1,2 a 2,5 mm. Além disso, para evitar danos de delaminação, foram empregadas brocas especiais como a mostrada na Figura (57).

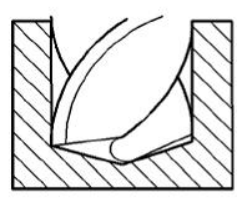

Arestas de corte com Comprimentos Iguais mas angulos desiguais

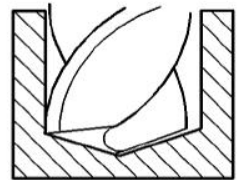

Arestas de corte com ângulos Iguais mas comprimentos desiguais
Inicio do Furo resulta em Diametro maior do que 0 especificado

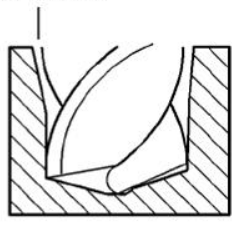

Arestas de corte Ângulos desiguais

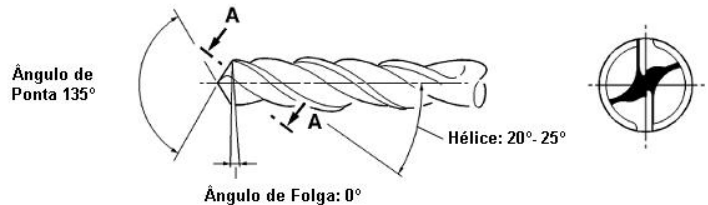

Figura 57 - Defeitos típicos de furações e broca recomendada para furação em compósito.

Recomenda-se também, que a furação seja feita com inicio na face da placa em compósito de forma que a face metálica opere como base de furação, que é comumente chamada de "backup plate". Tal procedimento é fundamental para se evitar delaminações. 
Além do cuidado necessário para evitar danos de delaminação, foi importante manter a temperatura da ferramenta controlada para se evitar danos causados por superaquecimento. Recomenda-se refrigeração por ar comprimido, de forma que a temperatura da ferramenta não ultrapasse $60^{\circ} \mathrm{C}$.

Por fim, para garantir a tolerância de perpendicularismo sugerida para a junta, foram utilizados "tripods" - Figura (58), sendo que os parâmetros de corte sugeridos são de 0,04 a 0,1 milímetros por revolução para velocidade de avanço e de 9 a 12 metros por minuto para velocidade de corte.

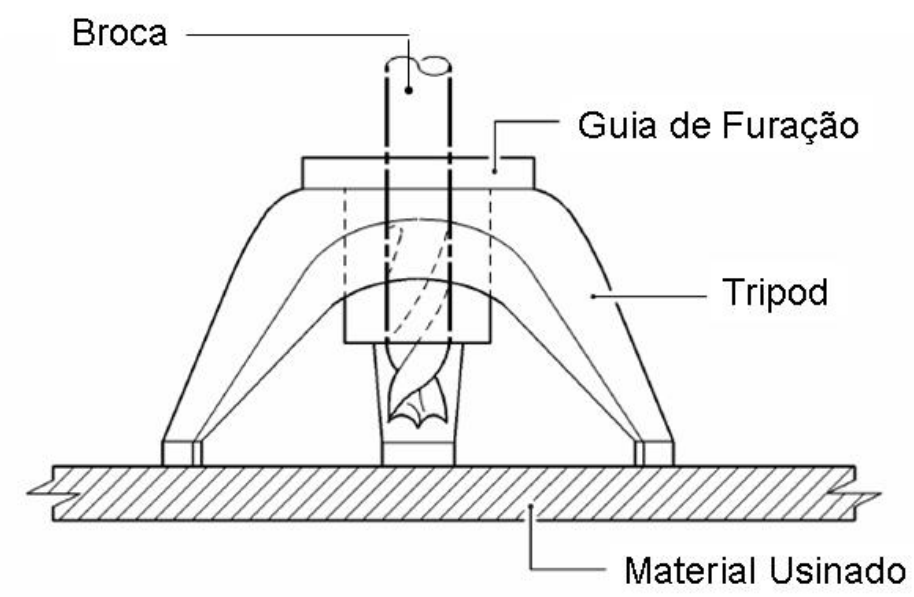

Figura 58 - Tripod: dispositivo de furação para garantir tolerâncias de perpendicularismo.

A Etapa 5 de furação final foi realizada, repassando-se o furo piloto com uma broca de diâmetro definido em função do fixador escolhido. Para tal operação, utilizou-se dados da Tabela (14). Nota-se que a furação final deve proporcionar um ajuste folgado, uma vez que ajustes interferentes com fixadores comuns do tipo sólido podem causar danos como a fratura de fibras durante a instalação dos fixadores. 
Tabela 14 - Diâmetros recomendados para fixadores sólidos.

\begin{tabular}{|c|c|c|c|c|c|}
\hline \multirow{2}{*}{$\begin{array}{c}\text { Diâmetro } \\
\text { Nominal }\end{array}$} & \multicolumn{4}{|c|}{ Diametro Recomendado para a Furaçäo } \\
\cline { 2 - 6 } mm & in. & $\mathrm{mm}$ & in. & $\mathrm{mm}$ & MIN. \\
\hline 1.6 & $1 / 16$ & 1.75 & 0.069 & 1.65 & 0.065 \\
\hline 2.4 & $3 / 32$ & 2.57 & 0.101 & 2.46 & 0.097 \\
\hline 2.8 & $7 / 64$ & 2.95 & 0.116 & 2.84 & 0.112 \\
\hline 3.2 & $1 / 8$ & 3.35 & 0.132 & 3.25 & 0.128 \\
\hline 3.6 & $9 / 64$ & 3.76 & 0.148 & 3.66 & 0.144 \\
\hline 4.0 & $5 / 32$ & 4.17 & 0.164 & 4.06 & 0.160 \\
\hline 4.4 & $11 / 64$ & 4.57 & 0.180 & 4.47 & 0.176 \\
\hline 4.8 & $3 / 16$ & 4.95 & 0.195 & 4.85 & 0.191 \\
\hline 5.2 & $13 / 64$ & 5.36 & 0.211 & 5.26 & 0.207 \\
\hline 5.6 & $7 / 32$ & 5.77 & 0.227 & 5.66 & 0.223 \\
\hline 6.0 & $15 / 64$ & 6.17 & 0.243 & 6.07 & 0.239 \\
\hline 6.4 & $1 / 4$ & 6.55 & 0.258 & 6.45 & 0.254 \\
\hline 6.8 & $17 / 64$ & 6.96 & 0.274 & 6.83 & 0.269 \\
\hline 8.0 & $5 / 16$ & 8.15 & 0.321 & 8.03 & 0.316 \\
\hline 9.6 & $3 / 8$ & 9.75 & 0.384 & 9.63 & 0.379 \\
\hline
\end{tabular}

Embora o ajuste folgado seja preferido, é importante notar que folgas excessivas também são prejudiciais, à medida que a junta passa a sofrer com efeitos localizados resultantes da rotação do fixador o que pode causar fratura das fibras, delaminação e/ou danificação da matriz polimérica do compósito. É, portanto, importante manter as furações dentro dos limites superiores e inferiores dos valores recomendados. Cabe ressaltar que os valores de tolerância sugeridos se tornam cada vez mais importantes à medida que o material do fixador se torna cada vez mais rígido. Durante a instalação, fixadores mais flexíveis se expandem mais facilmente, permitindo melhor acomodação no furo. Por outro lado, fixadores mais rígidos, como os de Monel, possuem fatores de expansão muito menores.

Nesta Etapa 5 de furação final recomenda-se o mesmo tipo de procedimento da Etapa 4, ou seja, que o processo de furação tenha início na placa de compósito. Após o processo de furação, recomenda-se que cada furo seja inspecionado quanto aos valores de diâmetros final e quantidade de rebarbas nas regiões próximas às arestas - Figura (59). 

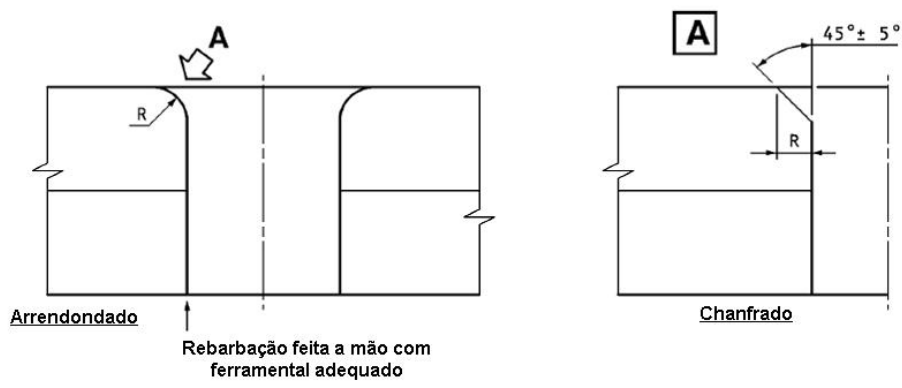

Nota: R entre 0,64 e 0,89 mm;

Figura 59 - Acabamento das arestas do furo.

Finalmente, a Etapa 6 consistiu da instalação e cravação dos fixadores, que iniciou-se com a escolha do comprimento adequado para o fixador, a qual deve ser função da espessura total a ser unida e do tipo de fixador utilizado. Nos casos em que fixadores sólidos serão utilizados, o comprimento do fixador deve ser suficientemente longo para que a formação da cabeça seja próxima do recomendado pelo fabricante, como mostra a Figura (60).

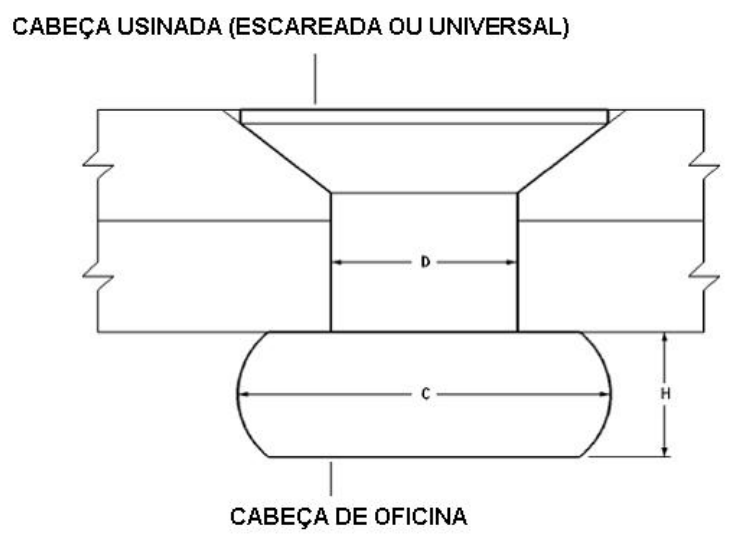

\begin{tabular}{|c|c|c|c|c|c|c|c|}
\hline \multirow{2}{*}{\multicolumn{2}{|c|}{$\begin{array}{c}\text { Diâmetro Nominal } \\
\text { (D) }\end{array}$}} & \multirow{2}{*}{\multicolumn{2}{|c|}{$\begin{array}{l}\text { Ø CABEÇA DE OFICINA } \\
\text { (C) } \\
\text { MIN IMUM }\end{array}$}} & \multicolumn{4}{|c|}{$\begin{array}{l}\text { ALTURA CABECCA DE OFICINA } \\
\text { (H) }\end{array}$} \\
\hline & & & & \multicolumn{2}{|c|}{ MAXIMUM } & \multicolumn{2}{|c|}{ MINIMUM } \\
\hline $\mathrm{mm}$ & in. & $\mathrm{mm}$ & in. & $\mathrm{mm}$ & in. & $\mathrm{mm}$ & in. \\
\hline 2.4 & $3 / 32 \quad(0.094)$ & 3.8 & 0.150 & 1.6 & 0.063 & 1.0 & 0.039 \\
\hline 3.2 & $1 / 8 \quad(0.126)$ & 5.0 & 0.197 & 2.0 & 0.079 & 1.3 & 0.051 \\
\hline 4.0 & $5 / 32(0.157)$ & 6.0 & 0.236 & 2.4 & 0.094 & 1.6 & 0.063 \\
\hline 4.8 & $3 / 16 \quad(0.189)$ & 7.3 & 0.287 & 2.9 & 0.114 & 1.9 & 0.075 \\
\hline 5.6 & $7 / 32 \quad(0.219)$ & 8.4 & 0.331 & 3.2 & 0.126 & 2.2 & 0.087 \\
\hline 6.4 & $(0.252)$ & 9.6 & 0.378 & 3.8 & 0.150 & 2.6 & 0.102 \\
\hline 8.0 & $5 / 16 \quad(0.312)$ & 11.8 & 0.465 & 4.6 & 0.181 & 3.1 & 0.122 \\
\hline
\end{tabular}

Figura 60 - Tolerâncias de montagem para fixadores do tipo sólido. 
Com o intuito de garantir a qualidade dos testes é sugerido que sejam inspecionadas, após instalação dos fixadores, a formação da cabeça e as regiões adjacentes ao fixador. Durante a instalação do fixador, pode ser comum ocorrer defeitos nas regiões adjacentes, capazes de gerar concentrador de tensões prejudiciais ao ensaio mecânico, por esta razão, após a instalação todos os fixadores foram inspecionados. Ressalta-se que para este trabalho os CDPs foram fabricados pela empresa TAM e que a mesma produz e inspeciona os CDPs baseando-se em procedimentos padrões.
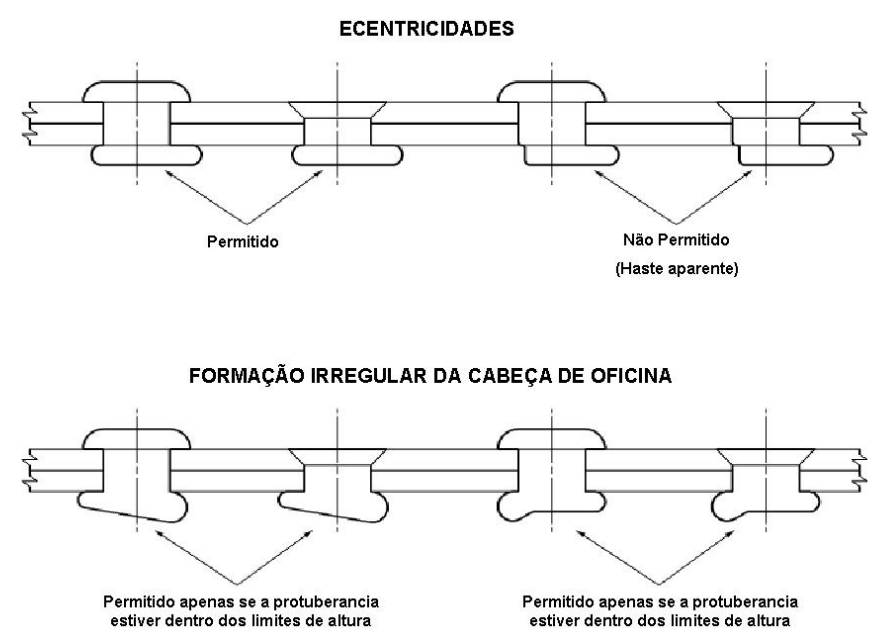

Figura 61 - Tolerâncias de montagem.

Para o procedimento de cravação é recomenda o uso de ferramentas compressão do tipo "galifon", mostrada na Figura (62).

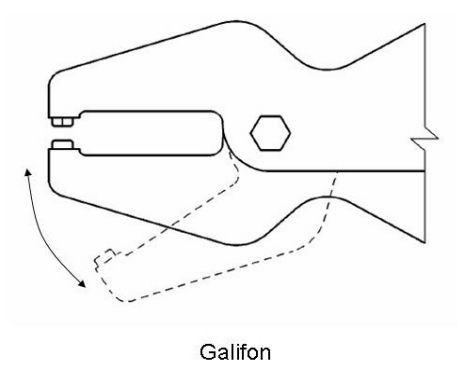

Figura 62 - Galifon: sistema de cravação hidráulico. 
Embora largamente utilizadas na cravação de fixadores sólidos em juntas metal-metal, as ferramentas de impacto podem ser consideravelmente prejudiciais às juntas compósitocompósito e metal-compósito, pois, o impacto gerado durante a instalação do fixador pode causar danos localizados e não visíveis a olho nu na matriz do compósito.

Deve-se destacar que na fabricação dos CDPs pela empresa TAM foram utilizadas brocas novas para garantir que a medida do furo ficasse dentro da tolerância especificada (Tabela 14) e ainda não foram utilizados marteletes pneumáticos para a instalação dos rebites, evitando-se possíveis surgimentos de danos nos espécimes.

\subsubsection{ENSAIOS DOS CORPOS-DE-PROVA}

Inicialmente, deve-se destacar que o presente texto aborda somente a metodologia empregada nos ensaios experimentais dos CDPs de materiais compósitos e de junções híbridas, sendo que os resultados obtidos, bem como discussões detalhadas sobre os mesmos encontram-se no Capítulo 4.

Segundo Carvalho (1996), há algumas particularidades relacionadas aos ensaios mecânicos em compósitos, tais como:

- Os ensaios mecânicos que são realizados para a determinação de propriedades mecânicas dos materiais, bem como para determinação dos valores de resistência mecânica estão fundamentados em conceitos básicos de mecânica. Tais conceitos são aplicados satisfatoriamente para materiais elásticos, homogêneos e isótropos. Entretanto, os materiais compósitos poliméricos reforçados possuem heterogeneidade, 
anisotropia e muitas vezes comportamento inelástico, dificultando assim, a aplicação de tais conceitos;

- Surgem grandes dificuldades na execução dos ensaios tais como:

* influência de efeitos de borda ("end-effects") que geram regiões de concentração de tensão próximas às arestas da amostra;

* aplicação de níveis de carregamento adequados sem causar falhas prematuras ao material;

* utilização de dimensões apropriadas (em particular espessura) em relação à escala de heterogeneidade do material.

- A anisotropia também propicia alguns problemas, tais como:

* agrava os efeitos de borda ("end-effects"), que dependem da geometria da amostra e do grau de anisotropia;

* promove falhas prematuras em regiões do corpo de prova que estão próximas às fixações;

* promove delaminações prematuras em arestas (“free edges"), gerando, assim, a formação de outros mecanismos de falha.

- Os testes em compósitos são de alto custo, pois:

* geralmente os materiais compósitos são caros;

* a fabricação de amostras demanda atenção meticulosa a detalhes;

- Em determinados casos, as normas tradicionais (ASTM, ISO, DIN, etc.) podem ser bastante adequadas; enquanto que em outros, podem ser totalmente impróprias. 


\section{ENSAIOS DO COMPÓSITO FABRICADO}

Os ensaios do material compósito utilizado nas juntas híbridas visam a não somente uma caracterização do material em si, mas também um entendimento mais completo do seu comportamento mecânico. Além disso, os dados obtidos dos ensaios são de suma importância para alimentar as simulações computacionais.

Tanto o ensaio dos CDPs de tração como os de cisalhamento foram realizado no equipamento de teste por meio de garras que solicitaram a amostra de forma monotônica e cíclica, sob tração, como mostrado na Figura (63). Através do ensaio monotônico, determinou-se as propriedades elásticas e os limites de resistência e de deformação. Além disso, foram realizados ensaios com ciclos de descarregamento e re-carregamento, visando a ter conhecimento do acúmulo de dano e de deformações permanentes no compósito. Segue abaixo os níveis de deslocamento onde foram realizados os ciclos de descarregamento e recarregamento por controle de deslocamento:

- $\operatorname{CDPs} 0^{\circ} / 90^{\circ}: 1 \mathrm{~mm} ; 2 \mathrm{~mm} ; 3 \mathrm{~mm} ; 4 \mathrm{~mm}$ e $20 \mathrm{~mm}$.

- $\operatorname{CDPs}+45^{\circ} /-45^{\circ}: 1 \mathrm{~mm} ; 3 \mathrm{~mm} ; 5 \mathrm{~mm} ; 9 \mathrm{~mm}$ e $20 \mathrm{~mm}$.

Alguns valores ficaram acima dos máximos observados no ensaio monotônico, como será demonstrado no Capítulo 4. O limite inferior do re-carregamento foi estipulado em $500 \mathrm{~N}$ a fim de possibilitar a manutenção dos CDPs tensionados.

Os CDPs foram carregados a uma velocidade de $0,5 \mathrm{~mm} / \mathrm{min}$ e monitorados por sensores de deformação (“strain-gages”), bem como por uma célula de carga. Dessa forma, podem-se obter os seguintes parâmetros: deformação e tensão máxima; módulo de elasticidade à tração e ao cisalhamento; coeficiente de Poisson. Recomenda-se dedicação extra na eliminação de qualquer fator que promova flexão do sistema de teste. A flexão do 
CDP pode ser o resultado do desalinhamento das garras ou mesmo do próprio CDP se os mesmos foram indevidamente instalados ou preparados. Cabe ressaltar que flexionar excessivamente um corpo de prova deve acarretar sua falha prematuramente e elevar o grau de incerteza na determinação do módulo de elasticidade. Sendo assim, deve-se ter uma série de cuidados com o tipo de equipamento a ser utilizado.

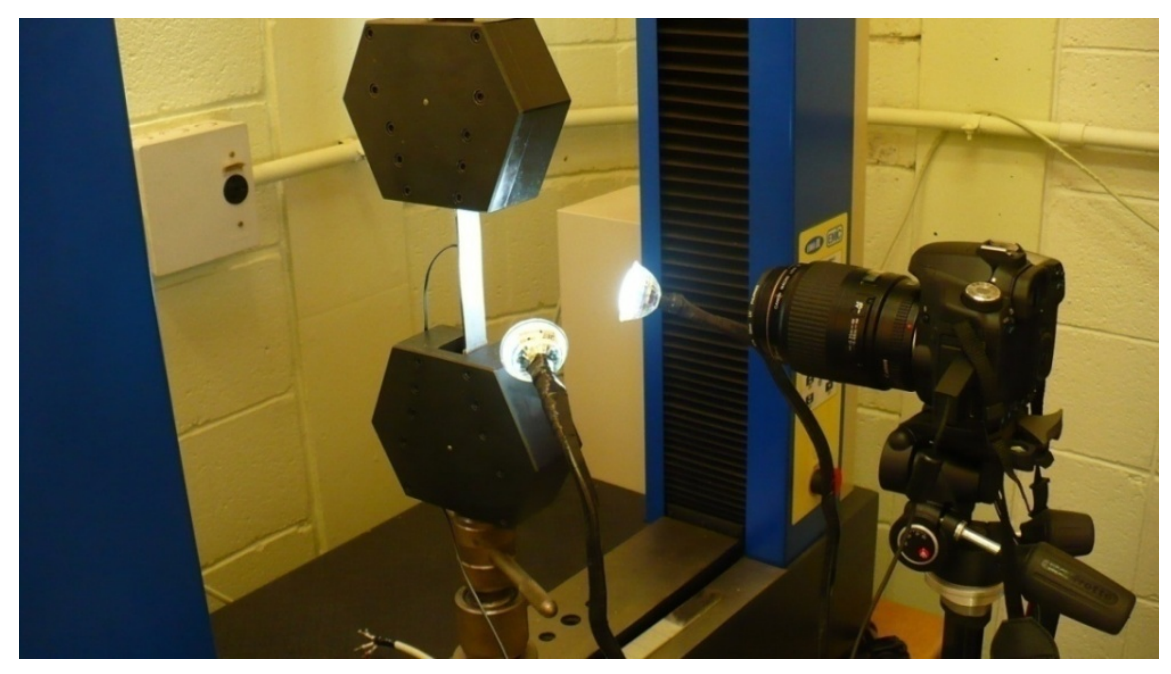

Figura 63 - CDP de compósito fixado à máquina de ensaios.

A seguir, tem-se um detalhamento maior sobre o equipamento utilizado e os procedimentos adotados:

- Máquina de ensaio: basicamente, a máquina de testes utilizada foi do tipo para ensaios mecânicos destrutivos de tração; compressão; flexão; cisalhamento e outros. A mesma permitiu que houvesse um movimento relativo controlado entre as garras que fixam o corpo de prova, sendo que a máquina utilizada nos ensaios é da marca EMIC;

- Mecanismo de movimento: o mecanismo da máquina de testes utilizado foi controlado para estabelecer uma taxa aproximadamente constante de deformação. Para isso, tem-se que os testes foram realizados de forma quase-estática, ou seja, com baixa velocidade de carregamento, descarregamento e re-carregamento; 
- Célula de carga (100 KN): de acordo com as normas da ASTM para obtenção de uma leitura adequada, a célula de carga deve proporcionar leituras com erros de $\pm 1 \%$ e o efeito de inércia nas taxas de deslocamento deve ser desprezível. Recomenda-se, assim, fundo de escala elevado para análises de tensão máxima de ruptura e mínima para determinação de módulos de elasticidade. Como ambos os parâmetros foram determinados, um equilíbrio entre os dois intervalos foi definido de forma que a leitura de ambos não fosse prejudicada. No presente trabalho foi utilizada a célula de carga da própria EMIC;

- Posicionamento das garras: as garras foram posicionadas de forma que houvesse uma sobreposição adequada, além da extremidade interna dos mordentes, no sentido da outra extremidade;

- Dispositivos para medição de deformação: foram utilizados "strain gages" da marca Vishay ${ }^{\mathrm{TM}}$ tanto do tipo uniaxial (Modelo: L2A-06-250LW-120) como do tipo roseta (Modelo: L2A-06-125WW-120), ambos atendendo plenamente os requisitos necessários, sendo que as quantidades de transdutores recomendadas, bem como a disposição dos mesmos na superfície do corpo de prova foram definidas em função do tipo de parâmetro a ser estimado. Nas medições para definição do coeficiente de Poisson foram utilizadas rosetas, já para a obtenção dos valores de elasticidade foram utilizados "strain gages" uniaxiais. No entanto, os CDPs com rosetas, também, foram utilizados para a determinação do módulo de elasticidade, e, principalmente, do módulo ao cisalhamento.

Sob posse dos resultados dos ensaios segundo a norma ASTM D3039, pôde-se realizar o cálculo de parâmetros de tração associados ao material compósito que será utilizado nas análises estruturais da junta via Método dos Elementos Finitos. Para o cálculo da tensão de ruptura por tração $\left(\mathrm{X}_{\mathrm{T}}\right)$, devem-se utilizar os valores encontrados nos gráficos da tensãodeformação, registrados pelo equipamento de ensaio e aplicá-los na equação: 


$$
X_{T}=\frac{P^{\max }}{A}
$$

Onde:

$$
\begin{aligned}
& \mathrm{P}^{\max }=\text { carga máxima antes da falha; } \\
& \mathrm{A}=\text { área inicial da secção transversal do CDP. }
\end{aligned}
$$

A deformação limite por tração $\left(\mathrm{X}_{\mathrm{T}}^{\prime}\right)$ pode ser obtida indiretamente através do deslocamento do travessão da máquina, bem como através de uma medida direta do "strain gage". O referido limite de deformação pode ser obtido indiretamente pela seguinte equação:

$$
X_{T}^{\prime}=\frac{\Delta_{l}}{L_{i}}
$$

Onde:

$$
\begin{aligned}
& \Delta_{\mathrm{l}}=\text { deslocamento do travessão da máquina; } \\
& \mathrm{L}_{\mathrm{i}}=\text { comprimento inicial do CDP. }
\end{aligned}
$$

O módulo de elasticidade a tração $\left(\mathrm{E}_{11}\right)$ é definido como sendo o coeficiente angular da primeira variação linear observada nos diagramas de ensaios de tensão-deformação dos CDPs, de acordo com a Figura (64), podendo ser calculado através da equação:

$$
E_{11}=\frac{\Delta \sigma}{\Delta X_{T}^{\prime}}
$$

Onde:

$\Delta \boldsymbol{\sigma}=$ variação de tensão (em regime elástico);

$\Delta \mathrm{X}^{\prime}{ }_{\mathrm{T}}=$ variação da deformação 
Há ainda um valor de deformação que identifica o ponto de transição entre a primeira e a segunda variação linear e que deve ser estimado por meio do seguinte procedimento: 1) Encontrar duas retas de forma que ambas sejam capazes de descrever, aproximadamente, os dois comportamentos de respostas lineares do ensaio de tensão-deformação do material, gerado pelo equipamento; 2) Prolongar estas retas até que se cruzem em algum lugar no espaço; 3) Identificar o valor correspondente de deformação associado ao ponto de cruzamento das retas - Figura (64).

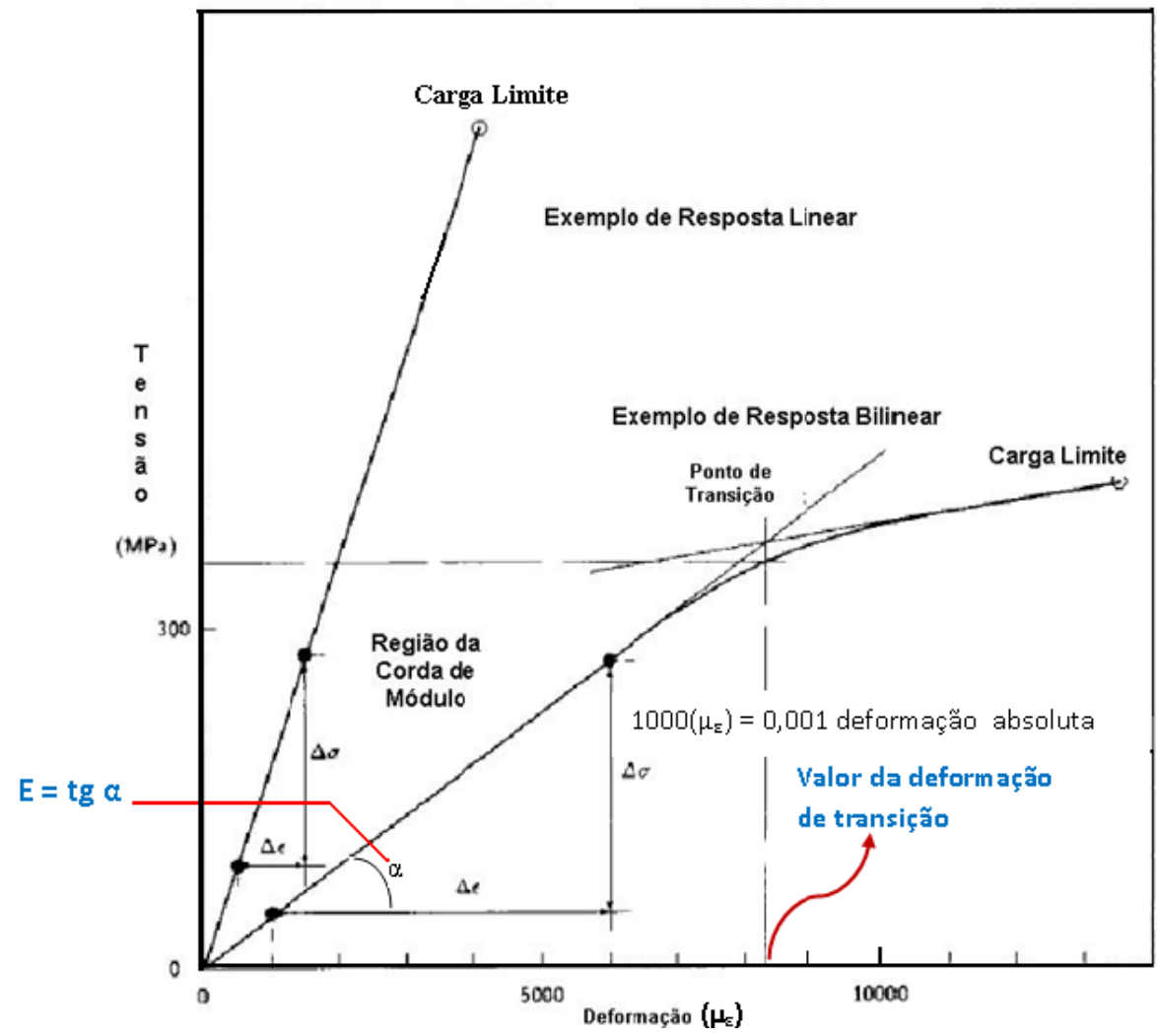

Figura 64 - Curva típica de tensão-deformação do ensaio de tração (ASTM D3039 (2006)).

Por fim, ainda sob posse dos resultados de tração, pode-se obter o coeficiente de Poisson $\left(v_{12}\right)$ no plano da lâmina como sendo a relação entre a deformação transversal $\left(\varepsilon_{t}\right)$ e a deformação axial $\left(\varepsilon_{\mathrm{a}}\right)$, expresso através da equação: 


$$
v_{12}=-\frac{\Delta \varepsilon_{t}}{\Delta \varepsilon_{a}}
$$

Onde:

$\Delta \varepsilon_{\mathrm{t}}=$ medida de deformação transversal devido à ação da carga axial;

$\Delta \varepsilon_{\mathrm{a}}=$ medida de deformação axial devido à ação da carga axial.

Ainda, de acordo com a especificação da norma ASTM D3039 (2006), os corpos de prova ensaiados podem apresentar diferentes modos de falha, como mostrado na Figura (65).
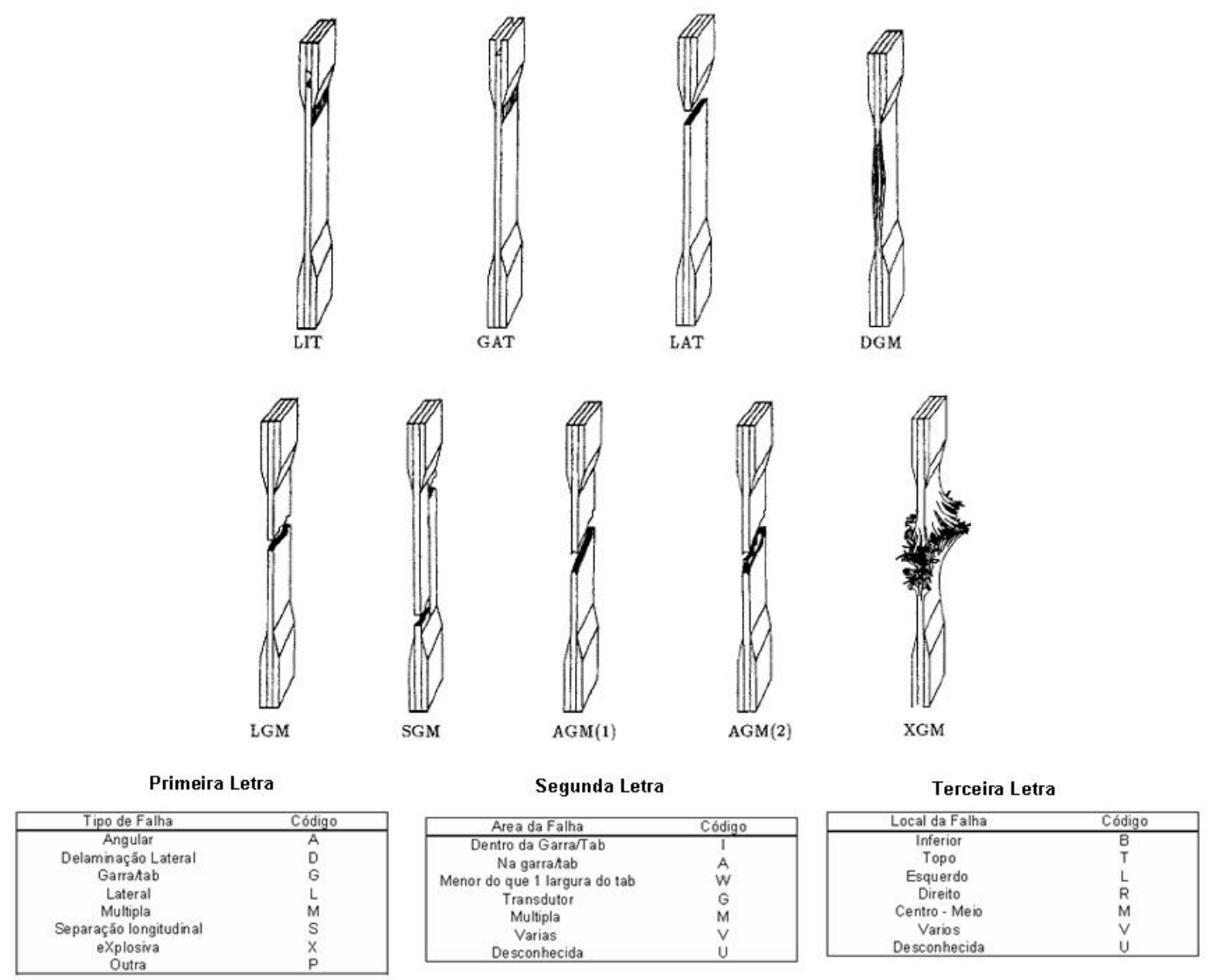

Figura 65 - Modos típicos de falhas e seus códigos para CDPs ensaiados sob tração (ASTM D3039 (2006)).

Sob posse dos resultados dos ensaios seguindo a ASTM D3518 (2001), pode-se realizar o cálculo de parâmetros de cisalhamento associados ao material compósito que será utilizado nas análises estruturais da junta via Método dos Elementos Finitos. Para o cálculo da 
tensão limite de cisalhamento $\left(\tau_{12}\right)$ é conveniente relembrar o Capítulo 2 (item 2.1), sendo que um laminado é constituído por camadas ou lâminas cujas fibras estão orientadas em ângulos de $\pm 45^{\circ}$ (coordenadas locais da camada) com relação ao sistema global. Como o ensaio é realizado sob tração na direção global do eixo x $\left(\boldsymbol{\sigma}_{\mathrm{xx}}\right)$, tem-se que a tensão de cisalhamento no plano da lâmina $\left(\tau_{12}\right)$ pode ser observada no sistema de coordenadas local (1-2) como mostra a Figura (66 (b)). Além disso, a referida tensão de cisalhamento apresenta uma resposta nãolinear em função da deformação como mostra a Figura (66 (a)).

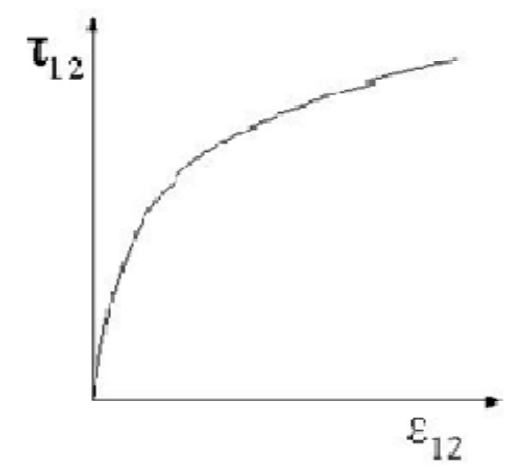

(a)

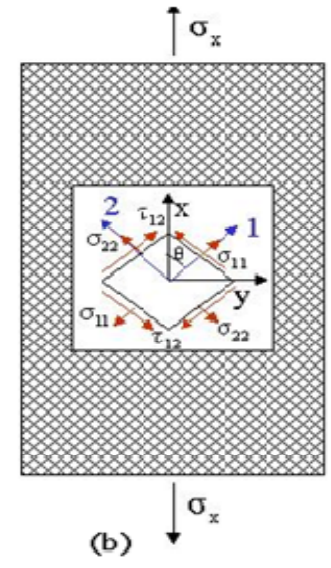

(b)

Figura 66 - (a) Curva de tensão de cisalhamento em função das distorções angulares; (b) Campo de tensões no plano 1-2 do corpo de prova para cisalhamento ensaiado sob tração.

Sendo assim, tem-se que:

$$
\tau_{12}= \pm \frac{\sigma_{x}}{2}
$$

Onde:

$$
\sigma_{\mathrm{x}}=\text { tensão aplicada durante o teste de tração. }
$$

Quanto às deformações, tem-se que: 


$$
\begin{gathered}
\varepsilon_{11}=\frac{\left(\varepsilon_{x}+\varepsilon_{y}\right)}{2} \\
\varepsilon_{22}=\frac{\left(\varepsilon_{x}+\varepsilon_{y}\right)}{2} \\
\varepsilon_{12}=\frac{\left(\varepsilon_{x}-\varepsilon_{y}\right)}{2} \text {.ou.. } \gamma_{12}=\left(\varepsilon_{x}-\varepsilon_{y}\right)
\end{gathered}
$$

Pela relação constitutiva pode-se obter uma expressão para calcular o módulo de cisalhamento no plano $1-2\left(\mathrm{G}_{12}\right)$, pois:

$$
\tau_{12}=G_{12} \cdot \gamma_{12}
$$

Onde:

$$
G_{12}=\frac{\frac{\sigma_{x}}{2}}{\left(\varepsilon_{x}-\varepsilon_{y}\right)}
$$

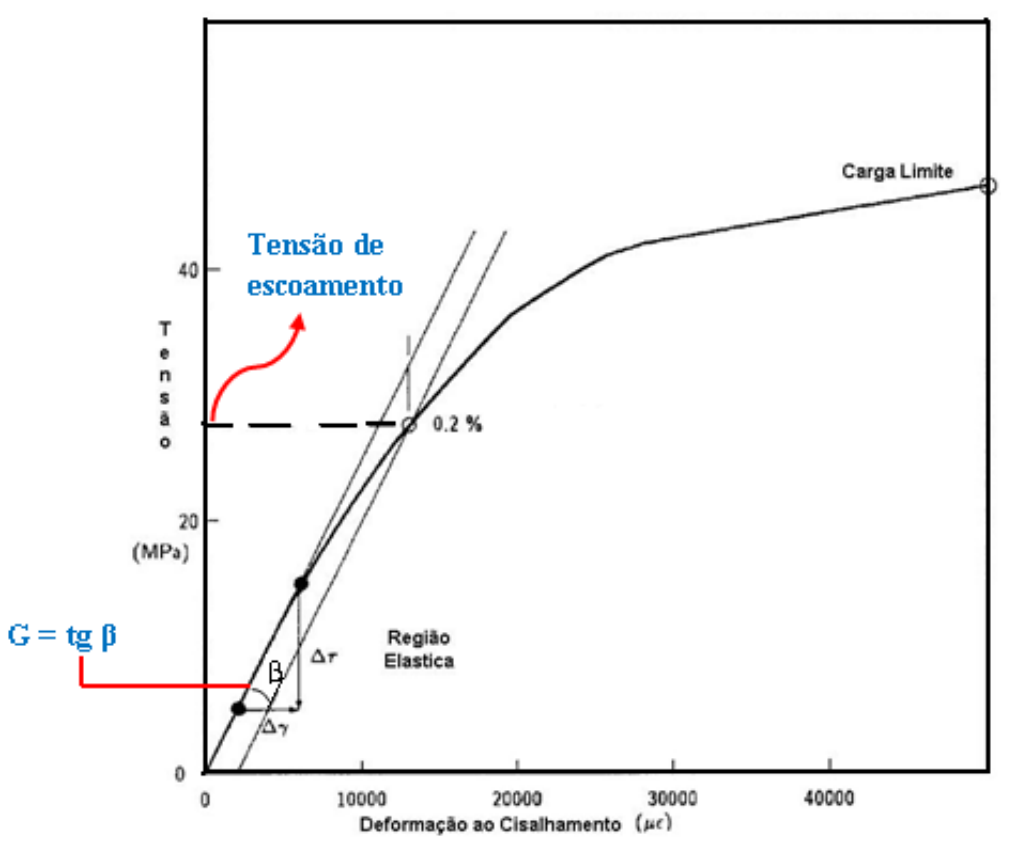

Figura 67 - Curva típica de tensão-deformação do ensaio de cisalhamento (ASTM D3518/D 3518M (2001)). 
Através deste ensaio pode-se também determinar uma espécie de tensão de "escoamento" ao cisalhamento $\left(\mathrm{S}_{\mathrm{esc}}\right)$. A determinação deste parâmetro se dá através da curva de tensão-deformação. Adota-se como parâmetro inicial que o corpo seja submetido a uma deformação permanente correspondente a $0,2 \%$. Por meio deste ponto, passa-se uma reta paralela a qual correspondente a função elástica determinada pelo ensaio do material. O ponto de encontro desta reta com a curva originada no ensaio definirá o valor da tensão de admissível ao cisalhamento de um dado laminado, como demonstrado na Figura (67).

\section{ENSAIOS DAS JUNÇÕES HÍBRIDAS CRAVADAS}

Os ensaios das junções híbridas constituem uma das principais atividades do presente de trabalho. Sendo assim, os mesmos foram realizados somente após a realização de simulações computacionais (detalhadas no Capítulo 4), que tiveram como intuito prever o comportamento das juntas, e assim, delinear as melhores estratégias para a execução dos ensaios experimentais. Dessa forma, o presente capítulo visa a apresentar alguns aspectos gerais relacionados aos ensaios das junções híbridas, sendo que outros aspectos poderão ser encontrados no Capítulo 4, tais como, a geometria detalhada dos CDPs.

Os ensaios experimentais das junções híbridas seguem algumas especificações da norma ASTM D5961/D5961M-05 (2007), Procedimento B, ou seja, são uniões ao simples cisalhamento, conforme anteriormente mencionado como "Single Lap Joint". Os CDPs possuem superfície plana e secção transversal retangular constante, sendo constituídos por dois fixadores instalados nos furos localizados próximo ao final de cada extremidade da junção, com a formação da cabeça localizada sempre na parte metálica da junta, ou seja, não há simetria na conformação dos rebites. A Figura (68) e Tabela (15) mostram um exemplo de 
configuração padronizada (simetria de conformação dos rebites). Além disso, a geometria dos CDPs segue em linhas gerais as orientações dadas pela norma. Portanto, verifica-se que as dimensões dos CDPs das juntas híbridas fabricadas não são exatamente iguais às dimensões citadas na norma.
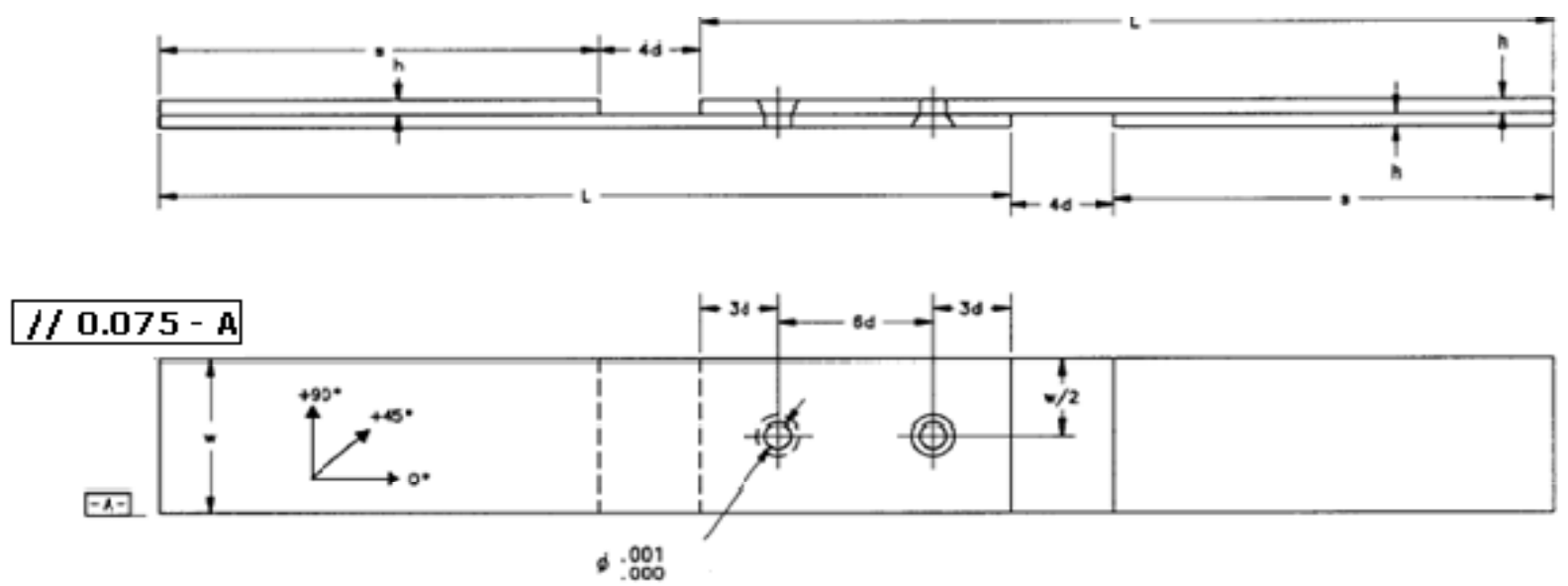

Figura 68 - CDP com dois fixadores ao simples cisalhamento (ASTM D5961/D5961M-05 (2007)).

Tabela 15 - Valores dos parâmetros para o CDP (ASTM D5961/D5961M (2007)).

\begin{tabular}{|c|c|}
\hline PARÂMETROS & PADRÃO DO CDP $(\mathrm{mm})$ \\
\hline Diâmetro do fixador $(\mathrm{d})$ & $6+0,00 /-0,03$ \\
\hline Diâmetro do furo $(\Phi)$ & $6+0,03 /-0,00$ \\
\hline Amplitude da espessura (h) & $3-5$ \\
\hline Comprimento (L) & 210 \\
\hline Largura (w) & $36+/-1$ \\
\hline Distância de borda (e $=3 \mathrm{~d})$ & $18+/-1$ \\
\hline Comprimento do calço (s) & 108 \\
\hline
\end{tabular}

Apenas a título de comentário, as configurações de ensaios por multifixadores descritas neste método de ensaio são similares a aquelas aplicadas pela indústria para investigar a "parcela de bypass" correspondente a resposta pela interação de "bearing-bypass" nas junções mecânicas, onde o CDP pode produzir tanto um modo de falha pelo efeito "bearing" quanto um por "bearing-bypass". Porém, este método pode ser referenciado apenas 
como uma orientação em programas de ensaios de interação entre "bearing-bypass", ficando focado aos modos de falhas somente por "bearing".

Os ensaios foram realizados até a ruptura dos CDPs, ou seja, trata-se da investigação sobre o efeito de "bearing" ou da interação de "bearing-bypass" nas configurações propostas, diferentemente do escopo desta especificação a qual tem por finalidade a determinação da resposta exclusivamente ao "bearing" e que a avaliação dos CDPs que apresentam modos de falhas por "bearing-bypass" (Capítulo 2) vai além da intenção deste procedimento de ensaios.

Ressalta-se, ainda, que a presente especificação estabelece requisitos de ensaios considerando unicamente as junções compósito-compósito. Conseqüentemente, a utilização da ASTM D5961/D5961M-05, para o estudo de CDPs de junções híbridas deve ser cautelosa. A metodologia para as especificações das propriedades mecânicas obtidas dos ensaios segue as orientações do MIL-HDBK-5H (1998), através da aplicação do Método do Módulo Secundário como descrito no Capítuo2. Esta opção justifica-se ainda pelo fato da dificuldade em se medir a tensão de "bearing" e a de "bypass" separadamente (Capítulo 2; fig. 33), as quais têm por finalidade a geração de um diagrama, por exemplo, da tensão de "bearing" x deformação por "bypass” (Capítulo 2; fig. 32).

Os ensaios experimentais foram realizados em um ambiente de temperatura $22^{\circ} \mathrm{C}$, umidade relativa do ar de 63\% com o emprego de uma máquina de tração EMIC (100KN), equipada com instrumento de medição de deslocamento ("Clip-Gage”), marca EMIC 50-63 $\mathrm{mm}$, bem como, instrumento de medição (paquímetro de resolução $0,02 \mathrm{~mm}$ ) e recursos de "software" e "hardware", conforme mostrado na Figura (69). 


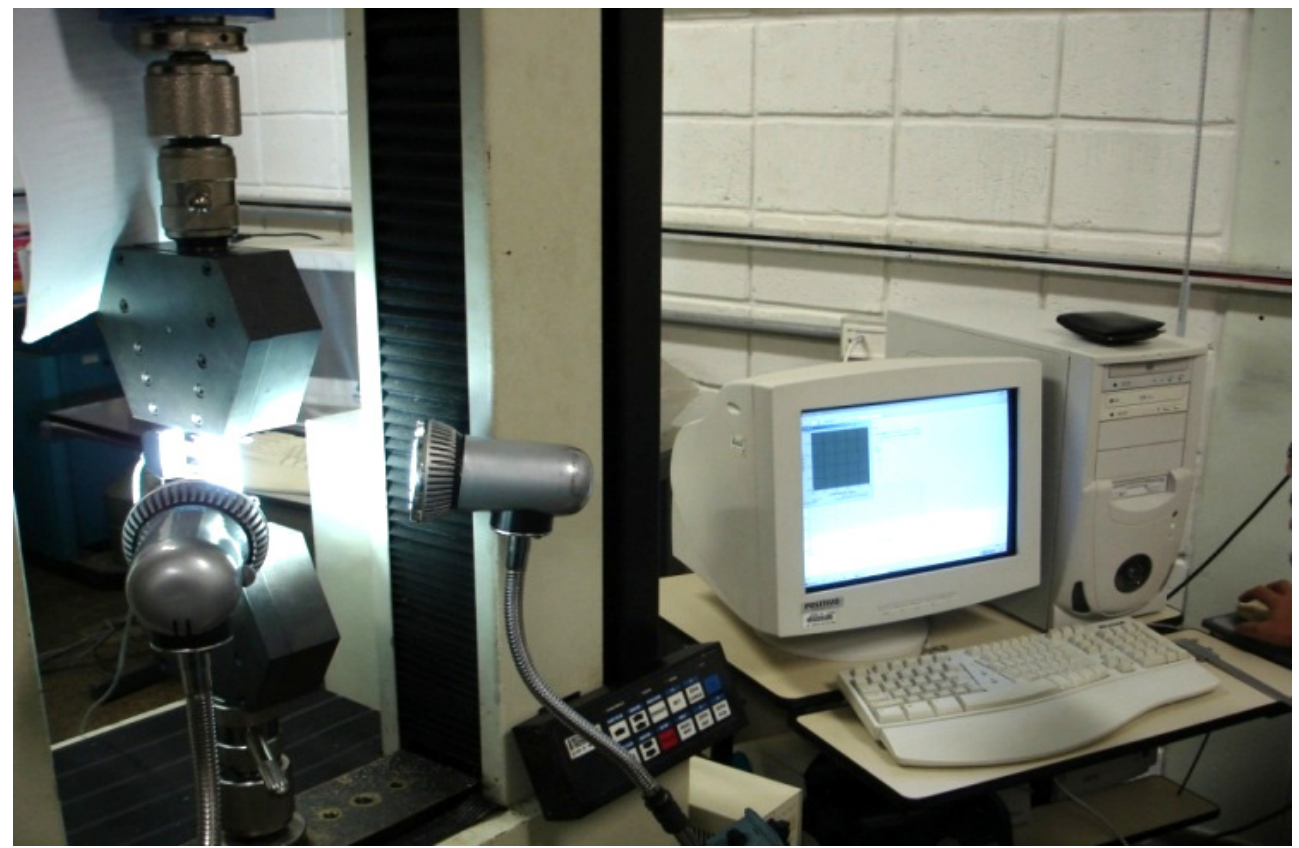

Figura 69 - Vista geral do aparato dos ensaios experimentais das junções híbridas.

A carga aplicada e a deformação associada aos furos e demais elementos são monitoradas. O CDP é carregado a uma velocidade de $0,5 \mathrm{~mm} / \mathrm{min}$ até que a carga de ruptura seja alcançada, onde o teste é encerrado, para garantir que o modo de falha pelo efeito de "bearing" ou "bearing-bypass" seja identificado. A resistência do conjunto é dada assim, pela carga máxima aplicada na junção.

As falhas produzidas na porção da união em material compósito poderão ser devido ao efeito de "bearing" ou "bearing-bypass", esta última, classificada como sendo de multimodo, é codificada pelo tipo da falha característica e precedida da letra "M", conforme indicado na Figura (70) e seus exemplos. 

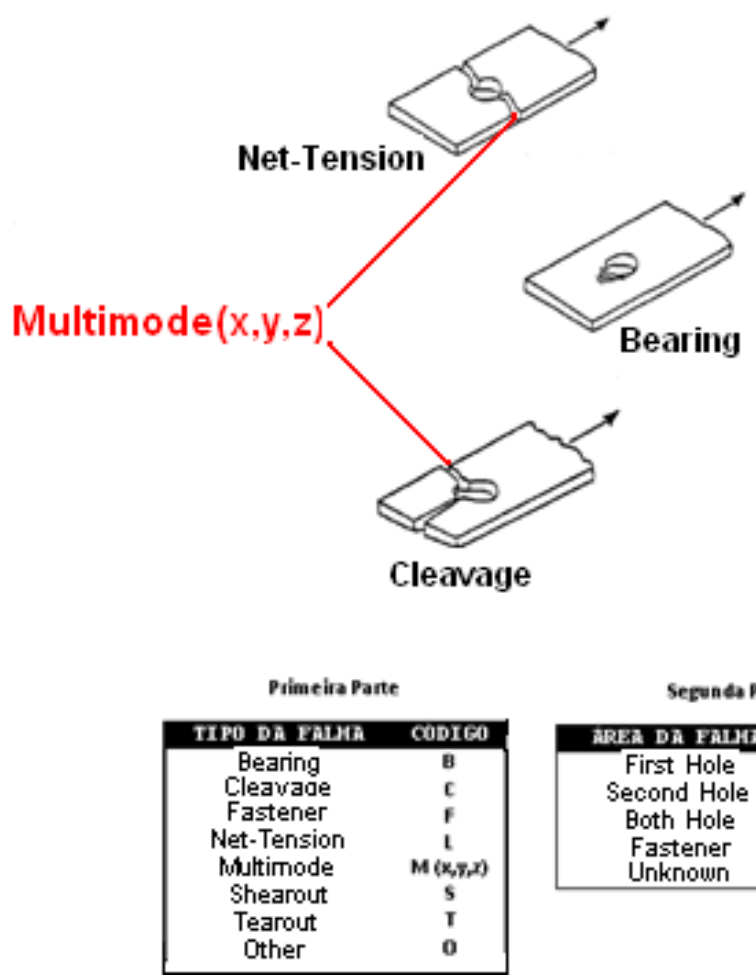

Segunda Parte

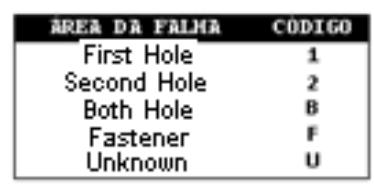

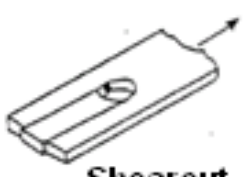

Shearout

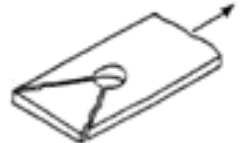

Tearout

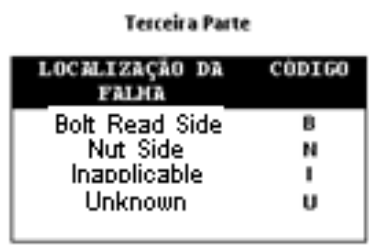

Figura 70 - Caracterização de falhas por "bearing" e "bearing-bypass" (ASTM D5961/D5961M (2007)).

Portanto, para que ocorra falha por multimodo tem que acontecer a separação de material em diferentes direções. Deste modo, as falhas por tração / compressão e combinada por tração / cisalhamento ficam caracterizadas como sendo de "bearing-bypass", por ocorrer à segregação em todos os seus eixos globais, e as demais pelo efeito de "bearing", inclusive a por próprio "bearing”, justamente por não ocorrer a separação do material.

Há inúmeros fatores que influenciam nas propriedades mecânicas da junta ensaiada, dentre os quais, destacam-se: seqüência do empilhamento das camadas do material compósito; velocidade do teste; temperatura e umidade do ensaio; existência de excentricidade na junção; distância de borda; relação entre o diâmetro do fixador e a largura do CDP; relação entre o diâmetro do fixador e a espessura do CDP; torque aplicado; quantidade e material dos elementos mecânicos de fixação; folga de montagem do elemento fixador; dimensionamento do fixador de cabeça angular (chanfrado); disposição dos 
reforçadores na parte em material compósito e o tipo do calço utilizado, como vistos anteriormente.

Diante do grande número de fatores que influencia no comportamento mecânico das juntas, apresenta-se a seguir, de forma mais detalhada, algumas sugestões/recomendações, que foram, dentro da medida do possível, empregadas durante os ensaios:

Materiais e preparação dos CDPs: deve-se ter cuidado ao fabricar os CDPs, pois a resistência ao "bearing" é sensível a: 1)Qualidade dos materiais (materiais metálicos com defeitos internos, normalmente fundidos - bolhas, vazios, inclusões, etc. e materiais compósitos onde haja falta de controle no alinhamento das fibras); 2)Defeitos induzidos pela fabricação imprópria do CDP (a preparação do furo é essencialmente crítica); 3)Defeitos de montagem, por exemplo, torque de instalação do fixador;

Excentricidades: a excentricidade produz um momento fletor secundário como mostra a Figura (71), a mesma pode ser proveniente tanto da fabricação e/ou montagem do CDP, bem como, da montagem do CDP no equipamento de ensaios, ou ainda, do próprio equipamento de ensaios.

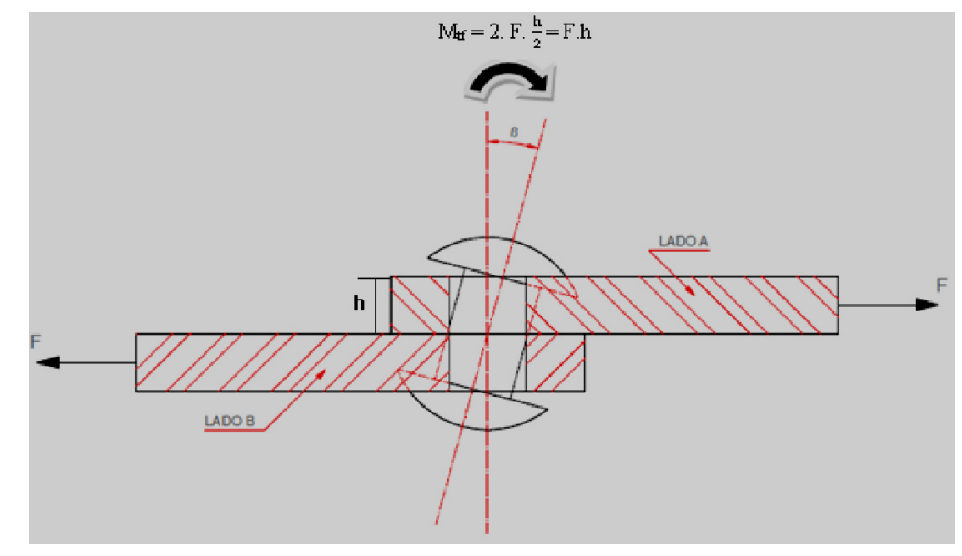

Figura 71 - Rotação imaginária do rebite devido à força de tração e a folga do conjunto. 
Problemas de excentricidade produzem o chamado Momento Secundário que gera uma sobrecarga na junção, resultando em uma distribuição de tensões não uniforme ao redor da parede do furo. O efeito desta excentricidade nos resultados dos ensaios é extremamente dependente de outros fatores, tais como: folga da junta; tamanho da cabeça do parafuso; área resistente da junta; coeficiente de fricção entre o CDP e as partes unidas; espessura e a dureza do CDP na região do furo e configuração dos calços. Os calços utilizados devem ser descartados após a realização de cada ensaio. Portanto, tomando-se o lado "A" da junta como referência - Figura (72), pode-se concluir que na parede deste lado do furo estão atuando a tensão devido à tração e a tensão adicional referente à de oposição ao momento fletor, ocorrendo uma sobreposição das mesmas. Na parede do lado “B” as tensões são semelhantes e opostas (Figura (72)).

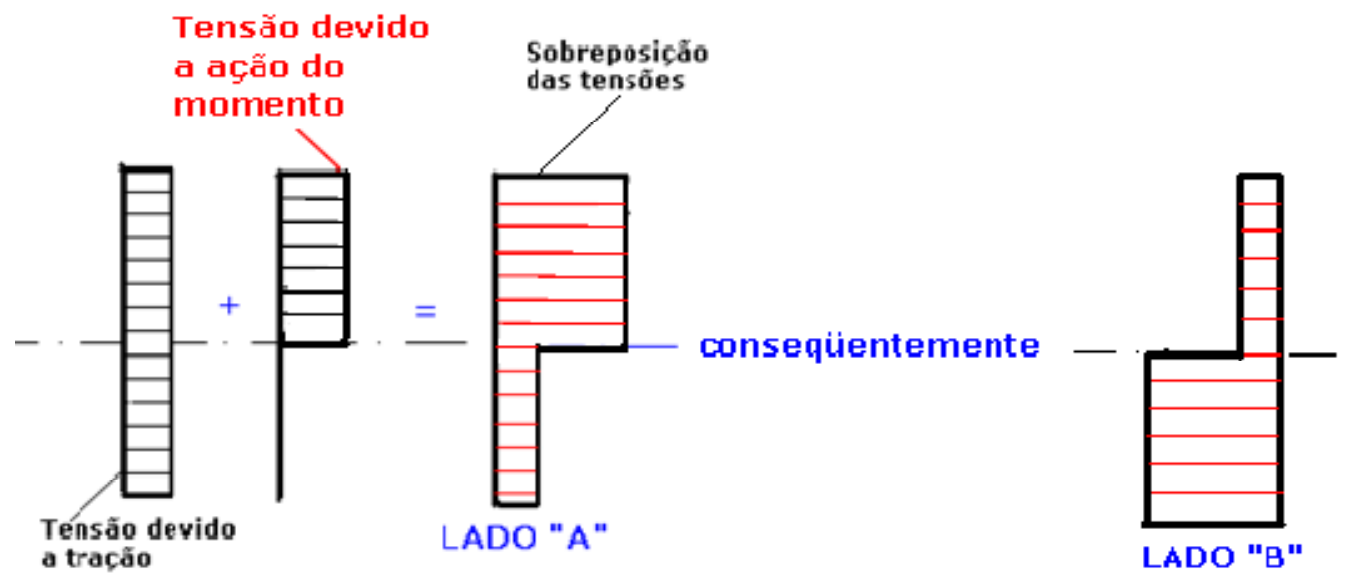

Figura 72 - Efeito da sobreposição na distribuição de tensões devido à ação do momento fletor no fixador e da folga na junta.

O funcionamento do conjunto, nesta condição, está representado na Figura (73). 


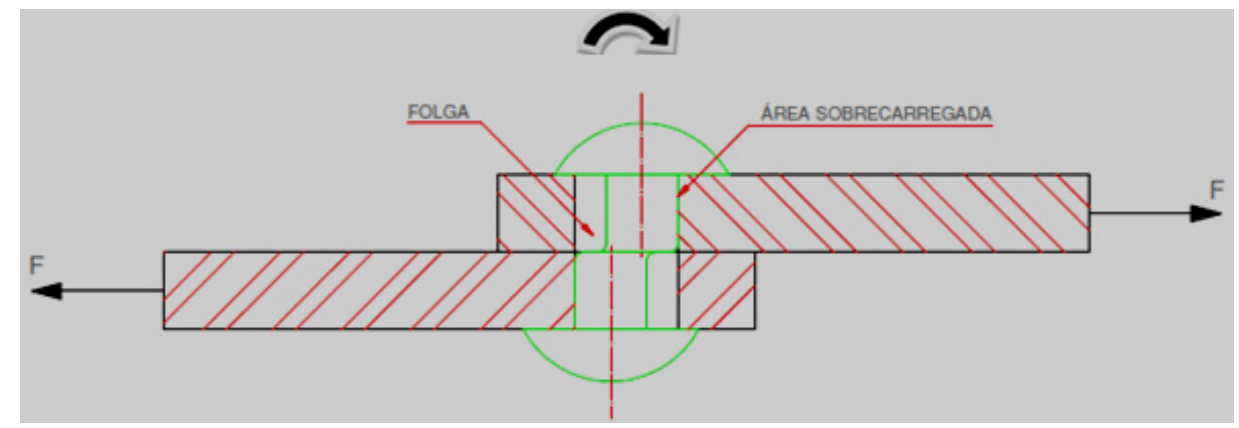

Figura 73 - Trabalho esquemático da junta em serviço, considerando-se somente o efeito do momento fletor no fixador e da folga do conjunto.

Furação: a preparação do furo torna-se importante, principalmente na parte em material compósito, pois, ocorrendo algum defeito na forma do furo, este afetará o resultado obtido, ou, em outras palavras, pode reduzir o valor da resistência do conjunto;

Folga entre o fixador e o furo: os resultados são afetados pelo surgimento das folgas originadas pela diferença entre os diâmetros do furo e fixador. A folga pode mudar o comportamento observado no CDP pelo retardamento da falha por "bearing", devido a ação da própria folga existente no conjunto. Já o defeito devido à insuficiência de folga durante a instalação do fixador afetará os resultados das resistências obtidas (como visto no Capítulo 2). Outro importante fenômeno também é a profundidade ou protuberância do assentamento de um fixador de cabeça angular no alojamento do furo, o qual afetará o resultado das resistências obtidas e pode afetar o modo de falha observado. Por estas razões, tanto o diâmetro do furo quanto o do fixador devem ser criteriosamente medidos e registrados. Uma tolerância típica da folga furo-fixador é $+75 /-0 \mu \mathrm{m}$ para projetos estruturais.

Torque ou Pré-Carga no elemento de fixação: os resultados são afetados pela précarga (pressão de travamento) atuante no elemento de fixação. Principalmente os 
laminados podem apresentar diferenças significativas tanto na carga de falha quanto no modo de falha, devido às variações ocorridas nesta pré-carga. As condições críticas podem variar dependendo do tipo de carregamento. A configuração nominal do ensaio utiliza um nível relativamente baixo para o torque de instalação, permitindo, desta forma, a obtenção de resultados de resistências conservativas. As resistências de “bearing” para CDPs com alta pressão de travamento são quase sempre maiores do que as correspondentes aos CDPs com baixa pressão de travamento;

Geometria do CDP: os resultados podem ser afetados pela relação da largura do CDP com o diâmetro do furo. Esta relação deve ser mantida em torno de seis (6) devido à possibilidade de ocorrer falha por "by-pass" (como visto no Capítulo 2). Já a relação do diâmetro do furo com a espessura deve permanecer em um intervalo de 1,5-3,0. É considerada também a influência do uso de fixadores com cabeça angular e a sua profundidade ao longo da espessura da junta, sendo que a relação preferida entre profundidade do assentamento da cabeça com a espessura é de $0,0-0,7$;

Materiais ortotrópicos: o grau de ortotropia de um laminado afeta fortemente o modo de falha e a resistência ao "bearing", ou seja, o empilhamento do laminado interfere no comportamento do laminado. Dessa forma, a orientação das fibras é um dos fatores muito importante para ser investigado e será previamente estudado através de simulações computacionais (maiores detalhes no Capítulo 4);

Ambiente de ensaio: as experiências demonstraram que temperaturas elevadas e ambientes úmidos são geralmente críticos, para o modo de falha por "bearing". Contudo, para o presente trabalho, os ensaios foram realizados em temperaturas amenas com controle de umidade, como comentado anteriormente; 
Tipo do carregamento: são considerados os de tração ou compressão, sendo que, geralmente, o comportamento inicial da tensão/deformação por "bearing" e os modos de falhas observados são independentes do tipo de carregamento, isto porque, os resultados encontrados estão diretamente associados às condições limites do furo. Contudo, a máxima tensão de "bearing" e os modos de falhas finais podem diferir, considerando-se carregamentos de tração e de compressão, devido às diferentes condições geométricas e constitutivas próximas aos furos. Por exemplo, um CDP sob tração pode apresentar falha por cisalhamento, devido ao carregamento externo, ou de forma combinada por tração e cisalhamento. Já no carregamento sob compressão, a resposta da tensão-deformação pode ser significativamente influenciada pela fricção entre o CDP e o suporte de fixação e também pelos efeitos da flambagem. Conseqüentemente, os modos de falhas não são tão evidentes. No presente trabalho, como comentado anteriormente, optou-se por realizar ensaios de tração.

Caso as recomendações supracitadas sejam seguidas, os ensaios das junções podem fornecer, com consistência, alguns resultados importantes, os quais serão tratados neste trabalho: os modos de falhas; tensão de ruptura; deformação máxima; módulo de elasticidade; tensão admissível e os fatores de concentração de tensões. 


\section{RESULTADOS E DISCUSSÕES}

\subsection{RESULTADOS EXPERIMENTAIS DOS COMPÓSITOS FABRICADOS}

Neste capítulo serão tratados e analisados os resultados experimentais das junções híbridas, mediante a aplicação dos conceitos e procedimentos mencionados no capítulo anterior.

Com relação aos $\operatorname{CDPs} 0^{\circ} / 90^{\circ}$, segundo a norma ASTM D3039, o resultado visualizado na Figura (74) mostra um exemplo de uma curva de tensão-deslocamento cíclica obtida com o auxílio da máquina de ensaios EMIC.

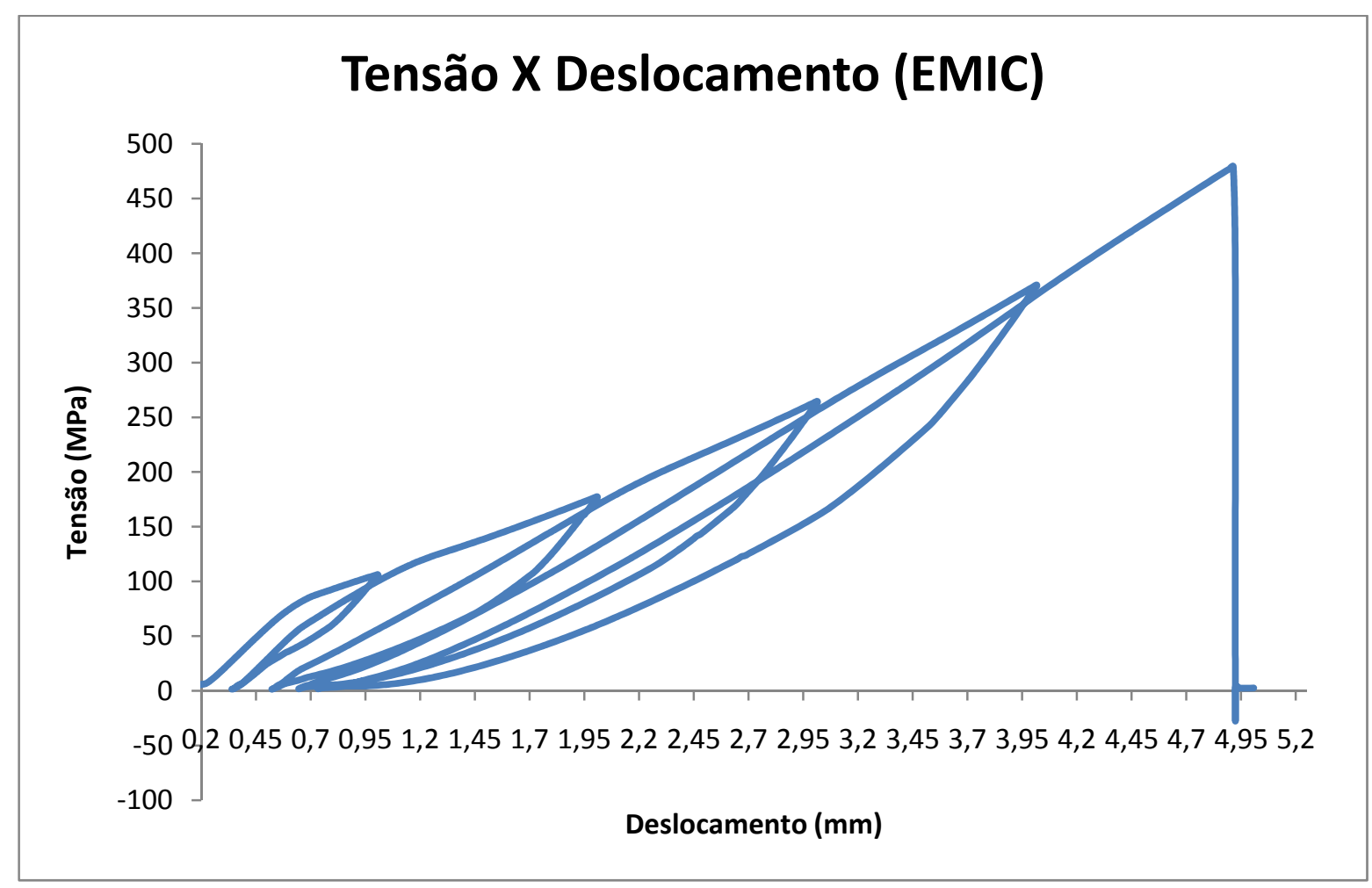

Figura 74 - Exemplo de ensaio cíclico $\left(\mathrm{CDP} 4-0^{\circ} / 90^{\circ}\right)$. 
Já a Figura (75) mostra um exemplo de uma curva de tensão-deslocamento monotônica obtida com o auxílio da máquina de ensaios EMIC.

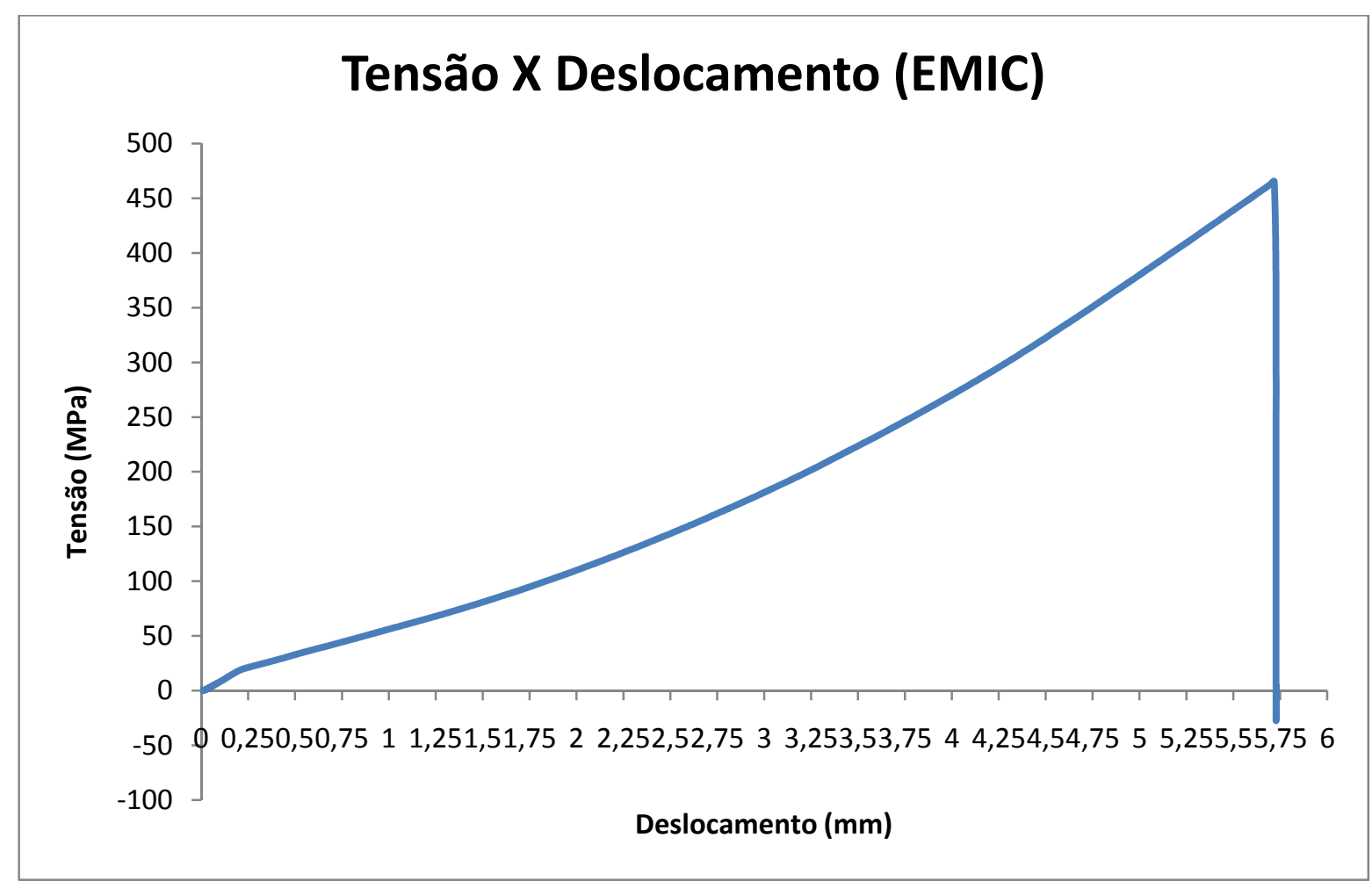

Figura 75 - Exemplo de ensaio monotônico (CDP5 - $\left.0^{\circ} / 90^{\circ}\right)$.

As curvas tensão-deformação, como, por exemplo, as mostradas na Figura (76), permitiram calcular os módulos de elasticidades $E_{11}$ e $E_{22}$ e o coeficiente de Poisson $v_{12}$, mostrados na Tabela (16). Além disso, esta tabela apresenta o resultado da tensão de ruptura $\left(\mathrm{X}_{\mathrm{T}}\right)$ obtida com o auxílio da célula de carga da máquina de ensaios, bem como, a máxima deformação $\left(\mathrm{X}^{\prime}{ }_{\mathrm{T}}\right)$. 


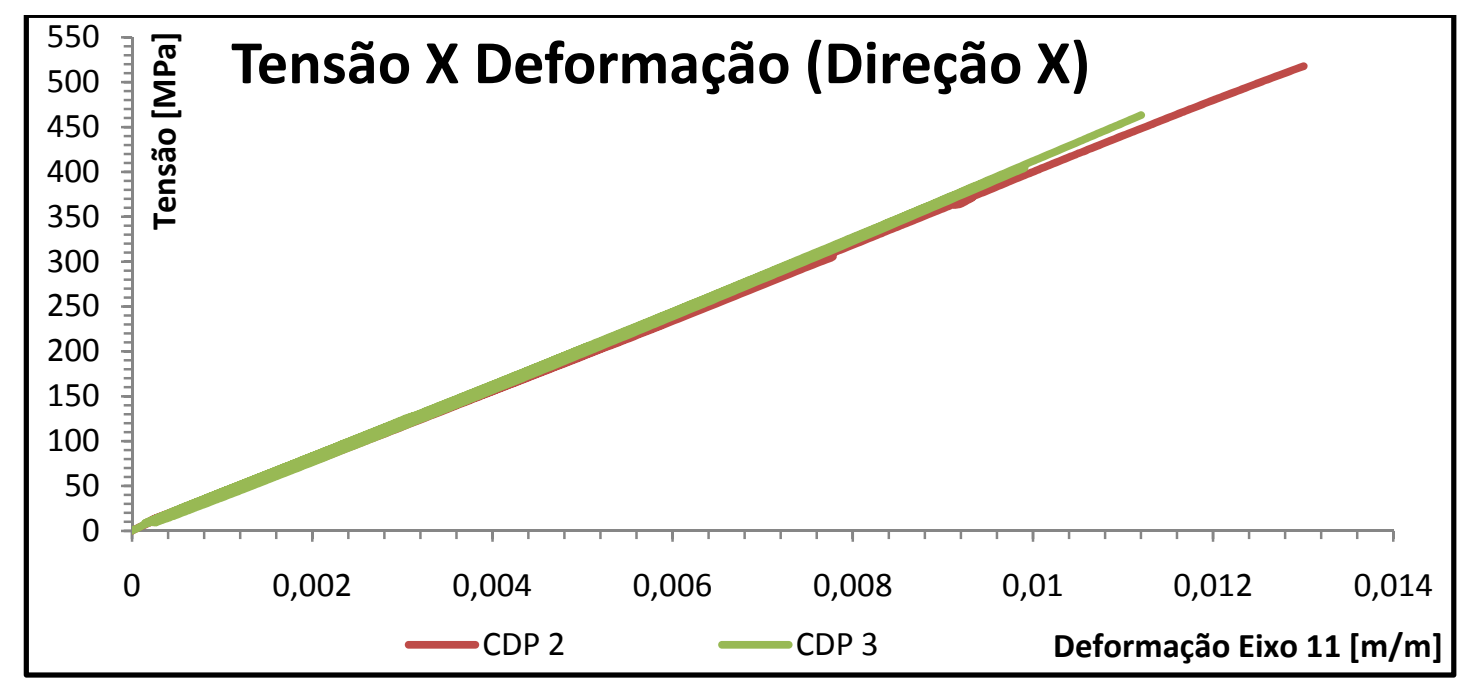

Figura 76 - Curvas resultantes dos ensaios dos CDPs $\left[0^{\circ} / 90^{\circ}\right]_{6}$.

Tabela 16 - Resultados dos ensaios dos CDPs de tração (ASTM D3039).

\begin{tabular}{cccccc} 
& $\mathrm{CP0}-2$ & $\mathrm{CP0}-3$ & $\mathrm{CP0}-4$ & MÉDIA & $\begin{array}{c}\text { DESVIO } \\
\text { PADR } \tilde{O} O\end{array}$ \\
\hline $\mathrm{E}_{11}[\mathrm{MPa}]$ & $\mathbf{3 8 7 2 6}$ & $\mathbf{4 1 6 6 9}$ & $\mathbf{4 3 8 4 3}$ & $\mathbf{4 1 4 1 3}$ & $\mathbf{2 5 6 3}$ \\
\hline $\mathrm{E}_{22}[\mathrm{MPa}]$ & $\mathbf{4 0 4 4 1}$ & $\mathbf{3 7 1 6 2}$ & $\mathbf{3 9 8 5 4}$ & $\mathbf{3 9 1 5 2}$ & $\mathbf{1 7 4 9}$ \\
\hline$v_{12}$ & $\mathbf{0 , 0 9 5}$ & $\mathbf{0 , 1 1 9 9}$ & $\mathbf{0 , 1 0 5 9}$ & $\mathbf{0 , 1 0 7}$ & $\mathbf{0 , 0 1 2}$ \\
\hline $\mathbf{X}_{\mathrm{T}}[\mathrm{MPa}]$ & $\mathbf{5 1 8}$ & $\mathbf{4 8 2}$ & $\mathbf{4 8 1}$ & $\mathbf{4 9 4}$ & $\mathbf{2 1}$ \\
\hline $\mathbf{X}_{\mathrm{T}}^{s}[\mathrm{~mm} / \mathrm{mm}]$ & $\mathbf{0 , 0 1 3 0}$ & $\mathbf{0 , 0 1 1 4}$ & $\mathbf{0 , 0 1 0 3}$ & $\mathbf{0 , 0 1 1 6}$ & $\mathbf{0 , 0 0 1 3}$ \\
\hline
\end{tabular}

Observa-se também que os valores das propriedades encontrados através dos resultados experimentais, diferem daqueles contidos na literatura (Tabela 6). Isto se deve ao fato que na literatura os valores de módulo de elasticidade e resistência referem-se a um compósito constituído de fibra de carbono unidirecional pré-impregnada com resina epóxi. Neste trabalho, foram utilizados reforços com tecido bi-direcional de fibra de carbono préimpregnado com resina epóxi. Somado a isto, as propriedades do material compósito dependem intrinsecamente do processo de fabricação.

Analogamente, com relação aos $\operatorname{CDPs}+45^{\circ} /-45^{\circ}$ no plano da lâmina $1-2$, segundo a norma ASTM D3518, o resultado visualizado na Figura (77) mostra um exemplo de uma curva tensão-deslocamento cíclica obtida com o auxílio da máquina de ensaios EMIC. 


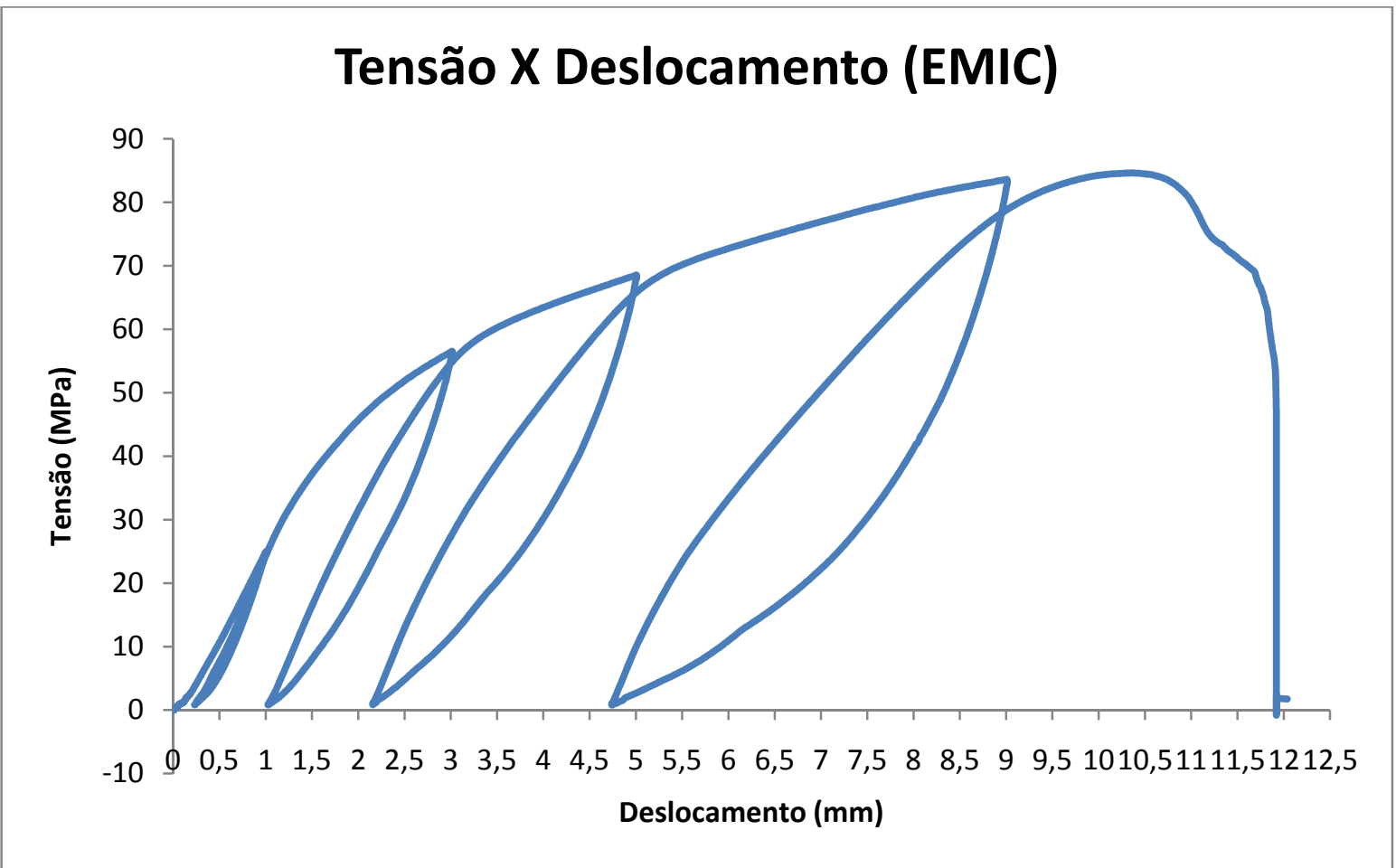

Figura 77 - Exemplo de ensaio cíclico (CDP5 $\left.-+45^{\circ} /-45^{\circ}\right)$.

Já a Figura (78) mostra um exemplo uma curva de tensão-deslocamento monotônica.

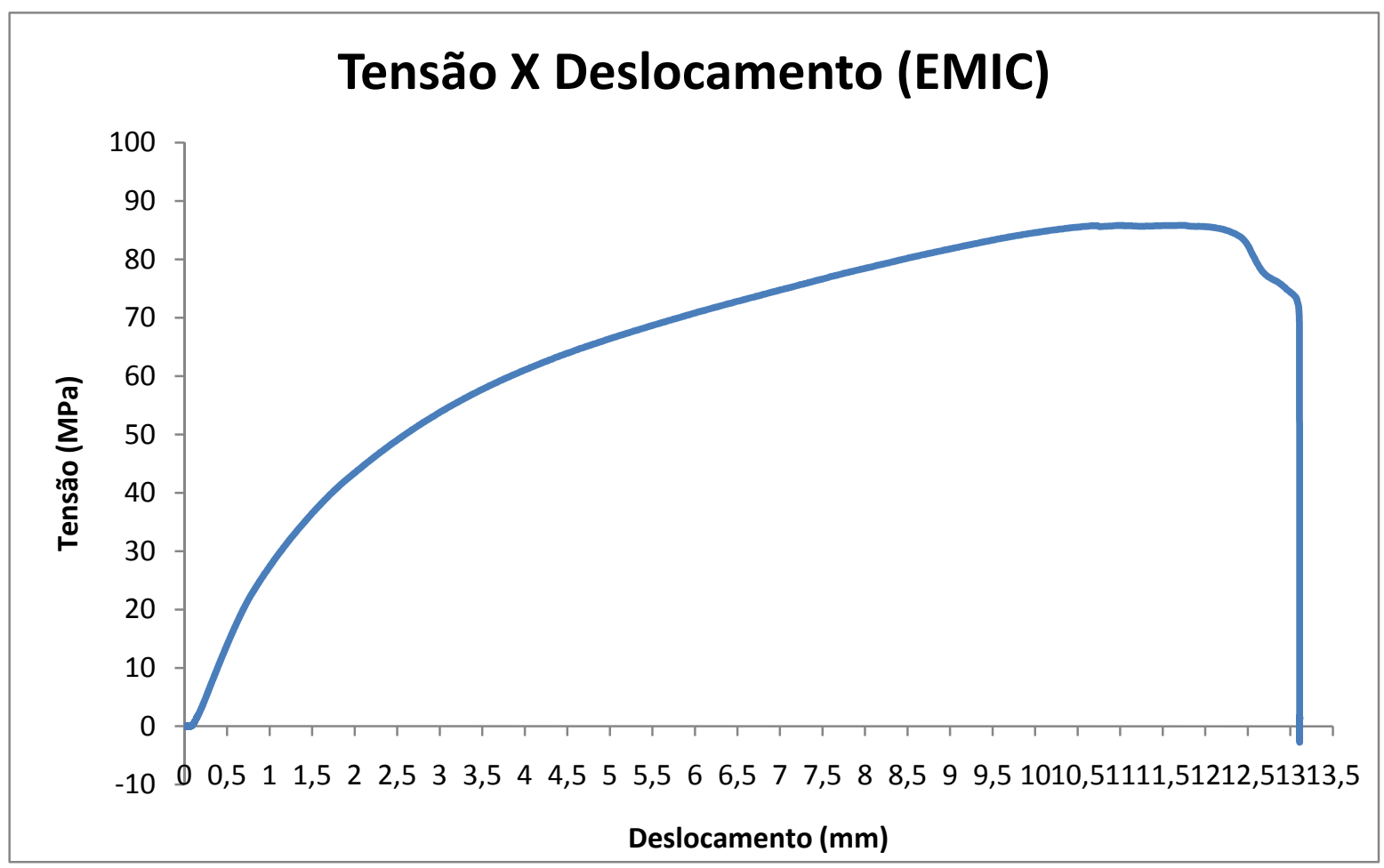

Figura 78 - Exemplo de ensaio monotônico (CDP4 $\left.-+45^{\circ} / 45^{\circ}\right)$. 
As curvas tensão de cisalhamento x distorções angulares, como mostradas na Figura (79), permitiram calcular o módulo ao cisalhamento $\left(\mathrm{G}_{12}\right)$, mencionado na Tabela (17). Além disso, esta tabela apresenta o resultado da tensão ruptura ao cisalhamento $\left(\mathrm{S}_{12}\right)$ obtida com o auxílio da célula de carga da máquina de ensaios.

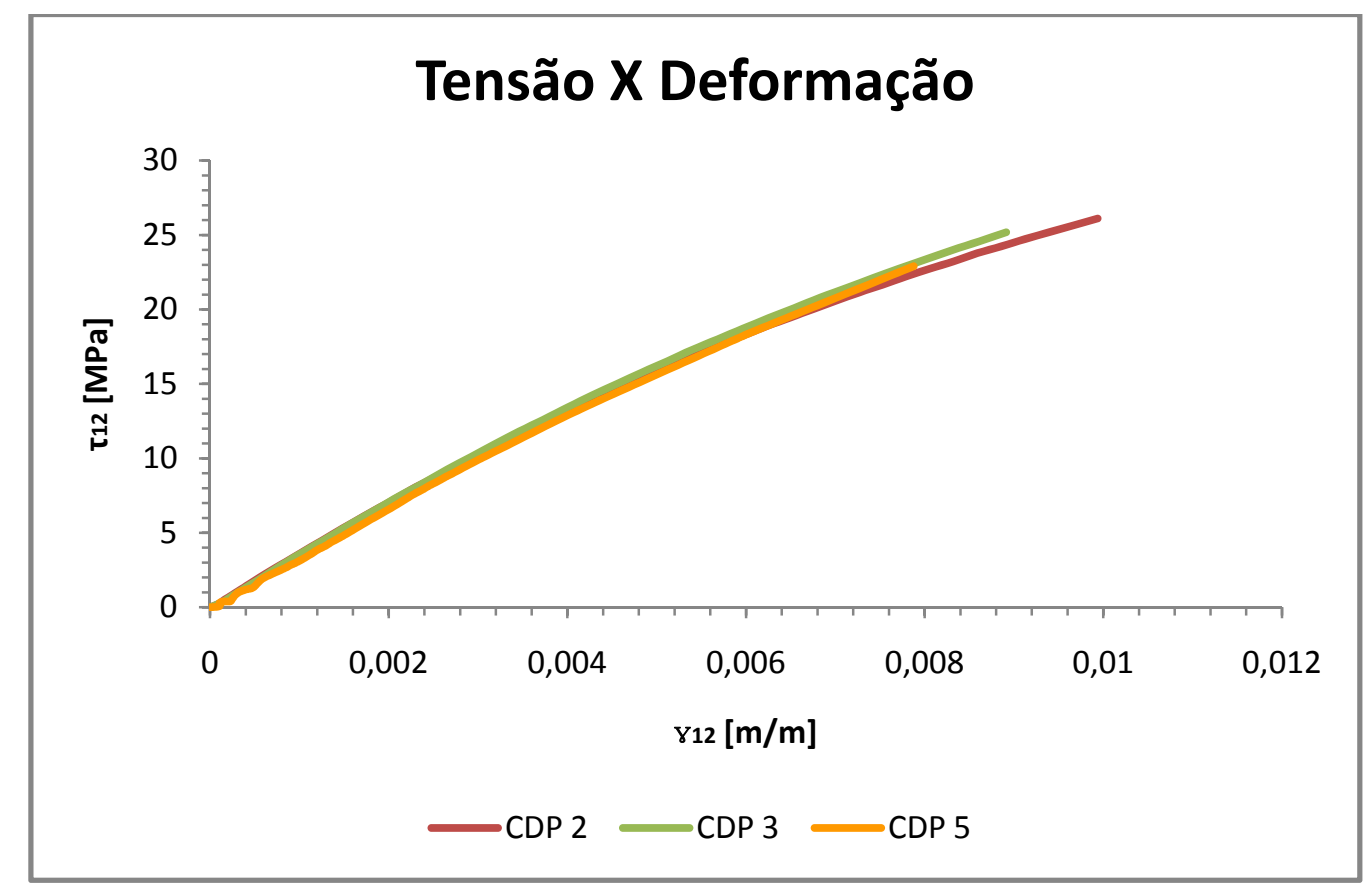

Figura 79 - Curvas resultantes dos ensaios dos CDPs $\left[+45^{\circ} /-45^{\circ}\right]_{6}$ - dados dos "strain-gages" (ASTM D3518).

Tabela 17 - Resultados dos ensaios dos CDPs de cisalhamento (ASTM D3518).

\begin{tabular}{cccccc} 
& CP45-2 & CP45-3 & CP45-5 & MÉDIA & $\begin{array}{c}\text { DESVIO } \\
\text { PADRÃO }\end{array}$ \\
\hline $\mathrm{G}_{12}[\mathrm{MPa}]$ & 2717 & 2596 & 3123 & 2812 & 276 \\
\hline $\mathrm{S}_{12}[\mathrm{MPa}]$ & $\mathbf{7 8}$ & $\mathbf{8 0}$ & $\mathbf{8 5}$ & $\mathbf{8 1}$ & 3 \\
\hline
\end{tabular}

Sob posse das propriedades elásticas do compósito, bem como, dos valores limites de tensão e de deformação, partiu-se, então, para as simulações computacionais. 


\subsection{RESULTADOS DAS SIMULAÇÕES COMPUTACIONAIS}

A análise via Elementos Finitos tem por objetivo fornecer informações preliminares do comportamento mecânico da estrutura a ser ensaiada. A modelagem da junção híbrida seguiu algumas especificações da norma ASTM 5961, como mostra a Figura (80), e possibilitou assim estimar a carga que produz os mecanismos de dano preliminares na estrutura. Os fixadores foram cravados de forma que as cabeças conformadas foram geradas na parte metálica da junção, seguindo orientações de procedimentos padrões utilizadas pela TAM LINHAS AÉRAS S.A., ou seja, os fixadores não estão conformados simetricamente. Todavia, acredita-se que isto não irá interferir de forma relevante nos resultados experimentais. Além disso, buscou-se através deste procedimento evitar danos prematuros na parte em compósito devido ao processo de cravação. Vale ressaltar que maior detalhe sobre a geometria do CDP simulado pode ser visto na Tabela (21), no próximo tópico.

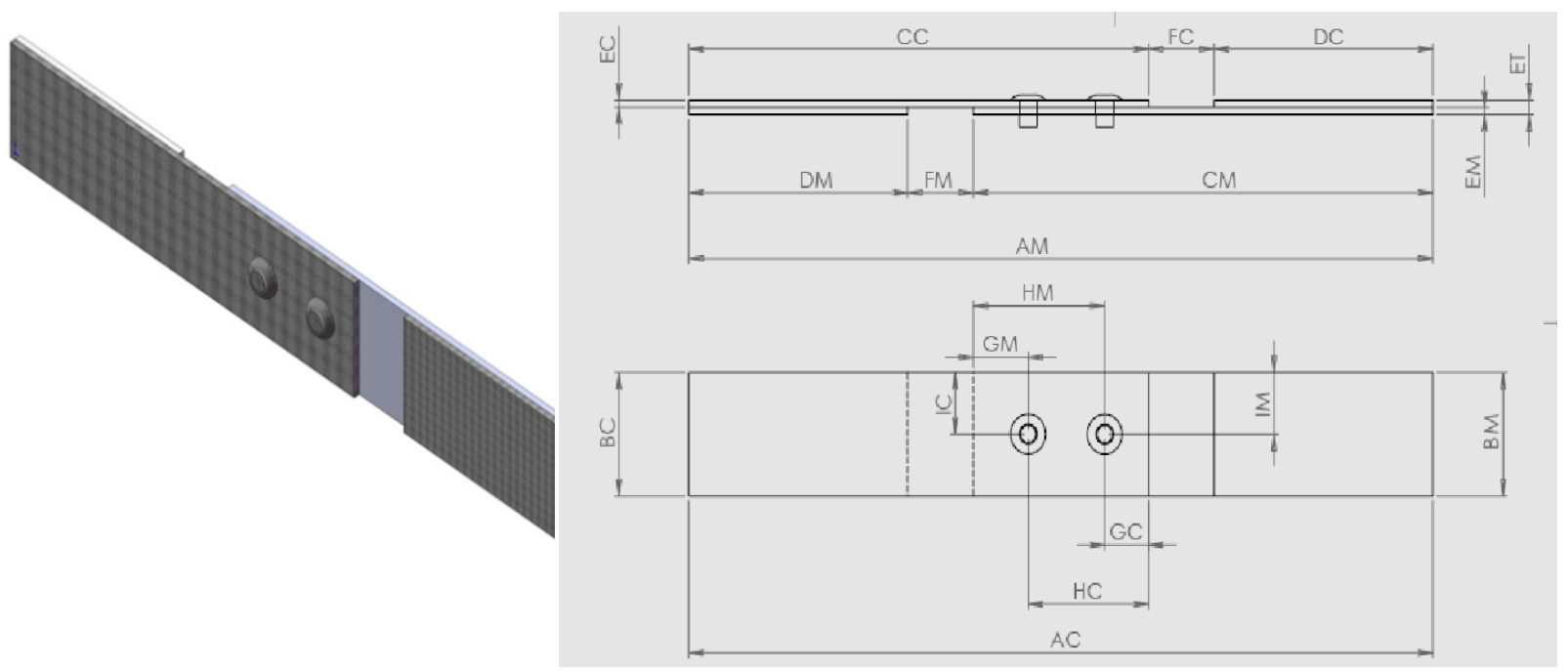

Figura 80 - CDP de ensaio seguindo as orientações da norma ASTM 5961. 
Utilizou-se o software NASTRAN/PATRAN e a geometria foi reproduzida sob a forma de superfícies coplanares no modelo, mostrada na Figura (81), portanto, não haverá influência do Momento Secundário. Verifica-se que as condições de contorno também foram aplicadas da seguinte forma: engaste no calço da esquerda; carga total (distribuída pelo programa nos nós selecionados) aplicada no calço da direita; deslocamento, sem restrição, somente na direção uniaxial (eixo x).

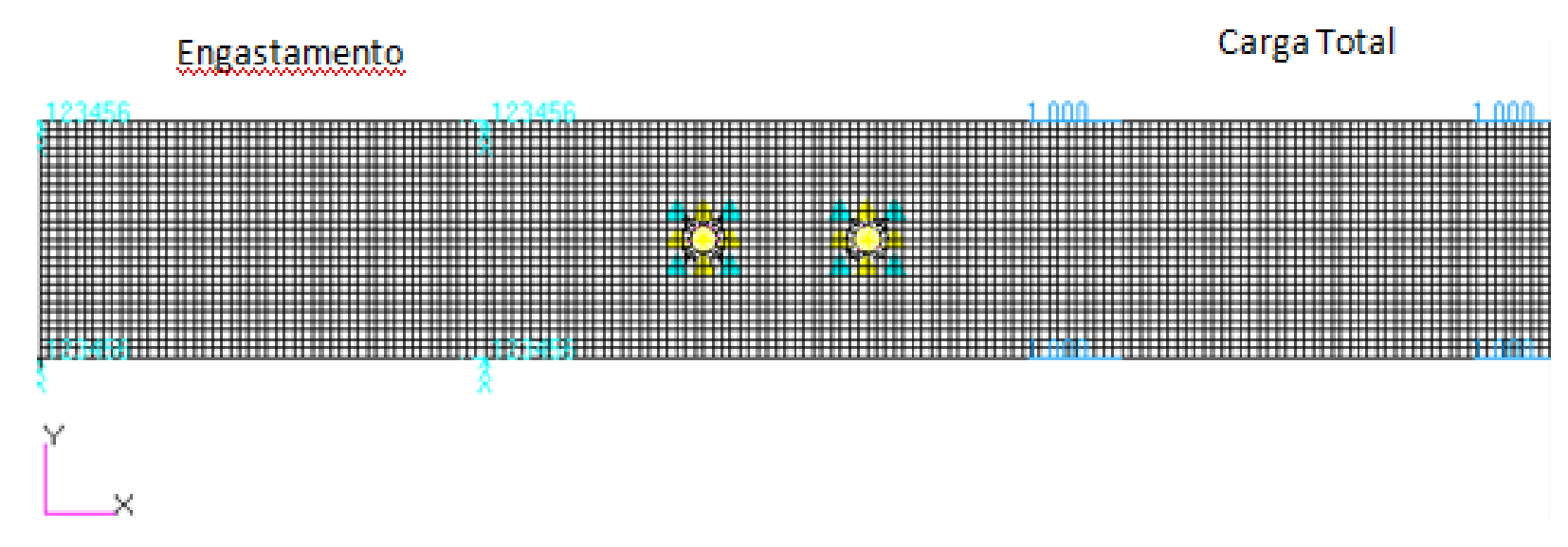

Figura 81 - Modelo MEF da junta: malha, condições de contorno e carregamentos.

Uma malha de elementos finitos foi então gerada com base na geometria. Os elementos utilizados foram do tipo CQUAD4 no programa (elementos quadriláteros com 4 nós por elementos, um em cada um dos vértices). Vale ressaltar que os respectivos elementos possuem 6 graus de liberdade por nó e, além disso, produzem estado plano de tensões.

$\mathrm{Na}$ modelagem dos fixadores os mesmos elementos foram utilizados, sendo que esta aproximação bidmensional do fixador limita o estudo sobre certo aspecto, pois impede o cálculo do seu cisalhamento (“Shear Rivet”), no entanto, a falha é esperada nos furos da junta, minimizando a preocupação quanto à modelagem do fixador. A Figura (82) mostra, em detalhe, como foi modelada a região do fixador. 


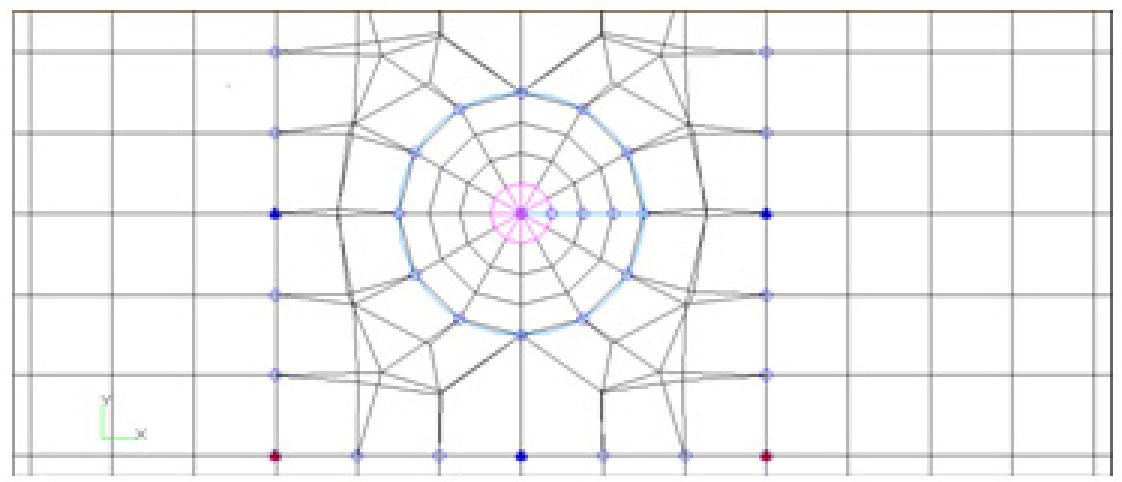

Figura 82 - Detalhe da malha de Elementos Finitos na região do fixador.

Para simular a transferência de carga de um componente da junta para o rebite e deste para o outro componente da junta, a técnica adotada foi: os nós da borda do furo pertencentes ao fixador e a cada um dos componentes da junta foram agrupados de forma a terem os mesmos graus de liberdade, e, conseqüentemente, os mesmos valores de deslocamento, como mostra a Figura (83). Essa configuração permite que o carregamento seja transferido simulando uma condição de contato "perfeita".

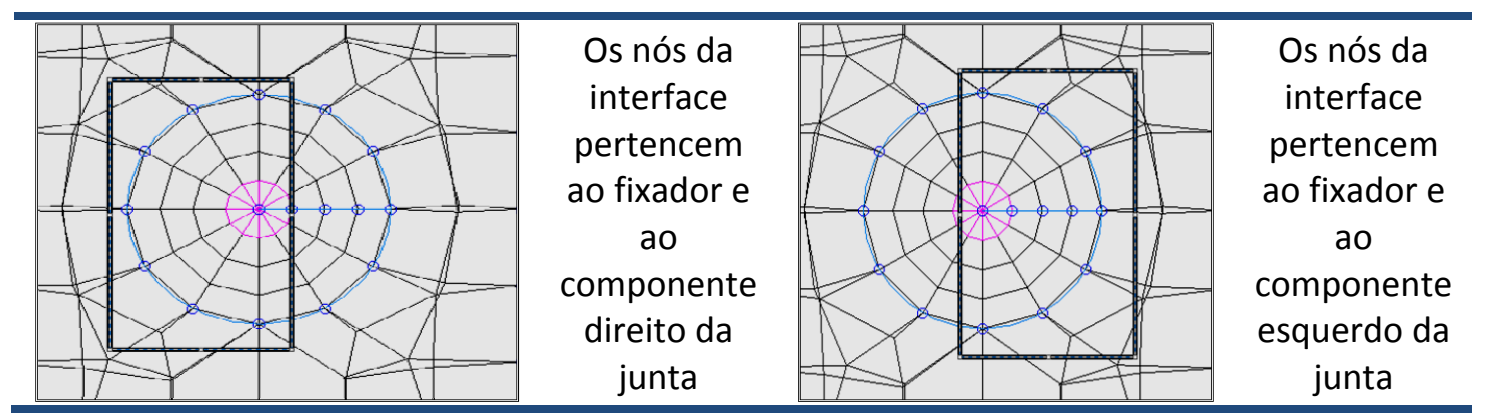

Figura 83 - Detalhe dos nós na região do fixador.

Os dados dos materiais metálicos, ou seja, fixadores e parte metálica da junta, foram obtidos do MIL-HDBK-5J, apresentados na Tabela (18). 
Tabela 18 - Valores extraídos da literatura para os materiais metálicos (MIL-HDBK-5J).

\begin{tabular}{cccc}
\hline Material & Módulo de Elasticidade (MPa) & Poison & Módulo de Cisalhamento (MPa) \\
\hline Calço (Rígido) & 999999 & 0 & 999999 \\
Monel & 170000 & 0.32 & 66000 \\
Ti6Al4V & 110300 & 0.31 & 42750 \\
\hline
\end{tabular}

Os dados do compósito foram obtidos dos ensaios de caracterização descritos no item 4.1 e são sumarizados na Tabela (19).

Tabela 19 - Propriedades mecânicas da camada em compósito.

\begin{tabular}{cc|}
\hline$E_{11}(\mathrm{MPa})$ & $\mathbf{4 1 4 1 3}$ \\
\hline $\mathrm{E}_{22}(\mathrm{MPa})$ & 39152 \\
$\mathbf{G}_{12}(\mathrm{MPa})$ & 2812 \\
\hline $\boldsymbol{V}_{12}$ & 0,107 \\
\hline Espessura Camada & 0.3 \\
\hline
\end{tabular}

Vale ressaltar que foram investigados dois casos de juntas, designados da seguinte forma:

- Compósitos 1: junta híbrida de Titânio-Compósito com empilhamento de lâminas a $\left[0^{\circ} / 90^{\circ}\right]_{6}$

- Compósitos 2: junta híbrida de Titânio-Compósito com empilhamento de lâminas a $\left[+45^{\circ} /-45^{\circ}\right]_{6}$.

A falha na união é esperada na porção em compósito em função da espessura da junção e dos valores de resistência obtidos anteriormente, assim, aplicou-se uma carga de $1 \mathrm{~N}$ onde o elemento mais solicitado foi selecionado e avaliado, conforme mostra a Figura (84). 


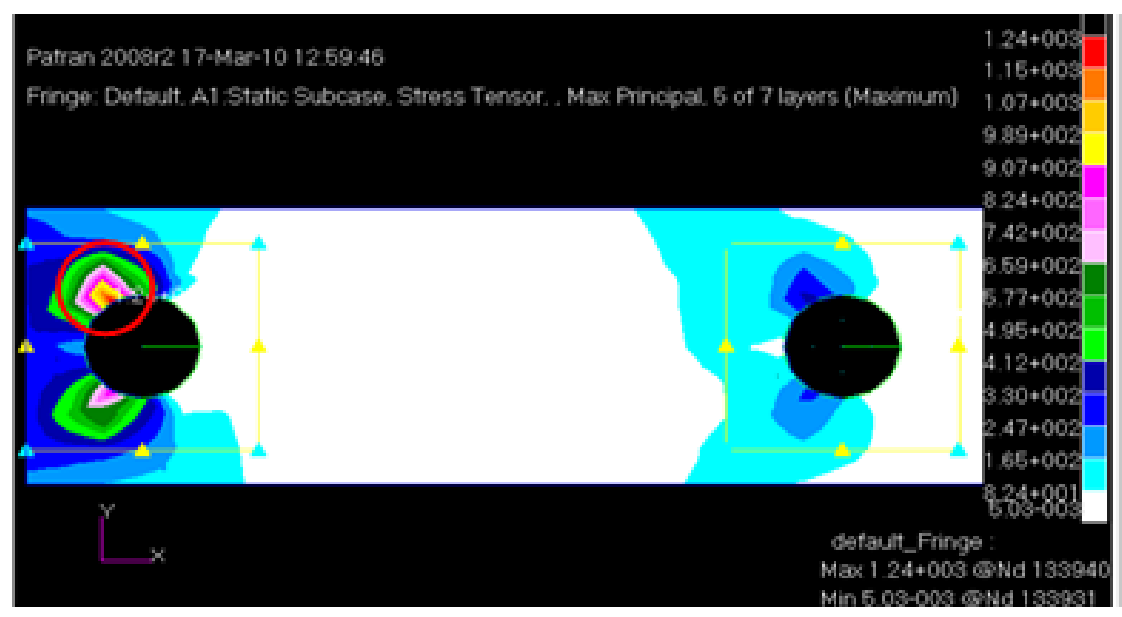

Figura 84 - Campo de Tensões Principais na junta (Compósito 1) - Detalhe do elemento mais solicitado.

Uma vez identificado o elemento mais solicitado em cada um dos casos de juntas analisados, os valores dos esforços atuantes no mesmo foram determinados, como mostram as Figuras (85 (a) e 85(b)). Apesar dos valores de tensão serem diferentes entre as análises, o elemento mais solicitado para ambos os casos foi o mesmo.

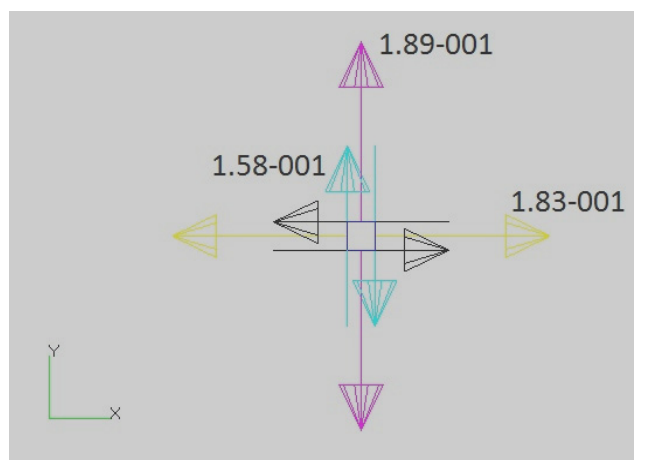

(a)

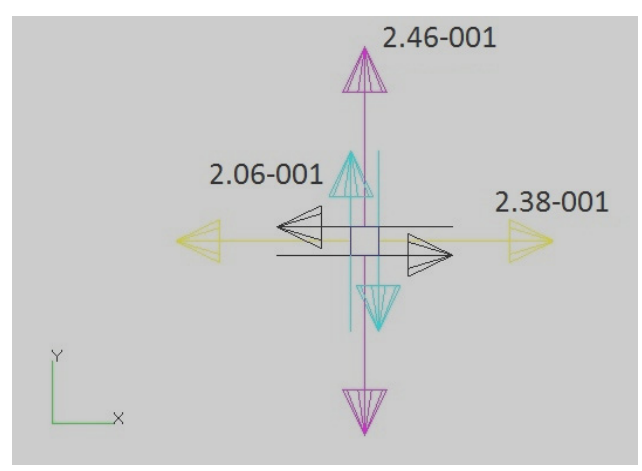

(b)

Figura 85 - Esforços atuantes nas juntas: (a) Compósito 1 (b) Compósito 2.

De posse do valor da tensão atuante neste elemento, foi realizada uma análise falha empregando o Critério de Tsai-Wu para possibilitar a determinação do Fator de Reserva do 
material (Tsai e $\mathrm{Wu}, 1971)$. O valor deste fator foi calculado usando uma ferramenta computacional (software para análise de tensões nas camadas dos materiais compósitos) desenvolvida em MatLab pelo aluno de graduação Marcus Vinícius Angelo - Tabela (20).

Tabela 20 - Fator de Reserva do elemento crítico em compósito da união.

\begin{tabular}{cc}
\hline Compósito & Fator [ N ] \\
\hline $\mathbf{1}(\mathbf{0} / 90)$ & 3351 \\
$\mathbf{2 ( + 4 5 / - 4 5 )}$ & 2473 \\
\hline
\end{tabular}

Ou seja, teoricamente, ao se aplicar uma carga de 3351 N, dar-se-á início a uma microfalha numa dada camada do material para o Compósito 1 e uma carga de $2473 \mathrm{~N}$ para o Compósito 2. Deve-se destacar que a partir desta falha da primeira camada, a resposta do material se torna extremamente não linear e uma análise progressiva do dano faz-se necessária para um valor mais preciso de carga de falha.

Vale ressaltar que, neste trabalho, foi considerada para a análise computacional somente o aspecto linear da junção, partindo-se da origem (carregamento e deslocamento nulos) e do ponto correspondente ao carregamento de $1 \mathrm{~N}$ e seu respectivo deslocamento, obtendo-se, desta maneira, uma função retilínea do comportamento da estrutura e considerando-se como se esta fosse à resposta real ao esforço externo solicitante. No próximo subitem, esta consideração será mostrada graficamente, juntamente com a sobreposição do diagrama obtido experimentalmente.

Nota-se, também, que a área da falha está localizada na região do entorno do furo, como era de se esperar, considerando-se a atuação, nesta região, de uma concentração de tensão mencionada no Capítulo 2, tanto para os materiais metálicos (Figura (7)), quanto para os materiais compósitos (Figura (18)). 
Desta maneira, a partir das análises realizadas via MEF, chegou-se a carga de falha acima apresentada. Isto demonstra que os CDPs estudados via MEF são de grande importância para orientar a realização dos ensaios experimentais, tais como: definição da capacidade da célula de carga; definição dos transdutores de deslocamento; monitoramento da falha na parte de compósito. Alem disso, uma vez validados experimentalmente, fornecem os campos de tensões e deformações em todo o domínio (camada a camada), ao invés de pontos isolados de medição, fato conseguido experimentalmente se usada, por exemplo, uma técnica correlação de imagens na superfície (camada externa). 


\subsection{RESULTADOS EXPERIMENTAIS DAS JUNTAS HÍBRIDAS CRAVADAS}

Em função dos resultados computacionais obtidos e seguindo as orientações descritas no Capítulo 3, foram fabricadas junções híbridas de titânio-compósito com fixadores de monel. Existem dois tipos de placas de compósitos, uma com empilhamento de lâminas a $\left[0^{\circ} / 90^{\circ}\right]_{6}$ (Figura $\left.86(\mathrm{a})\right)$ e outra com empilhamento a $\left[+45^{\circ} /-45^{\circ}\right]_{6}$ (Figura $\left.86(\mathrm{~b})\right)$.

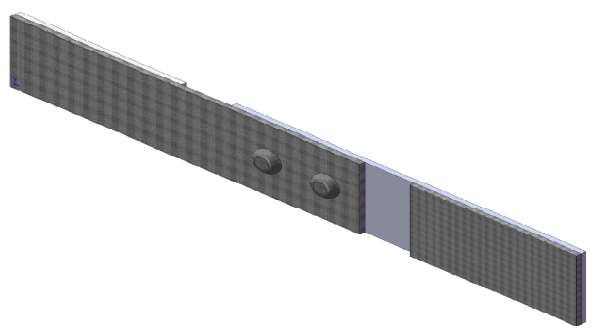

(a)

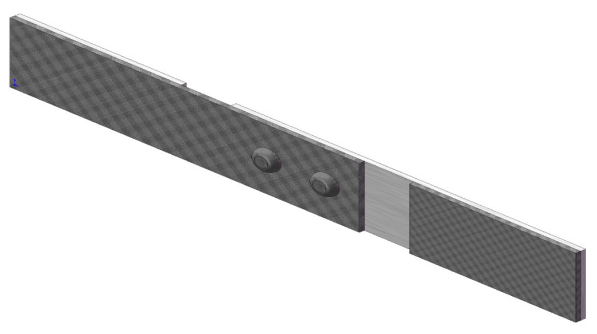

(b)

Figura 86 - CDPs de junções híbridas em metal-compósito $\left[0^{\circ} / 90^{\circ}\right]_{6}$ e $\left[+45^{\circ} /-45^{\circ}\right]_{6}$, respectivamente.

A figura (87) mostra as dimensões mapeadas dos CDPs das juntas que foram fabricados e as dimensões são especificadas na Tabela (21).

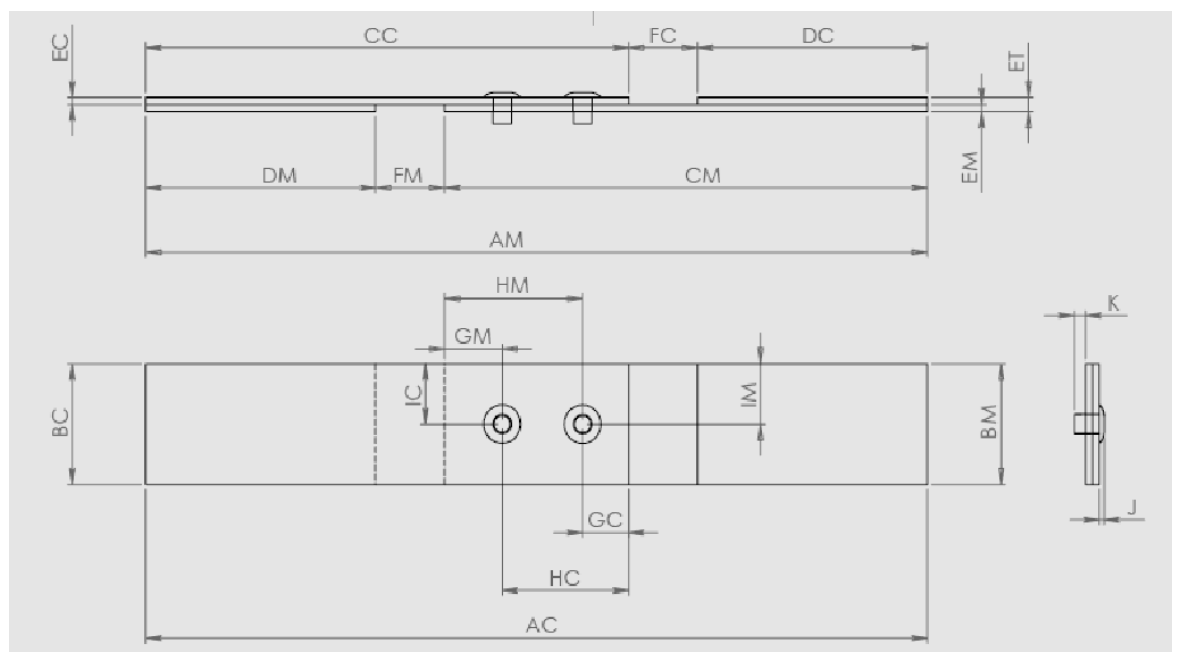

Figura 87 - Dimensões dos CDPs das juntas. 
Tabela 21 - Dimensões das juntas híbridas (onde: $\mathrm{C}$ indica uma medida no compósito; $\mathrm{M}$ indica uma medida no metal e $\mathrm{T}$ indica uma medida total).

\begin{tabular}{|c|c|c|c|c|c|c|c|c|c|c|c|c|c|c|c|c|c|c|c|c|c|}
\hline \multicolumn{110}{|c|}{ ENSAIO 0/90 } \\
\hline CDP & $\begin{array}{c}\text { A.C } \\
(\mathbf{m m})\end{array}$ & $\begin{array}{c}\text { A.M } \\
(\mathbf{m m})\end{array}$ & $\begin{array}{c}\text { B.C } \\
(\mathbf{m m})\end{array}$ & $\begin{array}{c}\text { B.M } \\
(\mathbf{m m})\end{array}$ & $\begin{array}{c}\text { C.C } \\
(\mathbf{m m})\end{array}$ & $\begin{array}{c}\text { C.M } \\
(\mathbf{m m})\end{array}$ & $\begin{array}{c}\text { D.C } \\
(\mathbf{m m})\end{array}$ & $\begin{array}{c}\text { D.M } \\
(\mathbf{m m})\end{array}$ & $\begin{array}{c}\text { E.C } \\
(\mathbf{m m})\end{array}$ & $\begin{array}{c}\text { E.M } \\
(\mathbf{m m})\end{array}$ & $\begin{array}{c}\text { E.T } \\
(\mathbf{m m})\end{array}$ & $\begin{array}{c}\text { F.C } \\
(\mathbf{m m})\end{array}$ & $\begin{array}{c}\text { F.M } \\
(\mathbf{m m})\end{array}$ & $\begin{array}{c}\text { G.C } \\
(\mathbf{m m})\end{array}$ & $\begin{array}{c}\text { G.M } \\
(\mathbf{m m})\end{array}$ & $\begin{array}{c}\text { H.C } \\
(\mathbf{m m})\end{array}$ & $\begin{array}{c}\text { H.M } \\
(\mathbf{m m})\end{array}$ & $\begin{array}{c}\text { I.C } \\
(\mathbf{m m})\end{array}$ & $\begin{array}{c}\text { I.M } \\
(\mathbf{m m})\end{array}$ & $\begin{array}{c}\text { J } \\
(\mathbf{m m})\end{array}$ & $\begin{array}{c}\text { K } \\
(\mathbf{m m})\end{array}$ \\
\hline 1 & 169,0 & 168,0 & 26,0 & 26,0 & 105,0 & 105,5 & 50,0 & 49,0 & 1,5 & 1,3 & 2,8 & 14,0 & 13,5 & 15,0 & 9,0 & 33,0 & 27,5 & 13,0 & 13,5 & 1,0 & 2,5 \\
\hline 2 & 167,5 & 168,0 & 26,5 & 26,0 & 105,0 & 106,5 & 48,0 & 49,0 & 1,5 & 1,3 & 2,8 & 14,5 & 12,5 & 16,0 & 10,0 & 34,0 & 27,0 & 14,0 & 13,5 & 1,0 & 2,5 \\
\hline 3 & 169,0 & 168,5 & 25,5 & 26,0 & 105,5 & 106,0 & 48,5 & 49,0 & 1,5 & 1,3 & 2,8 & 15,0 & 13,5 & 15,0 & 10,0 & 33,0 & 28,5 & 12,0 & 12,5 & 1,0 & 2,5 \\
\hline 4 & 169,0 & 169,0 & 27,0 & 26,0 & 106,0 & 106,0 & 48,5 & 49,5 & 1,5 & 1,3 & 2,8 & 14,5 & 13,5 & 15,5 & 10,0 & 33,5 & 28,0 & 13,5 & 13,0 & 1,0 & 2,5 \\
\hline 5 & 167,0 & 167,0 & 25,0 & 26,0 & 105,0 & 105,5 & 49,0 & 48,5 & 1,5 & 1,3 & 2,8 & 13,0 & 13,0 & 15,0 & 10,5 & 33,0 & 28,0 & 13,0 & 13,5 & 1,0 & 2,5 \\
\hline
\end{tabular}

\begin{tabular}{|c|c|c|c|c|c|c|c|c|c|c|c|c|c|c|c|c|c|c|c|c|c|}
\hline \multicolumn{22}{|c|}{ ENSAIO +45/-45 } \\
\hline CDP & $\begin{array}{c}\text { A.C } \\
(\mathrm{mm})\end{array}$ & $\begin{array}{l}\text { A.M } \\
(\mathrm{mm})\end{array}$ & $\begin{array}{c}\text { B.C } \\
(\mathrm{mm})\end{array}$ & $\begin{array}{c}\text { B.M } \\
(\mathrm{mm})\end{array}$ & $\begin{array}{c}\text { C.C } \\
(\mathrm{mm})\end{array}$ & $\begin{array}{c}\text { C.M } \\
(\mathrm{mm})\end{array}$ & $\begin{array}{c}\text { D.C } \\
(\mathrm{mm})\end{array}$ & $\begin{array}{c}\text { D.M } \\
(\mathrm{mm})\end{array}$ & $\begin{array}{c}\text { E.C } \\
(\mathrm{mm})\end{array}$ & $\begin{array}{l}\text { E.M } \\
(\mathrm{mm})\end{array}$ & $\begin{array}{c}\text { E.T } \\
(\mathrm{mm})\end{array}$ & $\begin{array}{c}\text { F.C } \\
(\mathrm{mm})\end{array}$ & $\begin{array}{c}\text { F.M } \\
(\mathrm{mm})\end{array}$ & $\begin{array}{c}\text { G.C } \\
(\mathrm{mm})\end{array}$ & $\begin{array}{c}\text { G.M } \\
(\mathrm{mm})\end{array}$ & $\begin{array}{c}\text { H.C } \\
(\mathrm{mm})\end{array}$ & $\begin{array}{l}\text { H.M } \\
(\mathrm{mm})\end{array}$ & \begin{tabular}{|} 
I.C \\
$(\mathrm{mm})$
\end{tabular} & $\begin{array}{l}\text { I.M } \\
(\mathrm{mm})\end{array}$ & $\begin{array}{c}\mathrm{J} \\
(\mathrm{mm})\end{array}$ & $\underset{(\mathrm{mm})}{\mathrm{K}}$ \\
\hline 1 & 167,5 & 7,5 & 5,0 & 26,0 & 05,0 & 106,0 & 47,5 & 49, & 1,5 & 1,3 & 2 & 5,0 & 12,5 & 16,0 & 10,0 & 34,0 & 28,0 & 13,0 & 13,0 & 1,0 & 2,5 \\
\hline 2 & 169,0 & 168,5 & 26,0 & 26,0 & 107,0 & 106,5 & 49,0 & 49,0 & 1,5 & 1,3 & 2,8 & 13,0 & 13,0 & 17,0 & 10,0 & 35,0 & 28,0 & 14,5 & 12,5 & 1,0 & 2,5 \\
\hline 3 & 169,0 & 169,0 & 25,0 & 26,0 & 105,0 & 105,0 & 45,0 & 40,3 & $1, J$ & 1, & 2, & 15,0 & | כ, & 14,0 & 10,0 & 32,5 & 28,0 & 13,0 & 14,0 & 1,0 & 2,5 \\
\hline 4 & 169,0 & 168,5 & 25,0 & 26,0 & 104,0 & 106,0 & 48,0 & 48,5 & 1,5 & 1,3 & 2,8 & 17,0 & 14,0 & 13,0 & 10,0 & 31,0 & 28,0 & 12,0 & 13,0 & 1,0 & 2,5 \\
\hline 5 & 68,0 & 168,0 & 5,0 & 26,0 & 106,0 & 105,0 & 48,5 & 50,0 & 1,5 & 1,3 & 2,8 & 13,5 & 13,0 & 15,5 & 10,0 & 34,0 & 27,5 & 12,0 & 12,5 & 1,0 & 2,5 \\
\hline
\end{tabular}

Assim, desenvolveu-se os ensaios tanto para as configurações $\left[0^{\circ} / 90^{\circ}\right]_{6}$ (Compósito 1) e $\left[-45^{\circ} / 45^{\circ}\right]_{6}$ (Compósito 2) sendo que as falhas ocorreram na parte em compósito, como previsto nas simulações via MEF. A Figura (88) mostra o aspecto geral das falhas para as configurações $\left[0^{\circ} / 90^{\circ}\right]_{6}$ e o aspecto geral das falhas para as configurações $\left[-45^{\circ} /+45^{\circ}\right]_{6}$, respectivamente.
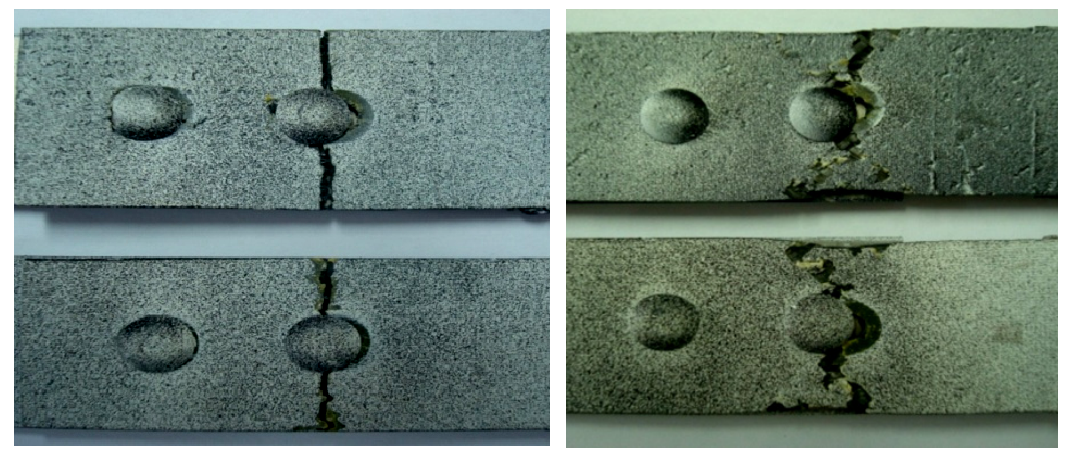

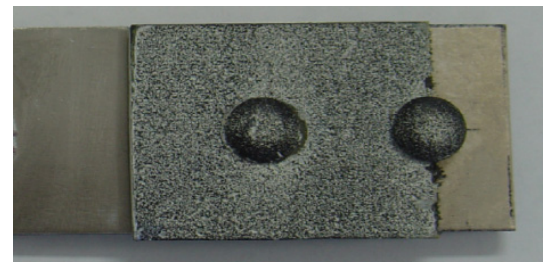

(a)

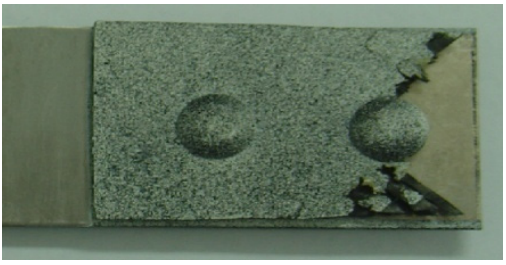

(b)

Figura 88 - Detalhamento da falha na parte em compósito da junta: (a) $0^{\circ} / 90^{\circ}$ e (b) $+45^{\circ} /-45^{\circ}$. 
Analisando-se as falhas, primeiramente a $0^{\circ} / 90^{\circ}$, pôde-se observar que ocorreram de modo semelhante em todos os CDPs. Notadamente, estas falhas são do tipo multimodo, devido à segregação do material em todos os seus eixos globais. De acordo com o que foi visto anteriormente (Capítulo 3), tratam-se de falhas pela interação de "bearing x bypass" (multimodo) tendo a ruptura ocorrida por tração na área crítica (“net-tension”).

Tomando-se como exemplo o CDP 1 do ensaio 0/90, tem-se que a Figura (89(a)) mostra uma deformação permanente devido à tensão de "bearing" na parede do furo, resultando em um formato oblongo, enquanto que a Figura (89(b)) demonstra que a fratura ocorreu com a separação em todas as direções globais do material devido à tensão de "bypass" na forma de tração.

Projetor de Perfil (10x)

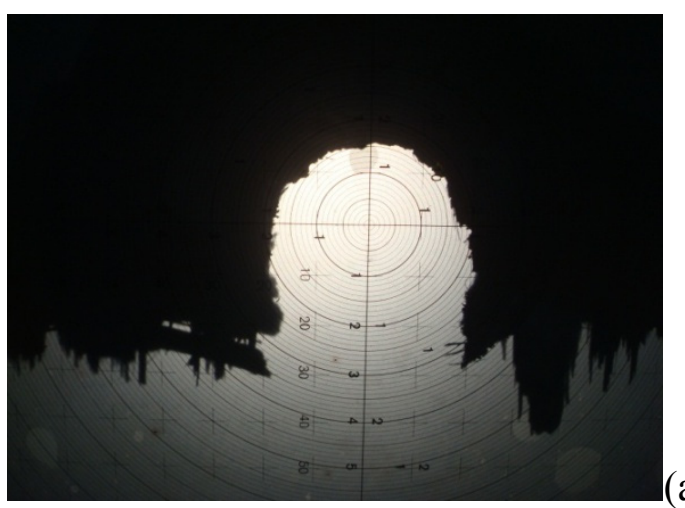

Maquina de Ensaio (100KN)

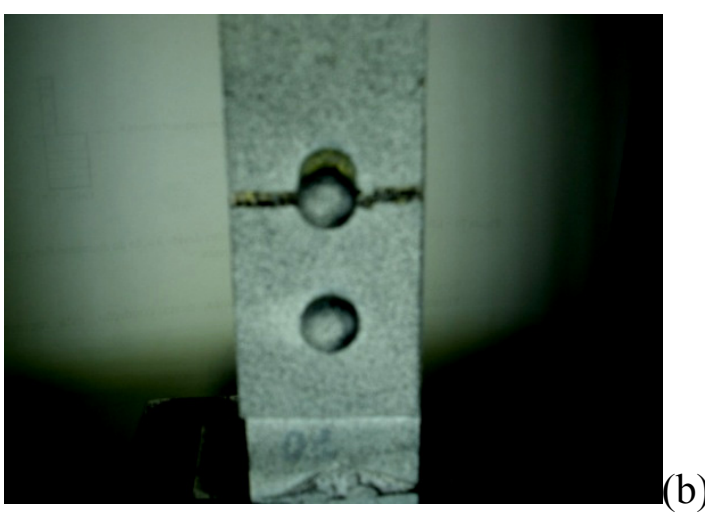

Figura 89 - (a) Deformação lateral da parede do furo devido à tensão de "bearing" - (b) Ruptura do material na parte em compósito devido à tensão de "bypass" na forma de tração (CDP 1 -0/90).

Pode-se afirmar então que a codificação do modo de falha, de acordo com o padrão ASTM D5961/D5961M (2007), para todos os CDPs ensaiados a 0\%/90 é: M(BL)1I, ou seja, falha multimodo pela ação de "bearing" na parede do furo, combinada com a ruptura pela ação da tensão de "bypass" na forma de tração ("net-tension”), no primeiro furo da porção em compósito da junção e localizada na área crítica da união. 
Além disto, existem fatores também que influenciam na resistência ao "bearing" da junção. Como visto anteriormente, um destes fatores é o $f_{1}$ (Capítulo 2; fig. 29) que reduz a resistência ao "bearing" quando as uniões apresentarem uma relação $\mathrm{D} / \mathrm{t} \leq 2,2$. As juntas ensaiadas no presente estudo possuem a relação $\mathrm{D} / \mathrm{t}=2,44$. O outro fator é o $\mathrm{f}_{2}$ (Capítulo 2; fig. 30) que reduz a resistência ao "bearing" quando os materiais dos calços dos CDPs não são rígidos e estiverem acima das tolerâncias dimensionais apropriadas. Os calços dos CDPs ensaiados neste trabalho foram fabricados em alumínio e em compósito e obedeceram as tolerâncias especificadas para juntas aeronáuticas. Conclui-se então que, neste caso, estes fatores não exerceram influência na resistência ao "bearing".

Torna-se também importante o conhecimento das outras propriedades mecânicas das junções, utilizando-se, assim, o Método do Módulo Secundário, mencionado no (Capítulo 2; fig. 8). Para que esta propriedade seja determinada de forma consistente, os furos das placas foram confeccionados com diâmetros variando de $3,30-3,35 \mathrm{~mm}$, padronizados para os diâmetros dos corpos dos fixadores de $3,175 \mathrm{~mm}(1 / 8$ "), atendendo aos requisitos estabelecidos na Tabela (2). Como visto no Capítulo 2, o Método do Módulo Secundário não especifica um procedimento para a determinação do valor da carga de descarregamento da junção. Neste trabalho, o Grupo de Estrutura Aeronáutica adotou o seguinte procedimento:

Realizou-se um ensaio monotônico para estimar o "módulo elástico" da junção;

Identificou-se o ponto de deslocamento $0,04 d$ (d é o diâmetro do furo da placa) no eixo das abscissas (deslocamento da estrutura);

Por este ponto traçou-se uma reta paralela à estimativa do "modulo elástico"; 
$>$ Quando esta reta cruzou a curva do ensaio, determinou-se o valor da carga mínima de descarregamento;

Optou-se, então, que o início do descarregamento da união ocorra para um valor ligeiramente acima do mínimo determinado, a fim de se garantir que o ciclo do descarregamento e o re-carregamento se desse posteriormente ao ponto de deslocamento 0,04d (Figura (90)).

A Figura (90) ilustra a seqüência acima mencionada.

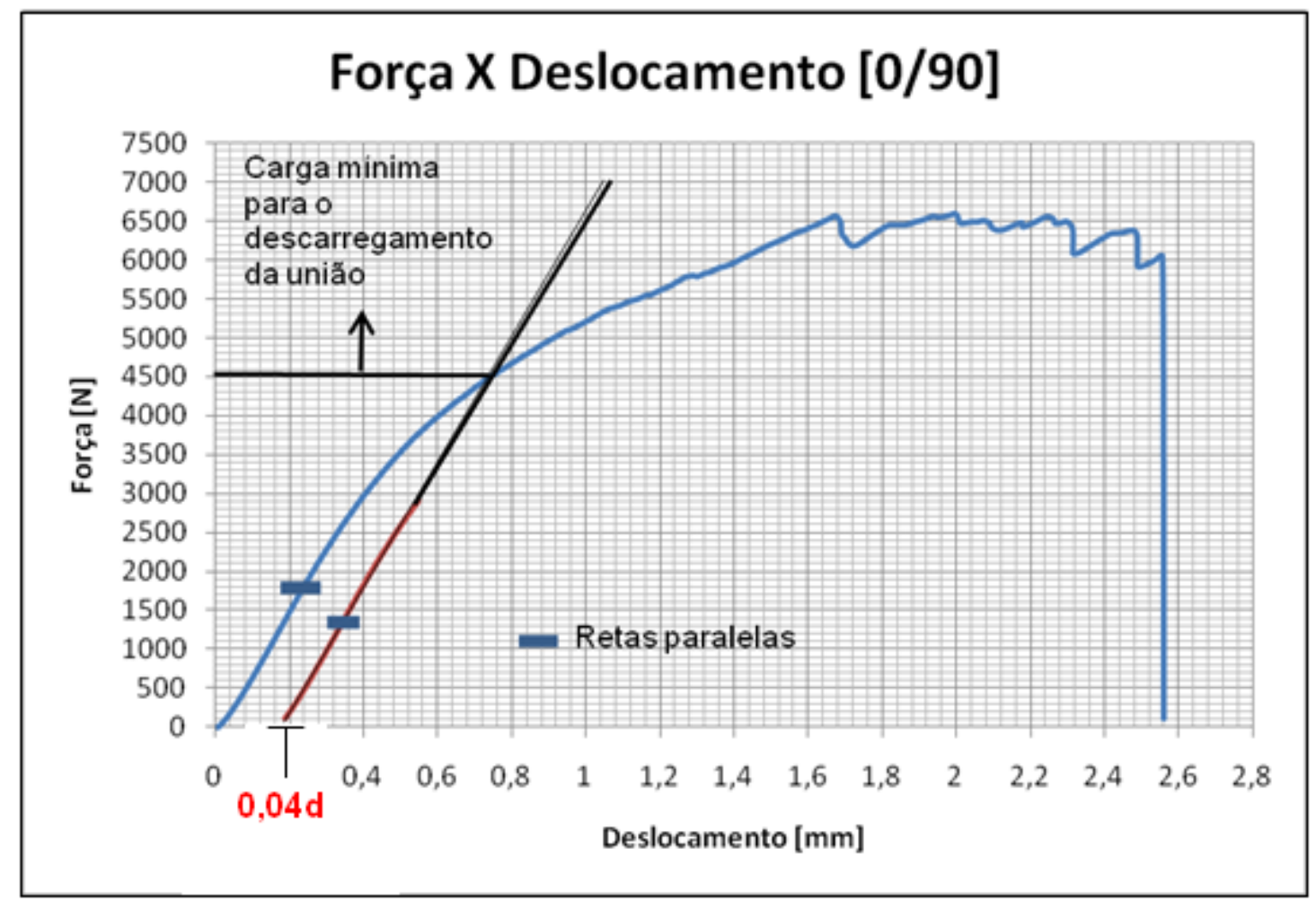

Figura 90 - Procedimento para a determinação da carga mínima de descarregamento e carregamento da junção - CDP Ti - Compósito $\left[0^{\circ} / 90^{\circ}\right]_{6}$.

Para o CDP1 (Compósito 1) a carga admissível (Fa), bem como a carga última ( $\mathrm{P}^{\mathrm{max}}$ ) foram indicadas na Figura (91(a)) e o módulo de elasticidade $\left(\mathrm{E}_{\mathrm{jh}}\right)$ está indicado na Figura (91(b)). 


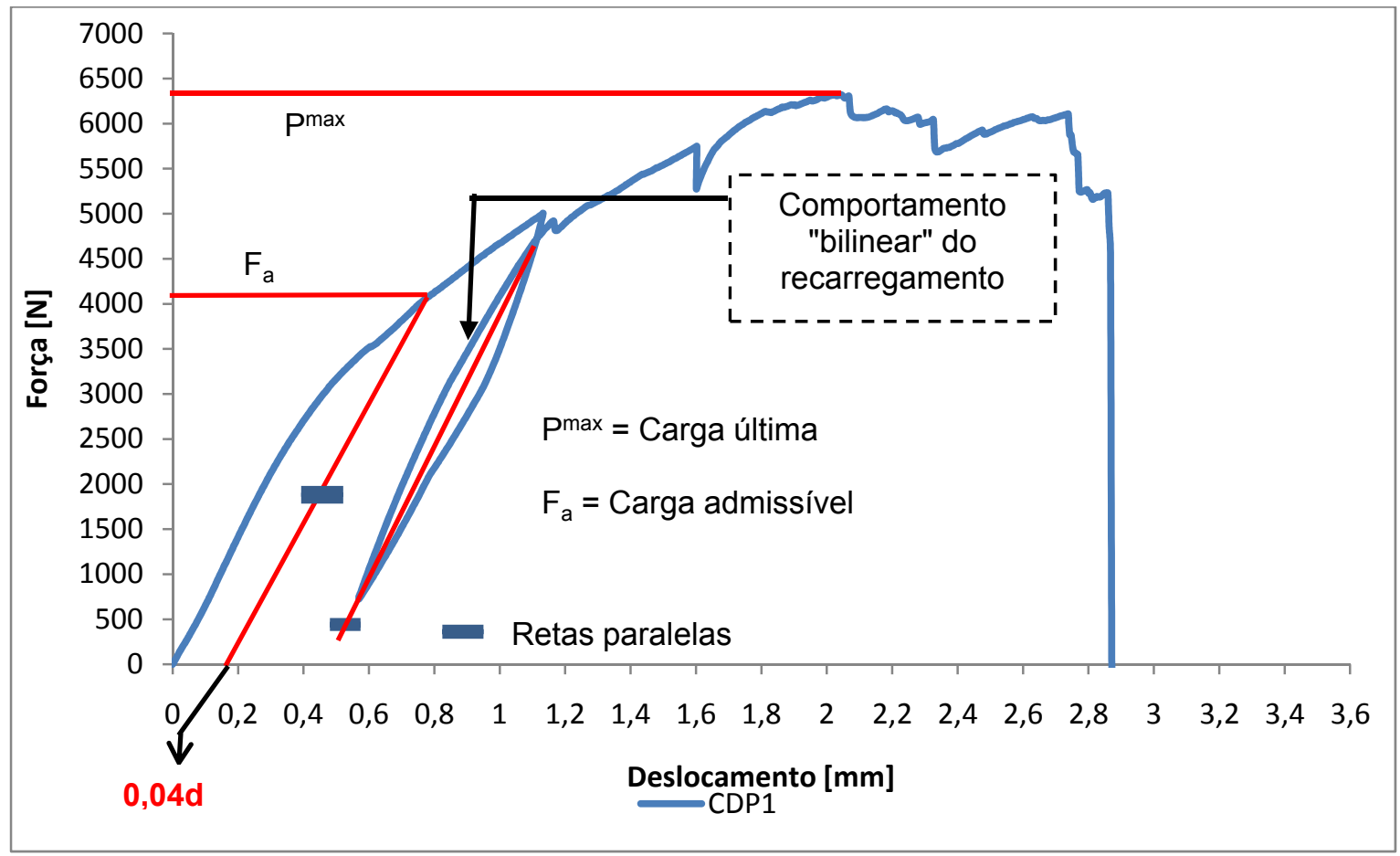

(a)

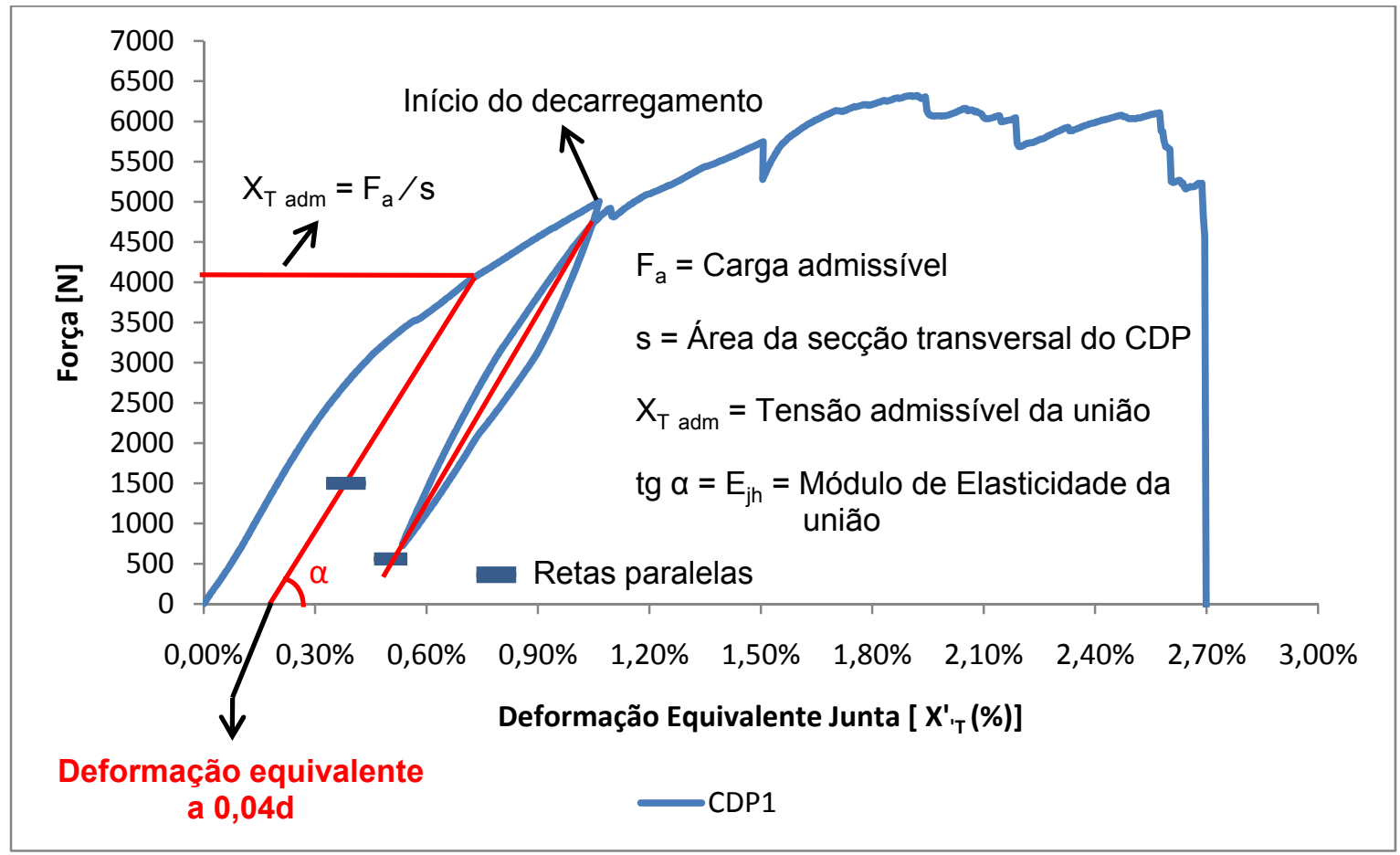

(b)

Figura 91 (a) e (b) - Propriedades mecânicas da união Ti - Compósito $\left[0^{\circ} / 90^{\circ}\right]_{6}$ obtidas através do Método do Módulo Secundário. 
Neste trabalho, foi adotada a metodologia de Herakovich (1998), onde o autor utiliza o método da secante para determinar propriedades em ensaios cíclicos de material compósito. Nota-se que os diagramas resultantes dos ensaios apresentaram um comportamento "bilinear" por ocasião do re-carregamento da união. De acordo com o princípio acima mencionado, traçou-se uma secante entre as curvas originadas pelo descarregamento e re-carregamento da união. Foi, então, extraída uma reta paralela junto a esta secante e transladada até encontrar o eixo das abscissas (deslocamento) correspondente ao valor de $0,04 \mathrm{~d}$, em conformidade com o especificado pelo Método do Módulo Secundário, sendo que, desta forma, foi possível a determinação das propriedades das estruturas híbridas.

Sendo a área (s) do CDP1 (Compósito 1) igual a 33,15 $\mathrm{mm}^{2}$ (a espessura real dos CDPs deve ser considerada como sendo 1,3mm) e utilizando-se as equações mencionadas no subtópico 3.2.2, tem-se que:

$$
\begin{aligned}
& X_{\mathrm{T} a d m}=\frac{F a}{s}=123 M P a \rightarrow \text { Tensão admissível da união } \\
& X_{T \max }=\frac{P^{\max }}{s}=191 M P a \rightarrow \text { Tensão de ruptura da união } \\
& E_{j h}=\frac{\Delta X_{T}}{\Delta X_{T}^{\prime}}=246 M P a \rightarrow \text { Módulo elástico da união }
\end{aligned}
$$

Considerando-se que o CDP1 (Compósito 1) foi ensaiado tomando-se o deslocamento como sendo o do travessão da máquina de ensaio, passa-se a analisar o CDP5 (Compósito 1), cujo deslocamento foi medido com o "Clip-Gage", diretamente na sua extensão.

Analogamente, tem-se que:

$$
X_{T \text { adm }}=144 \mathrm{MPa}
$$




$$
\begin{aligned}
& X_{T \text { max }}=192 M P a \\
& E_{j h}=266 M P a
\end{aligned}
$$

Segue o comportamento individual apresentado pelas uniões $\mathrm{Ti}$ - Compósito $\left[0^{\circ} / 90^{\circ}\right]_{6}$, conforme mostra as Figura (92 (a,b,c e d)).
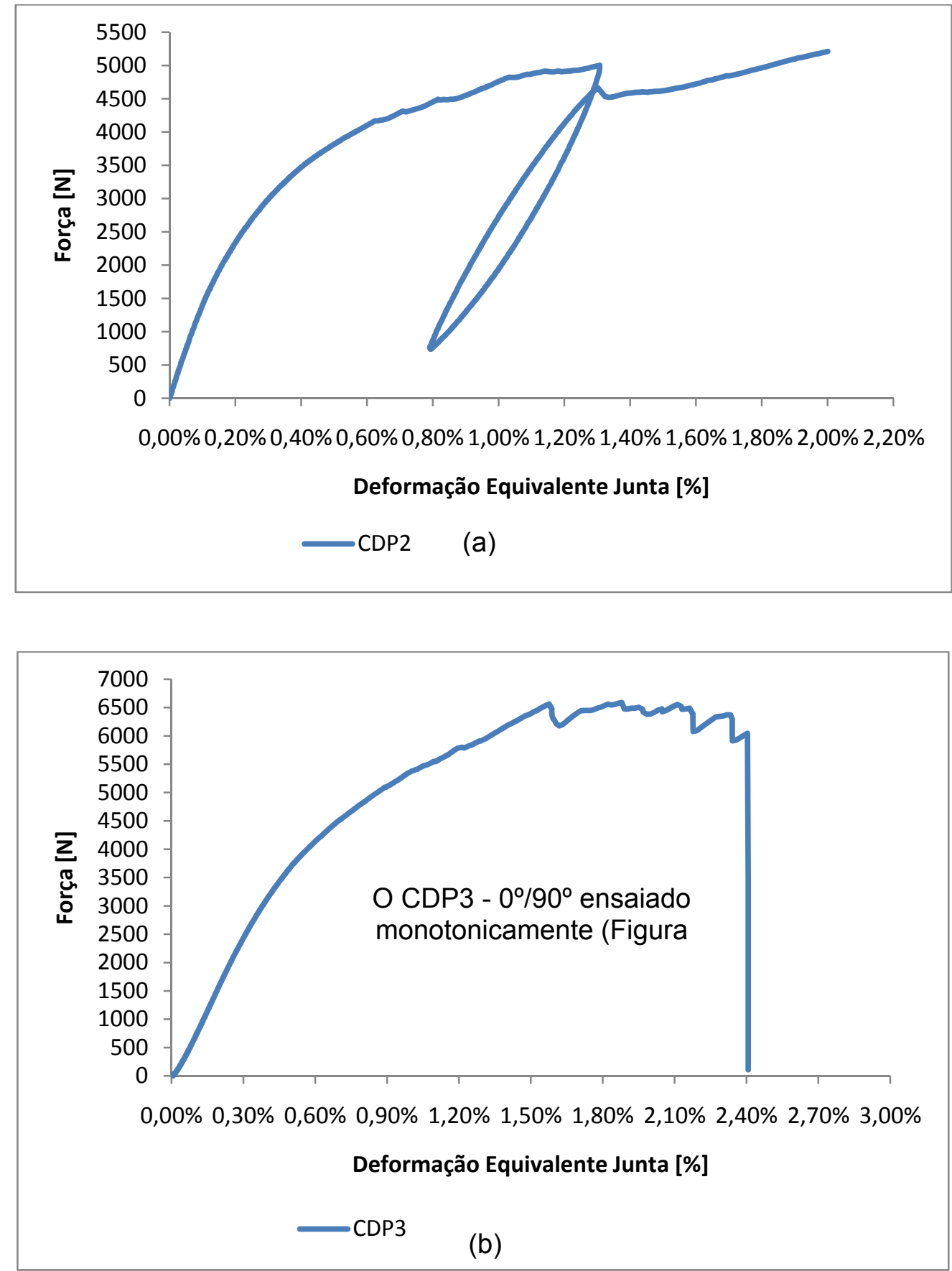

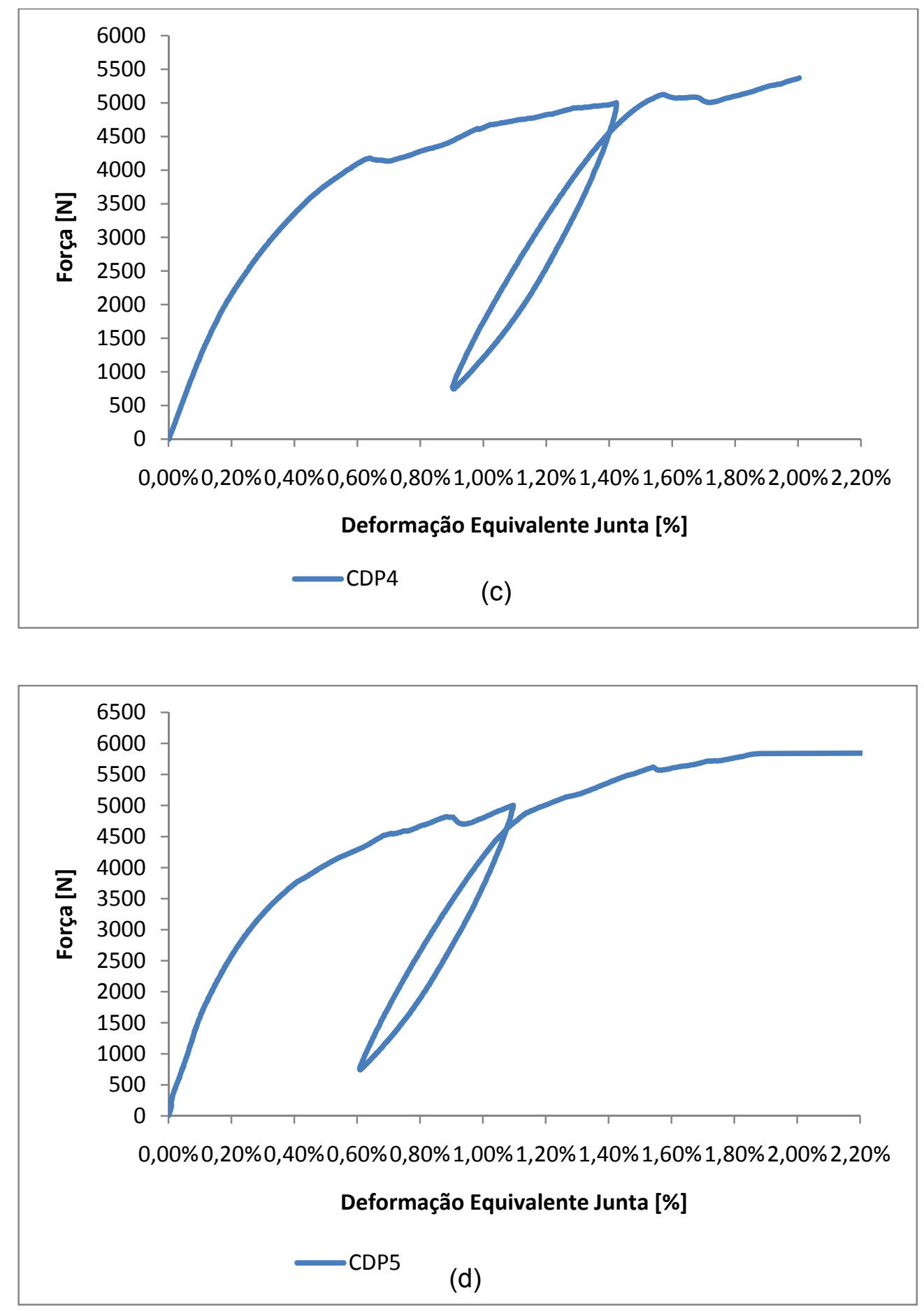

Figura 92 - Curvas da tensão x deformação individual das uniões Ti - Compósito $\left[0^{\circ} / 90^{\circ}\right]_{6}$.

O comportamento de todos os CDPs (Compósito 1) está representado de forma comparativa na Figura (93). 


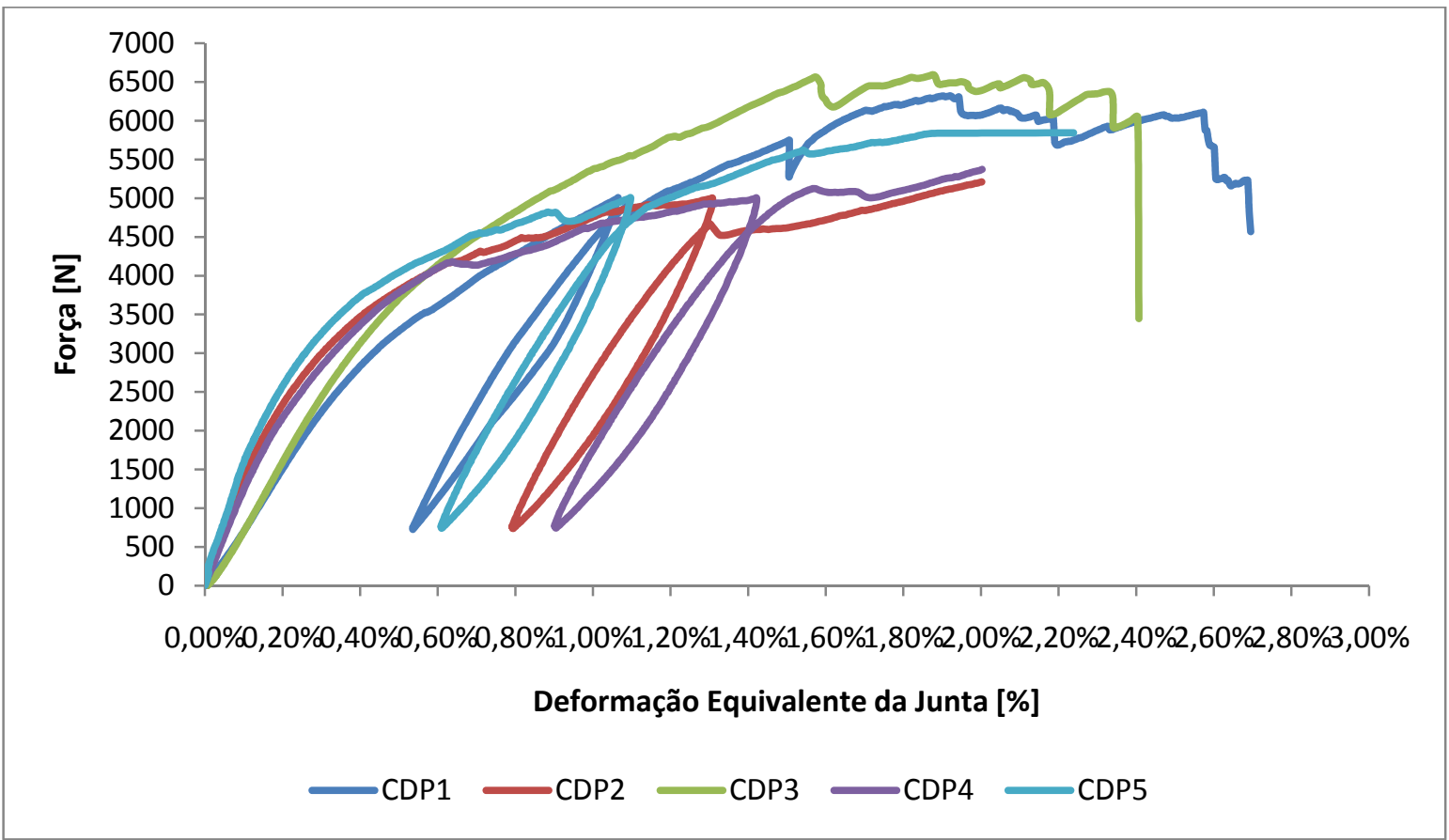

Figura 93 - Curva força x deformação do ensaio global das junções Ti - Compósito $\left[0^{\circ} / 90^{\circ}\right]_{6}$.

O CDPs medidos com o dispositivo "Clip-Gage" representam valores das propriedades mais próximo do real quando comparados com os CDPs medidos através do deslocamento do travessão da máquina de ensaios. Isto se deve ao fato da existência de folgas nos fusos e assessórios que conectam o CDP ao travessão. Desta forma, desconsiderou-se o resultado do CDP1, e, esta diferença é evidenciada na Tabela (22).

Tabela 22 - Diferença na forma da obtenção dos valores das propriedades dos CDPs $0^{\circ} / 90^{\circ}$.

\begin{tabular}{cccc}
\hline CDP & $\bar{X}_{\mathrm{T} a d m}$ & $\bar{X}_{\mathrm{T} \max }$ & $\bar{E}_{j h}$ \\
\hline Travessão & $123 \mathrm{MPa}$ & $191 \mathrm{MPa}$ & $246 \mathrm{MPa}$ \\
\hline “Clip-Gage” & $144 \mathrm{MPa}$ & $192 \mathrm{MPa}$ & $266 \mathrm{MPa}$ \\
\hline
\end{tabular}


Da mesma forma, analisando-se as falhas nos CDPs Ti - Compósito $\left[-45^{\circ} /+45^{\circ}\right]_{6}$, pôde-se observar que ocorreram de modo semelhante. Notadamente, estas falhas são devidas ao efeito da tensão de "bearing", pois não ocorreu uma segregação total nos eixos globais do laminado. Analogamente ao procedimento anterior, conclui-se que as falhas são do tipo trinca progressiva ("tear-out"). Tomou-se como exemplo o CDP1 (Compósito 2: $+45^{\circ} /-45^{\circ}$ ), onde a Figura (94(a)) mostra uma deformação permanente devido à tensão de "bearing" na parede do furo, resultando em um formato oblongo, enquanto que a Figura (94(b)) demonstra que a fratura ocorreu sem a separação em todas as direções globais do material devido, exclusivamente, a ação do efeito da tensão de "bearing".

Projetor de Perfil (10x)

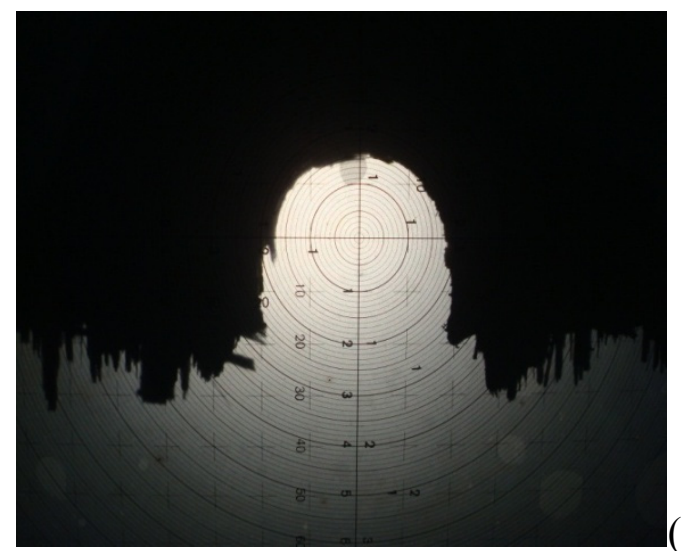

Maquina de Ensaio (100KN)

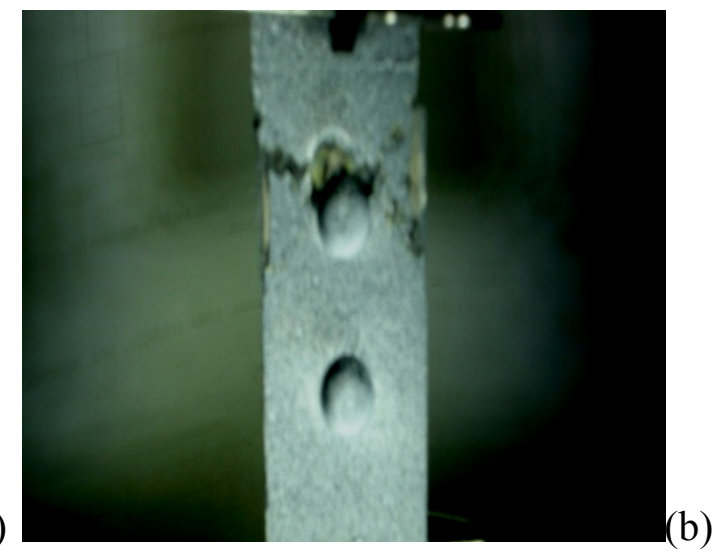

Figura 94 - (a) Deformação permanente na parede lateral do furo pelo efeito "bearing" - (b) Ruptura na parte em compósito devido à ação de "bearing" (CDP 1 - [+/-45 $\left.]_{6}\right)$.

Pode-se afirmar então que a codificação do modo de falha, de acordo com o padrão ASTM D5961/D5961M (2007), para todos os CDPs ensaiados a $\left[-45^{\circ} /+45^{\circ}\right]_{6}$ é: T1I, ou seja, falha pela ação de "bearing" na parede do furo, ocasionando trincas que se propagaram até as extremidades dos CDPs (“tear-out"), no primeiro furo da porção em compósito da junção e localizada na área crítica da união. 
Igualmente, procedeu-se a uma análise das propriedades mecânicas do CDP1 (Compósito 2) onde todos os espécimes desta classe foram ensaiados com o "Clip-Gage", como mostra a Figura (95 (a) e (b)). A área dos CDPs permanece a mesma $\left(33,15 \mathrm{~mm}^{2}\right)$.
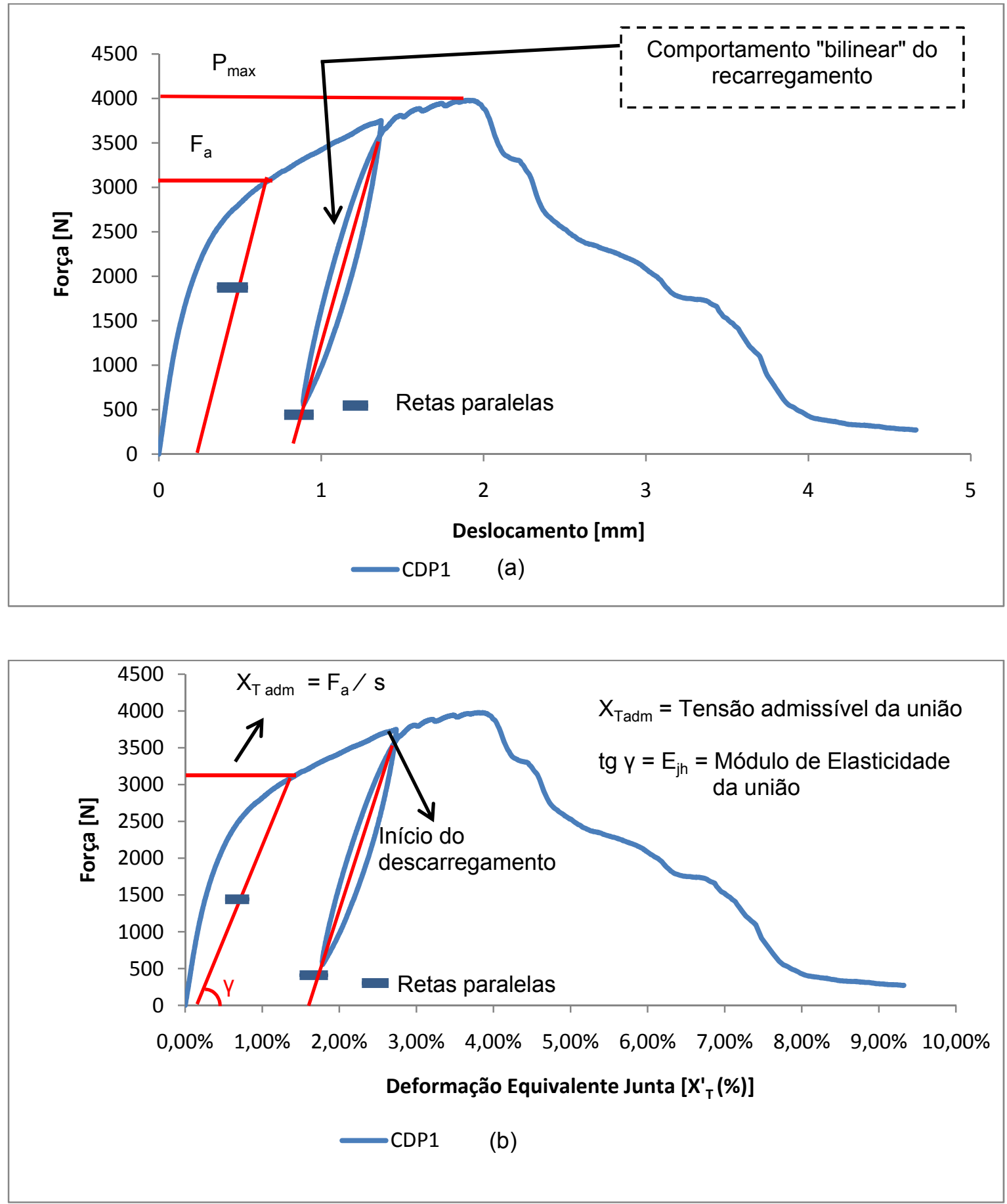

Figura 95 - Propriedades mecânicas da união Ti-Compósito $\left[ \pm 45^{\circ}\right]_{6}$ obtidas através do Método do Módulo Secundário. 
Procedendo-se de forma análoga ao cálculo das propriedades mecânicas, tem-se que:

$$
\begin{aligned}
& X_{\text {Tadm }}=\frac{F a}{s}=93,5 \mathrm{MPa} \rightarrow \text { Tensão admissível da união } \\
& X_{T \max }=\frac{P^{\max }}{s}=121 \mathrm{MPa} \rightarrow \text { Tensão de ruptura da união } \\
& E_{j h}=\frac{\Delta X_{T}}{\Delta X_{T}^{\prime}}=104 \mathrm{MPa} \rightarrow \text { Módulo elástico da união }
\end{aligned}
$$

A análise comparativa entre as duas configurações mostra que os CDPs (Compósito 2: $-45^{\circ} / 45^{\circ}$ ) apresentam propriedades mecânicas muito inferiores em relação aos CDPs (Compósito 1: $0^{\circ} / 90^{\circ}$ ), como ficou evidenciado através dos ensaios de caracterização entre ambos. Exemplificando, a rigidez das junções com CDPs $+45^{\circ} /-45^{\circ}$ corresponde a menos de $50 \%$ da rigidez encontrada nas junções com CDPs $0^{\circ} / 90^{\circ}$ e, ainda, a média de todas as cargas de rupturas são 4120N e 6196N, respectivamente. A Tabela (23) ilustra estas diferenças.

Tabela 23- Variação das propriedades das junções devido ao empilhamento das camadas.

$\begin{array}{ccc}\begin{array}{c}\text { Propriedades das junções } \\ \text { híbridas ensaiadas pelo } \\ \text { Método do Módulo } \\ \text { Secundário }\end{array} & \text { Ti - Compósito } & \text { Ti - Compósito } \\ \text { Tensão Ruptura (MPa) } & {\left[0^{\circ} / 90^{\circ}\right]_{6}} & {\left[+45^{\circ} /-45^{\circ}\right]_{6}} \\ \text { Tensão Admissível (MPa) } & 192 & \mathbf{1 2 1} \\ \text { Módulo de Elasticidade (MPa) } & \mathbf{1 4 4} & \mathbf{9 3 , 5} \\ & \mathbf{2 6 6} & \mathbf{1 0 4}\end{array}$

Isto demonstra nitidamente a influência do empilhamento do laminado tanto na rigidez como na resistência da junção, alterando, principalmente, algumas características específicas relacionadas ao modo de falha. 
Segue o comportamento individual apresentado pelas uniões $\mathrm{Ti}$ - Compósito $\left[+45^{\circ} /-45^{\circ}\right]_{6}$, conforme mostra as Figura (96 (a,b,c e d)).
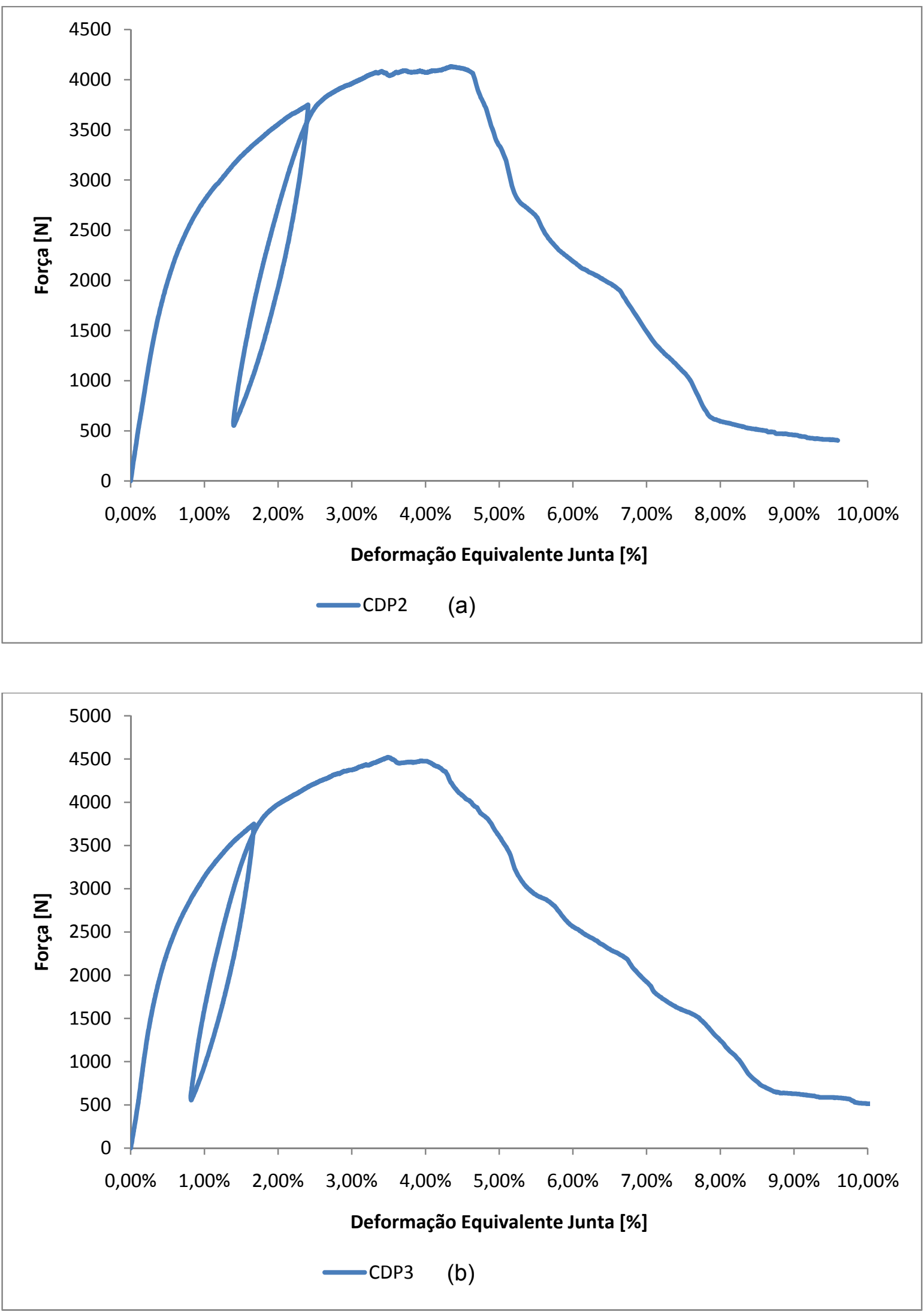

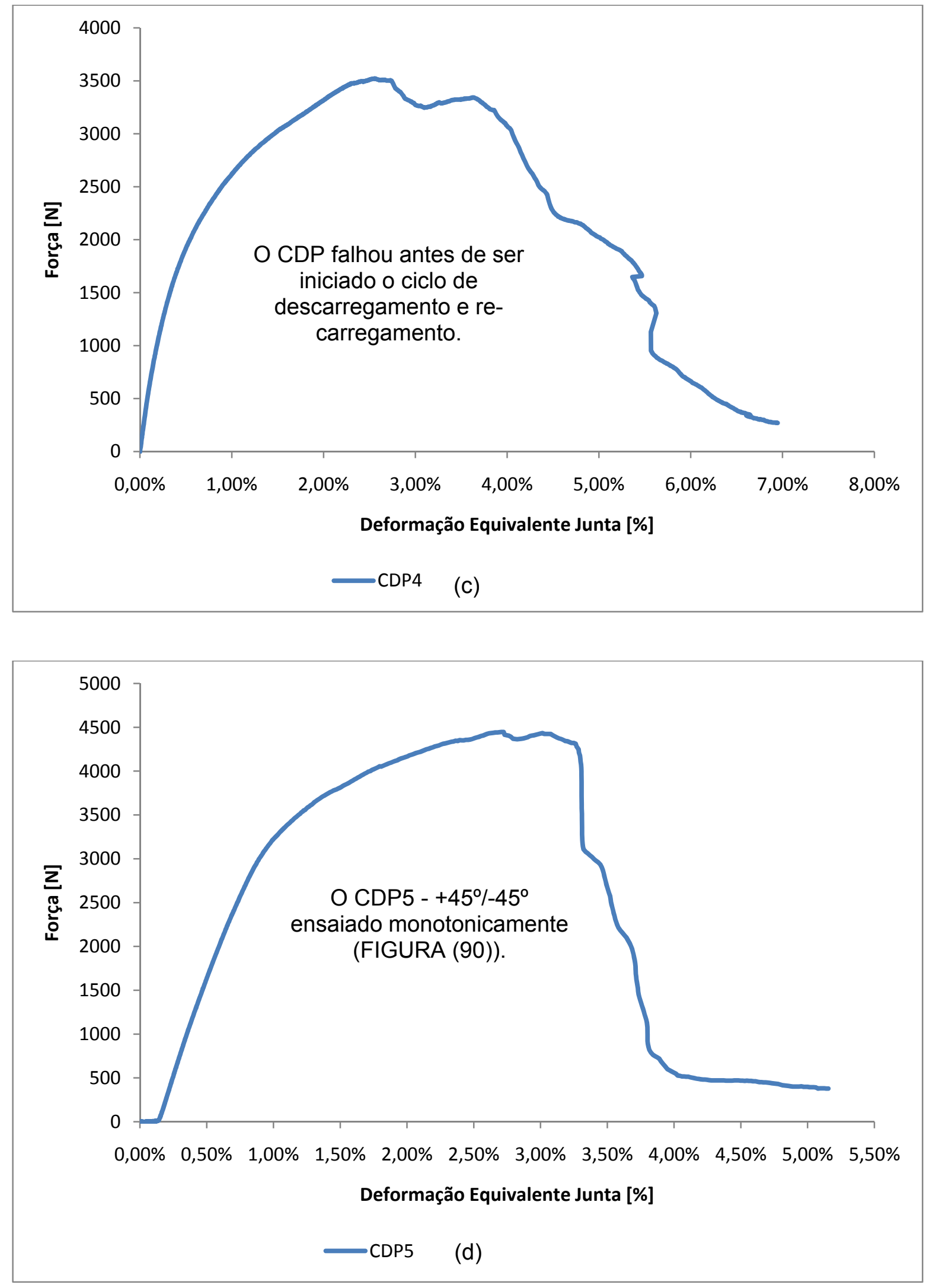

Figura 96 - Curvas da tensão x deformação individual das uniões Ti - Compósito $\left[+45^{\circ} / 45^{\circ}\right]_{6}$. 
O comportamento de todos os CDPs (Compósito 2) está representado de forma comparativa na Figura (97).

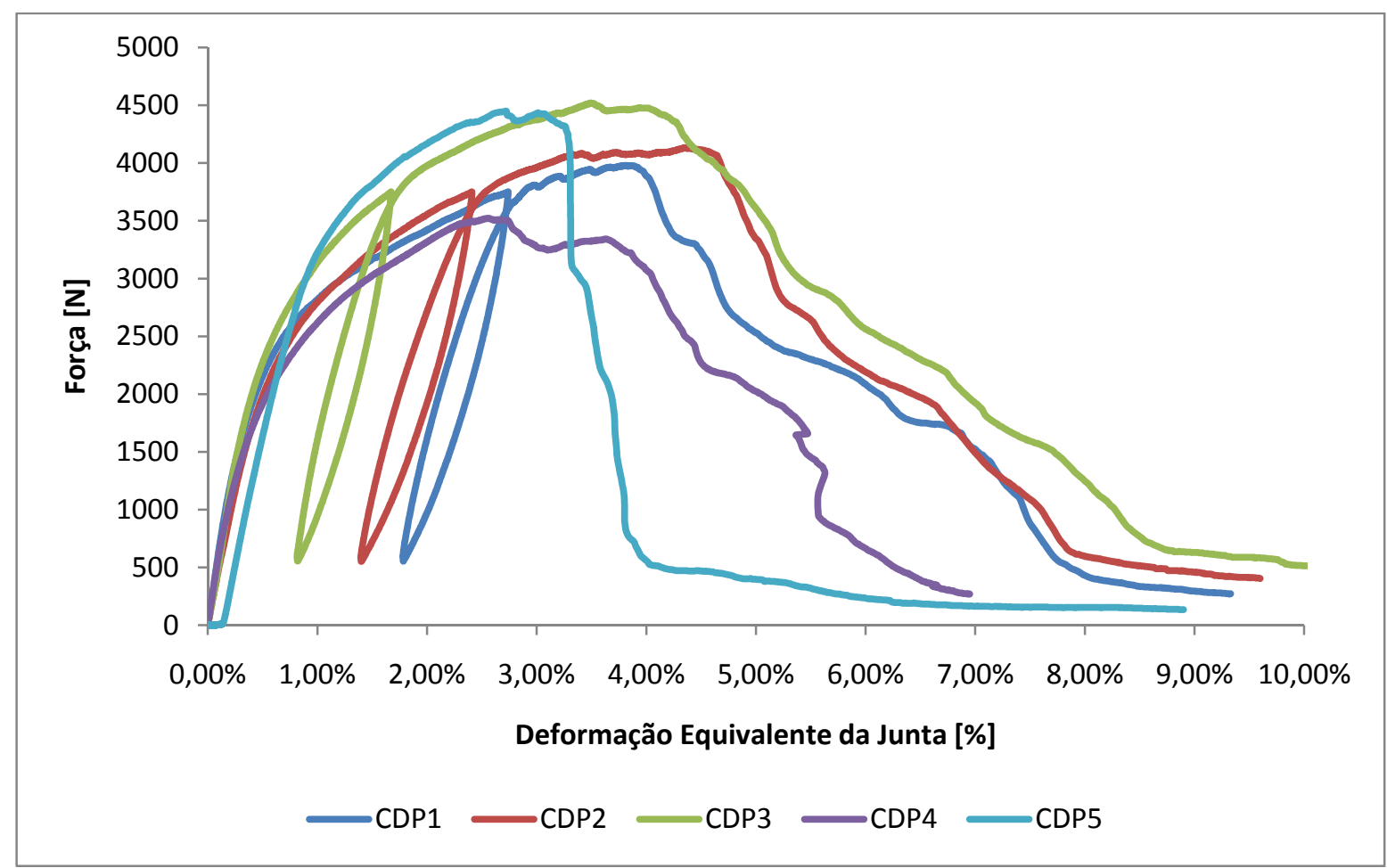

Figura 97 - Curva força $\mathrm{x}$ deformação do ensaio das junções Ti - Compósito $\left[-45^{\circ} /+45^{\circ}\right]_{6}$.

Os ensaios demonstraram que não ocorreram falhas por cisalhamento em ambas as configurações (Capítulo 2; fig. 35), o que era esperado, pois os CDPs foram confeccionados com uma distância de borda $(\mathrm{e})$ superior à mínima especificada para projeto $(\mathrm{e} / \mathrm{D}=3)$, como demonstra a (Tabela 21 - cotas “GC”).

Durante os ensaios notou-se, também, que o CDP $2\left(0^{\circ} / 90^{\circ}\right)$ apresentou uma separação das partes na região da união Figura (98), indicando a existência de desalinhamento no carregamento, originando um Momento Fletor Secundário (Capítulo 2; fig. 25). 
Projetor de Perfil (10x) - CDP 90.2

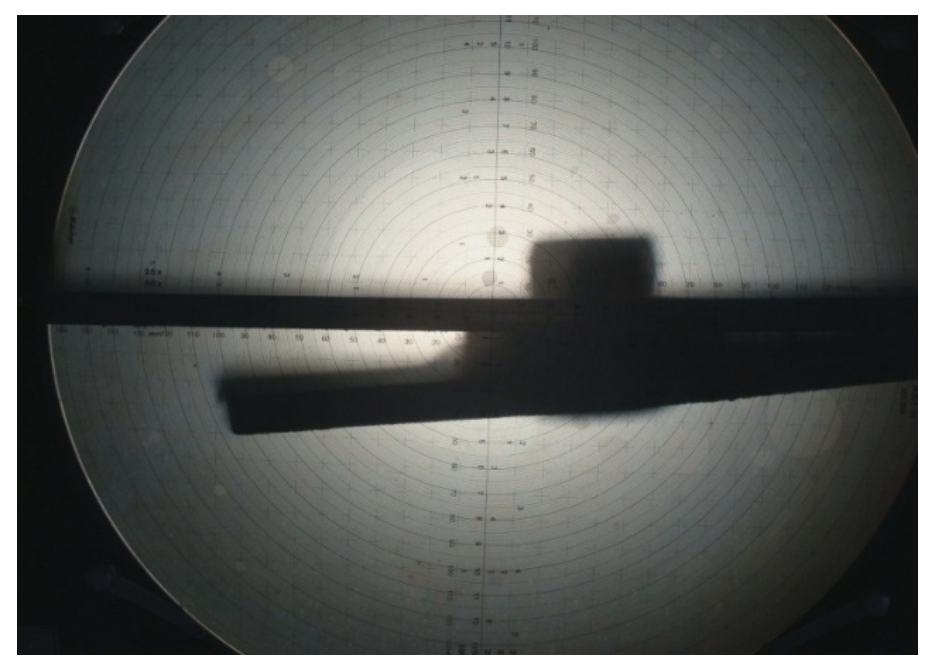

Figura 98 - Falha não prevista observada em um determinado CDP Ti - Compósito $\left[0^{\circ} / 90^{\circ}\right]$.

Os resultados dos ensaios reportaram as propriedades das juntas, considerando-se que foram utilizados os parâmetros da literatura para o titânio e os obtidos nos ensaios de caracterização dos compósitos. No entanto, para uniões fixadas mecanicamente, deve-se analisar, ainda, o efeito da existência dos fatores de concentração de tensão, tanto para a porção metálica quanto para a porção em compósito, atuantes na área crítica da união devido à presença do furo do fixador (Capítulo 2; fig. 7 e fig. 18, respectivamente), quando estas formam as partes integrantes de uma junção híbrida metal-compósito. Como visto no Capítulo 2, as tensões $\sigma^{\prime}{ }_{M}$, referente ao compósito, é uma função da tensão atuante ( $\left.\sigma^{\prime}\right)$ na união, assim como dos valores de tensões na parte metálica $\left(\sigma_{\mathrm{m}}^{\prime}\right)$. A título de exemplo, foi considerada uma tensão atuante qualquer, a qual, obviamente, deve ser inferior a tensão admissível da junção (previamente determinada), para a demonstração da influência dos fatores de concentração de tensões presentes em uma união híbrida metal-compósito, conforme mostra a Tabela (24). 


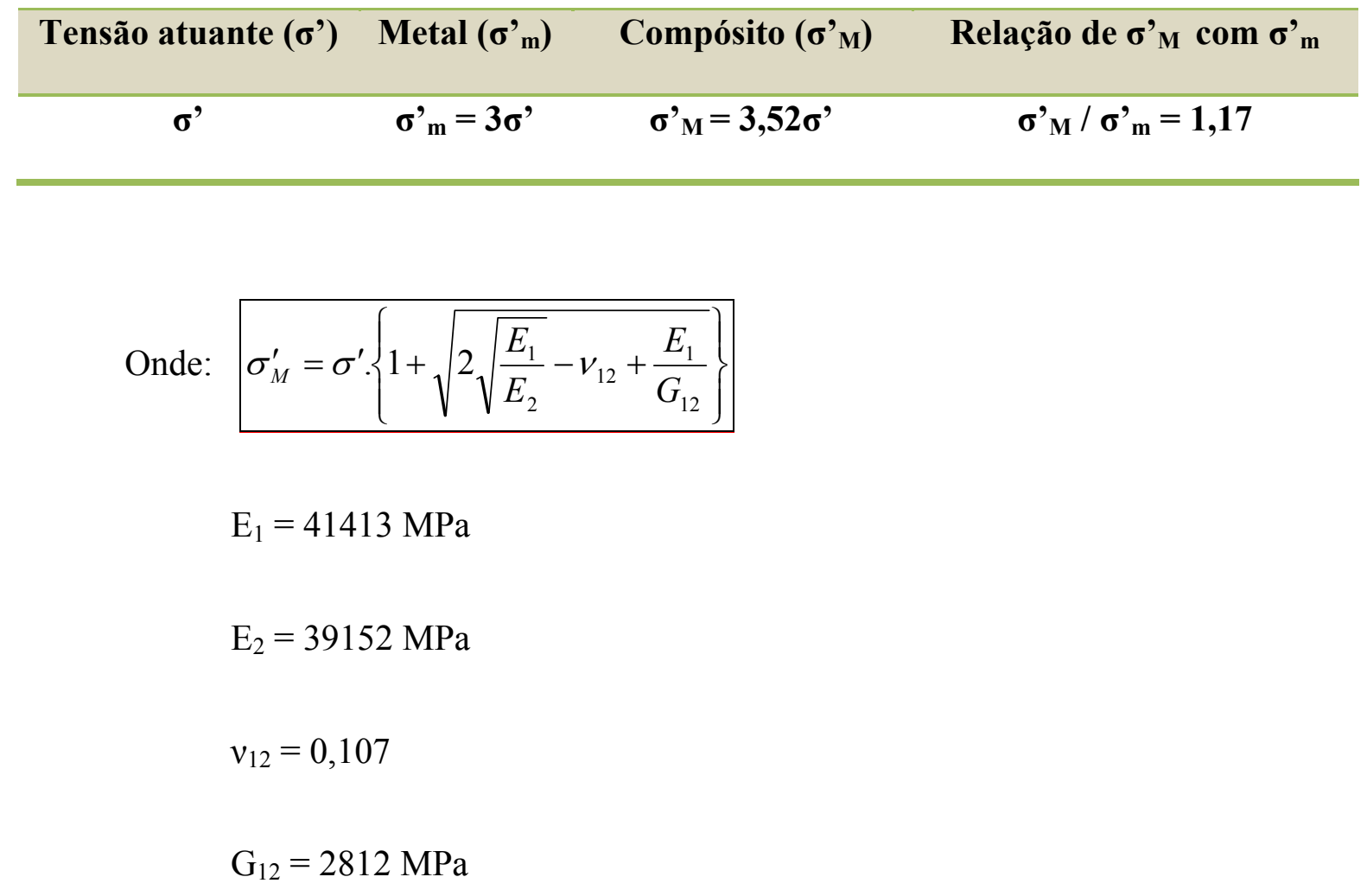

Fazendo-se os cálculos, tem-se que:

$$
\sigma^{\prime}{ }_{M}=3,52 \sigma^{\prime}
$$

Desta forma, comprova-se que a parte em compósito é a mais crítica, considerando-se as junções híbridas objeto deste estudo. Por outro lado, define-se, ainda, uma relação entre as tensões máximas admissíveis atuantes na porção metálica e na porção em compósito, respectivamente. Para uma chapa metálica o fator de concentração de tensões na extremidade do furo equivale ao triplo da tensão atuante na área crítica (Tabela 24). Isto significa dizer que a tensão admissível máxima, neste caso, será dada pela tensão de escoamento do Titânio dividida pelo fator 3. Para um laminado que falha devido à ação das tensões de "bearing / bypass", como de fato ocorreu, a transferência da carga de "by-pass", na forma de tração, não deve ultrapassar $20 \%$ da tensão de ruptura obtida nos ensaios de caracterização de tração dos compósitos (Capítulo 2; - MIL-HDBK-17), na forma de uma tensão admissível máxima para 
um laminado unido mecanicamente, ou seja, certamente este percentual estabelecido pela norma está considerando o efeito do fator de concentração de tensões atuante na extremidade do furo. Assim sendo, defini-se uma relação teórica entre estas tensões máximas admissíveis, conforme mostra a equação (30).

$$
r=\frac{\sigma_{m t}}{\sigma_{c t}}=\frac{\sigma_{e s c} / 3}{0,2 \cdot X_{T}}
$$

Onde:

$$
\begin{aligned}
& \boldsymbol{\sigma}_{\mathrm{mt}}=\text { tensão máxima admissível para a porção da junta em Titânio (Capítulo 3); } \\
& \boldsymbol{\sigma}_{\mathrm{ct}}=\text { tensão máxima admissível para o compósito com base em norma (Capítulo 2) }
\end{aligned}
$$

Tem-se, assim, que r é igual a 2,8 indicando que a tensão admissível do metal é $180 \%$ superior a do compósito, demonstrando o vasto campo que se abre para as pesquisas no sentido de uma maior aproximação da correlação entre estas tensões, aliadas a diminuição do peso das estruturas aeronáuticas projetadas em configurações híbridas.

Ressalta-se também que a tensão $\boldsymbol{\sigma}_{\mathrm{ct}}$ é igual a $98,8 \mathrm{MPa}$ e pode ser considerada como uma tensão "teórica" máxima admissível para a junta, por ser a mais crítica. De fato, ao ser comparado com as obtidas nos ensaios, fica evidente uma aproximação, porém, estatisticamente, ainda deve ser considerado insuficiente, necessitando-se de um banco de dados mais consistente para a comprovação desta veracidade.

Sumarizando-se, a carga teórica máxima admissível pela norma, a encontrada na análise via Elementos Finitos e a real obtida através dos resultados dos ensaios estão representadas na Tabela $(25)$. 
Tabela 25 - Métodos de obtenção das cargas teóricas máximas admissíveis em comparação com a obtida nos ensaios dos CDPs.

\begin{tabular}{ccc} 
MÉTODO & $\begin{array}{c}\text { CARGA TEÓRICA MÁXIMA } \\
\text { ADMISSÍVEL (N) }\end{array}$ & $\begin{array}{c}\text { CARGA MÁXIMA MÉdIA } \\
\text { OBTIDA NO ENSAIO (N) }\end{array}$ \\
\hline MIL-HDBK-17 (20\% DE $\left.\mathbf{X}_{\mathrm{T}}\right)$ & $\mathbf{3 2 7 5}(*)$ & NA \\
\hline MÉTODO DOS ELEMENTOS FINITOS & $\mathbf{3 3 5 1}$ & NA \\
\hline ENSAIOS DOS CDPs & NA & $\mathbf{4 0 7 0}$ \\
\hline
\end{tabular}

(NA): Não Aplicável - (*) "by-pass".

Analisando-se os valores da Tabela (25), pode-se concluir que existam duas abordagens teóricas com possibilidade de indicarem o comportamento mecânico da união, antecipadamente aos ensaios experimentais, com uma razoável margem de aproximação. A Figura (99) confirma isto, pois, apesar da discrepância do valor estimado 3351N para o valor obtido experimentalmente $6572 \mathrm{~N}$ da junção $\mathrm{Ti}$ - Compósito $\left[0^{\circ} / 90^{\circ}\right]_{6}$, tem-se que essa diferença pode ser explicada quando se faz a análise do ponto onde a curva experimental não mais apresenta linearidade. Nota-se que o ponto obtido via MEF e empregando-se o Critério de Tsai-Wu, praticamente, coincide com o valor onde a curva experimental deixa de apresentar linearidade. Isso pode ser explicado pelo fato de que a ferramenta em MatLab, mencionada no item anterior, baseia-se na Teoria Clássica de Laminados, bem como, no critério da falha da primeira camada (First Ply Failure), assim, o resultado obtido numericamente não corresponde ao colapso da junta, mas sim, ao inicio de uma micro-falha interna em uma das camadas.

Com relação ao valor da carga admissível obtida experimentalmente através da aplicação do Método do Módulo Secundário, fica evidenciado que esta apresentou um valor ligeiramente superior à encontrada via MEF. Uma das explicações é devido ao fato da metodologia experimental apresentar a ação inerente do momento secundário, enquanto que a 
análise via MEF considera uma junta perfeita. Além disso, o modelo computacional não prevê micro-mecanismos de falha, o que também está presente nos ensaios experimentais.

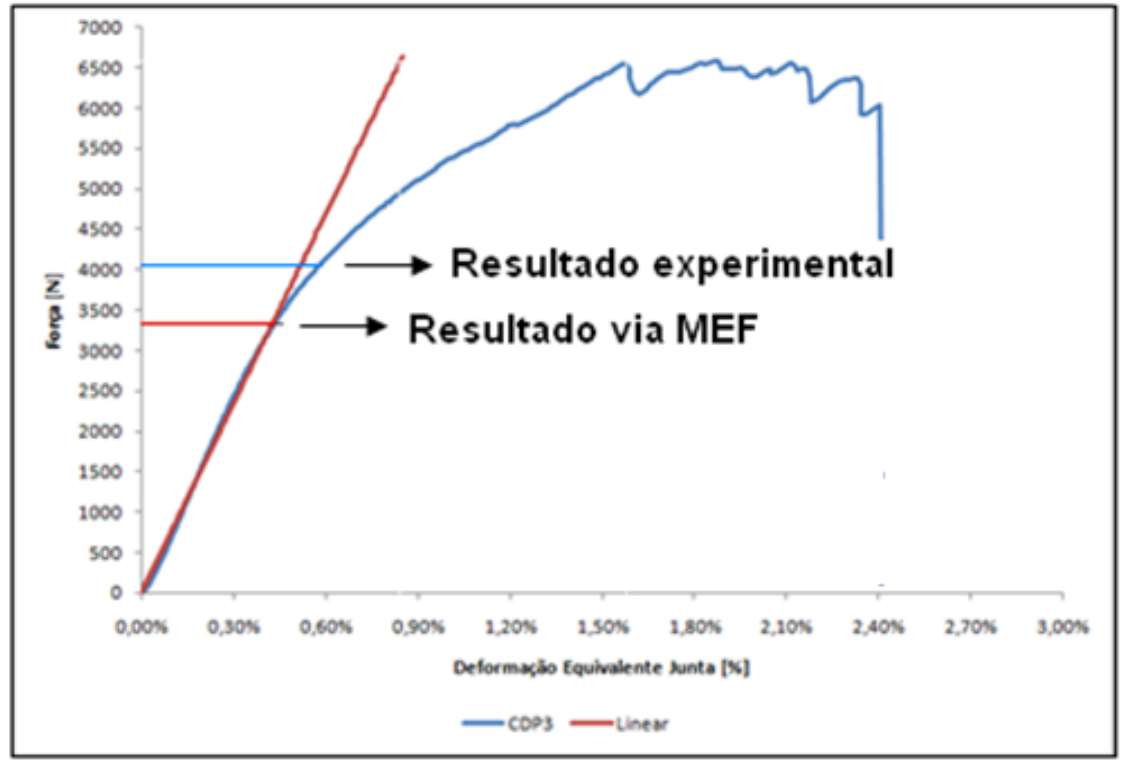

Figura 99 - Junções de Ti - Compósito $\left[0^{\circ} / 90^{\circ}\right]_{6}$ : Numérico x Experimental.

Uma análise análoga a supracitada pode ser realizada para a junção Ti-Compósito $\left[ \pm 45^{\circ}\right]_{6}$, como mostra a Figura (100).

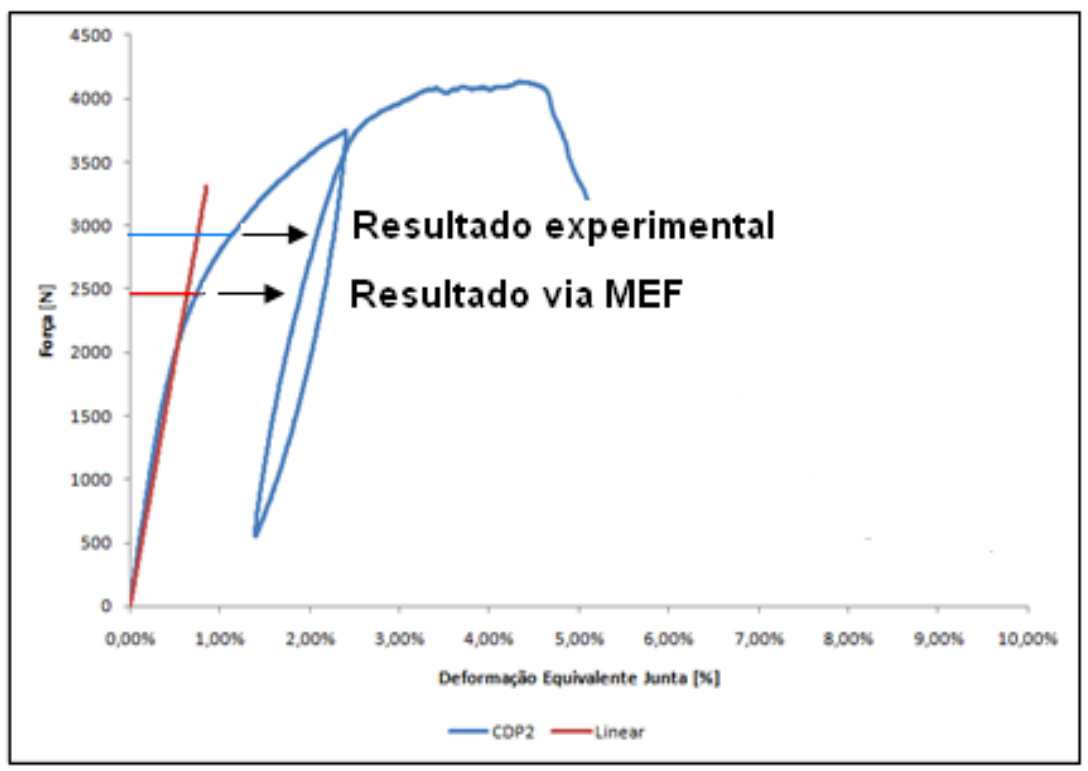

Figura 100 - Junções de Ti - Compósito $\left[ \pm \mathbf{4 5}^{\circ}\right]_{6}$ : Numérico x Experimental. 
Vale reforçar que as análises via MEF podem ainda ser melhoradas, empregando elementos mais poderosos, bem como, considerando o efeito da não-linearidade de contato (entre o fixador e o furo) e de não-linearidades de material (deformações permanentes nas junções e/ou mecanismos de danificação no compósito). O modelo em Elementos Finitos prevê que a montagem é perfeita, não existindo, portanto, nenhum tipo de desalinhamento. Porém, cabe ressaltar que o referido desalinhamento exerceu muito mais influência no comportamento da junta para valores mais elevados de deslocamento, ou seja, na fase nãolinear da resposta experimental.

Este conjunto global de dados conduz a algumas conclusões, as quais vão ser apresentadas no próximo capítulo. 


\section{CONCLUSÕES E PERSPECTIVAS PARA TRABALHOS FUTUROS}

Em função do estudo realizado, pode-se concluir que:

1) Os ensaios experimentais dos corpos-de-prova (CDPs) de materiais compósitos (epóxi reforçada com fibra de carbono) seguindo algumas orientações das normas ASTM 3039 e ASTM 3518 possibilitaram caracterizar, mecanicamente, os laminados utilizados nas juntas híbridas, alimentando, principalmente, as simulações computacionais;

2) O modelo computacional via $\mathrm{MEF}$, não só mostrou a viabilidade dos ensaios dos CDPs propostos, através de uma perfeita aproximação em relação às propriedades elásticas obtidas experimentalmente, mas também, possibilitou estimar a carga que teoricamente iniciou uma micro-falha em uma determinada camada do laminado das junções híbridas Ti Compósito, objeto deste estudo. Vale ressaltar que a análise via MEF pode ainda ser melhorada, empregando-se elementos mais poderosos, bem como, considerando-se os efeitos de não-linearidade de contato (entre o fixador e o furo) e de não-linearidades de material (deformações permanentes nas junções e/ou mecanismos de danificação no compósito). Conclui-se, portanto, que a ferramenta de Elementos Finitos é extremamente estratégica para o desenvolvimento de projetos de juntas híbridas;

3) Os ensaios realizados nas juntas híbridas podem sofrer a interferência de uma série de fatores, dentre esses fatores, tem-se que o presente trabalho investigou a seqüência do empilhamento das camadas do material compósito e a existência de excentricidade na junção e concluiu que realmente, ambos exercem uma influência elevada no comportamento das juntas. Por exemplo, com relação à seqüência de empilhamento, verificou-se que as juntas híbridas com o compósito orientado a 0/90 falham, basicamente, por "net-tension", ao passo 
que o compósito orientado a \pm 45 falham, basicamente, por "tear-out". Além disso, as junções com laminados orientados a \pm 45 falharam com uma carga bem inferior quando comparadas com as junções com laminados orientados a 0/90, demonstrando a influência do empilhamento na resposta do laminado e comprovando o previsto pela teoria. Com relação ao desalinhamento, verificou-se que o valor de resistência da junção medido experimentalmente no CDP 2 (Compósito 1) não estava compatível com os demais CDPs medidos pelo "ClipGage”, pois isto pode ter sido causado pela ação do Momento Fletor Secundário evidenciado no Projetor de Perfil;

4) O Método do Módulo Secundário demonstrou ser eficaz para a obtenção das propriedades mecânicas de uma junção híbrida metal-compósito. Pode-se afirmar que este método foi utilizado, até então, para obtenção das propriedades mecânicas em uniões metalmetal, sendo inovadora sua aplicação, por meio deste trabalho, em junções metal-compósito. A eficiência desta metodologia ficou comprovada ao se comparar os resultados dos ensaios realizados nas junções metal-compósito com os obtidos através da análise computacional via MEF ou com base na MIL-HDBK-17, possibilitando, assim, uma orientação no desenvolvimento de projetos de junções híbridas.

Além disso, constatou-se também que os valores de resistência a ruptura apresentados pelos CDPs de caracterização dos compósitos foram bem superiores quando comparados com os valores resultantes da falha da junção na parte em compósito. Isto vai ao encontro da literatura, pois a existência do furo nos CDPs das juntas e, conseqüentemente, a ação do fator de concentração de tensões na região da parede do furo causaram a falha precoce dos referidos CDPs.

Como proposta de trabalhos futuros, recomenda-se o estudo de juntas híbridas considerando a influência de outros parâmetros, tais como: passo entre os fixadores; a 
distância da borda; o diâmetro do furo; o diâmetro do fixador; o tipo da liga do fixador; a espessura e largura da junta; o tipo de liga da parte metálica; tipos diferentes de reforçadores e sua disposição nas camadas; estudo para aplicação de reforços na área correspondente a distância de borda a fim de se obter um ganho na resistência a falha por cisalhamento e, da mesma forma, no entorno dos furos a fim de se obter um ganho na resistência ao "by-pass" na forma de tração; estudo da influência da temperatura e umidade no modo de falha por "bearing".

Ainda, as medidas de deslocamento podem ser realizadas empregando, por exemplo, a Técnica de Correlação de Imagens. Sendo assim, é possível calcular a carga de "by-pass" transferida para a estrutura, utilizando-se também da Técnica de Correlação de Imagens.

Por fim, como perspectiva de trabalho futuro, pode-se estudar o comportamento de juntas híbridas sob fadiga, considerando, ou não, carregamento térmico, ou ainda, pode-se realizar um estudo sob carregamento impulsivo, avaliando efeitos relacionados à taxa de deformação. 


\section{REFERÊNCIAS BIBLIOGRÁFICAS}

AEROSPACE MATERIAL SPECIFICATION - 4907H. Titanium alloy, sheet, strip, and plate 6.0Al - 4.0V, extra low interstitial annealed. 2005. $11 \mathrm{p}$.

AMERICAN SOCIETY FOR TESTING AND MATERIALS - D 3039/D 3039M-95a. Standard test method for tensile properties of polymer matrix composite materials. Philadelphia: 2006. 13p.

AMERICAN SOCIETY FOR TESTING AND MATERIALS - D 5961/D 5961M -05. Standard test method for bearing response of polymer matrix composite laminates. West Conshohocken: 2007. 26p.

AMERICAN SOCIETY FOR TESTING AND MATERIALS - D3518/D3518M-94. Standard practice for in-plane shear response of polymer matrix composite materials by tensile test of $\mathbf{a} \pm \mathbf{4 5}^{\mathbf{0}}$ laminate. Philadelphia: 2001. $7 \mathrm{p}$.

ANDERSON, T. L. Fracture mechanics: fundamentals and applications. 2nd.ed. New York: CRC Press, 1995.

ASM INTERNATIONAL HANDBOOK COMMITTEE. Volume 21 - Composites. Ohio: 2005. 1143p.

CALLISTER JUNIOR, W. D. Ciência e engenharia de materiais: uma introdução. Rio de Janeiro: Livros Técnicos e Científicos, 2002.

CARVALHO, J. Computer integrated design optimization and manufacturing of filament wound parts. Thesis (PhD) - Faculty of Applied Sciences, Division PMA, 1996. $198 p$. 
COUTELLIER, D.; WALRICK, J. C.; GEOFFROY, P. Presentation of a methodology for delamination detection within laminated structures. Composites Science and Technology, 2006. v.66, p. 837-845.

DÁVILA, C.G.; CAMANHO, P.P.; MOURA, M.F. Progressive damage analyses of skin/stringer debonding. American Society of Composites Annual Technical Conference, 16. Blacksburg, Proceedings... Blacksburg, 200. 1 CD-ROM.

HERAKOVICH, CARL.T. Mechanics of fibrous composites. New York: Wiley, 1998c. $460 \mathrm{p}$

IANUCCI, L. Progressive failure modeling of woven carbon composite under impact. International Journal of Impact Engineering, 2006. v. 32, p. 1013-1043.

JONES, R. M. Mechanics of composite materials. Second Edition. Virginia: Blacksburg, 1999.

KEUNINGS, R. Macromechanics of composites. In: LEUVEN, K. U. European postgraduate education in polymer and composites engineering (EUPOCO), 1992. v.2, Module 4.

KOSTOPOULOS, V. et al. Finite element analysis of impact damage response of composite motorcycle safety helmets. Composites: part B. Oxford, 2002. v. 33, p. 99-107.

LESS, J.M.; MAKAROV, G. Mechanical/bonded joints for advanced composite structures. Proceedings of the Institution of Civil Engineers, p. 91-97, jan. 2004. Número 13391.

MATSUZAKI, R.; SHIBATA, M.; TODOROKI, A. Improving performance of GFRP/aluminum single lap joints using bolted/co-cured hybrid method. Science Direct, p. 154-163 Part A, nov. 2007. 
MATTEWS, F. L.; RAWLINGS, R. D. Composite materials: engineering and science. New York: Chapman-Hall, 1994.

MILITARY HANDBOOK - 17 1F. Polymer matrix composites guidelines for characterization of structural materials. Philadelphia: 2002. 586p.

MILITARY HANDBOOK - 17 3F. Polymer matrix composites materials usage, design, and analysis. Philadelphia: 2002. 693p.

MILITARY HANDBOOK - 5J. Metallic materials and elements for aerospace vehicle structures. Philadelphia: 1998. 1652p.

MILITARY SPECIFICATION - 20615. Rivet, solid-universal head brass, copper, nickelcopper alloy. 1995. 3p.

MORRIS, G. Defining a standard formula and test-method for fastener flexibility in lapjoints. Delft: 2004. 127p

NATIONAL AEROSPACE STANDARD - 1312-4. Fastener test methods: method 4 lap joint shear. Philadelphia: Aerospace Industries Association, 1997. 16p.

NIU CHUN-YUNG, M. Airframe structural design. California: Commits Press, 1988. 609 p.

PAEPEGEN, V. W.; BAERE, I.; DEGRIECK, J. Modeling the nonlinear shear stressstrain response of glass fiber-reinforced composites: experimental results (Part I). Composites Science and Technology, 2006a. v. 66, p.1455-1464.

PAEPEGEN, V. W.; BAERE, I.; DEGRIECK, J. Modeling the nonlinear shear stressstrain response of glass fiber-reinforced composites: model development and finite element simulations (Part II). Composites Science and Technology, 2006b. v. 66, p.1465-1478. 
PARÍS, F. A study of failure criteria of fibrous composite materials. EUA: NASA, 2001. Report n.CR-2001-210661/March 2001.

RENARD, J.; THIONNET, A. Damage in composites: from physical mechanisms to modeling. Composite Science and Technology, 2006. v. 66, p. 642-646

ROWLANDS, R. E. Strength (failure) theories and their experimental correlation. In: SIH, G. C.; SKUDRA, A. M. Failure mechanics of composite. Amsterdam: North-Holland, 1985. cap.2, p.71-127.

STEPHEN, R. H.; WISNOM, M. R. Numerical investigation of progressive damage and the effect of layup in notched tensile tests. Journal of Composite Materials, 2006. v. 40, p. $1229-1245$.

SUONG, V. H.; TSAI, S. W. Composite Materials: Design and Applications, 2002. CRC Press, 1. edition.

TITA, V. Contribuição ao estudo de danos e falhas progressivas em estruturas de material compósito polimérico. 2003. 193f. Tese (Doutorado em Estrutura Aeronáutica) Escola de Engenharia de São Carlos, Universidade de São Paulo, São Carlos, 2003.

TITA, V. Desenvolvimento de um método para avaliar a capacidade de absorção de energia ao impacto de componentes mecânicos a base de materiais compósitos poliméricos reforçados. São Carlos: Escola de Engenharia de São Carlos, 2002. EESC-USP / Relatório Científico 3, submetido à FAPESP, nº do processo: 98/16398-1.

TITA, V.; CARVALHO, J.; VANDEPITTE, D. A study of the dynamic behavior for low velocity impact on thin composite laminates. In: XII DINAME, 2007a, Ilha Bela. 
TITA, V.; CARVALHO, J.; VANDEPITTE, D. Experimental and finite element analysis of composite laminates on flexural and transverse shear loading. In: XIX COBEM, 2007b, Brasília.

TITA, V.; CARVALHO, J.; VANDEPITTE, D. Failure analysis of low velocity impact on thin composite laminates: experimental and numerical approaches. Journal of Composite Structures, 2008.

TITA, V.; CARVALHO, J; SANTOS, NC. Modelagem do comportamento mecânico de materiais compósitos utilizando o modelo dos elementos finitos. João Pessoa: Anais João Pessoa, 2002. Congresso nacional de engenharia mecânica 2, 1 CD-ROM.

TSAI, S.W.; WU, E.M. A general theory of strength for anisotropic materials. Journal of Composite Materials, 1971. v. 5, p. 58-80.

TURON, A. et al. A damage model for the simulation of delamination in advanced composites under variable-mode loading. Mechanics of Materials, 2006. v. 38, p. 10721089.

VINSON, J. R.; SIERKOWSKI, R. L. Behavior of structures composed of composite materials. Dordrecht: Martins Nijhoff, 1986.

WILLIANS, K. V; VAZIRI, R. Application of a damage mechanics model for predicting the impact response of composite materials: Computer \& Structures. New York, 2001. v. 79, n. 10, p. 997-1011. 